Andrews University

Digital Commons @ Andrews University

\title{
Differences Between Undergraduate and Graduate Students in Self-concept and Depression
}

Ann L. Woolley

Andrews University

Follow this and additional works at: https://digitalcommons.andrews.edu/dissertations

Part of the Other Psychology Commons, and the Psychiatric and Mental Health Commons

\section{Recommended Citation}

Woolley, Ann L., "Differences Between Undergraduate and Graduate Students in Self-concept and Depression" (2002). Dissertations. 1560.

https://digitalcommons.andrews.edu/dissertations/1560

https://dx.doi.org/10.32597/dissertations/1560

This Dissertation is brought to you for free and open access by the Graduate Research at Digital Commons @ Andrews University. It has been accepted for inclusion in Dissertations by an authorized administrator of Digital Commons@ Andrews University. For more information, please contact repository@andrews.edu. 


\section{Andrews \$university}

Seek Knowledge. Affirm Faith. Change the World.

Thank you for your interest in the

\section{Andrews University Digital Library of Dissertations and Theses.}

Please honor the copyright of this document by not duplicating or distributing additional copies in any form without the author's express written permission. Thanks for your cooperation. 


\section{INFORMATION TO USERS}

This manuscript has been reproduced from the microfilm master. UMI films the text directly from the original or copy submitted. Thus, some thesis and dissertation copies are in typewriter face, while others may be from any type of computer printer.

The quality of this reproduction is dependent upon the quality of the copy submitted. Broken or indistinct print, colored or poor quality illustrations and photographs, print bleedthrough, substandard margins, and improper alignment can adversely affect reproduction.

In the unlikely event that the author did not send UMI a complete manuscript and there are missing pages, these will be noted. Also, if unauthorized copyright material had to be removed, a note will indicate the deletion.

Oversize materials (e.g., maps, drawings, charts) are reproduced by sectioning the original, beginning at the upper left-hand comer and continuing from left to right in equal sections with small overlaps.

Photographs included in the original manuscript have been reproduced xerographically in this copy. Higher quality $6^{-1} \times 9^{n}$ black and white photographic prints are available for any photographs or illustrations appearing in this copy for an additional charge. Contact UMI directly to order.

ProQuest Information and Learning 300 North Zeeb Road, Ann Arbor, MI 48106-1346 USA 800-521-0600

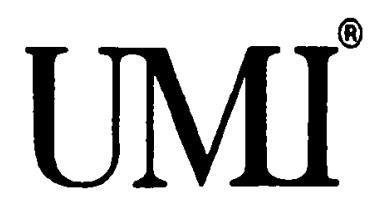


Andrews University

School of Education

DIFFERENCES BETWEEN UNDERGRADUATE AND GRADUATE

STUDENTS IN SELF-CONCEPT AND DEPRESSION

\author{
A Dissertation \\ Presented in Partial Fulfillment \\ of the Requirements for the Degree \\ Doctor of Philosophy
}

by

Ann L. Woolley

June 2002 
UMI Number: 3058318

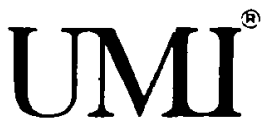

UMI Microform 3058318

Copyright 2002 by ProQuest Information and Learning Company.

All rights reserved. This microform edition is protected against unauthorized copying under Title 17, United States Code.

ProQuest Information and Learning Company

300 North Zeeb Road

P.O. Box 1346

Ann Arbor, MI 48106-1346 
A dissertation

presented in partial fulfillment

of the requirements for the degree of

Doctor of Philosophy

by

Ann L. Woolley

APPROVAL BY THE COMMITTEE:

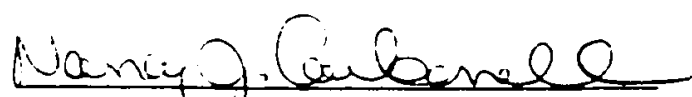

Chair: Nahcy J. Carbonell, Ph.D.
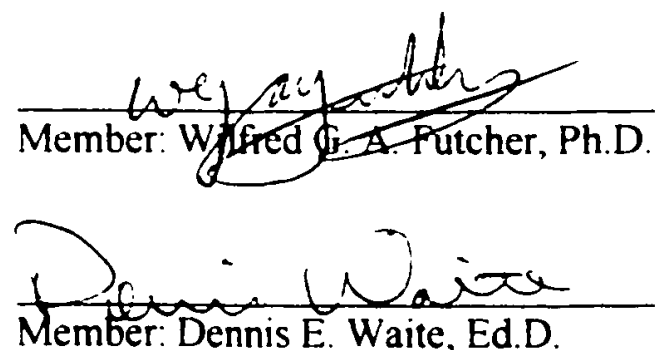

$\frac{\text { Kawe }}{\text { External: Karen Baer-Barkley, Ph.D. }}$

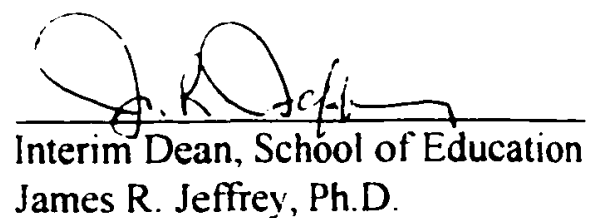

James R. Jeffrey, Ph.D. 


\begin{abstract}
DIFFERENCES BETWEEN UNDERGRADUATE AND GRADUATE STUDENTS IN SELF-CONCEPT AND DEPRESSION
\end{abstract}

by

Ann L. Woolley

Chair: Nancy J. Carbonell 


\title{
ABSTRACT OF GRADUATE STUDENT RESEARCH
}

Dissertation

Andrews University

School of Education

\author{
Title: DIFFERENCES BETWEEN UNDERGRADUATE AND GRADUATE \\ STUDENTS IN SELF-CONCEPT AND DEPRESSION \\ Name of researcher: Ann L. Woolley \\ Name and degree of faculty chair: Nancy J. Carbonell. Ph.D. \\ Date completed: June 2002
}

\section{Problem}

Students have an opportunity for personal growth as they learn about themselves and the world around them. However, their levels of self-concept and depression can influence how they view themselves, their relationships, and their world. This research compared undergraduate and graduate students with respect to their levels of self-concept and depression.

\section{Method}

A quantitative research design was used for an ex post facto study of 239 students from Andrews University and Western Michigan University. They completed the Demographic Questionnaire, the Tennessee Self-Concept Scale: Second Edition (TSCS:2), 
and the Beck Depression Inventory-II (BDI-II).

\section{Results}

Using 13 as the BDI-II cut score, the prevalence of depression found for undergraduate and graduate students combined was as follows: a total of $197\left(82.4^{\%}\right)$ were nondepressed, a total of $21(8.8 \%)$ demonstrated mild depressive symptoms, a total of $13(5.4 \%)$ demonstrated moderate depressive symptoms, and a total of $8(3.3 \%)$ demonstrated severe depressive symptoms.

The results indicated that undergraduate students demonstrated higher mean depression scores than the graduate students. However, there were no significant differences found between the proportion of undergraduate and graduate students in each BDI-II group.

There were no significant differences found in the level of self-concept between undergraduate and graduate students. There were significant differences found between the self-concept of students at different depression groups. For Identity Self-Concept only, the relationship between self-concept and depression was different for undergraduate and graduate students.

\section{Conclusions}

Although the majority of the participants were nondepressed, undergraduate students demonstrated higher mean depression scores than graduate students. Undergraduate and graduate students did not differ in their level of self-concept. There were significant differences found between the self-concept of students at different depression groups. In general, when undergraduate and graduate students were 
nondepressed or the less depressed they were, then the better they felt about themselves. Conversely, the more depressed they were, then the worse they felt about themselves. The relationship between self-concept and depression was different for undergraduate and graduate students for Identity. Self-Concept only. The results of this study suggested that therapeutic goals for students with symptoms of depression, undergraduate or graduate, would be similar. 
In loving memory of Dr. Andrew P. Woolley, Jr., Helen Machlan, and Abbey Woolley 


\section{TABLE OF CONTENTS}

LIST OF TABLES $\ldots \ldots \ldots \ldots \ldots \ldots \ldots \ldots \ldots \ldots \ldots \ldots \ldots \ldots \ldots$

ACKNOWLEDGMENTS $\ldots \ldots \ldots \ldots \ldots \ldots \ldots \ldots \ldots \ldots \ldots \ldots \ldots \ldots \ldots$

Chapter

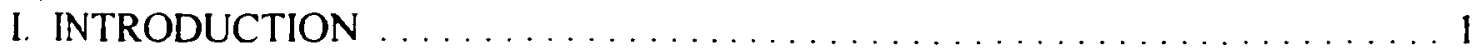

Background . . . . . . . . . . . . . . . . . . .

Statement of the Problem $\ldots \ldots \ldots \ldots \ldots \ldots \ldots \ldots \ldots$

Purpose of the Study . . . . . . . . . . . . . . . . . . . . 10

Research Questions . . . . . . . . . . . . . . . . . . . 10

Research Hypotheses to be Examined . . . . . . . . . . . . . . . . . 10

Theoretical Frameworks . . . . . . . . . . . . . . . . . . . . . . 11

Self-Concept Theory . . . . . . . . . . . . . . . . . . . . 11

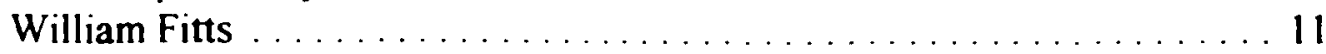

Depression Theory ............................ 13

Aaron Beck . . . . . . . . . . . . . . . . . . . . . . 13

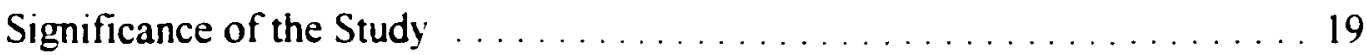

Definitions of Terms . . . . . . . . . . . . . . . . . 21

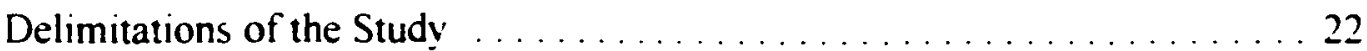

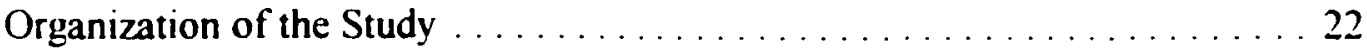

II. REVIEW OF THE LITERATURE $\ldots \ldots \ldots \ldots \ldots \ldots \ldots \ldots \ldots \ldots \ldots$

Introduction . . . . . . . . . . . . . . . . . . . . . . 23

Theories of Self-Concept $\ldots \ldots \ldots \ldots \ldots \ldots \ldots \ldots \ldots \ldots \ldots \ldots \ldots$

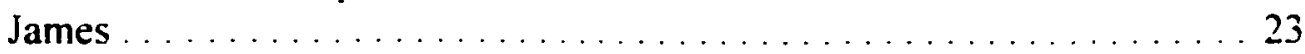

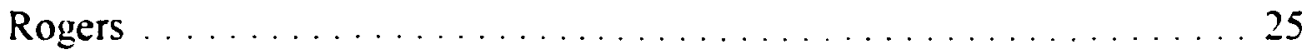

Maslow . . . . . . . . . . . . . . . . . . . . . . . . 26

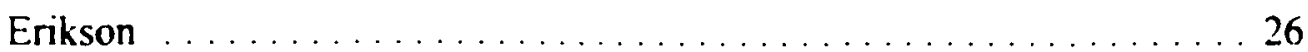

Self-Concept . . . . . . . . . . . . . . . . . . . . . . . . 29

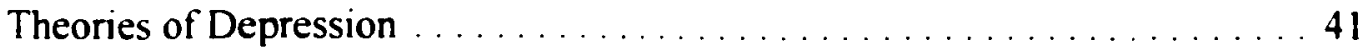

Abraham .......................... 41

Freud ............................... 41

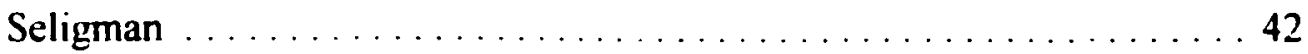

iv 
Depression................................... 44

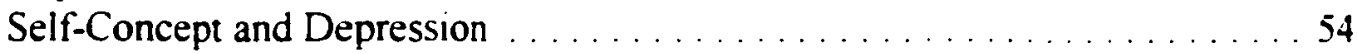

Undergraduate and Graduate Students $\ldots \ldots \ldots \ldots \ldots \ldots \ldots \ldots \ldots . \ldots \ldots$

Summary . . . . . . . . . . . . . . . . . . . . . . . . . . . . . 65

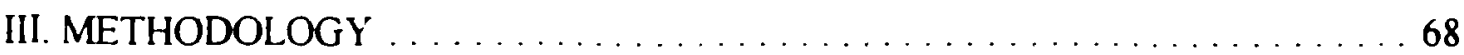

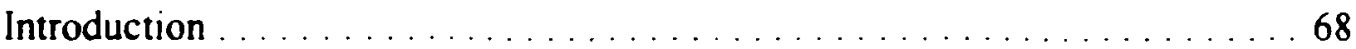

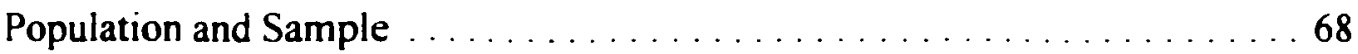

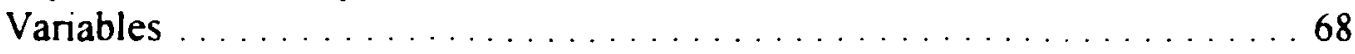

Instrumentation . . . . . . . . . . . . . . . . . . . . . . 69 69

Demographic Questionnaire ... . . . . . . . . . . . . . . . . . . . 69

Tennessee Self Concept Scale: Second Edition . . . . . . . . . . . . . . . 69

Beck Depression Inventory-II ... . . . . . . . . . . . . . . . . . . 74

Data Collection ................................. 78

Null Hypotheses and Methods of Analysis . . . . . . . . . . . . . . 81

Power Analysis . . . . . . . . . . . . . . . . . . . . . . . . . . . . 84

IV. PRESENTATION AND ANALYSIS OF DATA $\ldots \ldots \ldots \ldots \ldots \ldots$

Introduction . . . . . . . . . . . . . . . . . . . . . . . . 85

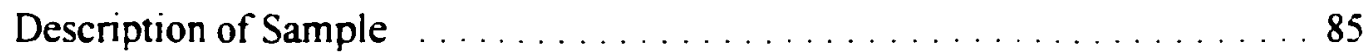

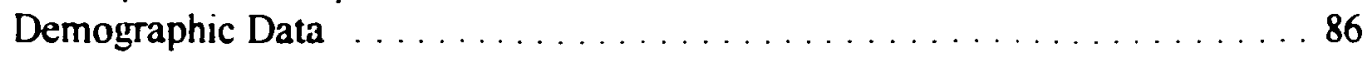

General Description of Instruments $\ldots \ldots \ldots \ldots \ldots \ldots \ldots \ldots \ldots \ldots$. 91

Testing the Hypotheses . . . . . . . . . . . . . . . . . . . . . . . 93

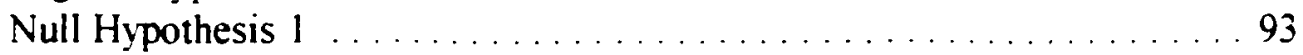

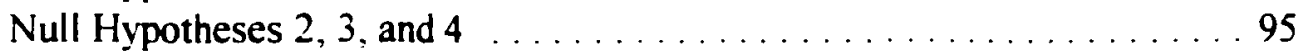

a. Physical Subscale ........................... 95

b. Moral Subscale . . . . . . . . . . . . . . . . . . . . . . . . . . 97

c. Personal Subscale . . . . . . . . . . . . . . . . . . . . . . . . . 99

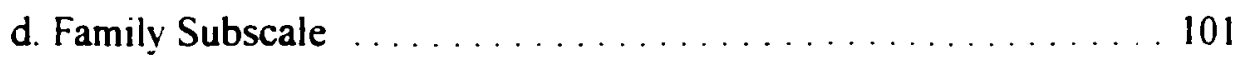

e. Social Subscale ............................. 103

f. Academic/Work Subscale . . . . . . . . . . . . . . . . . . . . . 105

g. Identity Subscale . . . . . . . . . . . . . . . . . . . . . . . . . . 107

h. Satisfaction Subscale ...................... 110

i. Behavior Subscale . . . . . . . . . . . . . . . . . . . 112

j. Total Scale . . . . . . . . . . . . . . . . . . . . . . . 114

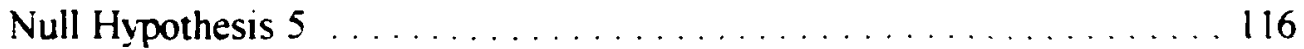

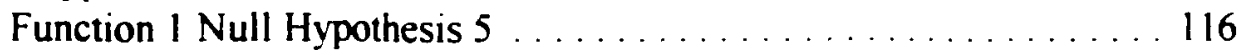

Function 2 Null Hypothesis $5 \ldots \ldots \ldots \ldots \ldots \ldots \ldots \ldots \ldots \ldots$

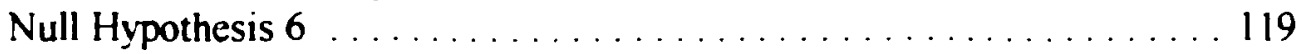

Function 1 Null Hypothesis $6 \ldots \ldots \ldots \ldots \ldots \ldots \ldots \ldots \ldots \ldots \ldots$

Summary of Hypothesis Testing . . . . . . . . . . . . . . . 121 
V. SUMMARY, DISCUSSION, CONCLUSIONS,

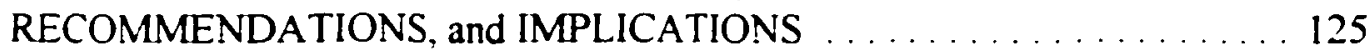

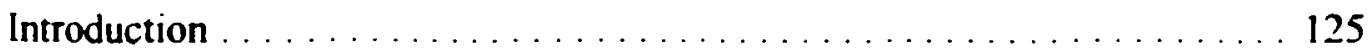

Summary . . . . . . . . . . . . . . . . . . . . . . . 125

Problem ............................ 125

Purpose of the Study . . . . . . . . . . . . . . . . . . . 126

Significance of the Study . . . . . . . . . . . . . . . . 127

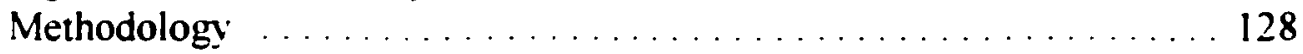

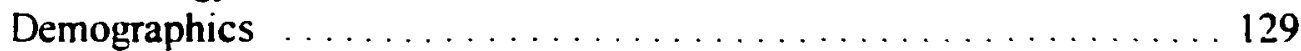

Discussion of the Results . . . . . . . . . . . . . . . . . . . . . . . . . . . . 129

Research Question $1 \ldots \ldots \ldots \ldots$. . . . . . . . . . . . . . . 130

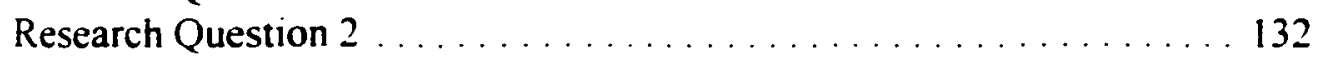

Research Question $3 \ldots \ldots \ldots 133$

Research Question $4 \ldots \ldots \ldots \ldots \ldots \ldots$. . . . . . . . . . . . . . . . . .

Conclusions .............................. 143

Recommendations . . . . . . . . . . . . . . . . . . . 145

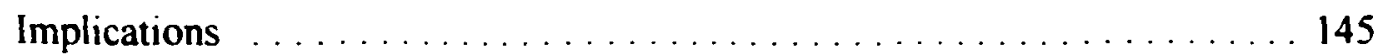

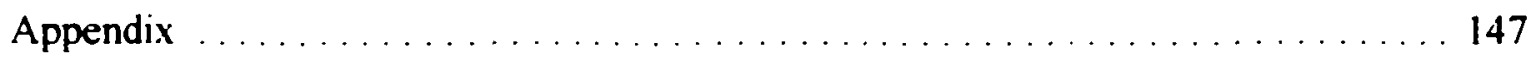

A. AUTHORIZATION TO PERFORM STUDY $\ldots \ldots \ldots \ldots \ldots \ldots \ldots \ldots$

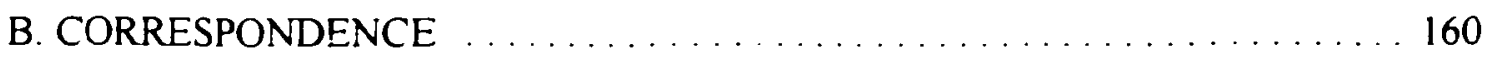

C. INSTRUMENTATION . . . . . . . . . . . . . . . . . . . 179

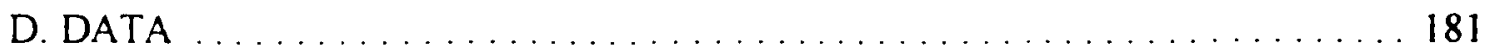

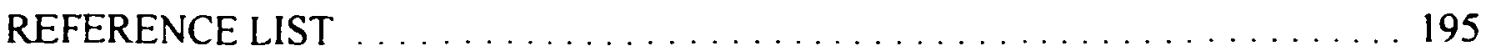

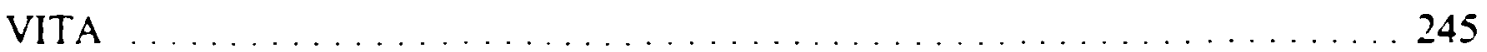

vi 


\section{LIST OF TABLES}

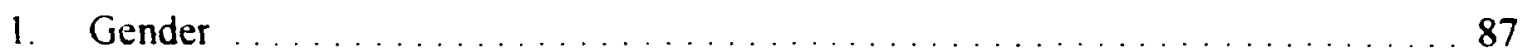

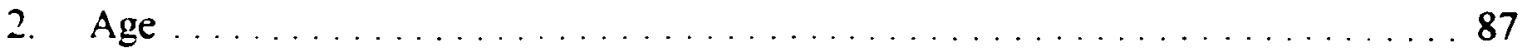

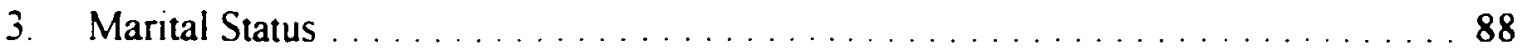

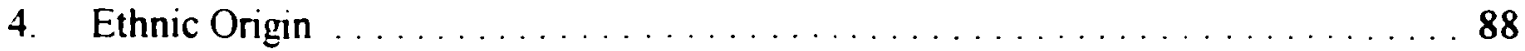

5. Current Program Level . . . . . . . . . . . . . . . . . . . . . 89

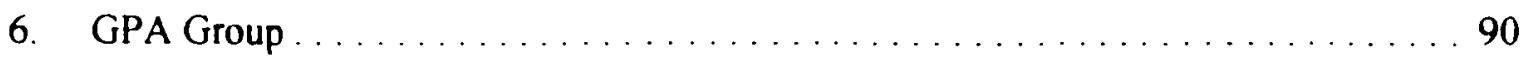

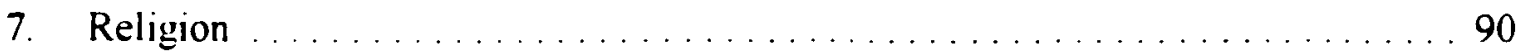

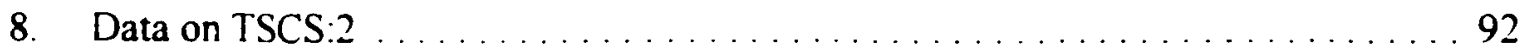

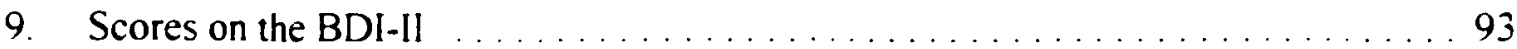

10. Contingency Table for Hypothesis 1 (b) (Percentages Given in Parentheses) . . . 94

11. Means Table for Physical TSCS:2 Subscale Score and BDI-II Groups . . . . . . . 96

12. Summary of the Analysis of Variance for Physical TSCS:2 Subscale and BDI-II Groups . . . . . . . . . . . . . . . . . . . . . . . . . . . . . 97

13. Means Table for Moral TSCS:2 Subscale Score and BDI-II Groups $\ldots \ldots \ldots .98$

14. Summañ of the Analysis of Variance for Moral TSCS:2 Subscale and BDI-II Groups . . . . . . . . . . . . . . . . . . . . . . . . . . 98

15. Means Table for Personal TSCS:2 Subscale Score and BDI-II Groups . . . . 100

16. Summary of the Analysis of Variance for Personal TSCS:2 Subscale and BDI-II Groups . . . . . . . . . . . . . . . . . . . . . . . . . . . . . 100

vii 
17. Means Table for Family TSCS:2 Subscale Score and BDI-II Groups 102

18. Summany of the Analysis of Variance for Family TSCS:2 Subscale and BDI-II Groups . . . . . . . . . . . . . . . . . . . . 102

19. Means Table for Social TSCS:2 Subscale Score and BDI-II Groups $\ldots \ldots \ldots 104$

20. Summary of the Analysis of Variance for Social TSCS:2 Subscale and BDI-II Groups .............................. 104

21. Means Table for Academic/Work TSCS:2 Subscale Score and BDI-II Groups

22. Summary of the Analysis of Variance for Academic/Work TSCS:2 Subscale and BDI-II Groups

23. Means Table for Identity TSCS:2 Subscale Score and BDI-II Groups $\ldots \ldots \ldots 108$

24. Summary of the Analysis of Variance for Identity TSCS:2 Subscale and BDI-II Groups

25. Simple Effects Tests for Identity 109

26. Means Table for Satisfaction TSCS:2 Subscale Score and BDI-II Groups

27. Summary of the Analysis of Variance for Satisfaction TSCS:2 Subscale and BDI-II Groups

28. Means Table for Behavior TSCS:2 Subscale Score and BDI-II Groups

29. Summary of the Analysis of Variance for Behavior TSCS:2 Subscale and BDI-II Groups

30. Means Table for Total TSCS:2 Score and BDI-II Groups

31. Summary of the Analysis of Variance for Total TSCS:2 Score and BDI-II Groups

32. Function 1 Null Hypothesis 5

33. Standardized Discriminant Function Coefficients Null Hypothesis 5-Function 1 
34. Function 2 Null Hypothesis 5

35. Standardized Discriminant Function Coefficients

Null Hypothesis 5-Function 2

36. Function I Null Hypothesis 6

120

37. Standardized Discriminant Function Coefficients

Null Hypothesis 6-Function 1 


\section{ACKNOWLEDGMENTS}

I would like to acknowledge the time, support, and contributions of my committee members: Dr. Nancy Carbonell. Dr. Wilfred Futcher, Dr. Dennis Waite, and Dr. Karen Baer-Barkley: I want to especially thank Dr. Futcher for all of his time, patience, support. encouragement. and compassion.

I want to thank each of my family members for their continued love and support: Mom. Andy. Fred. Linda. Lauren. Bunny. Jim. Mary Lou. Morton. Jane. and Mittie. I also want to thank my friends for being so encouraging and supportive: Caroline. Cindy. Don. Joyce. Karen. Kaye. Kris. Lynn. Margaret. Mary. Peggy. Peter. Tami. Sally, and Vickie. Although I cannot name each person or write about what they have specifically done or how they have specifically helped me, I want to give an extra thank-you to some of these people: my mother, Mrs. A. P. Woolley, who continuously praved and supported me; my oldest brother. Dr. Andrew P. Woolley III. who gave lots of his time, expertise, and extra encouragement; my contact person. Dr. Rober Brinkerhoff, for graciously agreeing to help me and giving of his time; Vicki Jansen at WMU for being such a helpful and kind contact person: Sue Weinberg of Wesiem Psychological Services for her kindness and support: Dr. Lloyd Erickson for his encouragement. support. and wonderful cxample: Dr. Linda Bedsole for her support and excellent example: and my mentor. Dr. Robent Wolford, for his support. encouragement. excellent example. and his belief in me. 
I want to give a very special thank-you to my study partner. W. Don Edwards, for his caring, support, and encouragement especially throughout the many years of statistics classes, internship, and the dissertation process; Vickie Boling for her continued prayers, support, caring, and encouragement; Joyce Jones, for her support and encouragement; Peter Mashni, for his kindness, support. and encouragement; and Bonnic Proctor for her expertise, kindness, and encouragement.

I am very grateful for all the professors who graciously allowed me to come into their classes to gather my data. I am also very grateful to all the undergraduate and graduate students who generously agreed to participate in this study. I could not have completed this research without their enormous help. 


\section{CHAPTER I}

\section{INTRODUCTION}

\section{Background}

Much has been written about the individual topics of self-concept and depression in the literature. Self-concept is considered a basic component of human existence. The idea of self-concept plays a main role in theory and research in psychology and is of interest to philosophers, educators, and scholars (Anderson, Reznik, \& Chen, 1997: Branden, 1994; Gray-Little \& Williams, 1997: Snodgrass \& Thompson, 1997). Human beings long to determine a purposeful identity, have a better understanding of themselves and others, and to answer the questions "Who am I?" and "How can I relate to others?" (Branden. 1993: Crider, Goethals, Kavanaugh, \& Solomon, 1989; Rachlin, 1997).

The term self-concept has been cited in the literature under a variety of names such as self-worth, self-respect. self-confidence, self-love, self-acceptance, and/or self-esteem (Bracken \& Mills, 1994: Frey \& Carlock. 1989: Wells \& Marwell, 1976). For this research. I am not using the terms self-concept and self-esteem interchangeably. The self-concept is all-encompassing but includes the self-esteem. Self-concept consists of those roles, characteristics. or abilities that one considers to be basically representative of oneself. It contains the beliefs about one's personal worth and is an overall summary of one's 
strengths, accomplishments. competencies, and deficiencies. Self-concept is basically what one thinks about oneself. Self-esteem is the evaluative component of the self-concept. Often, individuals use their self-esteem to evaluate the behavioral, psychological, and cognitive components of their self-concept. Self-esteem is basically what one feels about oneself (Bednar. Wells, \& Peterson. 1989: Hanwood. 1998: Rosenberg, 1985). Individuals examine the question "Who am I?" at different stages throughout their lives. Changes in their lives. such as the birth of a sibling. moving away from home. starting college, getting married or divorced, starting a career, the birth of a child, and/or losing a loved one can trigger further exploration of the self (Grayson \& Meilman. 1999: Hormuth, 1990). It is vital in today`s fast-paced society for persons to have a strong sense of self. to feel deserving and competent. Self-concept is related to issues in life such as contentment with self, achievement in school, relationships with others, choosing a career and'or mate, and general success in life (Bracken \& Mills, 1994: Hattie, 1992).

Depression is another widely discussed topic in the literature. Depression touches every ethnic and cultural group, age group, income status, social class, and educational level. It has been called "the common cold of mental health" with approximately 100 million people worldwide and 23 million adults in the United States diagnosed with depression each vear. In the United States alone, approximately $\$ 43-44$ billion is lost each year in social, economic, and personal areas from the effects of depression (Gotlib, Wallace, \& Colby, 1990: Karp, 1996; Lisser, 2002; Meyer \& Deitsch, 1996; National Institute of Mental Health [NIMH]. 1995. 1997. 1999).

Depression takes a toll on individuals and society with widespread effects in 
areas such as relationships with others. physical health, academic performance, work performance, feelings of self-worth, and the ability to handle stress. Even if individuals are experiencing a mild form of depression which does not meet specific diagnostic criteria, according to the American Psychiatric Association's (2000) Diagnostic and Statıstical Manual of Mental Disorders, Fourth Fdthon. Text Revision (I)SM-IV-TR), their ability to function in the above-mentioned areas may certainly be affected (Dunner, 1997; Flynn \& Cappeliez, 1993: Swallow \& Segal, 1995).

Adults are not the only group where depressive disorders are found. In fact, depressive disorders among young adults are rising with $20 \%$ of major depression cases being diagnosed before the age of 25 years. The peak for major depression ranges from 15 to 19 years of age in females and 21 to 25 years of age in males (Feaster, 1996: National Depressive and Manic-Depressive Association [National DMDA], 1999, 2000).

The widespread effects of depression are important reasons to examine the prevention, occurrence, and treatment of depression. In fact, one area that is vital to explore in depression is suicidal ideation. Suicidal ideation has to be taken very seriously due to its potential lethality. Any type of psychiatric illness increases the risk of suicide with $90^{\circ} \%$ of individuals who commit suicide also having a psychiatric illness. Of this $90 \%, 80 \%$ of individuals who commit suicide have a depressive disorder (Clark \& Beck, 1999: Munoz \& Ying, 1993: Robbins, 1993: Williams. 1995). Again, adults are not the only group at risk for suicidal ideation. Depression in children and adolescents also increases the risk of suicide. In 1996, in the age range of 15-24, suicide was the third leading cause of death (NIMH, 1999). 
As one can see. much has indeed been written about the individual topics of selfconcept and depression in the literature. The main characteristics of depression which have been universally accepted are low mood. pessimism, and self-criticism. Self-criticism is connected to feelings of low self-concept. These topics have also been examined together--exploring the relationship between self-concept and depression. Self-concept and depression are interrelated and intertwined (Beck, 1972; Blatt \& Bers, 1993; Fitts, 1965).

Individuals self-concept is key to the experience of depression. and depression always involves a component of the self. Persons experiencing depression often set unrealistic standards for themselves and make harsh judgments about themselves. These unrealistic standards and harsh judgments often lead them to view themselves as inadequate and worthless which tears down their self-concept. Depressed individuals also tend to extend their negative view of themselves to include their surrounding world and their future which Beck calls the cognitive triad (Beck, 1967, 1973: Fitts \& Warren, 1996: Prochaska, DiClemente. \& Norcross, 1992).

Transitions in life are turning points that all individuals experience such as starting college or graduate school. One's self-concept tends to be in a period of re-examination, expansion, and solidification during these transition points. These times of transition can be times for growth in the way persons perceive themselves, their surrounding environment. and the way they interact with that environment. Choosing a career and academic success in preparing for that career are very important components of this time of transition, which is a developmental task for the late adolescent and the young adult (Alfeld-Liro \& Sigelman, 1998; Sprinthall, Bertin, \& Whiteley, 1986). 
The school environment is very important in the development of the self-concept. The social aspect of peer relationships in school can be a feedback source for the developing sense of self. Those students who develop a positive self-concept in academic areas have a better chance of succeeding in later life. A major developmental task of late adolescents and young adulthood is solidifying a self-identity. During this period. late adolescents and young adults are making major decisions in relation to self, family, career, relationships, marriage, and religion (Frydenberg, 1997; Lucas, 1997: Magen, 1998).

Undergraduate students tend to be experiencing separation from family, friends, and other means of support while trying to adapt to a new environment, values, and activities. They are at a stage of transition which lends itself to exploring new values, behaviors, and relationships. Often, undergraduate students are heavily influenced in their career choice by the expectations of their family (Felix, 2000; Lent, Brown. \& Hackett, 2000: Lucas, Skokowski, \& Ancis, 2000).

Graduate students tend to be more self-directed in their learning and study skills. Often. their attendance in graduate school comes out of their own level of motivation and their strong sense of self. Graduate students have often explored the existential questions surrounding the meaning and purpose in life and have the desire to continue to explore those questions. Thus, they may tend to have a higher level of self-concept and a lower level of depressive symptoms (Steer, Ball, Ranieri. \& Beck. 1999: Wong \& Whitaker. 1993).

Approximately $60-75 \%$ of high-school graduates enter a university setting during the first year following graduation. Half of these individuals obtain some type of degree 
within 5 years. and approximately $25 \%$ obtain a bachelor's degree or higher. It has been estimated that $30-60 \%$ of first-year college students leave school and as high as $50 \%$ during the total undergraduate years. Approximately $33 \%$ of individuals who do complete college will enter graduate school the following year (Arnett. 2000; Gladieux \& Swail, 2000). U.S. universities tend to annually award approximately 387,000 master's degrees and 41,000 doctoral degrees. It is estimated that up to $50 \%$, with as high as $65 \%$, of entering graduate students do not complete their Ph.D. degree (Gumport, 1999).

Students often leave college by their own decision. Approximately, $85 \%$ of student withdrawals are voluntary. Students may leave because they are not navigating the transition period very well and feel isolated. These feelings of isolation and loneliness can contribute to a decrease in self-concept and an increase in depressive symptoms.

Depression, especially mild depression, is common in college students. If they have a low self-concept or feelings of depression. then they may have trouble being in a new environment, concentrating on school, making personal and career choices, making new friends, and making commitments to lifetime goals. These areas of difficulty may have a long-term impact on individuals (Haines, Norris, \& Kashy, 1996; Kutcher, Marton, \& Boulos. 1993: Maier. Gansicke, \& Weiffenbach, 1997: Munoz, Hollon, McGrath. Rehm. \& VandenBos, 1994: Padula, Conoley, \& Garbin, 1998).

Depression is often reported to be the leading emotional or psychiatric disorder found on university campuses. Depression, even if the depressive symptoms are mild or moderate, tends to be associated with decreased learning and academic performance, increased attrition rates, increased drug and alcohol usage, increased suicide rate, impaired 
social skills, and impaired parenting skills. It is vital that the symptoms of mild depression be acknowledged and addressed before they become more persistent and develop into a likely pattern of major depression. Universities can take an important step in recognizing depressive symptoms and offering excellent care for their students in the university counseling center (Bertoia, 1992; Feaster, 1996: Felix. 2000: Strauss. 1998).

Student retention tends to be better for all involved--the student and the university. Obtaining a college degree tends to be the standard just like obtaining a high-school diploma was previously in the century. College attendance opens the door for individuals to have a chance at the best jobs and the best chances in life. There are numerous variables that play into the rate of attrition or retention such as grades, developing a positive sense of self. level of depression. increasing participation in decisions. making and maintaining supportive relationships, and an increasing sense of belonging within the university environment (Gladieux \& Swail, 2000: Melendez. 1997).

The key to student retention is what the university can offer to facilitate the growth and success of its students. Faculty and administrative personnel can take an interest in students and aid in decreasing the attrition rates. They can help to motivate and affirm the students. The university and it's counseling center might develop what Beeber (1999) calls "anticipatory intervention programs." These anticipatory intervention programs might include an evaluative screening process of the incoming students for levels of self-concept and symptoms of depression, workshops, and/or seminars on self-concept, depression, and other relevant topics. When students learn about different areas. they expand their sense of self, find their talents, and broaden their goals for the future. Also, psychologists in the 
university counseling center can help them explore their intrapersonal issues. interpersonal conflicts, time-management skills, social skills, stress management skills, career interests, study skills, and decision-making skills. Students can take some time to examine these issues and decrease their level of depression and increase their level of self-concept (Lewinsohn. Antonuccio. Steinmetz, \& Teri, 1984: Wilson, Mason, \& Ewing. 1997).

\section{Statement of the Problem}

Research is well represented on the topics of self-concept and depression. individually and together. After reviewing the current literature, few specific studies have been noted that explore the potential differences in undergraduate and graduate students in relation to their level of self-concept and level of depression. Starting college or graduate school is a time of transition and students have an opportunity for personal growth as they learn more about themselves and the world around them. But this opportunity for personal growth can be colored by their level of self-concept and depression. If students have low self-concept and/or symptoms of depression, then they may have trouble being in this new environment, making new friends, concentrating on school, making personal and career choices, and/or making commitments to lifetime goals (Berzonsky \& Kuk. 2000: Clark \& Beck, 1999: Felix, 2000: Grayson \& Meilman, 1999: National DMDA, 2000; National Institutes of Health [NIH], 2000a).

Depression. especially mild depression. is on the rise for young adults on todays university campuses and is often reported to be the leading emotional or psychiatric disorder. College students tend to experience clinical depression and dysthymia twice as 
often as working individuals of similar ages and background environments. Also. when depression occurs then there is also an increased risk of suicide. Suicide has increased dramatically in young adults over the last few years and it has been reponted to be the second leading cause of death on university campuses. In fact, some researchers have noted that suicide is approximately twice as high in students when compared with non-students of the same age (American Psychiatric Association, 2000; Chang, 2000: Chang \& Rand, 2000: DeAngelis, 2001: Dixon, 2000: Dixon \& Reid. 2000: Hayes, 2000: McIntosh, 2000; NIMH, 1999; NIH, 2000b).

Universities can take an important step in recognizing depressive symptoms and offering excellent care for their students in the university counseling center. A university might incorporate an evaluation of self-concept and depression into the screening process of incoming undergraduate and graduate students via the counseling center as a type of anticipatory intervention program. Identified students struggling with low self-concept and/or symptoms of depression might receive individual therapy, group therapy, and/or training through workshops to aid in increasing the level of self-concept and lowering symptoms of depression. Another form of an anticipatory intervention program, if a screening process is not utilized, might be for psychologists to provide workshops and seminars for students on a range of topics such as personal, social, and academic issues, self-concept, and depression. These types of anticipatory intervention programs could assist individuals in building a more positive sense of self so they can be more productive in school and in life (Beeber. 1999: Gladieux \& Swail. 2000: Hermon \& Hazler, 1999; O'Connor, 2001; Rundle, 2000). 
Psychologists can greatly influence and assist students in their personal and professional growth. One way psychologists can assist students is by helping them to instill hope and to build a variety of strengths. Seligman (1998) offers examples of instilling hopefulness and building strengths as "courage, interpersonal skill, rationality, insight, optimism. honesty, perseverance. realism, capacity for pleasure, putting troubles into perspective, future mindedness and finding purpose" (p. 2).

\section{Purpose of the Study}

The purpose of this study is to compare undergraduate and graduate students with respect to their level of self-concept and level of depression.

\section{Research Questions}

This research project examined the following questions:

1. Do undergraduate and graduate students differ in respect to the level of depression?

2. Do undergraduate and graduate students differ in respect to the level of self-concept?

3. Do students at different depression levels differ in the level of self-concept?

4. Is the relationship between self-concept and depression different for undergraduate and graduate students?

\section{Research Hypotheses to Be Examined}

The general hypotheses upon which this research study is based are as follows: 
1. There will be a significant difference between undergraduate and graduate students with regard to the level of depression.

2. There will be a significant difference between undergraduate and graduate students with regard to the level of self-concept.

3. There will be a significant difference among students at different depression levels with regard to the level of self-concept.

4. There will be a significant difference in the relationship between self-concept and depression for undergraduate and graduate students.

The null hypotheses for this study are presented in Chapter 3

\section{Theoretical Frameworks}

This research study draws from two main theorists in examining the topics of self-concept and depression: William Fitts and Aaron Beck. The following sections provide an overview of their theories of self-concept and depression.

\section{Self-Concept Theory}

\section{William Fitts}

Fitts (1965, 1970, 1972a, 1972b: Fitts et al.. 1971: Fitts \& Hamner, 1969: Fitts \& Warren. 1996) described the self-concept as a complex and a very personal and private belief individuals hold about themselves and cannot be described by a single score or label. He belıeved that the self-concept is an important component of human behavior and placed self-esteem as an important evaluative component of the self-concept. The selfconcept is the lens through which individuals look at themselves. relationships. and the 
world around them. The self-concept is also the lens through which individuals look at information about other persons such as their thoughts, feelings, relationships, and mental health. Fitts believed that the self-concept, in an emotionally healthy person, was positive and basically consistent and stable across the different dimensions. But, some variability of the self-concept might occur based on the value or importance that the individual places on that specific level of self-concept at that current time (other sources which discuss Fitts' theory can be found in the following: Bishop. Walling. \& Walker, 1997: Duprez, 1987. Fleming \& Courtney, 1984: Gaber, 1984; Lang \& Vernon, 1977; Roid \& Fitts, 1989; Shirley, 1990; Workman, Bloland, Grafton, \& Kester, 1986-87).

Fitts (1965, 1970, 1972a, 1972b; Fitts et al., 1971; Fitts \& Hamner, 1969; Fitts \& Warren. 1996: reported that individuals self-concept is vital to communication and interpersonal relationships. When persons feel good about themselves then they are more open to the thoughts and feelings of others and can be more open to accepting of the individual differences. A positive self-concept also assisis individuals in their quest for greater self-actualization. more fulfilling lives, and an overall better society. In fact. Fitts believed that the self-concept of individuals today was a good baseline for their future success in life (other sources which discuss Fitts theory can be found in the following: Hoffman \& Gellen, 1983; Keith \& Bracken, 1996: Marsh \& Richards, 1988; McGuire \& Tinsleỹ, 1981: Roffe, 1981: Workman et al.. 1986-87: Wụlie, 1974).

Fitts (1965, 1970, 1972a, 1972b; Fitts et al., 1971; Fitts \& Hamner, 1969; Fitts \& Warren, 1996: Roid \& Fins, 1989) described the self-concept as being comprised of two main components: the judging self and the behavioral self. He further delineated these two 
main components into two sections: internal frame of reference (judging self) and external frame of reference (behavioral self). In fact, he utilized this basic premise in the design of his self-concept scale, the Tennessee Self-Concept Scale (TSCS), in 1965. The internal frame of reference contained three levels (Identity, Self-Satisfaction, Behavior) and the external frame of reference contained five levels (Physical, Moral, Personal, Family, Social) (other sources which discuss Fitts theory can be found in the following: Archambault, 1992: Bolton, 1976; Boyle \& Larson. 1981: Burns. 1979: Buros, $1972:$ Byrne, 1996a: Levin, Karni, \& Frankel, 1978; Marsh \& Hattie, 1996; Mitchell, 1983; Murphy, Conoley, \& Impara, 1994: Pound, Hansen, \& Putnam. 1977: Robinson \& Shaver, 1973: Stein, 1996: Tzeng, Maxey, Fortier, \& Landis, 1985: Vacchiano \& Strauss, 1968). Even with subsequent revisions. the TSCS continues to be widely used and cited in the literature. For example, Reed, Fitts, and Boehm (1980) listed approximately 1,350 TSCS references just for the vears $1965-1980$.

\section{Depression Theory}

\section{Aaron Beck}

In his clinical endeavors, Beck (1967, 1991; Beck, Steer, \& Garbin, 1988) was unable to support the psychoanalytic theory s premise that depression was anger turned inward. So, he started trying to find other ways to explain the symptoms of depression in his clients. In 1961, Beck. Ward, Mendelson, Mock. and Erbaugh developed the Beck Depression Inventory (BDI) as a way to measure depression. In 1967, Beck originally published his cognitive theory of depression (other sources which discuss Beck's theory 
can be found in the following: Barkham et al., 1996: Baron \& Campbell. 1993: Berndt \& Burgy, 1996; Byrne \& Baron, 1993; Byrne, Baron, \& Balev, 1998; Flett, Vredenburg, \& Krames, 1995: Goldston. O־Hara, \& Schartz. 1990: Gorenstein, Pompeia, \& Andrade, 1995: Gotlib, 1984; Hammond \& Romney, 1995; Hatzenbuehler, Parpal, \& Matthews, 1983: Hill, Kemp-Wheeler, \& Jones, 1986: Joseph, Lewis, \& Olsen, 1996: Kendall. Hollon, Beck, Hammen, \& Ingram, 1987; Lips \& Ng, 1985; Miranda \& Munoz, 1994; Scheier. Carver, \& Bridges. 1994: Stehouwer, 1985: Wiseman \& Guttfreund. 1995). Beck's (1967, 1972, 1976; Beck, Rush, Shaw, \& Emery, 1979) cognitive theory of depression proposes that depression contains three elements which are necessary for its beginning and maintenance: the cognitive triad, silent assumptions, and logical errors. The cognitive triad maintains that depressed individuals hold a negative outlook about themselves, their world, and their future. Depression is not mainly a problem with mood but a result of the negative way one views the elements of the cognitive triad. This negative outlook contributes to, upholds, and/or intensifies the symptoms of depression based often on the representation of loss. In fact, depressed people tend to have a systematic, negative way of thinking which colors the way they view themselves, the world. and their future (other sources which discuss Beck's theory can be found in the following: Alford \& Beck, 1997; Brown, Bifulco, \& Andrews, 1990a: Curtis, 1990; France \& Robson, 1997: Hammen, 1978: Jarrett \& Rush, 1996: Klermon. 1987: Kuiper. MacDonald, \& Derry. 1983; Lewinsohn \& Rohde, 1987; Maddux \& Meier, 1995; Mendels, 1970: Rehm, 1995; Robinson, Berman. \& Neimever, 1990: Williams, 1984). The first element of Beck's cognitive theory of depression (Beck, Freeman, \& 
Associates. 1990: Beck et al. 1979) is the cognitive triad. The first component of this cognitive triad is a negative view of self. This element of Beck's model was influenced by the psychoanalytic idea of the loss of self-esteem. Persons who are experiencing depression tend to view themselves as inferior, inadequate, unqualified, unworthy, incomplete, and or impaired in emotional. moral. or physical character. These individuals believe that they have physical, mental, or moral deficits which account for the unpleasant experiences. They tend to criticize themselves frequently. Their attributions toward their perceived inadequacies lend them to judge themselves to be personally unworthy. Because of this perceived personal unworthiness, they believe that they lack the ability to attain happiness and fulfillment and expect failure and rejection. Their negative view of themselves lends itself to establishing a foundation for negative views of the world and the future (other sources which discuss Beck's theory can be found in the following: Bemporad. 1995: Burns \& Beck, 1978: Chang \& Rand, 2000: Clark \& Beck. 1999; Duprez, 1987: Kernis ct al., 1998: Lightsey \& Christopher, 1997: Roba, 1988; Rush, 1987: Rush \& Giles, 1982).

The second component of the cognitive triad (Beck et al., 1990: Beck et al., 1979) is a negative view of the world. In light of their perceived inadequacies, they then interpret interactions with others and the environment as evidence for disappointment and loss. These individuals tend to see the world as blocking their ability to reach life goals. They tend to misinterpret these interactions in a consistently negative way. This evidence then supports the ideas of criticism. distress, and increased dependency on others and the environment. They may tend, when comparing themselves to others, to minimize positive 
experiences and emphasize failures (other sources which discuss Beck's theory can be found in the following: Carver, 1998; Clark, Beck, \& Stewar, 1990: Duprez, 1987; Rush, 1987: Rush \& Giles, 1982: Young. Beck. \& Weinberger, 1993)

The final component of the cognitive triad (Beck et al., 1979) is the negative view of the future. Depressed persons view the future as worthless and empty. They also view the future as one in which their current problems will always continue and they expect failure. They may then succumb to being more dependent on others due to perceived personal inadequacy. Depressed persons believe the future holds failure and/or other negative outcomes (other sources which discuss Beck"s theory can be found in the following: Duprez, 1987: Lightsey \& Christopher, 1997: Roba, 1988; Rush, 1987; Rush \& Giles, 1982).

The second element of Beck's cognitive theory of depression (Beck et al., 1979) is silent assumptions. Silent assumptions or "schemas" are unspoken ideas, beliefs. or rules that individuals hold which influence their thoughts, feelings, and behaviors. Schemas tend to be stable cognitive patterns because they comprise the baseline from which one screens and assimilates information about self, others, and the environment. Initially, children learn to evaluate themselves and the world through interaction with significant others and or the environment which builds reality or cognitive patterns. Adults then base their feelings and behaviors on these unspoken ideas. These schemas then lend themselves to automatic thoughts. Depression and relapse episodes often result from the arousal of these schemas. Therefore, schemas help to maintain one s level of depression (other sources which discuss Beck's theory can be found in the following: Bacon, 1993; Barnett \& Gotlib, 
1988: Brown. Bifulco. \& Andrews. 1990b: Brown \& Harris, 1978: Chamberlin. 2000; Hollon \& Carter, 1994: Hollon, DeRubeis, \& Seligman, 1992: Hollon, Shelton, \& Davis, 1993: Joseph. 1987: Kovacs \& Beck, 1978: Kuehlwein. 1993: Rehm. 1990: Schmidt. Joiner, Young, \& Telch, 1995; Swallow \& Segal, 1995).

In everyday life, persons are guided by the templates of the cultural. religious. family, gender, and age-related schemas which are developed from the experiences gathered throughout the years. Schemas are involved in the process of memory, thoughts. feelings, motivation, and behavior (Beck et al., 1979; Bemporad, 1995; Bricker, Young, \& Flanagan, 1993: Duprez, 1987: Freeman, 1993: Muran \& Safran, 1993: Roberts \& Monroe. 1994). As individuals face a specific situation, schemas are activated which are related to that situation. The activated schemas then act as a guide to the incoming information to which they evaluate the data or experience. Persons prone to depression, once schemas have been triggered by some stress. begin to view themselves, the world, and their future in a manner that is unrealistic and demeaning. Once the negative self-schemas are utilized to process information, the individuals overestimate the negative aspects of themselves and the situation (Alden, Bieling, \& Meleshko, 1995; Beck et al.. 1990: Beck et al., 1979; Craig \& Dobson. 1995: Eaves \& Rush, 1984: France \& Robson. 1997: Hirschfeld \& Cross, 1987: Rizley, 1978; Williams, 1984: Young et al., 1993).

The third element of Beck's cognitive theory of depression (Beck. 1991: Beck et al., 1990; Beck et al., 1979) is logical errors. Logical errors or structural errors in thinking are created by the negative automatic thoughts which the depressed persons hold about themselves, the world, and the future. These logical errors lead to the misinterpretation of 
events and reinforcement of the cognitive triad. Depressed individuals use these logical errors to maintain their belief that the negative concepts are valid in spite of conflicting evidence. Logical errors include: arbitrary inference, selective attention. overgeneralization, magnification or minimization, personalization, and dichotomous thinking (other sources which discuss Beck's theory can be found in the following: Carver, 1998; Craighead, Craighead, Kazdin, \& Mahoney, 1994; France \& Robson, 1997; Head, 1978; Jarrett \& Rush, 1996: Joseph, 1987: Kovacs \& Beck. 1978: Williams, 1995). Arbitrary inference refers to persons making a conclusion without evidence to support that conclusion. Selective abstraction or attention consists of individuals focusing on a detail, which is out of context, while disregarding other noticeable aspects of the situation. Then they conceptualize the entire experience based on that one detail. Overgeneralization is the tendency to draw a conclusion based on one or more single events and then applying that conclusion to all related and unrelated situations. Magnification and minimization are ways in which persons give extraordinary emphasis to a given part of an event and draw a mistaken conclusion from that event. Personalization is the individual"s tendency to connect external events to themselves without grounds for making any such association. Dichotomous thinking is the tendency to think in a concrete way such as, for example, black and white without any gray areas or all or nothing. The persons then place all events in one of the two opposite categories. Depressed individuals tend to choose the most negative category to describe themselves (Beck et al., 1979; France \& Robson, 1997; Joseph, 1987; Kovacs \& Beck, 1978; Rehm, 1990: Rush, 1987: Williams, 1984; Zimbardo \& Leippe, 1991). 
From the review of the above-mentioned theoretical frameworks of self-concept and depression, it can be summarized that these two subjects are vital to the better understanding of individuals and how they view themselves and relate to others. In the present study, undergraduate and graduate students are considered in regard to the potential differences in their level of self-concept and depression and how those differences can affect their current and future life choices.

\section{Significance of the Study}

Students enter a university setting from a fast-paced society that tends to demand a strong sense of self and a feeling of competency. Throughout the different stages in life. individuals examine the question "Who am I?" Changes in their lives, such as moving

away from home. starting college or graduate school. exploring new values, and or making new friends can trigger a period of re-examination of the self. Individuals view the entire world through their filter of self which influences all of their thoughts, feelings, and behaviors. This filter of self is a person's self-concept and contains the beliefs about your personal worth. characteristics, and roles. Individuals with a high level of self-concept tend to think well of themselves and others, value relationships with others, more easily accept differences in others. obtain a higher level of performance in the academic setting. and have lower leveis of hopelessness and depression (Chang, 2000: Dunning, 1993: Felix, 2000; Fitts \& Warren. 1996: Hattie \& Marsh. 1996: Magen, 1998: Rosenberg, 1985). As mentioned above, persons with higher levels of positive self-concept tend to have lower levels of hopelessness and depression. This is an important point because the 
literature shows that self-concept and depression are interrelated and intertwined. During times of depression, most individuals begin to set unrealistic standards, make self-belittling remarks, or make harsh judgments about themselves. Often these events lead them to see themselves as basically worthless, hopeless, and inadequate. One's level of self-concept and depression influences areas such as relationships. academic achievement. choosing to obtain a graduate level of education, choosing a career, and/or making commitments to lifetime goals (Beck. 1967, 1972, 1973, 1976: Clark \& Beck, 1999: NIH. 2000a, 2000b; NIMH, 2000; Roid \& Fitts, 1989).

Depression is a topic that is discussed many times without connecting it necessarily to self-concept. In fact, depression is called "the common cold of mental health." Depression often starts with mild symptoms in late adolescence/young adulthood and, with time, may slowly increase $i$ in the level of severity. Thus, persons with mild depressive symptoms tend to be at a higher risk for developing more severe depression. Even if individuals are experiencing mild depressive symptoms which do not meet specitic diagnostic criteria for a mood disorder, their ability to function may be hindered in areas such as relationships with others, physical health, academic/work performance, making personal and career choices, and feelings of self-worth. If left untreated, these mild symptoms may persistently recur and may eventually build a lifelong pattern of depressive symptoms and or pattern of major depression. Therefore, it is vital that the symptoms of mild depression be acknowledged and addressed before they become more persistent (American Psychiatric Association, 2000: Beck. 1967. 1972, 1973. 1976: Clark \& Beck, 1999; Feaster, 1996; Felix, 2000; Fitts, 1965; Hattie, 1992; Johnson, 2001; National 
DMDA. 1999, 2000: NIH. 2000a, 2000b; NIMH, 1995, 1997. 1999, 2000).

\section{Definitions of Terms}

The following section defines terminology as it is used in the present study:

Self-concept: How one views oneself as an overall person as measured by the Tennessee Self-Concept Scale: Second Edition (TSCS:2); basically what one thinks about oneself.

Self-Esteem: One component of self-concept; the evaluative part of the selfconcept: basically what one feels about oneself.

Depression (iroups: Scores of the students which fall within one of the four groups or diagnostic ranges of the Beck Depression Inventory-II (BDI-II) as presented by Beck. Steer, and Brown (1996): (1) 0-13 Minimal; (2) 14-19 Mild Range; (3) 20-28 Moderate Range: (4) 29-63 Severe Range.

Depression: Using the four BDI-ll groups, a cut score of 13 is used to designate nondepressed and depressed students. So, MinimaliNondepressed Range $(0-13)$ represents nondepressed (ND); Mild Range (14-19) represents mild symptoms of depression; Moderate Range (20-28) represents moderate symptoms of depression; and Severe Range (29-63) represents severe symptoms of depression.

lindergraduate students: Students who are currently enrolled in undergraduate classes in a university setting: ages 18-24.

(iraduate students: Students who have completed a 4-year college degree and are currently enrolled in a graduate degree program: ages 25 and over. 


\section{Delimitations of the Study}

This study employed a convenience sample of undergraduate and graduate students from Andrews University (AU) and Western Michigan University (WMU). The students were not randomly assigned but were asked to volunteer to participate in the study while enrolled in specific courses. Therefore, the results of this study are generalizable only to undergraduate and graduate students in Midwestern university settings.

\section{Organization of the Study}

Five chapters are contained in this study.

Chapter 1 presents an introduction to the research project, background, statement of the problem, purpose of the study, research questions, research hypotheses to be examined, theoretical frameworks, self-concept theory, depression theory, significance of the study, definition of terms, and delimitations of the study.

Chapter 2 contains a survey of the literature that focuses on theories of selfconcept, self-concept, theories of depression, depression, self-concept and depression, and undergraduate and graduate students.

Chapter 3 describes the methodology, which includes the introduction, population and sample. variables, instrumentation. data collection, and null hypotheses, methods of analysis, and power analysis.

Chapter 4 presents the data and analysis.

Chapter 5 provides an introduction, summary, discussion of the results, conclusions, recommendations for research, and implications for practice. 
CHAPTER II

\section{REVIEW OF THE LITERATURE}

\section{Introduction}

This chapter covers a comprehensive review of the literature relevant to this research study: theories of self-concept, self-concept, theories of depression, depression, self-concept and depression, and undergraduate and graduate students.

\section{Theories of Self-Concept}

The following section provides an overview of the most prevalent theories of self-concept.

\section{James}

Early in the process of psychology becoming a scientific discipline, William James initially brought the focus on the self to the forefront of psychology (Backman, Secord, \& Pierce, 1982: Dyk \& Adams, 1987; Hansen \& Maynard, 1973; Morton, 1984; Rosenberg, 1989: Wells \& Marwell, 1976). James s book in 1890, The Princuples of Psychologr: explored the role of the self. This interest in the self continues to be of interest today (Anderson. 1992: Burns, 1979). James began his writings on the self with a broad definition: "In its widest possible sense, however, a man's Self is the sum total of all that 
he CAN call his" (James, 1890, p. 291). James also widened his definition of the self to include the I-Me dichotomy which is divided into two aspects: the "known" and the "knower" (Hart \& Damon. 1985: Wells \& Marwell, 1976).

James described the self as the known and the knower. The self as known is the components of the self and the self as knower is involved with the development and alteration of the self-concept and how the self-concept influences one's perception (Morrel, 1983: van der Werff, 1990; Wells, 1992). James called the "I" the knower or "pure ego" and the "Me" the known or empirical self. The known or empirical self is all that one calls his/her own. James divided the empirical self into the spiritual self, the material self, and the social self (Bednar et al., 1989; Coopersmith, 1990: Epstein, 1980; Fitts et al.. 1971: Frev \& Carlock. 1989: Hansen \& Maynard. 1973: Harter. 1996: Hattie. 1992; Hormuth, 1990; James, 1890, 1985; Levin, 1992; Samuels, 1977; Sarbin, 1952; Strauman \& Higgins, 1993: Walsh \& Banaju, 1997; Wylie, 1974).

One's spiritual self is the source of will and choice, curiosity, activity, and interest. James viewed the spiritual self as the core self because he felt it was the most constant and innermost part of the self. The material self is one's body, family, property, and possessions such as clothes. The social self is connected to social interaction and the need to have recognition from others. James believed that we have many social selves and the social self or me develops from the acceptance that we receive from others (Bednar et al.. 1989; Coopersmith, 1990: Frey \& Carlock, 1989; Harter, 1996; Hattie, 1992: Hormuth, 1990: James, 1890, 1985; Levin, 1992: Natsoulas, 1998: Strauman \& Higgins, 1993 : Walsh \& Banaju, 1997). 


\section{Rogers}

Rogers (1942, 1951) believed that individuals strive to enhance and actualize themselves and called it the "self-theory." Persons have a need for positive regard for themselves and from others. Relationships based on unconditional positive regard are based on mutual empathic understanding (other sources which discuss Roger`s theory can be found in the following: Epstein, 1973; Fernald, 2000; Fitts et al., 1971; Frey \& Carlock, 1989: Hansen \& Maynard, 1973: Hattie, 1992; Rice, Ashby, \& Slaney, 1998: Samuels, 1977: Watkins, 1981). Rogers (1951) stated that the self-concept or self-structure is an organized configuration of perceptions of the self which are admissible to awareness. It is composed of such elements as the perceptions of one's characteristics and abilities: the percepts and concepts of the self in relation to others and to the environment, the value qualities which are perceived as associated with experiences and objects; and goals and ideals which are perceived as having positive or negative valence. It is, then, the organized picture . . of the self. (p. 501 )

Rogers (1942, 1951) thought that bringing one's self-concept closer in line with one's true desires was part of effective client-centered therapy. He thought this was so important because one's self-concept guides the actions, provides a sense of self, and gives a sense of continuity. Individuals are striving to become and remain authentic (other sources which discuss Roger's theory can be found in the following: Allen, 1990; Bednar et al., 1989; Coopersmith, 1990: Fitts, 1972a: Gergen, 1982: Hamachek, 1971: Hansen \& Maynard, 1973: McCrae \& Costa, 1982; Morton, 1984; Rosenberg, 1989; Wells \& Marwell. 1976: Wỵlie, 1961, 1974). 


\section{Maslow}

Maslow (1954, 1959) believed the highest need human beings strive for is "self-actualization." He portraved the needs in a hierarchy as follows: physical needs. safety needs, belongingness and love needs, esteem needs, and self-actualization needs. Due to the hierarchical structure of these needs, the higher needs such as esteem and self-actualization can be fulfilled only when the lower needs have been acknowledged and satisfied (other sources which discuss Maslow's theory can be found in the following: Allen, 1990; Bee, 1987; Burns, 1979; Fitts, 1970, 1972b; Fitts et al., 1971; Frey \& Carlock. 1989: Hamachek, 1971; Magen, 1998; Myers, Sweenev, \& Witmer, 2000: Papalia \& Olds, 1992; Samuels, 1977; Schultz \& Schultz, 1994; Stevens-Long, 1990; Stevens-Long \& Commons. 1992: Treadgold, 1999: Wylie, 1974).

\section{Erikson}

One of the most well-known theories for describing the stages for growth of the self-concept is by Erikson. Erikson s model $(1959,1968)$ explored the question of "Who am I?" in his universal eight stages of life: (1) trust versus mistrust (infancy, Birth-1 year); (2) autonomy versus shame and doubt (early childhood, 1-3 years): (3) initiative versus guilt (prepuberty, 3-5 years); (4) industry versus inferiority (puberty, 6-11 years): (5) identity versus role confusion/diffusion (adolescence, 12-18 years): (6) intimacy versus isolation (early adulthood, 18-35 years): (7) generativity versus stagnation (middle adulthood, 35-55 years); and (8) ego integrity versus despair (old age, 55 years and older) (other sources which discuss Erikson's theory can be found in the following: Anderson \& 
Haves, 1996: Bee, 1987; Chickering \& Havighurst, 1981: Eisenstadt, 1965: Hattie, 1992: Juhasz, 1992; Kaplan \& Sadock, 1998; Klar, 1992; Kohlberg \& Armon, 1984; Levin, 1992; Lieberman, 1992: Merriam \& Clark, 1991: Perkins. 1994: Samuels, 1977: Stevens-Long \& Commons, 1992: Treadgold, 1999; van der Werff, 1985).

The universal stages of development are "normal crisis points" and are expected to occur for all individuals. Although each stage is correlated with a certain age period, Erikson $(1959,1963,1965)$ also states that these age periods have a certain degree of flexibility. For example, the search for identity is a lifelong process and an important stage because it can affect the rest of one's decisions in life. Identity comes into focus during adolescence, which Erikson viewed as lasting until the mid-20s, as it did in his life until the age of 25 (other sources which discuss Erikson's theory can be found in the following: Archer, 1982; Arnett, 2000; Bimie-Lefcovitch, 1996: Burns, 1979; Calhoun, Glaser, \& Bartolomucci, 2001: Cote \& Levine, 1988: Dusek \& Flaherty, 1981; Erikson, 1959, 1968 : Frydenberg, 1997: Gravson \& Meilman, 1999; Jackson \& Bosma, 1990; Kroger, 1989; Kroger \& Haslett, 1991; Levy-Warren. 1996; Lucas, 1997: Magen, 1998: Marcia, 1987. Rangell, 1990; Regeth, 1997; Rosenberg, 1985, 1986; Schultz \& Schultz, 1994; Settlage, 1990: Tesser \& Campbell. 1983: van der Werff, 1990: Weigart, 1983).

Erikson $(1959,1965)$ strongly believed that one's sense of identity is ever-changing throughout all stages of life. Thus, persons need to successfully master each specific task in every stage before the next stage ideally can be successfully mastered. These crisis points have the potential of allowing persons to evaluate themselves and transform their self-concept (other sources which discuss Erikson`s theory can be found in the following: 
Allen. 1990: Anderson \& Hayes, 1996: Amstein. 1984b: Bee, 1987: Crider et al.. 1989:

Eisenstadt. 1965; Erikson. 1959, 1965; Evans, 1981; Geller, 1989: Gergen, 1982; Hattie, 1992: Kaplan \& Sadock. 1998: Klar, 1992: Levin. 1992: Lieberman. 1992: Noam, Kohnlert, \& Snarey, 1983: Papalia \& Olds, 1992; Samuels, 1977: Smith, Dixon, \& Baltes, 1989: Watkins. 1981).

Early self-concept instruments were characterized as unidimensional with an emphasis on global self-concept such as the Rosenberg Self-Esteem Scale (Revnolds. Ramirez, Magrina, \& Allen, 1980: Rosenberg, 1985, 1986; Rosenberg \& Pearlin, 1982; Savin-Williams \& Jaquish. 1981: Shevlin. Bunting. \& Lewis, 1995: Strein, 1993). Today, most researchers accept that self-concept is multidimensional. Since the mid-1970s, most self-concept instruments examine several facets of the self-concept in additional to a global component (Bishop et al., 1997; Bosson \& Swann, 1999; Byrne, 1996a: Gray-Little \& Williams, 1997: Hoge, 1999: Klar. 1992: Marsh \& Hattie, 1996: Marx \& Winne, 1980: Prout \& Prout, 1996).

Shavelson, Hubner, and Stanton (1976) developed a hierarchical and multifaceted model of self-concept. Their model contains domain-specific self-esteem elements, for example. social. physical. emotional. and academic self-concepts (other sources which discuss Shavelson et al.'s model can be found in the following: Bracken \& Mills, 1994; Byme, 1984: Fleming \& Courtney, 1984: Hattie, 1992: Hoge. 1999: Marsh, 1989, 1993: Marsh, Barnes, \& Hocevar, 1985; Marsh, Bưme, \& Shavelson, 1988; Marsh \& Hattie, 1996: Marsh, Hey, Roche. \& Perry. 1997: Marsh \& Smith, 1982: Marx \& Winne. 1978: Roid \& Fitts, 1989; Shavelson \& Bolus, 1982; Strein, 1993; Wylie, 1989). 


\section{Self-Concept}

The human race has always been interested in interpreting and understanding themselves. The concept of the self or individuality is an essential interest to philosophers, scholars, politicians, educators, and psychologists. Two famous philosophers, Socrates and Shakespeare, wrote about the importance of the self. Socrates emphasized the importance of knowing yourself as demonstrated by his famous words "Know thyself" and "An unexamined life is not worth living" (as cited in Hergenhahn, 1992, p. 37). Shakespeare also emphasized the importance of knowing yourself in the play Hamlet: "This above all: To thine own self be true." Lev 19:18 (KJV) also touches on the premise of the importance of the self-concept: "Thou shalt love thy neighbour as thyself." as well as Prov 23:7 (KJV) "For as he thinketh in his heart, so is he ...."

Curiosity about the self and the human need is to be connected to self and others are considered basic human needs (Anderson et al., 1997: Bishop et al., 1997; Branden, 1994: Fitts, 1965, 1972a, 1972b; Fitts \& Warren, 1996; Gray-Little \& Williams, 1997; Hattie, 1992: Snodgrass \& Thompson, 1997; Snyder \& Campbell, 1982: Thompson, 1997). In fact, one's self-concept is an essential and practical feature of human existence. The thirst for knowledge about ourselves. the longing for a purposeful identity, the search for answers to questions such as "Who am I?" and "How can I find me?" are components of the self. Self-help books are very numerous on the topic of the self and address, for example, topics such as finding ourselves, liking ourselves, and interacting with others. We want to be unique as persons as our individual sense of self distinguishes ourselves from others and gives meaning to how we view our experiences and how we live our lives 
(Bishop et al.. 1997: Brown, 1993b: Crider et al., 1989: Demo, 1985: Fitts, 1965, 1970. 1972a, 1972b; Fitts et al., 1971; Fitts \& Hamner, 1969: Fitts \& Warren, 1996; Gray-Little \& Williams, 1997: Hamachek, 1971: Hudson, 1991: Magen, 1998: Marsh \& Richards. 1988; Polster, 1995; Rachlin, 1997; Roid \& Fitts, 1989; Rosenberg, 1989; Shirley, 1990; Snyder \& Campbell, 1982: Wỵlie. 1989).

The self is the content of conversation, debate, and investigation in daily life. Although, the self is an essential interest to many people, it is not easily defined (Bandura, 1982; Gergen. 1982; Suls \& Mullen, 1982). James (1890) began the emphasis on the self in psychology with his book. The Principles of Psychology. He described the self as the "known" and the "knower." The self as known is the different parts of the self and the self as knower deals with the development and changing of the self-concept and how perceptions are influenced by self-concept. Kinch (1963) stated, "The self-concept is that organizatson of qualites that the individual attributes to himself (p. 481).

Rosenberg (1979) defined self-concept as "the totality of the individual's thoughts and feelings having reference to himself as object" (p. 7). Branden (1994) defined selfconcept this way: "Our self-concept is who and what we consciously and subconsciously think we are-our physical and psychological traits. our assets and liabilities. possibilities and limitations, strengths and weaknesses“ (p. 15). Coopersmith (1990) defined selfesteem, an evaluative component of the self-concept, as

the evaluation that the individual makes and customarily maintains with regard to himself: it expresses an attitude of approval or disapproval, and indicates the extent to which the individual believes himself to be capable, significant, successful, and worthy. In shor, s-e is a personal judgment of worthiness that is expressed in the attitudes the individual holds toward himself. (pp. 4-5) 
In today's literature, often the terms self, self-concept, and self-esteem are used interchangeably within the literature. Terms often used for self-concept include selfidentity, sense of self, self, self-perception, self-awareness, self-worth, and self-image. Terms often used for self-esteem include self-iespect, self-acceptance, self-regard, and self-evaluation (Burns, 1979; Bvrne, 1996b: Frey \& Carlock. 1989: Hattie, 1992:

Rosenberg, 1979, 1989; Wells \& Marwell, 1976). For this research, I do not use these two words interchangeably. The self-concept is all-encompassing and includes the self-esteem (Branden, 1994: Byrne, 1996a; Elliott, 1986; Fitts, 1965; Fitts et al., 1971; Fitts \& Warren, 1996: Fleming \& Courtney, 1984: Frydenberg, 1997: Hoge, 1999: Kagan, 1998: Maddux \& Meier, 1995; Novick, Cauce, \& Grove, 1996; Roid \& Fitts, 1989; Rosenberg, 1985; Shirley. 1990: Snodgrass \& Thompson, 1997, van der Werff, 1990).

Self-esteem is the evaluative component of self-concept and is how one evaluates self and behaviors. In fact, self-esteem is used by individuals to judge or evaluate the behavioral, psychological, and cognitive components of their self-concept (Abel, 1996; Allen, 1990: Bachman, O Malley, \& Johnston, 1978; Campbell, Chew, \& Scratchley. 1991: Christensen, 1981; Fitts, 1965, 1970; Fitts et al., 1971; Fitts \& Hamner, 1969; Fitts \& Warren, 1996; Frey \& Carlock. 1989: Greenwald, Bellezza, \& Banaji, 1988; Hoge, 1999: Maddux \& Meier, 1995: McGuire \& McGuire, 1982; Roid \& Fitts, 1989; Scheier et al., 1994: Sieber, 1996: Staub, 1980a: Wells, 1992). Hattie (1992) thought that high self-esteem occurs when "we consider aspects of our life as important and ... we have the confidence to fulfill our expectations“( themselves, feel competent, successful, loved, and worthy, and have a sense of belonging. 
Self-esteem is one of the most-often-used measured constructs in psychology research when looking at the self-concept (Fitts, 1965: Fitts \& Warren, 1996; Grav-Little \& Williams, 1997: Rosenberg, 1985: Samueis, 1977: Shirley, 1990: Wells \& Marwell, 1976: Wylie, 1974).

A persons self-concept is the essence of what they feel, think, and how they see themselves. This sense of self is mainly a subjective perception but it is an essential part of the individual. In fact, many of the opinions about yourself cannot be directly observed but they comprise your self-concept. Self-concept contains the beliefs about your personal worth, characteristics, and roles (Bednar et al., 1989; Blatt \& Bers, 1993; Byrne, 1984; Epstein \& Koerner. 1986; Fiske \& Chiriboga. 1990; Fitts, 1972a, 1972b; Glick \& Zigler, 1985; Harwood, 1998: Kinch, 1963; Neisser, 1997: Polster, 1995; Roid \& Fitts, 1989).

Self-concept includes how individuals think about their physical and emotional components, their potential, their limitations, and their strengths and inadequacies. Selfconcept is what qualities or characteristics persons believe themselves to have in other areas such as relationships. spirituality, and professional aspirations. The self is the total of these qualities or characteristics of which I can share with others or how I describe myself to others. Self-concept also includes ethnicity, gender, physical characteristics, and the perception of how we are perceived by others (Arnstein, 1979: Basch, 1983: Cooper, 1993: Fennell, 1992; Hansen \& Maynard, 1973; Levin, 1992; Levy-Warren, 1996; McGuire \& McGuire, 1982: Moore \& Britt, 1997; Perkins, 1994: Regeth, 1997: Rosenberg \& Pearlin, 1982: Spitzer, Couch, \& Stratton, 1971; van der Werff, 1990).

Persons run into new situations or experiences that are related to their existing view 
of their inner self which adds to the stability of the self-concept. Sometimes new situations or experiences are inconsistent with the existing view of thcir inner self and are likely to be rejected. The level of satisfaction with one's self-concept is important because it influences the degree to which new situations or experiences are incorporated or rejected. If individuals are highly satisfied with their self-concept. then they will tend to make active attempts to maintain the structure of their self-concept. If individuals are not highly satisfied with their self-concept, then they will tend to be more willing to consider elements of change in the structure of their self-concept, especially in a new or different environment (Bosson \& Swann, 1999; Demo \& Savin-Williams, 1992; Fitts, 1972b: Hormuth, 1990; Kaplan \& Sadock, 1998; Markus \& Kunda, 1986; Moore \& Britt, 1997; Swann, 1983: Swann \& Read, 1981).

Issues such as achievement in school, contentment with self, relationships with others, success in life. and happiness are related to the facets of how persons view themselves (Abel, 1996; Arnstein, 1979; Bednar et al., 1989: Bracken \& Mills, 1994; Branden, 1994: Fitts. 1972b: Fennell, 1992; Hansen \& Mavnard, 1973: Hoge, 1999; Lazarus, 1991; Levy-Warren, 1996; Maslach, 1982; Roid \& Fitts, 1989; Shavelson \& Bolus, 1982: Whybrow. 1996; Workman et al., 1986-87). Individuals with positive selfconcept value and accept themselves and have a sense of security. Persons with high selfconcept tend to be more adaptable to changes in their daily life, have more insight, obtain a higher level of performance in the academic setting, can more easily accept differences in others, and have better functioning in society as a whole. They feel that they are more in control of their own lives and take hold of new opportunities in their lives. Persons with 
negative self-concept tend to have low self-esteem. Persons with low self-concept tend to feel they are less in control of their own lives, less easily adapt to changes in daily life, and find it more difficult to tolerate the differences in others. They tend to take longer to take hold of new opportunities in their lives (Abel, 1996; Branden, 1994; Fitts, 1972a, 1972b; Frey \& Carlock. 1989: Hamachek. 1971: Hattie, 1992: Hormuth, 1990: Maslach, 1982: Morton, 1984; Myers et al., 2000; Rosenberg, 1985; Salmela-Aro \& Nurmi, 1997).

Self-concept is an overall summary of one's strengths, competencies, accomplishments, and deficiencies. Often, the overall summary includes the reactions and opinions of others called "reflected appraisals." The self-concept influences the establishing of short-term and long-term life goals (Allen, 1990; Arnstein, 1979; Christensen, 1981: Felson, 1993; Fitts, 1965; Fitts \& Warren, 1996; Frydenberg, 1997 . Gecas \& Mortimer, 1987; Harter, 1996; Marsh et al., 1985; Resnick, Fauble, \& Osipow, 1970; Salmela-Aro \& Nurmi, 1997; Schafer \& Keith, 1985: Shavelson \& Bolus, 1982; Suls \& Mullen, 1982; van der Werff, 1985). In fact, how you view yourself and evaluate yourself influences how you interact with others and what goals you pursue. The selfconcept is a basis for behavior which is influenced by one's perception of himself/herself in relation to others and life experiences (Arnstein, 1980: Bishop et al.. 1997: Craighead et al., 1994: Fitts, 1965, 1970, 1972a, 1972b; Fitts et al., 1971; Fitts \& Hamner, 1969; Fitts \& Warren, 1996: Futral, 1980: Kaplan \& Saccuzzo, 1993; Maddux \& Meier, 1995: Maslach, 1982; Roid \& Fitts, 1989; Swann, 1983; Wells, 1992).

Self-concept is a cognitive appraisal about one's attributes. It is a set of beliefs and the connection between these beliefs that we hold about ourselves. The self organizes past 
and present experiences and directs activity. The self is a resilient structure and a process - stable yet capable of growth (Bruner, 1997; Ferrari, 1998; Fitts, 1965, 1972a, 1972b: Fint et al., 1971: Fitts \& Warren. 1996: Frydenberg, 1997: Hattie, 1992: Hirst, Manier, \& Apetroaia, 1997; Hormuth, 1990; Kihlstrom \& Klein, 1997; Markus \& Kunda, 1986: Nemiroff \& Colarusso, 1990: Rachlin. 1997: Roid \& Fitts. 1989: Siebert, 1996: Silvernail, 1985). Stability is part of one's self-concept, but change is also a part. A person examines the question "Who am I?" at different times throughout his/her life. Changes in life, such as moving away from home, entering different stages of life, and losing a relationship, can color one`s answer to such a question (Basch, 1983: Blustein \& Palladino, 1991; Cheek \& Hogan, 1983; Demo \& Savin-Williams, 1992; Fitts, 1965, 1970; Fitts \& Warren. 1996: Frey \& Carlock. 1989: Hormuth, 1990; Jackson \& Bosma. 1990. Levin, 1992; Levy-Warren, 1996; Mortimer \& Lorence, 1981).

Self-concept is multi-faceted (Fitts, 1965, 1970, 1972a, 1972b: Fitts et al., 1971: Fitts \& Hamner, 1969; Fitts \& Warren, 1996; Harter, 1996; Hattie, 1992; Keith \& Bracken, 1996: Klar. 1992: Marsh \& Smith, 1982; Rachlin, 1997: Roid \& Fitts. 1989: Silvernail. 1985; Thompson, 1997). The effects of self-concept on self-esteem depend on whether one regards certain facets of one's self-concept to be important at that given time. One needs to value that facet of self-concept in order for it to affect the feelings of self-esteem. If individuals have high self-esteem, then they consider certain facets of their life as important and believe that they can fulfill others' expectations. One does not think of all facets of self-concept at once in all situations. For example. if I am exploring my physical capabilities as in swimming then I am not placing a high emphasis on academic/work or 
moral self-concept at that time (Coopersmith, 1989: Dukes \& Martinez, 1994: Fitts, 1965: Fitts \& Warren, 1996; Frey \& Carlock, 1989; Hamachek, 1971; Harter, 1985; Hattie, 1992; Marsh, 1993: Marsh. Smith, Barnes, \& Butler, 1983: Marx \& Winne, 1980: Revnolds et al., 1980; Roid \& Fitts, 1989; Wells \& Marwell. 1976).

Numerous factors contribute to the significance of a facet of our self-concept such as the amount of knowledge, education, and experience with a given facet, the level of motivation such as a need for peer approval. and the level of competence within that dimension (Bishop et al., 1997; Fitts, 1965, 1970, 1972a, 1972b; Fitts et al., 1971; Fitts \& Hamner, 1969: Fitts \& Warren, 1996; Hattie, 1992: Marsh \& Hattie, 1996; Marsh et al., 1983; Mortimer \& Lorence, 1981; Roid \& Fitts, 1989). In 1983, Hitch (as cited in Hattie, 1992 ) viewed the self as "made up of separate components like the jewels in a crown, each having its own moment of display according to where the light falls" (p. 69).

In today's fast-changing society, it is important for persons to carry a strong sense of who they are. to feel competent and deserving. The outside world is not stable so it is vital that each person feels stable in his or her sense of self. If one has low self-esteem, he/she is at a disadvantage in dealing with life. Individuals develop how they feel about themselves from internal ideals about themselves and by external messages they receive from the environment and significant others. Positive feeling about ourselves is essential to the self-concept. The self is what is presented to others and colors how we deal with life issues (Bednar et al., 1989; Branden, 1994; Brown, 1993a; Burns, 1979; Dunning, 1993: Fitts, 1965, 1970, 1972a, 1972b; Fitts et al., 1971: Fitts \& Hamner, 1969: Fitts \& Warren, 1996: Maslach, 1982; Roid \& Fitts, 1989; Siebert, 1996; Workman et al., 1986-87). 
Individuals level of self-concept affects their functioning in the work environment, how they deal with others, how high they are likely to advance, how much they are likely to achieve, whom they pick as friends, whom they choose to marry, how they interact with significant others, and the level of personal contentment they achieve. Positive selfconcept correlates with flexibility, increased independence, creativity, ability to handle change, and willingness to acknowledge mistakes and modify our behavior. Negative selfconcept correlates with inflexibility, increased interdependence, less originality. fear of change, and fear of imperfections of the self (Branden, 1994; Chang, 2000; Fitts, 1965, 1970. 1972a, 1972b: Fitts et al., 1971: Fitts \& Hamner, 1969: Fitts \& Warren, 1996: Frey \& Carlock, 1989; Grayson \& Meilman, 1999; Hamachek, 1971; Hoge, 1999; Resnick et al., 1970; Roid \& Fitts, 1989: Salmela-Aro \& Nurmi, 1997).

Individuals view the entire world through their filter of self which influences all of their thoughts, feelings, and behaviors (Amstein, 1979; Dunning, 1993: Fitts, 1965, 1970 , 1972a. 1972b; Fitts et al., 1971; Fitts \& Hamner, 1969; Fitts \& Warren, 1996: Frey \& Carlock. 1989; Hoffman \& Gellen, 1983: Marsh \& Richards. 1988; Rosenberg, 1986). A healthy self-concept is important because it can give an individual the feeling of power. If one feels attractive, intelligent, healthy, dynamic, influential. and'or remarkable, then he/she tends to feel a certain amount of personal power. Personal power can assist the individual in better meeting his/her needs in life. This personal power can assist the person in every area in life whether it is in the academic, work, social, relationship, physical/mental health, and/or religious areas. For example, individuals with a healthy self-concept tend to practice better daily health habits, utilize preventive medical services, 
and seek medical attention when ill (Blaine \& Trivedi, 1998: Brown, 1993b; Fitts. 1965 , 1970, 1972a, 1972b; Fitts et al., 1971; Fitts \& Hamner, 1969; Fitts \& Warren, 1996; Marsh \& Richards, 1988: McGuire \& Tinsley, 1981: Roid \& Fitts, 1989: Taylor, Kemeny, Reed. Bower, \& Gruenewald, 2000: Wolman, 1985).

The self-concept affects how individuals function in all areas of life. A high level of self-concept allows persons to think well of themselves, think well of others, value relationships with others, and view themseives as part of the universe. They can also view their mistakes as valuable parts of development (Bishop et al., 1997; Blaine \& Trivedi, 1998: Fitts, 1972a, 1972b; Fitts \& Warren, 1996; Frey \& Carlock, 1989: Hansen \& Maynard, 1973; Morton, 1984; Salmela-Aro \& Nurmi, 1997; Staub, 1980b). Persons with more positive self-concepts tend to have lower levels of hopelessness and depression. less illness and/or faster recovery period from any illness, experience more positive affect, and a higher level of satisfaction with life. Thus, a positive self-concept cerainly appears to play a vital role in individuals' physical and psychological well-being (Abramson, Metalsky, \& Alloy, 1989: Bachman et al., 1978: Baumeister, 1993: Clark \& Beck, 1999: Fitts, 1972b; Fitts \& Warren, 1996; Myers et al., 2000; Prout \& Prout, 1996; Roid \& Fitts, 1989: Rosenberg, 1985; Walsh \& Banaju, 1997; Wylie, 1979).

In relation to attributional studies, the idea of internal versus external attribution has sustained a great deal of attention. Often, when people do not reach their goals they do not place their failure on themselves but place the failure outside of themselves such as with luck or the actions of others. Some individuals, especially those who are depressed, tend to blame themselves for their problems and view their successes as resulting from 
experiences outside of themselves (Abramson et al.. 1989: Abramson. Seligman. \& Teasdale, 1978; Beatty \& Hewitt, 1995; Clark \& Beck, 1999; Ingram, Miranda, \& Segal, 1998: Lent et al., 2000: Roid \& Fitts, 1989: Seligman. 1990: Wall \& Hayes, 2000). This idea applies to academic arenas from grade school to university settings. There are always some students who evaluate their academic achievement or failure in line with their own behaviors. But, there are always some students who tend to blame their academic achievement or failure on forces outside of themselves. Men tend to place their academic achievement on themselves and place the blame for their failures on others. Women tend to place the cause of their academic achievement on others and place the blame for their failures on themselves (Lewis, 1997; Roid \& Fitts, 1989).

Higher education provides the knowledge and ability for persons to function more effectively in adult roles after they graduate. Higher education often provides students with a foundation for enjoving a much more enjoyable and rewarding life outside of their given profession. The benefits of experiencing a more enjoyable and rewarding life may include desiring to continue learning, increasing their level of participation in civic and community activities, increasing their knowledge and enjoyment in the worlds of art, literature, history, and science. expanding their support network, and developing personal values and qualities which lead to a higher level of self-confidence. As individuals continue to evolve and challenge themselves, the desire for continued self-exploration and expansion includes increasing the level of their self-concept (Bowen, 1997: Byrne, 1996a: Chickering \& Havighurst, 1981: Douvan, 1981: Fitts. 1965, 1970, 1972a, 1972b; Fitts et al., 1971; Fitts \& Hamner, 1969; Fitts \& Warren, 1996; Hoge, 1999; 
Noel, 1985: Sprinthall et al., 1986: Stodt, 1987: Weathersby, 1981).

Along with a more positive sense of self, higher education encourages individuals to be more independent, responsible, and critical of their moraliethical and political choices. Universities also need to consider the overall societal benefits that come with the higher education of persons from all age groups, ethnic origins. religions, marital status, and gender. Individuals who come from different backgrounds have something great to offer society and can reduce the cultural barriers in their community (Arnstein, 1980: Bachman et al., 1978; Bowen, 1997; Fitts, 1965, 1970, 1972a, 1972b; Fitts et al., 1971; Fitts \& Hamner, 1969: Fitts \& Warren, 1996: Grayson \& Meilman, 1999: Hansen \& Maynard, 1973; Shapiro, 1997; Vest, 1997; Wong \& Whitaker, 1993).

Research studies on self-concept have been conducted for many years. One study examined the effects of assertiveness training on self-concept, locus of control, anxiety, and level of assertiveness (Workman et al., 1986-87). Sixty-four female subjects from a large community college in southern California were assigned to the experimental group (assertiveness training) or the control group (rap group). The following instruments were given: Tennessee Self-Concept Scale, Rathus Assertiveness Scale, Personal Evaluation Scale. Rotter I-E Scale, and State-Trait Anxiety Scale. The researchers used a nonrandomized control-group, pretest-posttest design. Pretest comparisons demonstrated no significant differences between the experimental and control group means. Posttest comparisons demonstrated that the experimental group increased significantly in the dependent variables of self-concept, assertiveness, and internal locus of control. There was also a significant reduction in the level of anxiety. 


\title{
Theories of Depression
}

Due to the limited scope of this research, the neurobiology/physiology of depression will not be addressed. Also, the genetic, biochemical, and environmental factors that contribute to the occurrence of depression will not be discussed. The following is an overview of the most prevalent theories of depression.

\begin{abstract}
Abraham
The theory and treatment of depression from the psychoanalytic view was dominant well into the 1960s (Brown \& Harris, 1978: Clark \& Beck, 1999). Although Freud is considered the founder of psychoanalytic theory, Karl Abraham (Abraham \& Jones. 1979) wrote the first psychoanalvtic theory of depression in which he compared mourning (grief) and melancholia. He described a relationship between mourning and melancholia as related to the loss of an object. The main difference was that melancholia had an element of anger unlike mourning, which was a normal part after a loss of a loved object (other sources which discuss Abraham's theory can be found in the following: Brown \& Harris, 1978; Clark \& Beck, 1999; Gaylin, 1968; Mendels, 1970; Zaiden, 1982).
\end{abstract}

\section{Freud}

Sigmund Freud also stressed that both mourning and melancholia are a reaction to losing a loved object (1968). He expanded on Abraham`s theory but placed more emphasis on differentiating mourning from melancholia. Freud connected mourning to the pain related to a loss of an external object. He described melancholia as the angry feeling one turns inward related to a loss of an object. The object does not actually have to be external 
but can be. for example, losing an object of love. He stated that melancholia has an additional feature from mourning which is the decrease of self-esteem (other sources which discuss Freud's theory can be found in the following: Beck et al., 1979: Clark \& Beck, 1999; Gaylin, 1968; Jack, 1993; Kutcher et al., 1993; Mendels, 1970; Robbins, 1993; Roberts \& Monroe. 1994). Both Abraham and Freud placed emphasis on self-criticism and self-hatred which are so noticeable in depression (Clark \& Beck, 1999; Wolman. 1990).

\section{Seligman}

Cognitive theories of depression view depressive thoughts and behaviors as secondary to one s pessimistic expectancies and dysfunctional cognitive style. This dysfunctional cognitive style lends itself to the predisposition of an individual to depression. Two of the most prominent cognitive theories are from Seligman and Beck (please note that Beck was discussed in chapter 1) (Armor \& Taylor, 1998: Brandtstadler \& Renner. 1992: Hirschfeld \& Cross, 1987: Maddux \& Meier, 1995: Rizley. 1978).

In the 1960s, Seligman, as a graduate student, began exploring the idea of learned helplessness from experiments with dogs in the laboratory. In the 1970s. Seligman originally presented a cognitive theory that depression is related to the state of "learned helplessness“" and one's feeling of not being in control (Peterson \& Seligman, 1984: Seligman, 1990). In laboratory experiments, he discovered that when dogs were given a shock from which they could not escape (while they were restrained), they eventually showed a decrease in motivation and learning and eventually stopped trying to escape even 
when not restrained. The dogs appeared to give up because they expected that nothing they did would matter. This state of giving up was called learned helplessness. This theory also applied to human beings. When individuals are faced with uncontrollable negative events they "give up" and think that their actions will not change the outcome. Others have found that people apply this belief even to global future events and outcomes and remain passive (Alloy \& Abramson, 1982: Clark \& Beck, 1999; Corr \& Gray, 1996: Peterson, 2000; Petiprin \& Johnson. 1991: Rehm, 1990; Sweeney. Anderson, \& Bailey, 1986: Zimbardo \& Leippe, 1991).

Abramson et al. (1978) redirected the emphasis of the theory to the attributions (cognitions) that one makes to his/her feeling of not being in control, which may result in depression. The actual presence of a negative event was not enough to produce a helpless state (state of depression), but the perception that the event was out of the person "s control and the person's explanation were important. If individuals believe that they are responsible for not being able to control the environment and believe that they are inwardly deficient in interacting with the environment and start feeling helpless about future interactions with the environment, then depression, with a lowered self-esteem, may occur (other sources which discuss Abramson et al.'s theory can be found in the following: Bemporad, 1995: Clark \& Beck. 1999: Corr \& Gray, 1996: Hirschfeld \& Cross, 1987; Kao, Nagata, \& Peterson, 1997; Kuiper et al., 1983; Lazarus, 1991; Peterson \& Seligman, 1984: Peterson et al.. 1982; Rush. 1987; Seligman, 1990; Tennen \& Herzberger, 1986).

The manner in which an individual thinks or the attributions he/she makes in 
regard to life events and stressors may aid in producing depression. If the person feels that the cause of the event is connected with some deficiency within themselves (internal vs. external) instead of something within the given situation. then this may produce lower self-esteem. If the person thinks that the cause of the event is enduring (unstable vs. stable) instead of fleeting. then this may produce chronic symptoms of depression. If the person thinks the cause of the event affects many areas of his life (global vs. specific) instead of just a specific realm. then that person may be prone to depression (Abramson et al., 1978; Clark \& Beck, 1999; Frydenberg, 1997; Higgins, Zumbo, \& Hay, 1999; Hirschfeld \& Cross, 1987: Ingram et al., 1998; Pecuch, 1997; Peterson, 2000; Petiprin \& Johnson, 1991; Rehm, 1990: Seligman, 1990; Seligman, Abramson, Semmel, \& von Baever, 1979: Sweeney et al., 1986: Wall \& Haves, 2000: Xenikou. Furnham, \& McCatrey, 1997).

Abramson et al. (1989) presented a further revision of this theory called the hopelessness theory of depression (other sources which discuss Abramson et al. 's theory can be found in the following: Clark \& Beck, 1999: Hollon et al., 1992; Peterson, 2000). Abramson et al. (1989) suggested that in addition to one's attributional style. it is important to observe the inferences about the self in relation to the consequences of the event (other sources which discuss Abramson et al. s theory can be found in the following: Clark \& Beck, 1999; Ingram et al., 1998).

\section{Depression}

Depression is a widely discussed topic in today`s society and literature. In fact, 
depression has been affecting mankind throughout all cultures and sections of history: The Greeks used the term "melancholia" to describe depression during the fifth century B.C. (Beck. 1973: Davison \& Neale. 1994: Formanek \& Gurian. 1987: Ingram et al.. 1998: Kaplan \& Sadock, 1998; Kovacs \& Beck, 1978: Roba, 1988; Robbins, 1993). Famous figures throughout history have experienced depression such as King Saul of the Bible, Job, Napoleon Bonaparte, Abraham Lincoln, Winston Churchill, Ernest Hemingway, Chopin. Handel, Vincent van Gogh, Sigmund Freud. Monica Seles, Ted Turner. Mike Wallace, Tipper Gore, and Princess Diana of Wales (Bacon, 1993: Kaplan \& Sadock, 1998: Kovacs \& Beck, 1978; National DMDA, 1999, 2000; Papolos \& Papolos, 1997 : Robbins, 1993).

Depression is a universal experience and has been called "the common cold of mental health" or "the world's number one public health problem." It does not exclude any group of people because it invades every geographical boundary, ethnic and cultural group, age group, income status, social class, and occupational andor educational level (Barnes, 1993: Bosse et al., 1975; Burns, 1980; Chang \& Strunk, 1999; Clark \& Beck. 1999; Gotlib et al.. 1990: Ingram et al.. 1998: Karp, 1996; Lewinsohn. Munoz, Youngren, \& Zeiss, 1986; McLean. 1982; Meyer \& Deitsch, 1996; Munoz \& Ying, 1993; National DMDA, 1999. 2000: NIMH, 1995, 1997. 1999: Papolos \& Papolos, 1997: Robbins, 1993: Secunda, Katz, Freedman, \& Schuyler, 1973; Swallow \& Segal, 1995).

The National Institute of Mental Health (NIMH. 1999) cited a recent study by the World Health Organization (WHO) and the World Bank that found that major depression (unipolar), in the United States and worldwide, is the leading cause of disability. In fact, 
depression afflicts approximately 100 million people worldwide each year. If a person is depressed, this does not mean that he/she is crazy, abnormal, weak, and/or flawed in character. A person who is depressed cannot simply will, wish, and or work harder to make the depression go away. Since depression is a common reaction to the ups and downs of life, not a rare condition. there are numerous people who need assistance in dealing with depression (Abrahamson, Hornyak, \& Rehm, 1998; Allen, 1990: Clark \& Beck, 1999; Frvdenberg. 1997: Gravson \& Meilman, 1999; Lewinsohn et al., 1986: National DMDA, 1999, 2000; NIH, 2000a, 2000b; NIMH, 2000).

Approximately $\$ 30-44$ billion is lost each year in the United States from the effects of depression in the following areas: social, economic, and personal (Clark \& Beck, 1999: Culberson, 1997: National DMDA, 1999, 2000: NIMH, 1995, 1997, 1999: Papolos \& Papolos, 1997; Schmitt, 1999; Vredenburg, Krames, \& Flett, 1985; Williams, 1995). Ingram et al. (1998) and the National DMDA $(1999,2000)$ state some facts about the costs of depressive illnesses (affective disorders): Total costs equal $\$ 43$ billion a year: $\$ 12.4$ billion $(27 \%)$ in direct treatment, for example, inpatient, outpatient and medication treatment: $\$ 7.5$ billion $(17 \%)$ in deaths associated with suicide, for example, loss of lifetime earnings: $\$ 11.7$ billion (28\%) in absenteeism: and $\$ 12.1$ billion $(28 \%)$ in lost productivity.

In the United States each year, more than 23 million adults will be diagnosed, according to specific DSM-IV-TR criteria, with a depressive disorder-approximately 1 out of 7 to 10 (American Psychiatric Association, 2000). The National DMDA $(1999,2000)$ reports that depression, although it can occur at any age, often develops between the age 
range of $25-44$. However, the problem of depressive disorders is not found just in adults. Depressive disorders are rising among young adults, with $20 \%$ of major depression cases being diagnosed before the age of 25 years. The peak for major depression ranges between 15 to 19 years of age in females and ranges between 21 to 25 years of age in males (Astin, 1993: Benoia, 1992: Cappeliez \& Flynn. 1993: Clark \& Beck, 1999: Dean \& Ensel. 1983: Feaster, 1996; Felix, 2000: Ingram et al., 1998; Kutcher et al., 1993; McGuire, 1998: Munoz et al., 1994: Offer \& Spiro. 1987; Regier et al., 1988: Roba, 1988: Robbins. 1993: Steer et al., 1999; Tousignant \& Hanigan, 1993; Walter, 1989). According to the National Institute of Mental Health (1999), approximately $2.5 \%$ of children and $8.3 \%$ of adolescents in the United States experience depression. The U.S. Department of Health and Human Services (cited in National DMDA, 2000) reports that approximately 1 in 33 children and 1 in 8 adolescents experience depression.

Research has indicated that the onset of depression is beginning earlier in persons born in the more recent decades. According to Meyer and Deitsch (1996), 1\% of Americans born before 1905 experienced major depression by age 75 and $6 \%$ of Americans born after 1955 experienced major depression by age 30. If depression begins earlier in life. it tends to be more persistent with numerous recurrences and continues into the adult years. Individuals who have one episode of major depression have a $50 \%$ chance of recurrence. Persons who have two episodes of major depression have a $70 \%$ risk of recurrence, and those who have three or more episodes have a $90 \%$ risk of recurrence (American Psychiatric Association. 1994: Angst \& Merikangas. 1997: Beck, 1967, 1973: Cappeliez \& Flynn, 1993; Clark \& Beck, 1999; Ernst, Schmid, \& Angst. 1992; Felix, 2000; 
Horwath. Johnson, Klerman, \& Weissman. 1992: Ingram et al., 1998: Lightsey \& Christopher, 1997; Meyer \& Deitsch, 1996; Munoz et al., 1994; Munoz \& Ying, 1993; Robinson et al.. 1990).

Research studies have found that women tend to experience depression more frequently, approximately twice as much as males (Beeber, 1999: Brown \& Harris. 1978: Clark \& Beck, 1999; Culbertson, 1997; Flynn \& Cappeliez, 1993; Formanek \& Gurian, 1987: Horwath et al., 1992; Ingram et al.. 1998; Jack, 1993: Kelly. Kelly. Brown, \& Kelly, 1999; Lewinsohn et al., 1984; Munoz \& Ying, 1993; National DMDA, 1999, 2000: NIMH, 2000; Regier et al., 1988: Robbins, 1993; Stoppard, 1993: Williams. 1995). Prevalence rates for males and females have varied in the literature with as high as $20-21 \%$ for females and 12-13\% for males (Clark \& Beck. 1999: Ingram et al., 1998). Kaplan and Sadock (1998) reported the lifetime prevalence rate for major depressive disorder is $10-25 \%$ for women and $5-12 \%$ for men. The National DMDA (2000) reported that the lifetime prevalence rate for major depression is $24 \%$ for women and $15 \%$ for men. Interestingly enough, often in college students, male and female students do not differ on the rating of depression. This finding may be due to the idea that college students are made of a more similar sample in terms of roles, values, and expectations for male and female students (Alfeld-Liro \& Sigelman, 1998; Baron \& Perron, 1986; Daughtry \& Kunkel. 1993; Felix, 2000: Lopez-Culver, 1991: McLennan, 1992: Oliver \& Burkham. 1979; O’Neil \& Marziali, 1976: Robbins, 1993; Shirley, 1990; Steer \& Clark, 1997; Wiseman \& Guttreund, 1995). College students tend to experience clinical depression and dysthymia twice as often as working individuals of similar ages and background 
environments (Benoia, 1992; Buckman, 1988: Bumberry, Oliver. \& McClure, 1978: Dixon, 2000; Dixon \& Reid, 2000: Feaster. 1996: Felix. 2000; Roba, 1988; Shirley, 1990; Strauss. 1998).

Depression takes its toll on individuals and society as a whole. It affects not only the person living with depression but with the family and friends (Clark \& Beck, 1999: NIMH, 2000: Shirley, 1990; Swallow \& Segal, 1995). The effects of depression are widespread and can be associated with the following problem areas: relationships with others and community, divorce, parenting, academic performance difficulties and attrition, health difficulties, absenteeism at work, work performance difficulties, lower feelings of self-worth, and impaired ability to handle stress and typical everyday problems. Persons may also experience a reduction in their level of educational attainment and annual income (Affsprung, 1998; Clarke et al., 1990; Dixon \& Reid, 2000: Dunner, 1997; Flynn \& Cappeliez. 1993: Haines et al., 1996: Ingram et al., 1998: Kendell et al., 1987; Kutcher et al., 1993: Lewinsohn et al., 1984; Lewinsohn et al., 1986: Munoz \& Ying, 1993; Newman \& Beck. 1990; Wilson \& Krane, 1980).

Even more common, individuals may have a milder form of a depressive disorder which does not involve enough svmptoms to meet specific DSM-IV-TR criteria (American Psychiatric Association, 2000). However, even these few depressive symptoms may affect their ability to function in the above-mentioned problem areas (Clark \& Beck, 1999: Grayson \& Meilman, 1999; Haines et al., 1996; Hammen, 1995: Munoz, 1993; Munoz et al. 1994: Oliver \& Burkham, 1979; Roberts \& Monroe, 1994; Rush \& Giles, 1982). According to Lightsey and Christopher (1997), approximately $18 \%$ of the population, at 
any given time, is experiencing mild depressive symptoms.

If left untreated, these mild symptoms may persistently recur and eventually build a lifelong pattern of depression, decreased social and physsical functioning, and increased suicide attempts (Angst \& Merikangas, 1997; Clark \& Beck, 1999: Dunner, 1997; Maier et al., 1997: Munoz \& Ying. 1993: Strauss. 1998). It is imperative that children and adolescents who are experiencing depression be accurately diagnosed and treated to prevent problems in social, academic, emotional, and behavioral areas (Astin, 1993: Beck et al., 1990; Cappeliez \& Flynn, 1993: Chan, 1995; Clark \& Beck, 1999; Clarke, Lewinsohn, \& Hops, 1990: Dunner, 1997; Hammen, 1995; Kutcher et al., 1993; Lopez. 1986; NIMH. 1999: Nolen-Hoeksema \& Girgus, 1994).

The health risks associated with depression are astounding. Depression often occurs with a variety of other physical disorders such as heart disease, diabetes, stroke, hypertension, lowered immune system. gastrointestinal problems, and cancer. In fact, approximately $50 \%$ of people with depression have heart disease, approximately $25 \%$ of people with depression have cancer, and $10-27 \%$ of people with depression have experienced a stroke. Depression can also increase the potential for other physical illnesses. disability, and premature death (Chang \& Strunk. 1999: Curtis, 1990: Johnson, 2001; Munoz \& Ying, 1993; NIMH, 1995, 1997, 1999, 2000; Salovey, Rothman, Detweiler, \& Steward, 2000: Taylor et al., 2000).

For example, a recent NIMH-supported study (1999) reported that persons who have experienced major depression, as compared to persons without a history of major depression, were more than four times as likely to have a heart attack within a 12-13-year 
follow-up period. When compared to individuals without a history of mild depression, individuals who have a history of mild depression for 2 or more weeks were more than twice as likely to have a heart attack. It is important to note that associations were found between some psychotropic medications and the risk of heart attacks. The NIMH study found that the above-mentioned associations were merely a reflection of the primary relationship between the experiences of depression and heart trouble (Munoz \& Ying. 1993: NIMH, 1997, 2000).

In addition to associated health problems, another reason to examine the prevention, occurrence. and treatment of depression is the factor of suicide, which ranks eighth as the cause of death in the United States. Schmitt (1999) reported that approximately 31,000 Americans commit suicide every year and approximately 500,000 need emergency room attention after a suicide attempt. According to the NIMH (1997) and the National DMDA $(1999,2000)$. approximately $15 \%$ of those hospitalized for depression and $15 \%$ of those who receive no treatment for severe depression someday commit suicide. Suicidal ideation has to be taken veñ seriously with appropriate intervention provided due to its potential lethality (American Psychiatric Association, 1994: DeAngelis, 2001: Frydenberg, 1997: McIntosh, 2000: NIH, 2000a: Robbins. 1993: Westefeld, Cardin, \& Deaton, 1992; Williams, 1995).

The presence of depression and feelings of hopelessness and isolation increase the risk of life-threatening behavior such as suicide gestures and attempts (Barnes, 1993; Clark \& Beck, 1999: Enelow, 1970: Frydenberg, 1997: Ingram et al., 1998: Lewinsohn et al., 1984: Munoz \& Ying, 1993; Robbins, 1993; Rogers, 2001; Williams, Friedman, \& 
Secunda. 1970). Also, having any kind of psychiatric sllness increases the risk for suicide. with $90 \%$ of individuals who commit suicide having a psychiatric illness at the time of their death. Of that $90 \%, 80 \%$ of individuals who commit suicide have a depressive disorder (Clark \& Beck, 1999; Gotlib et al., 1990).

It appears that suicidal ideation occurs at approximately the same rate for males and females who are experiencing major depression. Regarding suicidal attempts, women attempt suicide more often than men. but men tend to be more successful in completing their suicide attempt. In fact. men commit suicide at a rate of four times that of women (Clarke et al., 1990: DeAngelis, 2001: McIntosh, 2000: NIMH. 2000). When depression occurs in children and adolescents, there is an increased risk of suicide. Suicide has increased dramatically in young adults over the last few years (Hayes, 1997. Haves, 2000: Mendels, 1970: Mever, 2000; NIH, 2000b; Rice \& Meyer, 1994; Rush, 1982; Tousignant \& Hanigan. 1993). Rudd (1989) stated that from 1960 to 1980 the suicide rate among 15-24-year-olds almost tripled. In 1996-2000, in the age range of 15-24, suicide was the third leading cause of death (Allen, 1990: DeAngelis. 2001: Frvdenberg, 1997: Haves, 2000; McIntosh, 2000; NIMH, 1999; Schmitt, 1999).

In fact, some researchers have noted that suicide is approximately twice as high in students when compared with non-students of the same age (Bertoia, 1992: Buckman, 1988: Cappeliez \& Flynn, 1993: Felix. 2000: Gravson \& Meilman. 1999; Halgin \& Leahy. 1989; Lopez, 1986; McLennan, 1992; Roba, 1988; Shirley, 1990; Strauss, 1998). A greater level of perfectionistic tendencies, often found in college students. may lend itself to more negative psychological symptoms and greater suicidal ideation. In fact, it has been reported 
that suicide was the second leading cause of death on university campuses (Chang, 2000: Chang \& Rand, 2000: Dean \& Range, 1996; Jobes, Jacoby, Cimbolic, \& Hustead, 1997; Rice et al. 1998: Vrendenburg, Flett. \& Krames, 1993).

Due to the limited scope of this research and the confidentiality criteria established by $\mathrm{AU}$ `s Human Subjects Review Board (HSRB) and WMU`s Human Subjects Institutional Review Board (HSIRB), as discussed in the Data Collection section in Chapter 3. the presence or absence of subjects suicidal ideation was not further explored. In this research study, I chose to tell each class in my introduction that I did not anticipate anything happening but, for example, if answering any of the questions brought up thoughts and feelings and/or issues for them, then I recommended that they contact the counseling center to talk with someone.

Although there are numerous instruments used to identity depression, the BDI has been utilized in a wide range of research studies. Factor analytic studies of the BDI often vield a small number of factors that concisely summarize the 21 test items. For example, 303 undergraduate students from a large southwestern university (125 male, 178 female) completed a packet of mood questionnaires that included the BDI. Principle-axis factor analysis on the students ${ }^{*}$ responses yielded a 2-factor solution which accounted for $33 \%$ of the variance in BDI scores: Negative Self-attitude dimension and Performance Impairment dimension. These findings were consistent with previous studies that evaluated the BDI's factor structure (Killgore, 1999).

Miranda and Munoz (1994) examined the effectiveness of early intervention for minor depressive symptoms in primary care patients. The subjects were 150 medical 
patients randomly assigned to a control condition or an 8-week cognitive-behavioral course. The symptoms of depression were measured by the BDI. The results supported the effectiveness of early intervention. with subjects demonstrating a reduction in depressive symptomatology through a 1-year follow-up program.

\section{Self-Concept and Depression}

Throughout the years, the descriptions of depression have maintained some consistency. Although some writers have disagreed on some of the descriptions in the past. general agrecment exists about many of the characteristics of depression. The main characteristics of depression that have been universally accepted are, for example, low mood, pessimism, and self-criticism (Abramson et al., 1978; Bailey, 1997: Beck, 1967, 1973: Blatt \& Bers, 1993: Fitts, 1965: Harter. 1986; Kendell et al., 1987: Kernis. 1993: Lazarus, 1991; NIH, 2000a, 2000b; NIMH, 2000; Prout \& Prout, 1996).

Self-criticism is a characteristic that relates to low self-esteem and thereby to low self-concept. Much has been written about the relationship between depression and self-concept, both of which are complex subjects. Depression and self-concept are intertwined and interrelated. Individuals' self-concept is key to the experience of depression, and depression always involves a component of the self. During times of depression, most individuals begin to set unrealistic standards, make self-belittling remarks, or make harsh judgments about themselves. Often these events lead them to see themselves as basically worthless and inadequate. Consequently, the self-concept is torn down during these times of depression (Abramson et al., 1978: Bailey, 1997: Beck. 1967. 
1972, 1973: Blan \& Bers, 1993; Bush. Ballard. \& Fremouw, 1995: Conway \&

Giannopoulos, 1992; Fitts, 1965: Harter, 1996; Jack, 1993; Karp, 1996; Lutterman, 1991;

Maier et al.. 1997: Mendelson, 1990: Millon \& Kotik-Harper, 1995; Mortimer \& Lorence, 1981: NIH, 2000a, 2000b; NIMH, 2000; Prochaska et al., 1992; Prout \& Prout, 1996; Roid \& Fitts, 1989: Rosenberg, 1965: Rush, 1987: Segal \& Mural, 1993: Shirk \& Renouf. 1992: Watkins, 1981; Williams, 1984; Wylie, 1979; Zaiden, 1982).

The more subjective symptoms of depression, for example. feelings of worthlessness and hopelessness, self-dislike, lowered self-esteem, and depressed mood, are central elements of a lowered self-concept (Blaine \& Crocker, 1993: Blatt \& Bers, 1993: Burns, 1979; Clark \& Beck, 1999: Conway \& Giannopoulos, 1992; Fitts, 1965; Frey \& Carlock. 1989: Frydenberg. 1997: Hammond \& Romney, 1995; Karp, 1996: Katz, 1969. Lazarus, 1991; Meyer \& Deitsch, 1996; Schwab, 1970: Wolman, 1990).

Loss, or the feeling of loss, which is so often associated with depression, may be an actual loss or the loss of self-esteem which reflects on the total self-concept. The loss, which leads to a decrease in self-esteem, may be connected to a specific event. a long-term upsetting life circumstance, or by an internal thought process. The loss of self-esteem may be connected to one's being unable to achieve a set goal (Blaine \& Crocker. 1993: Brown et al., 1990a: Burns, 1989: Cantor, 1990; Gold, 1990; Mead, 1970; Robbins, 1993; Schwab. 1970: Whybrow, 1996).

Cognitive functions that have been related to depression are low self-esteem. negative self-concept, self-disparaging thoughts, irrational beliefs. and negative attributions (Beck, 1967, 1973: Birtchnell, 1996; Brown \& Harris, 1978: Clarke et al., 
1990: Copeland, 1996: Curtis, 1990); Fitts, 1965: Frydenberg, 1997: Hallett, 1998;

Mortimer \& Lorence, 1981 : Rehm, 1987; Robbins, 1993; Rosenberg, 1986; Rosenberg \& Kaplan, 1982: Segal \& Mural, 1993: Verkuyten, 1995). Each time a person reinforces the negative evaluation of behavior or thoughts, then the feelings of self-worth are lowered and lead to more feelings of sadness and feelings of worthlessness (Beck, 1976; Burns, 1980; Clark \& Beck, 1999: Hokanson, Rubert, Welker, Hollander, \& Hedeen, 1989; Treadgold, 1999). And, according to Beck $(1967,1973)$ these cognitive functions tie into one's concept of the negative cognitive triad. Persons with depression tend to experience distorted thoughts toward themselves. their world, and their future, which tends to devalue their self-concept (these ideas have been further supported by the following: Blatt, 1995; Dixon \& Reid, 2000; Freeman. 1993: Grayson \& Meilman, 1999; Kemis, Grannemann, \& Mathis, 1991: Kernis et al., 1998: Pelham, 1993: Rush \& Giles, 1982; Shirk \& Renouf, 1992: Smits \& Oliver, 1982: Tennen \& Affleck, 1993: Williams, 1984).

As persons develop, they come to view themselves, their attitudes, goals, attributes, and values in a certain way, called concepts or schemas. Schemas evolve from their own personal experiences, from interactions with their environment, from others opinions of them. and from identifications with key figures such as parents. Therefore, schemas are building blocks for the self-concept. The self-concept is a mixture of one's schemas within different areas or domains, for example. school, work, family. and social. Individuals view themselves, the world, and the future through the lens of their personal concept which may tend to be positive or negative. If their self-concept is positive, they may then see themselves as intelligent, capable, attractive, and lovable. If their self-concept is negative, 
they may then see themselves as inferior, unattractive, and unlovable. When individuals are depressed, their negative self-concept surfaces with great strength and power (Beck et al., 1990: Blant \& Bers, 1993; Campbell \& Lavellee, 1993: Clark \& Beck, 1999: Curtis, 1990; Freeman, 1993; Hattie, 1992; Mueller, Johnson, Dandoy, \& Keller, 1992; Oliver \& McGee, 1982: Rosenberg, 1985: Rosenberg \& Kaplan. 1982: Schmidt et al., 1995: Shirk \& Renouf, 1992; Treadgold, 1999).

Persons' self-concept is built on past experiences on which ideals are formed. These ideals are what they use to measure their level of achievement. Self-concept has a main function of determining if they have met their ideals that they established for themselves (Beatty \& Hewitt, 1995: Freeman. 1993: Morse \& Gergen, 1982; Oyserman \& Markus, 1993; Whybrow, 1996). A poor self-concept can magnify small mistakes or imperfections into overwhelming images of personal failure. One`s self-concept contributes to the decisions in life. Low self-concept can demonstrate itself, for example, in the choice of a marriage parner which leads to an unhappy marriage, a career which leaves dreams and goals unfulfilled, chronic depression, and destructive life habits. Positive self-concept does not guarantee that one will not have troubles in life, but it enables the person to be more resilient in coping with changes and problems in life (Alfeld-Liro \& Sigelman, 1998; Blaine \& Crocker, 1993; Branden, 1994: Conway \& Giannopoulos, 1992: Fitts, 1965, 1970, 1972a, 1972b; Fitts et al., 1971; Harter, 1996; Hoge. 1999: Roid \& Fitts, 1989).

Studies have been conducted on psychiatric patients and the relationship between depression and self-concept. In the 1960s, Beck and Stein utilized the Beck Depression 
Inventory (BDI) and a self-concept test they developed which consisted of certain characteristics and traits such as appearance, intelligence, and selfishness. They had the patients rate themselves on a 5-point scale and how they felt about these characteristics. Beck and Stein found a significant inverse relationship $(r=-.66)$ between depression and self-concept. They concluded that depressed patients. as compared to nondepressed patients, exhibited low self-concept and held a negative view of themselves (Beck, 1967; Rush \& Giles, 1982). Another study in 1964 by Laxer (as cited in Rush \& Giles, 1982) also found that depressed psychiatric inpatients had lower self-concept than "other" types of psychiatric inpatients at the time of admission. But at the time of discharge, their level of self-concept was increased, which was presumed to be connected to their decreased level of depression (Beck, 1967).

\section{Undergraduate and Graduate Students}

College is a time of transition, so it is natural that one's self-concept tends to also be in a period of re-examination (Arnstein, 1989; Berzonsky \& Kuk, 2000; Burns, 1979; Gergen. 1982: Gravson, 1989: Hudson, 1991: Jackson \& Bosma, 1990: Kroger, 1989. Madison, 1969: Mortimer \& Lorence, 1981; NIH, 2000a; Olbrich, 1990; Regeth, 1997; Sprinthall et al.. 1986: van der Werff. 1990; Whiteley, 1982). Transitions in life are turning points that all individuals experience. Thev can be generated by internal states and/or external events. These times of transition can be times for growth in the way persons perceive themselves, their surrounding environment, and the way they interact with that environment. Growth may certainly contribute to an increasing level of self-concept 
(Alfeld-Liro \& Sigelman, 1998; Amstein, 1979; Birnie-Lefcovitch. 1996: Dỵk \& Adams, 1987; Erikson \& Erikson, 1997; Fiske \& Chiriboga, 1990; Frey \& Carlock, 1989: Kaplan \& Sadock, 1998: Lewinsohn et al., 1986: Little. 1993: Mosher, 1986: Weinmann \& Newcombe, 1990).

Choosing a career and academic success in preparing for that career are very important components of the developmental task for individuals in their late adolescence and young adulthood. Often, students entertain a possible career path in light of how they view their abilities or the level of their self-concept. It is also important during this period that the self-concept be examined, expanded, and solidified. If individuals strive for intimacy with others before the level of their self-concept is increased, then the self may be overwhelmed and/or lost (Arnstein, 1980; Bee, 1987: Blustein \& Palladino, 1991: Byme, 1996a: Chickering \& Havighurst, 1981: Douvan, 1981: Dyk \& Adams, 1987: Gaff \& Gaff, 1981: Gecas \& Mortimer, 1987; Hansen \& Maynard, 1973; Kaplan \& Sadock, 1998; Katz, 1975: Lucas, 1997: Marsh et al., 1997: NIH. 2000b: Regeth, 1997: Salmela-Aro \& Nurmi, 1997; Seiffge-Krenke, 1990; Stevens-Long \& Commons, 1992; Trusty, Robinson, Plata, \& Ng, 2000; Whiteley, 1982)

Undergraduate students tend to be experiencing separation from family, friends, and other means of suppon while trving to adapt to a new environment. values. and activities. They are at a stage of transition which lends itself to exploring new values, behaviors, and relationships. Often undergraduate students are heavily influenced in their career choice by the expectations of their family (Arnstein, 1980; Blocher \& Rapoza, 1981: Douvan. 1981; Felix. 2000: Forrest, 1997; Frudenberg, 1997; Grayson \& Meilman, 
1999: Hallett, 1998: Haves, 1997; Hoge, 1999: Kenny \& Perez, 1996: Lent et al., 2000: Lopez-Culver, 1991; Lucas et al., 2000; Melendez, 1997; Mortimer \& Lorence, 1981; Noel. 1985: Paul \& Brier, 2001: Seiffge-Krenke, 1990; Shilkret \& Nigrosh, 1997: Simmons, 1987; Smith, 1997; Watkins, 1981 ).

Graduate students tend to be more self-directed in their learning and study skills. Often, their attendance in graduate school comes out of their own level of motivation and their strong sense of self. Graduate students have ofien explored the existential questions surrounding the meaning and purpose in life and have the desire to continue to explore those questions. Therefore, they may tend to have a higher level of self-concept and a lower level of depressive symptoms (Anderson \& Hayes, 1996; Amstein, 1980, 1984a; Bachman et al., 1978: Beck et al., 1988: Chickering \& Havighurst. 1981: Hamachek, 1971: Hoge, 1999; Kaplan \& Sadock, 1998; Kreger, 1995; Marsh, 1989, 1993; Oliver \& Burkham, 1979: Pappas \& Loring, 1985; Shavelson \& Bolus, 1982: Shirley, 1990; Steer et al., 1999; Wong \& Whitaker, 1993).

The number of young adults who enter university settings in the year after high school is approximately $60-75 \%$. Half of these individuals obtain some type of degree within 5 years, and approximately $25 \%$ obtain a bachelor's degree or higher. But, over the next 4 years, approximately $32 \%$ of individuals ages $25-29$ have actually completed 4 or more vears of college. Of these individuals who do complete college, approximately $33 \%$ will enter graduate school the following year (Amett, 2000; Gerdes \& Mallinckrodt, 1994; Gladieux \& Swail, 2000).

Overall, U.S. universities tend to annually award approximately 387,000 master`s 
degrees and 41,000 doctoral degrees. It is estimated that up to $50 \%$. with as high as $65 \%$, of entering graduate students do not complete their $\mathrm{Ph} . \mathrm{D}$. degree. Some attrition from graduate programs is anticipated, but the loss of so many denotes a genuine loss to the university and the community (Gumpor, 1999; National Research Council, 1996).

It has been estimated that $30-60 \%$ of first-year college students leave school and as high as $50 \%$ during the total undergraduate years. Minority students, especially African Americans, Spanish Americans, and Native Americans, have a higher attrition rate than Caucasians or Asians. Sometimes students drop out of college, after borrowing to finance their education, and may be in a worse situation than before they started. For example, they may leave college without a degree and a large amount of debt to repay (Bray, Braxton, \& Sullivan, 1999: Forrest, 1997: Gerdes \& Mallinckrodt, 1994: Gladieux \& Swail, 2000; Griffin, 1992; Hines, 1998: Lopez, 1986; Martin, 1996; Melendez, 1997; Neisler, 1992: Offer \& Spiro, 1987: Papalia \& Olds, 1992: Watkins, 1981: Witherspoon, Long, \& Chubick, 1999)

The key to student retention is what the university can offer to facilitate the growth and success of its students. When students learn about different areas, they expand their sense of self, find their talents, and broaden their goals for the future. Faculty and administrative personnel can take an interest in students and aid in decreasing the attrition rates. Also, the university counseling center can be of great assistance to students. The counseling center might use anticipatory intervention programs which might include an evaluative screening process of the incoming students for levels of self-concept and depression, workshops, and or seminars on various topics. The psychologists can help 
them explore their intrapersonal issues, interpersonal conflicts, time-management skills. social skills, relaxation skills, assertiveness skills, stress management skills, career interests. study skills, and decision-making skills. Students can take some time to examine these issues and decrease their level of depression and increase their level of self-concept (Anderson, 1985: Amstein. 1980: Astin. 1993: Bachman et al., 1978; Blinne \& Johnston. 1998: Blocher \& Rapoza, 1981; Curtis, 1990: Gordon, 1985: Hermon \& Hazler, 1999; Lewinsohn et al.. 1984: Mendels. 1970: Miller \& Jones. 1981: Noel, 1985: OConnor. 2001: Shapiro, 1997: Silvernail, 1985; Stodt, 1987: Toy, 1985: Williams, 1995; Wilson et al.. 1997).

Student retention tends to be better for all involved--the student and the university. Obtaining a college degree tends to be the standard just like obtaining a high-school diploma was in the previous century. College attendance opens the door for individuals to have a chance at the best jobs and the best chances in life. Today sob market often puts a premium on education beyond high-school-always looking for credentials (Gardner. 1992: Gladieux \& Swail, 2000: Hines. 1998: Kiah, 1992: Martin. 1996; Melendez, 1997).

According to Kaplan and Sadock (1998), 30\% of college graduates decide to obtain some type of graduate education. It is more cost effective for the university to keep the students than enrolling new or transfer students. Student retention is aided by faculty and student interactions. student participation in campus activities, and interaction with peers. It appears that there is a relationship between student involvement and student achievement which helps to retain the students. There are numerous variables that play 
into the rate of attrition or retention such as grades, developing a positive sense of self, level of depression, increasing participation in decisions, making and maintaining supportive relationships, and an increasing sense of belonging within the university environment and community. Other identified areas that contribute in student retention are orientation to the new campus, supportive academic advisors, mentors, supportive peer relationships, proper disbursement of financial aid, developmental courses offered in the class schedule, and the availability of career counseling (Anderson \& Haves. 1996; Astin. 1993: Beck et al., 1990; Beeber, 1999; Dunphy, Miller, Woodruff, \& Nelson, 1987; Gerdes \& Mallinckrodt. 1994: Gladieux \& Swail, 2000; Martin, 1996; Mendels. 1970; Miller \& Jones, 1981; Neisler, 1992: O’Neil \& Marziali, 1976; Papalia \& Olds, 1992). Students often leave college by their oun decision. Approximately, $85 \%$ of student withdrawals are voluntary. Students may leave because they are not navigating the transition period very well and feel isolated. These feelings of isolation and loneliness can contribute to a decrease in self-concept and an increase in depressive symptoms. Depression, especially mild depression, is common in college students. If they have a low self-concept or feelings of depression, then they may have trouble being in a new environment. concentrating on school, making personal and career choices, making new friends, and making commitments to lifetime goals. These areas of difficulty may have a long-term impact on individuals. It is vital that the symptoms of mild depression be acknowledged and addressed before they become more persistent and develop into a pattern of major depression (Affsprung, 1998: Anderson, 1985: Angst \& Merikangas. 1997: Bachman et al., 1978: Beeber, 1999: Birnie-Lefcovitch, 1996; Bosse et al., 1975; 
Buckman, 1988: Bumberry et al., 1978: Chan. 1995: Chickering \& Havighurst. 1981: Clark \& Beck, 1999; Clark, Crewdson, \& Purdon, 1998; Dean \& Ensel, 1983; Dunner, 1997: Feaster, 1996: Felix, 2000: Flynn \& Cappeliez, 1993: France \& Robson, 1997: Gotlib, 1984: Grayson \& Meilman, 1999; Haines et al., 1996: Kutcher et al., 1993; Lopez, 1986; Maier et al., 1997: McWhirter. 1997: Munoz et al., 1994; National DMDA, 2000: Oliver \& Burkham, 1979; Padula et al., 1998; Salmela-Aro \& Nurmi, 1997; Shirley, 1990; Tinto, 1985: Tough, 1981: Wilson et al., 1997; Wiseman \& Guttfreund. 1995).

Depression is often reported to be the leading emotional or psychiatric disorder found on university campuses. Depression tends to be associated with decreased learning and academic performance, increased attrition rates, increased drug and alcohol usage, increased suicide rate, impaired social skills, impaired parenting skills--even if the depressive symptoms are mild or moderate (Bertoia, 1992; Buckman, 1988; Feaster, 1996; Felix, 2000; Foxhall, 2001: Golin \& Hartz, 1979; Lopez-Culver, 1991: NIH, 200la: Roba. 1988: Shirley, 1990; Strauss, 1998). Overall, approximately $25-35 \%$ of individuals with depression get "good care." Universities can take an important step in recognizing depressive symptoms and offering excellent care for their students in the university counseling center. One study even suggested that students who receive counseling are $14^{\circ} \%$ more likely to remain in college as compared to those students who do not receive counseling (Rundle, 2000: Wilson et al.. 1997).

The university environment is very important in the development of the selfconcept. The sccial aspect of peer relationships in school can be a feedback source for the developing sense of self. Those students who develop a positive self-concept in academic 
areas have a better chance of succeeding in later life. A major developmental task of late adolescents and young adulthood is solidifying a self-identity. During this period, late adolescents and young adults are making major decisions in relation to self, family, friends, career, relationships, marriage, and religion (Arnstein. 1980, 1984a; Astin, 1993; Bee. 1987: Broughton. 1983: Dornbusch, 2000; Fiske \& Chiriboga. 1990: Frey \& Carlock, 1989; Frydenberg, 1997: Gottschalk, 1990; Hansen \& Maynard, 1973: Harter, 1985: House, 1992: Jackson \& Bosma. 1990: Levy, 1997: Levy-Warren, 1996; Lucas, 1997: Magen, 1998: Moore \& Britt, 1997; Mortimer \& Lorence, 1981: Newman \& Newman, 1978: NIH, 2000a, 2000b; Paul \& Brier, 2001: Schultheiss \& Blustein. 1994; Weinmann \& Newcombe, 1990; Whiteley, 1982; Willemsen \& Waterman, 1991).

\section{Summary}

In summary, the review of the literature highlights the importance of self-concept in relation to how individuals live their lives. Throughout the different stages in life, individuals examine the question "Who am l?" Changes in their lives, such as moving away from home, starting college or graduate school, exploring new values, andior making new friends can trigger a period of re-examination of the self. Individuals view the entire world through their filter of self which influences all of their thoughts. feelings. and behaviors. Persons with more positive self-concepts tend to have lower levels of hopelessness and depression. less illness and/or faster recovery period from any illness. and a higher level of satisfaction with life. Thus, a positive self-concept certainly appears to play a vital role in individuals physical and psychological well-being (Chang. 2000: 
Clark \& Beck. 1999: Felix. 2000: Fitts \& Warren, 1996: Hattie \& Marsh. 1996; Magen. 1998: Rosenberg, 1985).

Depression is occurring earlier and earlier in today's society. It was once generally accepted that depression stanted between the ages of $30-40$ but research has now documented that mild depressive symptoms often begin in late adolescence/young adulthood. Depression takes a toll on individuals and society with widespread effects in areas such as relationships with others, physical health, academic performance, work performance, feelings of self-worth. and the ability to handle stress (Dunner, 1997: Flynn \& Cappeliez, 1993; Swallow \& Segal, 1995).

Depression and self-concept are intertwined and interrelated. Individuals`selfconcept is key to the experience of depression, and depression always involves a component of the self. During times of depression, most individuals begin to set unrealistic standards, make self-belittling remarks, or make harsh judgments about themselves. Often these events lead them to see themselves as basically worthless and inadequate. Consequently, the self-concept is torn down during these times of depression (Beck, 1967, 1972. 1973: Fitts, 1965: NIH, 2000a. 2000b: NIMH, 2000: Roid \& Fitts, 1989).

Depression, especially mild depression. is common in college students and is often reported to be the leading emotional or psychiatric disorder found on university campuses. Late adolescence/young adulthood is just the time when numerous changes are occurring and when the effects of lowered self-concept and depression can have a great impact on their future. If they have a low self-concept or feelings of depression, then they may have trouble being in a new environment, concentrating on school. making personal and career 
choices, making new friends, and making commitments to lifetime goals. These areas of difficulty may have a long-term impact on individuals. It is vital that the symptoms of mild depression be acknowledged and addressed before they become more persistent and develop into a likely pattern of major depression (American Psychiatric Association. 2000; Beck, 1967. 1972. 1973, 1976: Clark \& Beck, 1999: Felix, 2000: Hattie, 1992: National DMDA, 2000; NIH, 2000a, 2000b).

Universities can take an important step in recognizing depressive symptoms and offering excellent care for their students in the university counseling center. Psychologists can fill an important role for students by offering workshops and seminars for students on a range of topics such as personal, social, and academic issues. self-concept, and depression. Students armed with these factors can more confidently enter society and be more productive and satisfied in their lives (Gladieux \& Swail, 2000: Hermon \& Hazler. 1999: O'Connor, 2001: Rundle, 2000). 
CHAPTER III

\section{METHODOLOGY}

\section{Introduction}

This chapter describes the quantitative research design used for an ex post facto study of the differences between undergraduate and graduate students with respect to their level of self-concept and level of depression.

\section{Population and Sample}

The population for this study consists of undergraduate and graduate students from Andrews University (AU) and Western Michigan University (WMU). The sample was a convenience sample which was obtained by asking various professors from different departments permission to administer the research packet (the Demographic Questionnaire, the Tennessee Self-Concept Scale: Second Edition [TSCS:2], and Beck Depression Inventory-II [BDI-II]) to the students in each of their classes.

\section{Variables}

The Independent variables in this study are program level and, for some hypotheses, depression group or self-concept subscale scores. The Dependent variables in this study are self-concept subscale scores and, for some hypotheses, 
depression raw scores or depression group.

\section{Instrumentation}

Data collection was accomplished by the use of three instruments: (1) the Demographic Questionnaire, (2) the Tennessee Self-Concept Scale (TSCS:2), and (3) the Beck Depression Inventory-II (BDI-II). Descriptions of each instrument are provided below.

\section{Demographic Questionnaire}

The Demographic Questionnaire, which I constructed, requests information concerning gender. age group. marital status, ethnic origin, current program level. GPA, and religion (Appendix C). Instructions asked the participants to check the appropriate box in response to each question. The Demographic Questionnaire requires less than 1 minute to complete.

\section{Tennessee Self Concept Scale: Second Edition}

The Tennessee Self-Concept Scale (TSCS) was originally developed by William Fitts in 1965 but this research utilized the Tennessee Self-Concept Scale: Second Edition (TSCS:2) as developed by Fitts and Warren in 1996. This edition was updated and redesigned to give clinicians and researchers a self-concept test that was easier to use while still keeping the basic characteristics that have been associated with the Tennessee Self Concept Scale (TSCS) over the years. For example, the TSCS:2 retained the two frames of reference (facets): the Internal frame of reference (Identity, Satisfaction, 
Behavior), and the External frame of reference (Physical, Moral-Ethical, Personal. Family, Social). The TSCS:2 was shortened from 100 questions to 82 questions but is psychometrically equivalent to the 1988 revised edition (median correlation $=.94$ of the scale scores in both editions). So, one can use the TSCS:2 while still drawing from the voluminous existing literature utilizing the TSCS (Fitts \& Warren, 1996).

Most of the original items of the TSCS were preserved but an important item, the Academic Work Self-Concept scale, was added to the external frame of reference of the TSCS:2. The Academic/Work Self-Concept scale, according to Fitts and Warren (1996), measures how "people perceive themselves in school and work settings, and of how they believe they are seen by others in those settings" (p. 24). The TSCS:2 was restandardized using a sample from across the United States which consisted of over 3,000 subjects who ranged in age from 7 to 90 years of age $(1,944$ adults). The sample included a broad spectrum of subjects such as public high-school students, college students, members of church groups, members of community groups, and public school staff members. The TSCS: 2 has two forms--the Adult Form with 82 items and the Child Form with 76 items (Fitts \& Warren, 1996).

TSCS:2's reliability was estimated by two types: internal consistency (Cronbach's alpha) and test-retest reliability. The internal consistency estimates for the TSCS:2 Adult Form range from .73 to .95 . The test-retest reliability estimates, with the test-retest period of 1-2 weeks, for the TSCS:2 Adult Form range from .47 (Inconsistent Responding score) to .82 (Total Self-Concept score). The content validity of the TSCS:2 is built on the method used in the original TSCS. For the new Academic/Work Self-Concept scale, the 
items were reviewed by four psychologists who agreed upon the items (Fitts \& Warren, 1996).

The concurrent validity studies compare the TSCS to other measures that were thought to be related to the general self-concept. In 1979, Van Tuinen and Ramanaiah demonstrated a correlation of .75 between the TSCS Total Scores and the Coopersmith Self-Esteem Inventory. In 1988. Marsh and Richards examined the TSCS scores and the scores on the Self-Description Questionnaire III and found a correlation of .71 for the Total scores on each instrument. Yonker, Blixt, and Dinero (1974) and Shavelson and Bolus (1982) (as cited in Fitts \& Warren, 1996; Roid \& Fitts, 1989) studied the PiersHarris Children's Self-Concept Scale (PHSCS) and the TSCS Total Score and obtained correlations ranging between .51 to .80 .

The Adult Form, which was used in this study, contains self-descriptive statements which the subject uses to paint a picture of himself or herself while using five response categories: (1) "Always False"; (2) "Mostly False": (3) "Partly False and Partly True": (4) Mostly True": and (5) "Always True." This form can be given individually or in groups and completed in 10 to 20 minutes. The Adult Form can be completed by individuals with a third-grade reading level or higher, ages 13 and older. There are two different forms for scoring the Adult Form: hand scoring and computerized scoring and interpretation. The hand scoring or AutoScore ${ }^{\mathrm{TM}}$ (Fitts \& Warren, 1996, p. 5) form was used in this study. The Adult Form, with the Profile Sheet detached, is given to each participant and the instructions are read aloud.

The TSCS:2 Adult Form consists of 82 items designed to measure self-concept on 
numerous dimensions. It has several categories: (1) Validity scores: Inconsistent Responding, Self-Criticism, Faking Good, and Response Distribution; (2) Summary scores: Total Self-Concept and Conflict: (3) Self-Concept scales: Physical, Moral, Personal. Family, Social, and Academic/Work; (4) Supplementary scores: Identity, Satisfaction, and Behavior (Fitts \& Warren, 1996). This research study examined 10 components of the above-mentioned four categories: Physical, Moral, Personal, Family, Social, Academic/Work, Identity, Satisfaction, Behavior, and Total.

The Physical Self-Concept scale score represents how persons view their body image, fitness, physical appearance, physical capabilities, and sexuality. Individuals with a high Physical Self-Concept scale score $(T \geq 60)$ tend to feel healthy and positive about the way their body looks and functions. Persons with a low Physical Self-Concept scale score $(T \leq 40)$ tend to feel dissatisfied with the way their body looks and functions. The Moral Self-Concept scale score represents how persons view their level of moral and ethical standards and contentment with their religion. Persons with a high Moral Self-Concept scale score $(T \geq 60)$ tend to be content with the manner in which they conduct themselves. Individuals with a low Moral Self-Concept scale score $(T \leq 40)$ tend to exhibit difficulty in impulse control or uphold an unrealistically high level of moral/ethical standards (Crain, 1996; Fitts, 1965, 1970, 1972a, 1972b; Fitts et al., 1971; Fitts \& Hamner, 1969; Fitts \& Warren, 1996; Levy, 1997: McGuire \& Tinsley, 1981: Roffe, 1981; Roid \& Fitts, 1989. Stein, 1996; Wells \& Marwell, 1976; Wylie, 1974).

The Personal Self-Concept scale score represents how persons view their worth and their level of self-evaluation, which does not come from their body or interactions with 
others. Individuals with a high Personal Self-Concept scale score $(T \geq 60)$ tend to feel positive about themselves and their relationships with others. Persons with a low Personal Self-Concept scale score ( $\mathrm{T} \leq 40)$ tend not to have a solid sense of self and sway with the differing opinions of others. The Family Self-Concept scale score represents how persons view their worth in their family and how they view their relationships with family. Individuals with a high Family Self-Concept scale score $(T \geq 60)$ tend to feel accepted, valued, and supponed by their relationships with family. Persons with a low Family Self-Concept scale score $(T \leq 40)$ tend to feel separated, disconnected, and dissatisfied with their relationships with family (Bishop et al., 1997: Bracken, 1996: Feiring \& Taska, 1996: Fitts, 1965, 1970, 1972a, 1972b; Fitts et al., 1971; Fitts \& Hamner, 1969; Fitts \& Warren, 1996: Lely. 1997: Roffe, 1981: Roid \& Fitts, 1989: Wylie. 1974).

The Social Self-Concept scale score represents how individuals feel valued and competent in their social environment. Persons with a high Social Self-Concept scale score $(T \geq 60)$ tend to be outgoing, cooperative, and friendly. Individuals with a low Social SelfConcept scale score $(T \leq 40)$ tend to feel uneasy in social situations and isolated (Berndt $\&$ Burgy, 1996: Bishop et al., 1997; Bracken, 1996; Feiring \& Taska, 1996; Fitts, 1965, 1970, 1972a, 1972b: Fitts et al., 1971: Fitts \& Hamner, 1969; Fitts \& Warren, 1996; Levy, 1997 . Roid \& Fitts, 1989). The Academic/Work Self-Concept scale score represents how persons perceive themselves as functioning in school or work and how others perceive them. Persons with a high Academic/Work Self-Concept scale score $(T \geq 60)$ tend to feel selfassured. capable, and secure in their academic and work environments. Individuals with a low Academic/Work Self-Concept scale score $(\mathrm{T} \leq 40)$ tend to express difficulty, and a lack 
of confidence, in performing in their academic and work environments (Bracken, 1996: Byrne, 1996a; Fitts \& Warren, 1996; Hattie \& Marsh, 1996).

The Identity Self-Concept score represents how persons identify themselves and says, "This is who I am." The Satisfaction Self-Concept score represents the perception of their level of self-acceptance and contentment and says. "This is how satisfied I am with myself." The Behavior Self-Concept score represents the perception of their actions and behavior and says, "This is the way I act or what I do" (Bishop et al., 1997; Fitts, 1965, 1970, 1972a, 1972b; Fitts et al., 1971; Fitts \& Hamner, 1969; Fitts \& Warren, 1996: Fleming \& Courtney, 1984: Harter, 1996; Marsh \& Hattie, 1996; McGuire \& Tinsley, 1981; Roid \& Fitts, 1989; Wells \& Marwell, 1976; Wylie, 1974).

The Total Self-Concept score is an important summary score because it indicates the overall self-concept and the affiliated level of self-esteem. Persons with a high Total Self-Concept score ( $T \geq 60)$ tend to view themselves as worthy. competent. and confident. Individuals with a low Total Self-Concept score $(T \leq 40)$ tend to view themselves as unworthy, incompetent, and unsure of themselves and their abilities. They may also exhibit symptoms of depression (Bishop et al., 1997; Fitts, 1965, 1970, 1972a, 1972b; Fitts et al., 1971: Fitts \& Hamner, 1969; Fitts \& Warren, 1996; Fleming \& Courtney, 1984; Keith \& Bracken, 1996; Levin et al., 1978; Levy, 1997; Marsh \& Hattie, 1996: McGuire \& Tinsley, 1981: Roffe, 1981: Roid \& Fitts, 1989: Wells \& Manvell, 1976: Wylie, 1974).

\section{Beck Depression Inventory-II}

The Beck Depression Inventory (BDI) was originally developed by Beck et al. in 
1961 but this research is utilizing the Beck Depression Inventory-II (BDI-II) which was revised in 1996 by Beck, Steer, and Brown (Beck, Steer, Ball, \& Ranieri, 1996; Hill et al., 1986: Merkley, 1997: Steer, Ball, Ranieri, \& Beck. 1997: Steer et al., 1999: Steer, Rissmiller, \& Beck, 2000; Whisman, Perez, \& Ramel, 2000). The BDI-II consists of 21 items designed to assess the level of depression in clinical and non-clinical populations. Each item contains a list of four statements which are placed in an increasing level of severity regarding a certain svmptom of depression. The BDI-II takes 5 minutes to complete and continues to be used with ages 13-80 (Beck, Steer, Ball, et al., 1996; Beck, Steer, \& Brown, 1996: Hill et al., 1986; Merkley, 1997; Smith \& Erford, 1998; Steer et al., 1999; Steer, Clark, Beck, \& Ranieri, 1998).

The BDI-II tends to represent and measure the cognitive-affective and somatic dimensions of depressive symptomatology. The 21 items claim to measure the "following symptoms and attitudes": Sadness, Pessimism, Past Failure, Loss of Pleasure, Guilty Feelings, Punishment Feelings, Self-Dislike, Self-Criticalness, Suicidal Thoughts or Wishes. Crying, Agitation. Loss of Interest, Indecisiveness. Worthlessness, Loss of Energy. Change in Sleeping Pattern, Irritability, Change in Appetite, Concentration Difficulty, Tiredness or Fatigue, and Loss of Interest in Sex. The total score is obtained by summing the highest rating of each circled item and adding the total number of points for all items. Each item has four choices and is rated on a 4-point scale which ranges from zero to three points. The guidelines for scoring ranges are: 0-13 Minimal/Nondepressed Range; $14-19$ Mild Range; 20-28 Moderate Range; 29-63 Severe Range (Beck, Steer, Ball, et al., 1996: Beck, Steer, \& Brown, 1996; Steer et al., 1999: Steer \& Clark, 1997; Steer, Kumar, 
Ranieri, \& Beck, 1998: Steer et al., 2000; Whisman et al., 2000).

From the initiation of research using the BDI and continuing with the BDI-II, researchers have used a wide range of cut scores to designate nondepressed asymptomatic and depressed groups. This wide range of cut scores varies with the purpose of the research study and the sample. Researchers, in many studies using the BDI, pick a cut score of 9 (Minimal) which correlates to 13 (Minimal) in the BDI-II. Other researchers using the BDI have picked a cut score of 19 (Mild: Mild-Moderate) which also correlates to 19 (Mild) in the BDI-II. The cut score of 19 is often used when researchers are dividing the subjects into two categories: nondepressed/asymptomatic and depressed. When examining college students, many researchers select 13 (Minimal) for a cut score. Therefore, I have chosen to also use 13 as the cut score in looking at undergraduate and graduate students. One cannot assume that if subjects from a nonclinical sample receive high $\mathrm{BDI}-\mathrm{II}$ scores this accurately reflects a depressive disorder. Also, one cannot assume that if subjects from a nonclinical sample receive low BDI-II scores that this accurately reflects the absence of a depressive disorder (American Psychiatric Association, 2000: Beck et al., 1988; Beeber, 1999; Clark et al., 1998: Golin \& Hartz, 1979; Gorenstein et al., 1995: Hammen, 1978: Hatzenbuehler et al., 1983: Smits \& Oliver, 1982: Steer, Ball, et al.. 1997; Steer \& Clark, 1997: Wiseman \& Guttfreund, 1995; Zimmerman, 1986).

An advantage of the BDI-Il is being aligned with the American Psychiatric Association's (1994) Diagnostic and Statistical Manual of Mental Disorders, Fourth Edirıon (DSM-IV) and the DSM-IV-TR criteria for depression. In order to be aligned with the $I S S M-I V$ and the $D S M-I V-T R$ criteria for depression, some important changes in the 
BDI-II were accomplished: (1) the time line for depressive symptoms was changed from 1 week to 2 weeks: (2) sleep and appetite disturbances were revised to assess both ends of the spectrum--increases and decreases: (3) names of several items were changed, for example: irritability changed to agitation: body image changed to worthlessness; and work difficulty changed to loss of energy (American Psychiatric Association, 1994, 2000: Beck, Steer, Ball, et al., 1996; Beck, Steer, \& Brown, 1996: Endler, Rutherford. \& Denisoff, 1999: Osman et al., 1997: Steer, Ball, et al.. 1997: Steer et al.. 1999; Steer \& Clark. 1997. Steer, Clark, et al., 1998; Steer, Kumar, et al., 1998; Steer et al., 2000; Waller, 1998: Whisman et al., 2000).

In 1996, Beck, Steer, Ball, et al. compared the amended Beck Depression Inventory (BDI-IA) and the BDI-II by administering the instruments to 140 adult psychiatric outpatients and found coefficient alphas of .89 (BDI-IA) and .91 (BDI-II) (Steer, Kumar, et al., 1998: Steer et al., 2000; Whisman et al., 2000). Beck. Steer. and Brown (1996) tested the original and new items with an outpatient sample $(N=500)$ and a college student sample $(N=120)$. The BDI-Il demonstrated reliability (Coefficient Alpha $=.92$, $p<.001$ for the outpatient sample; Coefficient Alpha $=.93, p<.001$ for the college student sample) higher than the BDI (Coefficient Alpha $=86$ ). The test-retest reliability estimate $=.93$ with the test-retest period approximately 1 week apart. The researchers examined convergent validity by correlating scores on the BDI-II with scores on the Revised Hamilton Psychiatric Rating Scale for Depression (HPRSD-R) $(r=.71)$. In 1997, Steer, Ball, et al. examined convergent validity by correlating scores on the BDI-Il with scores on the Symptom Checklist-90- Revised (SCL-90-R) $(r=.89)$. The researchers then concluded 
that the BDI-II can be presently utilized while still pulling from the sizable existing literature on the BDI (Beck, Steer, Ball, et al., 1996; Beck, Steer, \& Brown, 1996; Smith \& Erford, 1998; Steer \& Clark. 1997; Steer et al., 1999: Steer, Clark, et al., 1998).

The BDI-II is a screening tool and is not designed to be the sole factor in diagnosing a DSM-IV-TR mood disorder. Beck, Steer, and Brown (1996) stated:

The BDI-II was developed as an indicator of the presence and degree of depressive symptoms consistent with the DSM-IV, not as an instrument for specifying a clinical diagnosis. The BDI-II should be used cautiously as the sole diagnostic measure because depression may accompany a variety of primary diagnostic disorders ranging from panic disorder to schizophrenia. (p. 6)

So, the total BDI-II score is a way to represent the presence/absence of depressive symptoms, not clinical depression (American Psychiatric Association, 2000; Beck ei al., 1988: Beeber. 1999: Clark et al., 1998; Golin \& Hartz, 1979; Gorenstein et al., 1995: Hammen, 1978; Hatzenbuehler et al., 1983; Smits \& Oliver, 1982; Steer, Ball, et al., 1997; Steer \& Clark, 1997: Wiseman \& Guttfreund, 1995: Zimmerman, 1986).

\section{Data Collection}

During Fall Semester 2000, I applied to AU`s Human Subjects Review Board (HSRB) for permission to conduct this research study. After HSRB approval from AU was obtained, a copy of this HSRB approval and the completed WMU application for Human Subjects Institutional Review Board (HSIRB) was sent to WMU. While awaiting HSIRB approval from WMU, classes were chosen from the Fall 2000/Winter 2001 catalogs from $\mathrm{AU}$ and WMU on the undergraduate and/or graduate level. Each professor of the selected class at AU was contacted, informed of the research study, and asked to participate. Class 
times were scheduled for me to meet the class and collect the data. After HSIRB approval from WMU, each professor of the selected class at WMU was contacted, informed of the research study, and asked to participate. Class times were scheduled for me to meet the class and collect the data.

I met, at the agreed upon date, with each instructor and class. Due to the different specifications of AU's HSRB approval and WMU's HSIRB approval, slightly different introductory instructions were given. These are the introductory instructions given at AU. At the beginning of my scheduled time, I distributed one manila envelope (packet) to each student and I said the following: "My name is Ann Woolley. I am a doctoral student in Counseling Psychology at Andrews University. I am currently working on my dissertation which basically looks at what people think and feel about themselves, their world, and their future. I am here today to ask for your participation in this research study which will take about 15-20 minutes to complete three research instruments. Your name or identification (ID) number will not be used in any way so your responses will be confidential and anonymous. I want to emphasize that your participation in this study is completely voluntary. If you choose to not participate, you will not be penalized in any way. If you choose to paricipate, you are still free to withdraw at any time during the testing process without any penalty. I do not anticipate anything happening but, for example. if answering any of the questions brings up thoughts and feelings andior issues for you. I recommend that you contact the counseling center here at Andrews to talk with someone. Are there any questions? Those that do not wish to participate may leave the room now and I will let you know when we are finished. So. let's get started. I'd like you 
to use a pen, if possible, to complete the instruments."

These are the introductory instructions given at WMU. At the beginning of my scheduled time, I distributed one manila envelope (packet) to each student and I said the following: "My name is Ann Woolley. I am a doctoral student in Counseling Psychology at Andrews University. 1 am currently working on my dissertation which basically looks at what people think and feel about themselves, their world, and their future. I am here today to ask for your participation in this research study which will take about $15-20$ minutes to complete three research instruments. Your name or identification (ID) number will not be used in any way so your responses will be anonymous. I want to emphasize that your participation in this study is completely voluntary. If you choose to not participate, you will not be penalized in any way. If you choose to participate, you are still free to withdraw at any time during the testing process without any penalty. I do not anticipate anything happening but. for example. if answering any of the questions brings up thoughts and feelings andior issues for you, I recommend that you contact the counseling center here at Western to talk with someone. Are there any questions? Those who choose to not participate may return the blank forms and stay in your seats. So, let's get started. I'd like you to use a pen. if possible, to complete the instruments."

Then, as I held up my copy of the Demographic Questionnaire, I asked each student to take out the first page of the packet, which was the Demographic Questionnaire. I then asked the students to read the instructions, ask any questions, and then complete the Demographic Questionnaire which would take I minute or less. Next. as I held up my copy of the TSCS:2, I asked them to take out the second page of the packet, which was 
the TSCS:2. I reminded them not to fill in any identifying information but to read the instructions, ask any questions. and then complete the TSCS:2, which would take about 12 minutes. I instructed them that when they were through with the first page. which took approximately 6 minutes, to just turn it over without tearing off anything and complete the second page. Next. as I held up my copy of the BDI-II. I asked each student to look at the last page of the packet which was the BDI-II. Again, they were reminded not to fill in any identifying information but to read the instructions. ask any questions, and complete the instrument, which would take about 2-5 minutes. After the BDI-Il was completed, I asked the students to return the three research instruments to the manila envelope. seal it, and give it to me. I then thanked them for their participation.

\section{Null Hypotheses and Methods of Analysis}

Six null hypotheses were tested. Null Hypothesis 1 related to Research Question 1 and Research Hypothesis 1. Null Hypothesis 2 looked at Research Question 2 and Research Hypothesis 2. Null Hypothesis 3 and Null Hypotheses 5 and 6 looked at Research Question 3 and Research Hypothesis 3 , as I studied these questions with univariate and multivariate analyses. Finally, Null Hypothesis 4 related to Research Question 4 and Research Hypothesis 4.

Null Hypothesis $l$. There is no significant difference between undergraduate and graduate students with respect to the scores on the BDI-II.

This hypothesis was tested in 2 ways: (1) by the r-test for means of independent samples using the raw BDI-II scores and the independent variable was program level and 
the dependent variable was depression scores., and (2) by chi-square analysis using the proportion of undergraduate and graduate students at each of the four groups of depression as indicated by the BDI-II.

Null Hypothesis 2. There is no significant difference between the undergraduate and graduate students with respect to the mean scores on the TSCS:2.

This hypothesis leads to 10 subhypotheses:

a. There is no significant difference between the undergraduate and graduate students with respect to the mean score on the Physical subscale score of the TSCS:2.

b. There is no significant difference between the undergraduate and graduate students with respect to the mean score on the Moral subscale score of the TSCS:2.

c. There is no significant difference between the undergraduate and graduate students with respect to the mean score on the Personal subscale score of the TSCS:2.

d. There is no significant difference between the undergraduate and graduate students with respect to the mean score on the Family subscale score of the TSCS:2.

e. There is no significant difference between the undergraduate and graduate students with respect to the mean score on the Social subscale score of the TSCS:2.

f. There is no significant difference between the undergraduate and graduate students with respect to the mean score on the Academic/Work subscale score of the TSCS:2.

g. There is no significant difference between the undergraduate and graduate students with respect to the mean score on the Identity subscale score of the TSCS:2.

$h$. There is no significant difference between the undergraduate and graduate 
students with respect to the mean score on the Satisfaction subscale score of the TSCS:2.

i. There is no significant difference between the undergraduate and graduate students with respect to the mean score on the Behavior subscale score of the TSCS:2.

j. There is no significant difference between the undergraduate and graduate students with respect to the mean score on the Total subscale score of the TSCS:2.

Null Hypothesis 3. There is no significant difference among the four BDI-Il groups with respect to the mean scores on the TSCS:2.

This hypothesis leads to 10 subhypotheses ( $3 \mathrm{a}$ to $3 \mathrm{j}$ ) parallel to those under Hypothesis 2.

Null Hypothesis + . There is no significant interaction between BDI-II group and program level with respect to scores on the TSCS:2.

This hypothesis leads to 10 subhypotheses ( $4 a$ to $4 \mathrm{j}$ ) parallel to those under Hypothesis 2

Hypotheses $2-4$ were tested by two-way ANOVA $(2 \times 4)$. The two factors, or independent variables. were program level and BDI-II group and the dependent variable was the TSCS:2

Null Hypothesis 5 . There is no linear combination of the nine TSCS:2 subscale scores which significantly discriminates among the four BDI-II groups for undergraduate students.

Null Hypothesss 6 . There is no linear combination of the nine TSCS:2 subscale scores which significantly discriminates among the four BDI-II groups for graduate students. 
Null Hypotheses 5 and 6 were tested by discriminant analysis. The independent variable was TSCS:2 scores and the dependent variable was BDI-II group.

All hypotheses were tested with alpha at .05 .

\section{Power Analysis}

With alpha $=.05$, power $=.90$, and medium effect size $f=.25$, sample size tables (Cohen, 1969, p. 377) yield the following:

1. For main effect BDI-II, with four levels and $d f=3$, the minimum sample size is 58 for each of the four levels, $58 / 2=29$ per cell for a total $N$ of 232 .

2. For main effect program, with two levels and $d f=1$, the minimum sample size is 85 for each class, $85 / 4=21.25$ per cell for a total $n$ of 170 .

Therefore, to ensure power of 90 , a sample size of 232 was sought.

For the discriminant analysis, with nine subscale scores, a total $N$ of 232 provides over 25 subjects per scale. This more than meets the suggested criterion of at least 10 subjects per scale. 


\section{CHAPTER IV}

\section{PRESENTATION AND ANALYSIS OF DATA}

\section{Introduction}

This chapter presents descriptive data relating to the sample and the instruments. It also presents the results of testing the hypotheses.

\section{Description of Sample}

The sample for this study consisted of 239 undergraduate and graduate students from Andrews University (AU) and Western Michigan University (WMU). Participation in the study was completely voluntary. The convenience sample was obtained by asking various professors from different departments for permission to administer the research packet (the Demographic Questionnaire, the Tennessee Self-Concept Scale: Second Edition [TSCS:2], and Beck Depression Inventory-II [BDI-II]) to the students in each of their classes. Although a total of 280 research packets was distributed, 7 packets were not used due to the age (17 or below) of the subjects, 19 packets were not used due to improper completion of instruments by the subjects, and 15 packets were not used due to improper instruction by a class professor, which left the total number of participants to be $239(N=239)$. 


\section{Demographic Data}

Table I presents a description of the sample in terms of gender. Table 2 presents a description of the sample in terms of age. The findings in Table 1 indicate that the majority of the participants were female $(58.6 \%)$ and $41 \%$ were male. The findings in Table 2 indicate that, of the 239 total participants, $49.8 \%$ were between the ages of $18-24$ and $29.7 \%$ were between the ages of $25-34$.

Table 3 presents a description of the sample in terms of marital status. The findings in Table 3 indicate that the majority of the participants were single $(63.2 \%)$ and $30.5 \%$ were married. Table 4 presents a description of the sample in terms of ethnic origin. The findings in Table 4 indicate that just over 50\% (50.6) of the participants were Caucasian, 13\% were Asian Origin, 10.9\% were African American, $7.5 \%$ were of Caribbean Origin, and $6.3 \%$ were Latino/Hispanic.

Table 5 presents a description of the sample in terms of current program level. The findings in Table 5 indicate that in the breakdown of the participants in their current program level, $20.9 \%$ were seniors on the undergraduate level, $14.6 \%$ were freshmen on the undergraduate level, $28.0 \%$ were master's students $\left(\mathrm{I}^{\mathrm{st}}\right.$ year $)$ on the graduate level, $15.9 \%$ were master's students ( $2^{\text {nd }}$ year) on the graduate level, and $6.3 \%$ (combined total) were $\mathrm{Ph} . \mathrm{D}$. students. 
Table 1

Gender

\begin{tabular}{lcc} 
Gender & Frequency & Percentage \\
\hline Male & 98 & 41.0 \\
Female & 140 & 58.6 \\
No response & 1 & 0.4 \\
\hline
\end{tabular}

Table 2

Age

\begin{tabular}{lcc}
\hline Age & Frequency & Percentage \\
\hline 17 or below & 0 & 0.0 \\
$18-24$ & 119 & 49.8 \\
$25-34$ & 71 & 29.7 \\
$35-44$ & 32 & 13.4 \\
$45-54$ & 14 & 5.9 \\
$55-64$ & 1 & 0.4 \\
65 and over & 0 & 0.0 \\
No response & 2 & 0.8 \\
\hline
\end{tabular}


Table 3

Marital Status

\begin{tabular}{lcc}
\hline Marital Status & Frequency & Percentage \\
\hline Single & 151 & 63.2 \\
Cohabited & 5 & 2.1 \\
Married & 73 & 30.5 \\
Separated/Divorced & 10 & 4.2 \\
Widowed & 0 & 0.0 \\
\hline
\end{tabular}

Table 4

Fithic Origin

\begin{tabular}{lcc}
\hline Ethnic Origin & Frequency & Percentage \\
\hline African American & 26 & 10.9 \\
African Origin & 9 & 3.8 \\
Asian American & 6 & 2.5 \\
Asian Origin & 31 & 13.0 \\
Caribbean Origin & 18 & 7.5 \\
Caucasian & 121 & 50.6 \\
Latino/Hispanic & 15 & 6.3 \\
Multiracial & 4 & 1.7 \\
Native American & 2 & 0.8 \\
Other & 6 & 2.5 \\
No Response & 1 & 0.4 \\
\hline
\end{tabular}


Table 5

Current Program Level

\begin{tabular}{|c|c|c|}
\hline Description & Frequency & Percentage \\
\hline \multicolumn{3}{|l|}{ Undergraduate } \\
\hline Freshmen & 35 & 14.6 \\
\hline Sophomore & 16 & 6.7 \\
\hline Junior & 18 & 7.5 \\
\hline Senior & 50 & 20.9 \\
\hline \multicolumn{3}{|l|}{ Graduate } \\
\hline MA I ( (1 ${ }^{\text {st }}$ Year $)$ & 67 & 28.0 \\
\hline MA $2 \quad\left(2^{\text {nd }}\right.$ Year $)$ & 38 & 15.9 \\
\hline PhD 1 ( $1^{\text {st }}$ Year $)$ & 12 & 5.0 \\
\hline PhD 2 ( $2^{\text {nd }}$ Year $)$ & 3 & 1.3 \\
\hline $\begin{array}{r}\text { PhD } 3+\left(3^{\text {rd }} \text { Year }\right. \\
\text { and }+)\end{array}$ & 0 & 0.0 \\
\hline
\end{tabular}

Table 6 presents a description of the sample in terms of GPA group. Table 7 presents a description of the sample in terms of religion. The findings in Table 6 indicate that 96 of the participants $(40.2 \%)$ reported having a GPA that fell between the range of 3.9-3.5. There were $29.7 \%$ of the participants who reported their GPA to be between 3.4-3.0. The findings in Table 7 indicate that the majority of the participants $(69.4 \%)$ reported being Protestant and $17.6 \%$ reported "other" as their religion. 
Table 6

GPA Group

\begin{tabular}{lll}
\hline GPA Group & Frequency & Percentage \\
\hline 4.0 & 27 & 11.3 \\
$3.9-3.5$ & 96 & 40.2 \\
$3.4-3.0$ & 71 & 29.7 \\
$2.9-2.5$ & 33 & 13.8 \\
$2.4-2.0$ & 4 & 1.7 \\
$1.9-1.5$ & 0 & 0.0 \\
$1.4-1.0$ & 0 & 0.0 \\
No Response & 8 & 3.3 \\
\hline
\end{tabular}

Table 7

Religlom

\begin{tabular}{lcc}
\hline Religion & Frequency & Percentage \\
\hline Protestant & 166 & 69.4 \\
Catholic & 17 & 7.1 \\
Jewish & 0 & 0.0 \\
Islamic & 4 & 1.7 \\
Other & 42 & 17.6 \\
No Response & 10 & 4.2 \\
\hline
\end{tabular}




\section{General Description of Instruments}

Table 8 presents a description of the data on the TSCS:2. The Alpha levels for the nine subscales reached .78 or higher and each appears to be fully adequate for the study. These findings are compatible with the internal consistency estimate ranges of the TSCS:2 (.73 to .95$)$. All of the nine TSCS:2 subscale variables utilized the upper end of the possible range of scores while not utilizing the lower end. This finding indicates that the participants appeared to respond less negatively when reporting on their seifconcept.

Table 9 presents the frequency of cases in the four BDI-II groups for undergraduate and graduate students. The four BDI-II groups are as follows: Group 1(0-13) Minimal/Nondepressed (ND) Range, Group 2 (14-19) Mild Range, Group 3 (20-28) Moderate Range, and Group 4 (29-63) Severe Range. The possible range of BDI-II scores was 0-63 with the actual range of scores being 0-56. The findings in Table 9 indicate the following for both undergraduate and graduate students: BDI-II Group 1 (0-13 Minimal/Nondepressed (ND) Range) held the vast majority of participants ( $n=197)$ : BDl-Il Group 2 (14-19 Mild Range) held a total of 21 participants: BDI-II Group 3 (20-28 Moderate Range) held a total of 13 participants; and BDI-II Group 4 (29-63 Severe Range) held the fewest participants $(n=8)$. So, the comparison among the BDI-II groups tends not to be very strong because there are so few participants in Group 4. 
Table 8

Dala on TSCS:2

\begin{tabular}{|c|c|c|c|c|c|}
\hline TSCS:2 & $\begin{array}{l}\text { Possible Range } \\
\text { of Scores }\end{array}$ & $\begin{array}{l}\text { Actual Range } \\
\text { of Scores }\end{array}$ & $\begin{array}{l}\text { Mean of } \\
\text { Scores }\end{array}$ & $\begin{array}{l}\text { Standard } \\
\text { Deviation }\end{array}$ & $\begin{array}{l}\text { Reliability } \\
\text { Coefficient } \\
\text { Alphas }\end{array}$ \\
\hline Physical & $14-70$ & $27-68$ & 53.87 & 7.15 & .83 \\
\hline Moral & $12-60$ & $24-60$ & 47.64 & 6.51 & .84 \\
\hline Personal & $12-60$ & $23-60$ & 48.30 & 5.86 & .82 \\
\hline Family & $12-60$ & $24-60$ & 47.78 & 6.47 & 81 \\
\hline Social & $12-60$ & $33-60$ & 48.11 & 5.63 & .79 \\
\hline $\begin{array}{l}\text { Academic } \\
\text { Work }\end{array}$ & $12-60$ & $27-60$ & 46.30 & 6.13 & .78 \\
\hline Identity & $21-105$ & $59-104$ & 90.27 & 8.17 & .85 \\
\hline Satisfaction & $21-105$ & $43-102$ & 78.41 & 10.88 & .86 \\
\hline Behavior & $20-100$ & $50-98$ & 77.03 & 8.35 & .81 \\
\hline Total & $82-410$ & & & & \\
\hline
\end{tabular}


Table 9

Scores on the BDI-II

Program Level

BDI-Il Groups

Total

1

$2 \quad 3$

\begin{tabular}{lrrrrr}
\hline Undergraduate & 93 & 11 & 8 & 7 & 119 \\
Graduate & 104 & 10 & 5 & 1 & 120 \\
\hline Total & 197 & 21 & 13 & 8 & 239 \\
\hline
\end{tabular}

\section{Testing the Hypotheses}

Each of the six null hypotheses is presented along with the appropriate statistical analỵsis.

\section{Null Hypothesis 1}

Null Hypothesis 1 . There is no significant difference between undergraduate and graduate students with respect to the scores on the BDI-II.

This null hypothesis was tested in two ways: (1) by the t-test for means of independent samples using the raw BDI-II scores; and (2) by chi-square analysis using the proportion of undergraduate and graduate students in each of the four depression groups as indicated by the BDI-II. The independent variable was program level and the dependent variable was depression scores.

Null Hypothesis 1 was tested by means of the t-test for independent samples. The means of the undergraduate and graduate groups were 8.83 and 6.73 respectively. The 
variances were significantly different $(p=0.0122)$, so the separate sample $l$-test was used, yielding a $t$ of 2.01 and a probability level of 0.046 . The difference between the two means, undergraduate and graduate, is significant. When the raw scores were compared, the undergraduate mean depression score was significantly higher than the graduate mean depression score. Undergraduate students demonstrated higher mean depression scores on the BDI-II than the graduate students. This null hypothesis is thus rejected.

Null Hypothesis 1 was also tested by chi-square analysis. Table 10 presents the frequency and percentage of the four BDI-II groups and the program levels. The results of the test given are $\chi^{2}=5.85$ with $d f=3$ and $p=0.1191$. The findings in Table 10 indicate that although the obtained raw scores are significantly different, when they are placed in the four BDI-II groups, there is no significant difference between the proportion of undergraduate and graduate students in each BDI-II group. The hypothesis is thus retained.

Table 10

Contingency Table for Hypothesis I (b) (Percentages (iven in Parentheses)

BDI-II Groups

Program Level

Total

$\overline{\text { Undergraduate } \quad \text { Graduate }}$

\begin{tabular}{|c|c|c|c|}
\hline Nondepressed & $93(78.2)$ & $104(86.7)$ & $197(82.4)$ \\
\hline Mild & $11 \quad(9.2)$ & $10 \quad(8.3)$ & $21 \quad(8.8)$ \\
\hline Moderate & $\begin{array}{ll}8 & (6.7)\end{array}$ & $\begin{array}{ll}5 & (4.2)\end{array}$ & $13 \quad(5.4)$ \\
\hline Severe & $7 \quad(5.9)$ & $1 \quad(0.8)$ & $8 \quad(3.3)$ \\
\hline
\end{tabular}

Total

119

120 


\section{Null Hypotheses 2, 3, and 4}

These three null hypotheses were tested by a single analysis, two-way ANOVA (2 X 4). This analysis was done 10 times, once for each of the sub-hypotheses $(a-j)$ for each subtest and the total. They are therefore presented together. The two factors, or independent variables, were program level and BDI-II group and the dependent variable was the TSCS:2

Null Hypothesis 2. There is no significant difference between the undergraduate and graduate students with respect to the mean scores on the TSCS:2.

Null Hypothesis 3 . There is no significant difference among the four BDI-II groups with respect to the mean scores on the TSCS:2.

Null Hypothesis 4 . There is no significant interaction between the BDI-II group and program level with respect to scores on the TSCS:2.

Null Hypotheses 2, 3, 4a, Physical subscale

Table 11 presents the means for the Physical TSCS:2 subscale score and the BDI-II groups. Table 12 presents the results of the analysis of variance. As there is no significant interaction, Null Hypothesis $4 \mathrm{a}$ is retained and main effects may be studied. Null Hypothesis 2a is retained because there is no significant difference between undergraduate and graduate students on Physical Self-Concept. Null Hypothesis 3a is rejected because there is a significant difference among the BDI-II groups on Physical Self-Concept.

Because of the very different group sizes or frequencies, a post hoc Scheffé test 
was used to compare all pairs of observed group means. As this test is so conservative, an alpha of .10 was used, as recommended by Scheffé (Scheffé, 1959). This test indicated that Group 1 is significantly higher than Groups 2, 3, and 4: Groups 2 and 3 are significantly higher than Group 4; and Groups 2 and 3 are not significantly different with respect to means on the Physical subscale of the TSCS:2. Thus, those who are nondepressed show significantly higher Physical Self-Concept scores than those with mild, moderate, and severe depression: those with mild and moderate depression show significantly higher Physical Self-Concept scores than those with severe depression: and there is no significant difference in Physical Self-Concept scores between those with mild and moderate depression.

Table 11

Means Table for Physical TSCS:2 Subscale Score and BDI-II (iroups

Physical

BDI-II Groups

Total

$\overline{N D} \quad$ Mild $\quad$ Moderate Severe

Undergraduate

54.968

50.091

49.500

37.143

53.101

Graduate

55.654

47.600

48.800

49.000

54.642

Total

55.330

48.905

49.231

38.625

53.875 
Table 12

Summary of the Analysis of Variance for Physical TSC S:2 Suhscale and BIDI-II (iroups

\begin{tabular}{lrrrrrl}
\hline Physical & \multicolumn{1}{c}{ SS } & $d f$ & MS & $\digamma$ & Level of Sig. \\
\hline BDI-I! Groups & 1590.276 & 3 & 530.092 & 13.658 & $.000^{*}$ \\
Program Level & 52.090 & 1 & 52.090 & 1.342 & .248 \\
Program x BDI-II & 165.849 & 3 & 55.283 & 1.424 & .236 \\
\hline & & & & & & \\
\hline
\end{tabular}

$* p=.05$

Null Hypotheses 2, 3, 4b, Moral subscale

Table 13 presents the means for the Moral TSCS:2 subscale score and the BDI-II groups. Table 14 presents a summary of the analysis of variance. As there is no significant interaction, Null Hypothesis $4 \mathrm{~b}$ is retained and main effects may be studied. Null Hypothesis $2 \mathrm{~b}$ is retained because there is no significant difference between undergraduate and graduate students on Moral Self-Concept. Null Hypothesis $3 b$ is rejected because there is a significant difference among the BDI-II groups on Moral Self-Concept.

The Scheffe test $(p=.10)$ findings are that Group 1 is significantly higher than Groups 2, 3, and 4; and Groups 2, 3, and 4 are not significantly different with respect to means on the Moral subscale of the TSCS:2. Thus, those who are nondepressed show significantly higher Moral Self-Concept scores than those with mild, moderate, and 
severe depression: and there is no significant difference in Moral Self-Concept scores among those with mild, moderate, and severe depression.

Table 13

Means Table for Moral TSC S:2 Subscale Score and BDI-II Groups

Mora

BDI-II Groups

Total

\begin{tabular}{llll}
\hline ND & Mild & Moderate & Severe
\end{tabular}

\begin{tabular}{llllll}
\hline Undergraduate & 47.624 & 43.546 & 44.250 & 39.714 & 46.555 \\
Graduate & 49.683 & 44.200 & 37.600 & 48.000 & 48.708 \\
\hline Total & 48.711 & 43.857 & 41.692 & 40.750 & 47.636 \\
\hline
\end{tabular}

Table 14

Summary of the Analysis of Variance for Moral TSC S:2 Subscale and BDI-II Groups

\begin{tabular}{lccccl}
\hline Moral & $S S$ & $d f$ & $M S$ & $\digamma$ & Level of Sig. \\
\hline BDI-II Groups & 1101.509 & 3 & 367.170 & 10.140 & $.000^{*}$ \\
Program Level & 11.266 & 1 & 11.266 & .311 & .578 \\
Program x BDI-II & 263.497 & 3 & 87.832 & 2.426 & .066 \\
\hline
\end{tabular}

Total $\quad 552473.000 \quad 239$

${ }^{*} p=.05$ 
Null Hypothesis 2, 3, 4c, Personal subscale

Table 15 presents the means for the Personal TSCS:2 subscale score and the BDI-II groups. Table 16 presents a summary of the analysis of variance. As there is no significant interaction, Null Hypothesis $4 \mathrm{c}$ is retained and main effects may be studied. Null Hypothesis 2c is retained because there is no significant difference between undergraduate and graduate students on Personal Self-Concept. Null Hypothesis $3 \mathrm{c}$ is rejected because there is a significant difference among the BDI-II groups on Personal Self-Concept.

The Scheffé test $(p=.10)$ findings are that Group 1 is significantly higher than Groups 2. 3, and 4: Groups 2 and 3 are significantly higher than Group 4; and Groups 2 and 3 are not significantly different with respect to means on the Personal subscale of the TSCS:2. Thus, those who are nondepressed show significantly higher Personal Self-Concept scores than those with mild, moderate, and severe depression; those with mild and moderate depression show significantly higher Personal Self-Concept scores than those with severe depression; and there is no significant difference in Personal Self-Concept scores between those with mild and moderate depression. 
Table 15

Means Table for Personal TSC:S:2 Subscale Score and BDI-ll Groups

\begin{tabular}{llllll}
\hline Personal & \multicolumn{4}{c}{ BDI-Il Groups } & Total \\
\cline { 2 - 5 } & ND & Mild & Moderate & Severe & \\
\hline Undergraduate & 49.376 & 45.909 & 40.500 & 34.143 & 47.563 \\
Graduate & 49.875 & 43.900 & 43.200 & 42.000 & 49.033 \\
\hline Total & 49.640 & 44.952 & 41.539 & 35.125 & 48.301 \\
\hline
\end{tabular}

Table 16

Summary of the Analysis of Variance for Personal TSC:S:2 Subscale and BI)I-II Groups

\begin{tabular}{lrrrrr}
\hline Personal & \multicolumn{1}{l}{ SS } & df & MS & $F$ & Level of Sig. \\
\hline BDI-II Groups & 1441.408 & 3 & 480.469 & 20.068 & $.000^{*}$ \\
Program Level & 48.741 & 1 & 48.741 & 2.036 & .155 \\
Program x BDI-II & 95.231 & 3 & 31.744 & 1.326 & .267 \\
\hline Total & 565802.000 & 239 & & & \\
\hline
\end{tabular}

$* p=.05$. 
Null Hypothesis 2, 3, 4d, Family subscale

Table 17 presents the means for the Family TSCS:2 subscale score and the BDI-II groups. Table 18 presents a summary of the analysis of variance. As there is no significant interaction, Null Hypothesis $4 \mathrm{~d}$ is retained and main effects may be studied. Null Hypothesis $2 \mathrm{~d}$ is retained because there is no significant difference between undergraduate and graduate students on Family Self-Concept. Null Hypothesis $3 \mathrm{~d}$ is rejected because there is a significant difference among the BDI-II groups on Family Self-Concept.

The Scheffe test $(p=.10)$ findings are that Group 1 is significantly higher than Groups 2, 3, and 4: Group 2 is significantly higher than Group 4: Groups 2 and 3 are not significantly different with respect to means on the Family subscale of the TSCS:2; and Groups 3 and 4 are not significantly different with respect to means on the Family subscale of the TSCS:2. Thus, those who are nondepressed show significantly higher Family Self-Concept scores than those with mild, moderate, and severe depression: those with mild depression show significantly higher Family Self-Concept scores than those with severe depression: there is no significant difference in Family Self-Concept scores between those with mild and moderate depression; and there is no significant difference in Family Self-Concept scores between those with moderate and severe depression. 
Table 17

Means Table for Family TSC:S:2 Subscale Score and BDI-II Groups

\begin{tabular}{llllll}
\hline Family & \multicolumn{4}{c}{ BDI-II Groups } & Total \\
\cline { 2 - 5 } & ND & Mild & Moderate & Severe & \\
\hline Undergraduate & 48.656 & 46.182 & 42.750 & 35.143 & 47.235 \\
Graduate & 49.404 & 41.300 & 41.200 & 42.000 & 48.325 \\
\hline Total & 49.051 & 43.857 & 42.154 & 36.000 & 47.782 \\
\hline
\end{tabular}

Table 18

Summary of the Analysis of Varianc' for Family TSCS:2 Suhscale and BDI-II Groups

\begin{tabular}{lrrrrr}
\hline Family & \multicolumn{1}{c}{$S .5$} & df & \multicolumn{1}{c}{ MS } & $F$ & Level of Sig. \\
\hline BDI-II Groups & 1346.143 & 3 & 448.714 & 13.580 & $.000^{*}$ \\
Program Level & .820 & 1 & .820 & .025 & .875 \\
Program x BDI-II & 198.205 & 3 & 66.068 & 1.999 & .115 \\
\hline & & & & & \\
\hline
\end{tabular}

$* p=.05$. 
Null Hypothesis 2, 3, 4e. Social subscale

Table 19 presents the means for the Social TSCS:2 subscale score and the BDI-II groups. Table 20 presents a summary of the analysis of variance. As there is no significant interaction, Null Hypothesis $4 \mathrm{e}$ is retained and main effects may be studied. Null Hypothesis $2 \mathrm{e}$ is retained because there is no significant difference between undergraduate and graduate students on Social Self-Concept. Null Hypothesis 3e is rejected because there is a significant difference among the $\mathrm{BDI}-\mathrm{Il}$ groups on Social Self-Concept.

The Scheffe test $(p=.10)$ findings are that Group 1 is significantly higher than Groups 2 and 4: Groups I and 3 are not significantly different with respect to means on the Social subscale of the TSCS:2; and Groups 2,3 , and 4 are not significantly different with respect to means on the Social subscale of the TSCS:2. Thus, those who are nondepressed show significantly higher Social Self-Concept scores than those with mild and severe depression: there is no significant difference in Social Self-Concept scores between those who are nondepressed and those with moderate depression; and there is no significant difference in Social Self-Concept scores among those with mild, moderate, and severe depression. 
Table 19

Means Table for Social TSC S:2 Subscale Score and BDI-II Groups

Social

BDI-II Groups

Total

$\overline{N D} \quad$ Mild $\quad$ Moderate Severe

\begin{tabular}{lccccc}
\hline Undergraduate & 48.817 & 45.000 & 45.375 & 41.429 & 47.798 \\
Graduate & 48.856 & 46.000 & 47.400 & 33.000 & 48.425 \\
\hline Total & 48.838 & 45.476 & 46.154 & 40.375 & 48.113 \\
\hline
\end{tabular}

Table 20

Summary of the Analysis of Variance for Social TSC S:2 Subscale and BDI-II (jroups

\begin{tabular}{llllll}
\hline Social & $S S$ & $d f$ & $M S$ & $l$ & Level of Sig. \\
\hline BDI-II Groups & 694.883 & 3 & 231.628 & 7.956 & $.000^{*}$ \\
Program Level & 17.142 & 1 & 17.142 & .589 & .444 \\
Program x BDI-II & 79.474 & 3 & 26.491 & .910 & .437 \\
\hline
\end{tabular}

Total $\quad 560835.000 \quad 239$

${ }^{*} p=.05$ 
Null Hypothesis 2. 3. 4f, Academic Work subscale

Table 21 presents the means for the Academic/Work TSCS:2 subscale score and the BDI-Il groups. Table 22 presents a summary of the analysis of variance. As there is no significant interaction, Null Hypothesis $4 \mathrm{f}$ is retained and main effects may be studied. Null Hypothesis $2 \mathrm{f}$ is retained because there is no significant difference between undergraduate and graduate students on Academic/Work Self-Concept. Null Hypothesis $3 \mathrm{f}$ is rejected because there is a significant difference among the BDI-ll groups on Academic/Work Self-Concept.

The Scheffé test $(p=.10)$ findings are that Groups 1,2, and 3 are significantly higher than Group 4: and Groups 1, 2, and 3 are not significantly different with respect to means on the Academic/Work subscale of the TSCS:2. Thus, those who are nondepressed and those with mild and moderate depression show significantly higher Academic/Work Self-Concept scores than those with severe depression; and there is no significant difference in Academic/Work Self-Concept scores among those who are nondepressed and those with mild and moderate depression. 
Table 21

Means Tuble for Academic Work TSCS:2 Subscale Score and BDI-II Groups

\begin{tabular}{llllll}
\hline Academic/Work & \multicolumn{4}{c}{ BDI-Il Groups } & Total \\
& ND & Mild & Moderate & Severe & \\
\hline Undergraduate & 45.839 & 44.182 & 44.625 & 33.286 & 44.866 \\
Graduate & 47.990 & 47.500 & 43.800 & 42.000 & 47.725 \\
\hline Total & 46.975 & 45.762 & 44.308 & 34.375 & 46.301 \\
\hline
\end{tabular}

Table 22

Summany of the Analysis of V'ariance for Academic Work TSCS:2 Subscale and BDI-II (iroups

\begin{tabular}{lllllll}
\hline Academic/Work & $S S$ & $d f$ & MS & $F$ & Level of Sig. \\
\hline BDI-II Groups & 381.518 & 3 & 127.173 & 4.006 & $.008^{*}$ \\
Program Level & 106.285 & 1 & 106.285 & 3.348 & .069 \\
Program x BDI-II & 71.951 & 3 & 23.984 & .755 & .520 \\
\hline
\end{tabular}

Total $\quad 521342.000 \quad 239$

$* p=.05$. 
Null Hypothesis 2, 3, 4g, Identity subscale

Table 23 presents the means for the Identity TSCS:2 subscale score and the BDI-II groups. Table 24 presents a summary of the analysis of variance. Because of the significant interaction, Null Hypothesis $4 \mathrm{~g}$ is rejected and simple effects had to be studied. The results of these 6 one-way ANOVAs are given in Table 25.

Table 25 indicates that there is a significant difference among the BDI-II groups for undergraduates. The post hoc Scheffe test, with $p=.10$. was used to compare the pairs of group means. Group 1 is significantly higher than Groups 3 and 4; Group 2 is significantly higher than Groups 3 and 4: Group 3 is significantly higher than Group 4: and Groups 1 and 2 are not significantly different with respect to group means on the Identity subscale of the TSCS:2. Thus, for undergraduate students, those who are nondepressed or those with mild depression show significantly higher Identity Self-Concept scores than those with moderate and severe depression; those with moderate depression show significantly higher Identity Self-Concept scores than those with severe depression; and there is no significant difference in Identity Self-Concept scores between those who are nondepressed and those with mild depression.

Table 25 indicates that there is a significant difference among BDI-II groups for graduates (used Groups 1, 2, and 3 only because Group 4 had only one subject). The post hoc Scheffé test. with $p=.10$, was used to compare the pairs of group means. Group 1 is significantly higher than Group 2; Groups I and 3 are not significantly different with respect to group means on the Identity subscale of the TSCS:2: and Groups 2 and 3 are not significantly different with respect to group means on the Identity subscale of the TSCS:2. 
Table 23

Means Table for Identity TSCS:2 Subscale Score and BI)I-ll (iroups

\begin{tabular}{|c|c|c|c|c|c|}
\hline \multirow[t]{2}{*}{ Identity } & \multicolumn{4}{|c|}{ BDI-II Groups } & \multirow[t]{2}{*}{ Total } \\
\hline & $\overline{N D}$ & Mild & Moderate & Severe & \\
\hline Undergraduate & 91.505 & 88.546 & 79.750 & 69.714 & 89.160 \\
\hline Graduate & 92.423 & 83.800 & 85.600 & 86.000 & 91.367 \\
\hline Total & 91.990 & 86.286 & 82.000 & 71.750 & 90.268 \\
\hline
\end{tabular}

Table 24

Summary of the Analysis of Vartance for ldentity TSC S:2 Subscale and BDI-II (iroups

\begin{tabular}{lcccccc}
\hline Identity & SS & df & MS & $\digamma$ & Level of Sig. \\
\hline BDI-II Groups & 2112.827 & 3 & 704.276 & 14.935 & $.000^{*}$ \\
Program Level & 199.616 & 1 & 199.616 & 4.233 & $.041^{*}$ \\
Program x BDI-II & 449.482 & 3 & 149.827 & 3.177 & $.025^{*}$ \\
\hline & & & & & \\
\hline
\end{tabular}

${ }^{*} p=.05$. 
Table 25

Simple Effects Tests for Idenuny

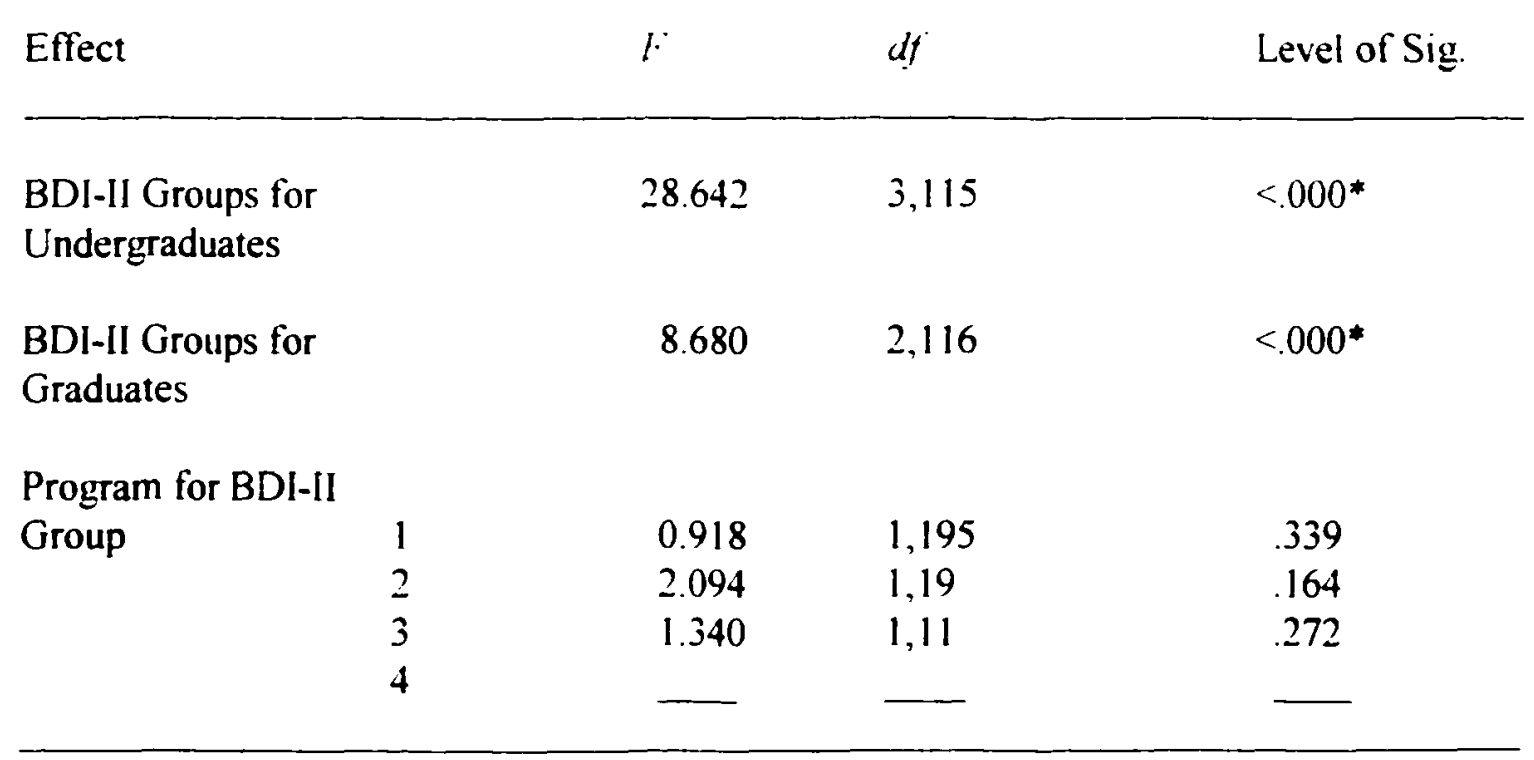

${ }^{*} p=.05$.

Thus, for graduate students, those who are nondepressed show significantly higher Identity Self-Concept scores than those with mild depression: there is no significant difference in Identity Self-Concept scores between those who are nondepressed and those with moderate depression: and there is no significant difference in Identity Self-Concept scores between those with mild and moderate depression.

Table 25 also shows that there is no significant difference between the undergraduate and graduate students for BDI-II Groups 1, 2, and 3 with respect to group means on the Identity subscale of the TSCS:2. Thus, there is no significant difference in Identity Self-Concept scores between undergraduate and graduate students for those who 
are nondepressed and those with mild and moderate depression.

This result may be surprising in light of the fact that Table 24 shows a significant main effect for program level, despite the interaction. Two factors account for the loss of significance in the simple effects. First, the error degrees of freedom are reduced from 232 to 195,19 . and 11 respectively. Secondly, and more important, the one graduate student in BDI-II Group 4 had a very high Identity score, and made no contribution to the error variance, as this student was the only score in the group.

I therefore reran the ANOVA omitting this individual, and thus using only $3 \mathrm{BDI}-\mathrm{II}$ groups. This analysis produced no significant interaction $(p=.180)$ and no significant program level effect $(p=.313)$ The BDI-Il group effect was significant $(p=.000)$.

Null Hypothesis 2, 3, 4h. Satisfaction subscale

Table 26 presents the means for the Satisfaction TSCS:2 subscale score and the BDI-II groups. Table 27 presents a summary of the analysis of variance. As there is no significant interaction, Null Hypothesis 4 h is retained and main effects may be studied. Null Hypothesis $2 \mathrm{~h}$ is retained because there is no significant difference between undergraduate and graduate students on Satisfaction Self-Concept. Null Hypothesis $3 \mathrm{~h}$ is rejected because there is a significant difference among the BDI-II groups on Satisfaction Self-Concept.

The Scheffé test $(p=.10)$ findings are that Group 1 is significantly higher than Groups 2, 3, and 4; Group 2 is significantly higher than Group 4: Group 3 is significantly higher than Group 4, and Groups 2 and 3 are not significantly different with respect to 
means on the Satisfaction subscale of the TSCS:2. Thus, those who are nondepressed show significantly higher Satisfaction Self-Concept scores than those with mild, moderate, and severe depression; those with mild or moderate depression show significantly higher Satisfaction Self-Concept scores than those with severe depression; and there is no significant difference in Satisfaction Self-Concept scores between those with mild and moderate depression.

Table 26

Means Table for Satisfaction TS( $: 2$ Subscale Score and BI)I-II Groups

\begin{tabular}{llllll}
\hline \multirow{2}{*}{ Satisfaction } & \multicolumn{4}{c}{ BDI-Il Groups } & Total \\
\cline { 2 - 6 } & ND & Mild & Moderate & Severe & \\
\hline Undergraduate & 79.903 & 71.091 & 70.875 & 55.286 & 77.034 \\
Graduate & 81.731 & 69.000 & 65.000 & 59.000 & 79.783 \\
\hline Total & 80.868 & 70.095 & 68.615 & 55.750 & 78.414 \\
\hline
\end{tabular}


Table 27

Summary of the Analysis of Variance for Satisfactuon TSCS:2 Subscale and BDI-ll (iroups

\begin{tabular}{lrrrrr}
\hline Satisfaction & \multicolumn{1}{l}{ SS } & df & \multicolumn{1}{l}{ MS } & \multicolumn{1}{l}{ L } & Level of Sig. \\
\hline BDI-II Groups & 5498.586 & 3 & 1832.862 & 21.210 & $.000^{*}$ \\
Program Level & 3.500 & 1 & 3.500 & .040 & .841 \\
Program x BDI-II & 234.995 & 3 & 78.332 & .906 & .439 \\
\hline Total & 1497825.000 & 239 & & & \\
\hline
\end{tabular}

$* p=.05$

Null Hypothesis 2, 3, 4i. Behavior subscale

Table 28 presents the means for the Behavior TSCS:2 subscale score and the BDI-II groups. Table 29 presents a summary of the analysis of variance. As there is no significant interaction, Null Hypothesis $4 i$ is retained and main effects may be studied. Null Hypothesis $2 \mathrm{i}$ is retained because there is no significant difference between undergraduate and graduate students on Behavior Self-Concept. Null Hypothesis $3 \mathrm{i}$ is rejected because there is a significant difference among the BDI-Il groups on Behavior Self-Concept.

The Scheffé test $(p=.10)$ findings are that Group 1 is significantly higher than Groups 2, 3, and 4: and Groups 2, 3, and 4 are not significantly different with respect to means on the Behavior subscale of the TSCS:2. Thus, those who are nondepressed show significantly higher Behavior Self-Concept scores than those 
with mild. moderate, and severe depression: and there is no significant difference in

Behavior Self-Concept scores among those with mild, moderate, and severe depression.

Table 28

Means Table for Behavior TSC S:2 Subscale Score and BDI-II Groups

Behavior

BDI-II Groups

Total

\begin{tabular}{llllll} 
& ND & Mild & Moderate & Severe & \\
\hline Undergraduate & 78.032 & 71.091 & 71.750 & 62.571 & 76.059 \\
Graduate & 79.317 & 70.200 & 67.600 & 69.000 & 77.983 \\
\hline Total & 78.711 & 70.667 & 70.154 & 63.375 & 77.025 \\
\hline
\end{tabular}

Table 29

Summary of the Analysis of Variance for Behavior TSC S:2 Subscale and BDI-II Groups

\begin{tabular}{lrrrrr}
\hline Behavior & \multicolumn{1}{c}{ SS } & df & \multicolumn{1}{l}{ MS } & \multicolumn{1}{l}{ L } & Level of Sig. \\
\hline BDI-Il Groups & 2478.556 & 3 & 826.185 & 14.707 & $.000^{*}$ \\
Program Level & 4.254 & 1 & 4.254 & .076 & .783 \\
Program x BDI-II & 129.270 & 3 & 43.090 & .767 & .514 \\
\hline Total & 1434619.000 & 239 & & & \\
\hline
\end{tabular}

$* p=.05$. 
Null Hypothesis 2, 3,4j, Total scale

Table 30 presents the means for the Total TSCS:2 scale score and the BDI-II

groups. Table 31 presents a summary of the analysis of variance. As there is no significant interaction, Null Hypothesis $4 \mathrm{j}$ is retained and main effects may be studied. Null Hypothesis $2 \mathrm{j}$ is retained because there is no significant difference between undergraduate and graduate students on Total Self-Concept. Null Hypothesis $3 \mathrm{j}$ is rejected because there is a significant difference among the BDI-II groups on Total Self-Concept.

The Scheffé test $(p=.10)$ findings are that Group 1 is significantly higher than Groups 2, 3, and 4: Group 2 is significantly higher than Group 4: Group 3 is significantly higher than Group 4; and Groups 2 and 3 are not significantly different with respect to means on the Total subscale of the TSCS:2. Thus, those who are nondepressed show significantly higher Total Self-Concept scores than those with mild, moderate, and severe depression: those with mild or moderate depression show significantly higher Total Self-Concept scores than those with severe depression; and there is no significant difference in Total Self-Concept scores between those with mild and moderate depression. 
Table 30

Means Table for Total TSCS:2 Score and BDI-II (iroups

Total

BDI-II Groups

Total

\begin{tabular}{llllll} 
& ND & Mild & Moderate & Severe & \\
\hline Undergraduate & 295.280 & 274.909 & 267.000 & 220.857 & 287.118 \\
Graduate & 301.462 & 270.500 & 262.000 & 256.000 & 296.858 \\
\hline Total & 298.543 & 272.810 & 265.077 & 225.250 & 292.008 \\
\hline
\end{tabular}

Table 31

Summary of the Analysis of Variance for Total TSCS:2 Score and BDI-II (iroups

\begin{tabular}{lrrrrrr}
\hline Total & \multicolumn{1}{c}{ SS } & df & MS & $F$ & Level of Sig. \\
\hline BDI-II Groups & 34681.809 & 3 & 11560.603 & 19.031 & $.000^{*}$ \\
Program Level & 606.631 & 1 & 606.631 & .999 & .319 \\
Program x BDI-II & 1634.709 & 3 & 544.903 & .897 & .443 \\
\hline & & & & & & \\
\hline
\end{tabular}

$* p=.05$. 


\section{Null Hypothesis 5}

There is no linear combination of the nine TSCS:2 subscale scores which significantly discriminates among the four BDI-II groups for undergraduate students.

Null Hypothesis 5 was tested by discriminant analysis. The Behavior TSCS:2 subscale was not included because it did not pass the tolerance test which meant it was not making a significant contribution. There are two significant functions.

\section{Function 1 Null Hypothesis 5}

Table 32 presents the means for the BDI-II groups on Function 1. Table 33 presents the standardized discriminant function coefficients of the remaining eight variables. Following a common convention, I have considered those variables whose weights are at least $50 \%$ of the maximum weight. These are then ranked 1 to 4 . These findings indicate that a randomly selected undergraduate student who scores high in Identity and Satisfaction and low in Moral and Social is more likely to be in BDI-II Group 1 or 2 than in the other groups and more likely to be in Group 3 than Group 4 . Thus, any undergraduate student who has high Identity Self-Concept scores, high Satisfaction Self-Concept scores, low Moral Self-Concept scores, and low Social Self-Concept scores is more likely to be nondepressed or to be experiencing mild depression than moderate and severe depression and more likely to be experiencing moderate depression than severe depression. 
Table 32

Function I Null Hypothesis 5

\section{Means}

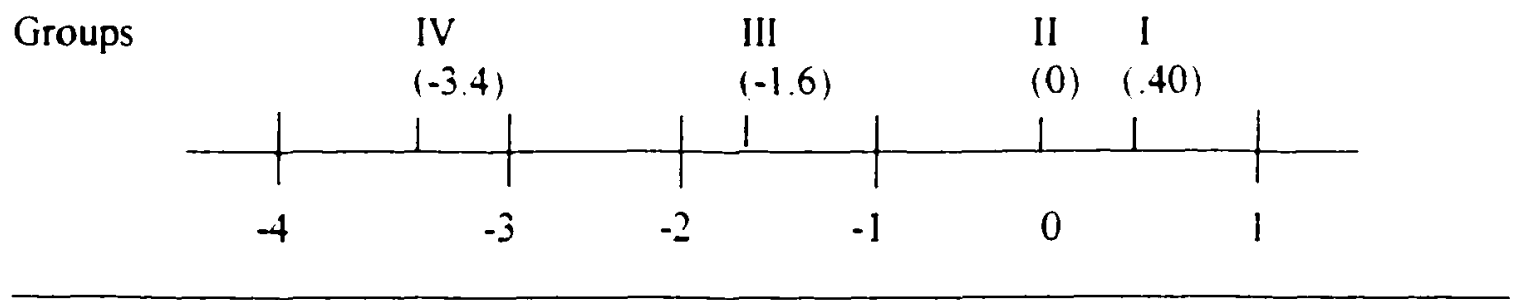

Table 33

Standardized Discriminant Function Coefficients Null Hypothesis 5-Function I

TSCS:2 Subscales

Function 1

Physical

$-.162$

Moral

$-.539(3)$

Personal

.312

Family

$-.033$

Social

$-.439(4)$

Academic/Work

.049

Identity

$.895(1)$

Satisfaction

$632(2)$ 
Function 2 Null Hypothesis 5

Table 34 presents the means for the BDI-II groups on Function 2. Table 35 presents the standardized discriminant function coefficients of the remaining eight variables. Following a common convention. I have considered those variables whose weights are at least $50 \%$ of the maximum weight. These are then ranked 1 to 2 . These findings indicate that a randomly selected undergraduate student who scores low on Identity and high on Physical is more likely to be in BDI-II Group 3 than the other groups and more likely to be in Group 1 than in Groups 2 or 4 . Thus, any undergraduate student who has low Identity Self-Concept scores and high Physical Self-Concept scores is more likely to experience moderate depression than to be nondepressed or to be experiencing mild or severe depression and more likely to be nondepressed than experiencing mild or severe depression.

Table 34

Functoon 2 Null Hypothesis 5

Means

\begin{tabular}{|c|c|c|c|c|}
\hline Groups & $\begin{array}{l}\text { II } \\
(-.86)\end{array}$ & $\begin{array}{l}\text { IV } \\
(-.64) \\
1\end{array}$ & $\begin{array}{l}\text { I } \\
(0) \\
1\end{array}$ & $\begin{array}{l}\text { III } \\
(1.3) \\
1\end{array}$ \\
\hline & & & 0 & \\
\hline
\end{tabular}


Table 35

Standardized Discriminant Function ('oefficients Null Hypothesis 5-liunction 2

TSCS:2 Subscales

Function 2

Physical

$1.191(2)$

Moral

Personal

$-.483$

Family

Social

.238

Academic Work

.565

Identity

$-1.386(1)$

Satisfaction

.022

\section{Null Hypothesis 6}

There is no linear combination of the nine TSCS:2 subscale scores which significantly discriminates among the four BDI-Il groups for graduate students.

Null Hypothesis 6 was tested by discriminant analysis. The Behavior TSCS:2 subscale was not included because it did not pass the tolerance test which meant it was not making a significant contribution. There is one significant function. Again, used BDI-II Groups 1, 2. and 3 only because Group 4 had only one subject. 
Function 1 Null Hypothesis 6

Table 36 presents the means for the BDI-II groups on Function 1. Table 37 presents the standardized discriminant function coefficients of the remaining eight variables. Following a common convention, I have considered those variables whose weights are at least $50 \%$ of the maximum weight. These are then ranked 1 to 8 . These findings indicate that a randomly selected graduate student who scores high on Moral. Family, Physical, low on Identity, Social, Academic/Work, and high on Personal and Satisfaction is more likely to be in BDI-II Group 1 than in Groups 2 and 3. Thus, any graduate student who has high Moral Self-Concept scores, high Family Self-Concept scores, high Physical Self-Concept scores, low Identity Self-Concept scores, low Social Self-Concept scores, low Academic/Work Self-Concept scores. high Personal Self-Concept scores, and high Satisfaction Self-Concept scores is more likely to be nondepressed than to be experiencing mild and moderate depression.

Table 36

Function I Null Hypothess 6

Means

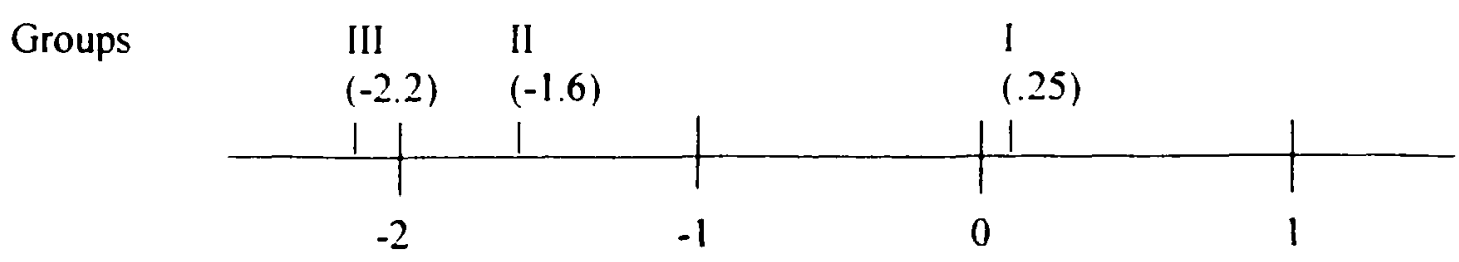


Table 37

Standardized Discriminant Function (oefficients Null Hypothesis 6-Function I

TSCS:2 Subscales

Function 1

Physical

$522(3)$

Moral

Personal

$.335(7)$

Family

$.525(2)$

Social

Academic/Work

$-.419(6)$

Identity

$-.513(4)$

Satisfaction

$.296(8)$

\section{Summary of Hypothesis Testing}

Six null hypotheses were examined in this study. Null Hypothesis I studied the difference between undergraduate and graduate students with respect to the scores on the $\mathrm{BDI}-\mathrm{Il}$ and indicated that undergraduate students demonstrated higher mean depression scores than the graduate students on the BDI-II when the raw scores were compared. There was, however, no significant difference found between the proportion of undergraduate and graduate students in each BDI-II group. In other words, although the four depression groups contained the same number of undergraduate and graduate 
students, the undergraduates received higher mean depression scores

Null Hypotheses 2, 3, and 4 are presented together. Except for TSCS:2 subscale g, Identity, there was no significant interaction found (Null Hypothesis 4). No significant differences of undergraduate and graduate students on level of self-concept were found (Null Hypothesis 2). Significant differences between the self-concept of subjects at different depression groups were found (Null Hypothesis 3).

Null Hypotheses 2-4a, c, h, and j (Physical, Personal, Satisfaction, and Total) showed results that were identical. Those who were nondepressed received significantly higher Physical, Personal, Satisfaction. and Total Self-Concept scores than those with mild, moderate, and severe depression; those with mild or moderate depression received significantly higher Physical. Personal, Satisfaction. and Total Self-Concept scores than those with severe depression; and there was no significant difference found in Physical, Personal, Satisfaction, and Total Self-Concept scores between those with mild and moderate depression.

Null Hypotheses 2-4b and i (Moral, Behavior) showed results that were identical. Those who were nondepressed received significantly higher Moral and Behavior SelfConcept scores than those with mild, moderate, and severe depression; and there was no significant difference found in Moral and Behavior Self-Concept scores among those with mild, moderate, and severe depression.

Null Hypotheses 2-4d (Family) showed that those who were nondepressed received significantly higher Family Self-Concept scores than those with mild, moderate, and severe depression; those with mild depression received significantly higher Family Self-Concept 
scores than those with severe depression: there was no significant difference found in Family Self-Concept scores between those with mild and moderate depression; and there was no significant difference found in Family Self-Concept scores between those with moderate and severe depression.

Null Hypotheses 2-4e (Social) showed that those who were nondepressed received significantly higher Social Self-Concept scores than those with mild and severe depression; there was no significant difference found in Social Self-Concept scores between those who were nondepressed and those with moderate depression: and there was no significant difference found in Social Self-Concept scores among those with mild, moderate. and severe depression.

Null Hypotheses 2-4f (Academic/Work) showed that those who were nondepressed and those with mild and moderate depression received significantly higher Academic 'Work Self-Concept scores than those with severe depression; and there was no significant difference found in Academic/Work Self-Concept scores among those who were nondepressed and those with mild and moderate depression.

Null Hypotheses $2-4 \mathrm{~g}$ (Identity) showed that those undergraduate students who were nondepressed or those with mild depression received significantly higher Identity Self-Concept scores than those with moderate and severe depression: those with moderate depression received significantly higher Identity Self-Concept scores than those with severe depression: and there was no significant difference found in Identity Self-Concept scores between those who were nondepressed and those with mild depression. For graduate students, those who were nondepressed received significantly higher Identity 
Self-Concept scores than those with mild depression: there was no significant difference found in Identity Self-Concept scores between those who were nondepressed and those with moderate depression: and there was no significant difference found in Identity: SelfConcept scores between those with mild and moderate depression. Also, for each of the first three BDI-II groups (minimal. mild, and moderate) there was no significant difference found in Identity Self-Concept scores between undergraduate and graduate students for those who were nondepressed and those with mild and moderate depression.

Null Hypothesis 5 showed that any undergraduate student who had high Identity Self-Concept scores, high Satisfaction Self-Concept scores, low Moral Self-Concept scores. and low Social Self-Concept scores was more likely to be nondepressed or to be experiencing mild depression than moderate and severe depression and more likely to be experiencing moderate depression than severe depression. Also, any undergraduate student who had low Identity Self-Concept scores and high Physical Self-Concept scores was more likely to be experiencing moderate depression than to be nondepressed or experiencing mild or severe depression and more likely to be nondepressed than to be experiencing mild or severe depression.

Null Hypothesis 6 showed that any graduate student who had high Moral SelfConcept scores, high Family Self-Concept scores, high Physical Self-Concept scores, low Identity Self-Concept scores, low Social Self-Concept scores, low Academic/Work SelfConcept scores. high Personal Self-Concept scores, and high Satisfaction Self-Concept scores was more likely to be nondepressed than to be experiencing mild and moderate depression. 


\section{CHAPTER V}

\section{SUMMARY, DISCUSSION, CONCLUSIONS, RECOMMENDATIONS, AND IMPLICATIONS}

\section{Introduction}

This chapter first summarizes the problem, purpose of the study, significance of the study, methodology, and demographics. The next section is organized under the four research questions of Chapter I. Under each question, the relevant hypotheses are stated and the results are summarized and discussed. Finally, the conclusions are drawn, recommendations are made for further research, and implications are made for practice.

\section{Summary}

\section{Problem}

Research is well represented on the topics of self-concept and depression, individually and together. After reviewing the current literature, few specific studies have been noted that explore the potential differences in undergraduate and graduate students in relation to their level of self-concept and level of depression. Starting college or graduate school is a time of transition and students have an opportunity for personal growth as they learn more about themselves and the world around them. But this opportunity for personal growth can be colored by their level of self-concept and depression. If students have low 
self-concept and/or symptoms of depression, then they may have trouble being in this new environment, making new friends, concentrating on school, making personal and career choices, and/or making commitments to lifetime goals (Berzonsky \& Kuk, 2000; Clark \& Beck, 1999; Felix, 2000; Grayson \& Meilman, 1999; National DMDA, 2000; NIH, 2000a).

Universities can take an important step in offering excellent care for their students in the university counseling center. A university might incorporate an evaluation of selfconcept and depression into the screening process of incoming undergraduate and graduate students via the counseling center as a type of anticipatory intervention program. Identified students struggling with low self-concept and/or symptoms of depression might receive individual therapy, group therapy, and/or training through workshops to aid in increasing the level of self-concept and lowering symptoms of depression. Another form of an anticipatory intervention program, if a screening process is not utilized, might be for psychologists to provide workshops and seminars for students on a range of topics such as personal, social, and academic issues, self-concept, and depression. These types of anticipatory intervention programs could assist individuals in building a more positive sense of self and lowering symptoms of depression so they can be more productive in school and in life (Beeber. 1999; Gladieux \& Swail, 2000: Hermon \& Hazler, 1999; O’Connor, 2001; Rundle, 2000).

\section{Purpose of the Study}

The purpose of this study is to compare undergraduate and graduate students with respect to their level of self-concept and level of depression. 


\section{Significance of the Study}

Students enter an university setting from a fast-paced society that tends to demand a strong sense of self and a feeling of competency. Throughout the different stages in life, individuals examine the question "Who am I?" Changes in their lives, such as moving away from home. starting college or graduate school, exploring new values, and/or making new friends can trigger a period of re-examination of the self. Individuals view the entire world through their filter of self which influences all of their thoughts, feelings, and behaviors. This filter of self is a persons' self-concept and contains the beliefs about your personal worth, characteristics, and roles. Individuals with a high level self-concept tend to think well of themselves and others, value relationships with others, more easily accept differences in others, obtain a higher level of performance in the academic setting, and have lower levels of hopelessness and depression (Chang, 2000; Clark \& Beck, 1999; Dunning, 1993: Fitts \& Warren, 1996; Hattie \& Marsh, 1996: Felix. 2000: Magen, 1998: Rosenberg, 1985).

As mentioned above, persons with a high level of positive self-concept tend to have lower levels of hopelessness and depression. This is an important point because the literature shows that self-concept and depression are interrelated and intertwined. During times of depression, most individuals begin to set unrealistic standards, make selfbelittling remarks, or make harsh judgments about themselves. Often these events lead them to see themselves as basically worthless, hopeless, and inadequate. One's level of self-concept and depression influences areas such as relationships, academic achievement, choosing to obtain a graduate level of education, choosing a career, andior making 
commitments to lifetime goals (Beck, 1967, 1972, 1973. 1976: Clark \& Beck. 1999; NIH, 2000a, 2000b; NIMH, 2000; Roid \& Fitts, 1989).

Depression is a topic that is discussed many times without connecting it necessarily to self-concept. In fact, depression is called "the common cold of mental health." Depression often starts with mild symptoms in late adolescence/young adulthood and, with time, may slowly increase in the level of severity. So, persons with mild depressive symptoms tend to be at a higher risk for developing more severe depression. Even if individuals are experiencing mild depressive symptoms which do not meet specific diagnostic criteria for a mood disorder, their ability to function may be hindered in areas such as relationships with others, physical health, academic/work performance, making personal and career choices, and feelings of self-worth. If left untreated, these mild symptoms may persistently recur and may eventually build a lifelong pattern of depressive symptoms and/or pattern of major depression. So, it is vital that the symptoms of mild depression be acknowledged and addressed before they become more persistent (American Psychiatric Association, 2000: Beck, 1967, 1972, 1973, 1976: Feaster. 1996: Felix, 2000: Hattie, 1992; Johnson, 2001; NIH, 2000a, 2000b; NIMH, 1995, 1997, 1999, 2000).

\section{Methodology}

This study used a quantitative research design for an ex post facto study of the differences between undergraduate and graduate students with respect to their level of self-concept and level of depression. The population for this study consisted of undergraduate and graduate students $(N=239)$ from Andrews University (AU) and 
Western Michigan University (WMU). The sample was a convenience sample which was obtained by asking various professors from different departments permission to administer the research packet (the Demographic Questionnaire, the Tennessee SelfConcept Scale: Second Edition [TSCS:2], and the Beck Depression Inventory-II [BDI-II]) to the students in each of their classes. Data collection was accomplished by the use of three instruments: (1) the Demographic Questionnaire, (2) the Tennessee Self-Concept Scale (TSCS:2), and (3) the Beck Depression Inventory-II (BDI-II).

\section{Demographics}

Regarding the demographics, the majority of the participants were female ( $58.6 \%)$, the majority of the participants were single $(63.2 \%)$ and $30.5 \%$ were married, just over $50 \%$ (50.6) of the participants were Caucasian, $13 \%$ were Asian Origin, and $10.9 \%$ were African American. and the majority of the participants were Protestant $(69.4 \%)$ and $17.6 \%$ reported "other" as their religion. Almost half of the participants $(49.8 \%)$ were between the ages of $18-24$ and $29.7 \%$ were between the ages of $25-34$ with approximately the same number $(50 \%)$ of undergraduate and graduate students. The findings also indicated that $40.2 \%$ of the participants reported a GPA that fell between the range of $3.9-3.5$ and $29.7 \%$ of the participants that reported their GPA to be between 3.4-3.0.

\section{Discussion of the Results}

The results of this study are organized under the four research questions of Chapter I. Under each question, the relevant hypotheses are stated and the results are summarized and discussed. 


\section{Research Question 1}

Research Question 1. Do undergraduate and graduate students differ in respect to the level of depression?

Research Question I was answered by looking at Null Hypothesis 1. Null Hypothesis 1 stated that there is no significant difference between undergraduate and graduate students with respect to the scores on the BDI-II. This hypothesis studied the difference between undergraduate and graduate students with respect to the scores on the BDI-II by using $t$-test for means of independent samples. The independent variable was program level and the dependent variable was depression scores. Additionally, chi-square analysis was used to compare the proportion of undergraduate and graduate students at the four BDI-II groups. The independent variable was program level and the dependent variable was depression groups.

The results of this study answered yes to Research Question 1. When comparing group means, the results indicated that undergraduate students demonstrated higher mean depression scores than the graduate students. The finding that undergraduate students demonstrated higher mean depression scores than graduate students was consistent with authors such as Anderson and Hayes (1996), Hoge (1999), and Steer et al. (1999). However, when the depression groups were compared, there were no significant differences found between the proportion of undergraduate and graduate students in each BDI-II group. Using the BDI-II cut score of 13 to identify depression, the prevalence of depression found for the combined undergraduate and graduate students was as follows:

(1) a total of 197 participants or $82.4 \%$ were nondepressed; (2) a total of 21 participants or 
$8.8 \%$ demonstrated mild symptoms of depression: (3) a total of 13 participants or $5.4 \%$ demonstrated moderate symptoms of depression, and (4) a total of 8 participants or $3.3 \%$ demonstrated severe symptoms of depression.

Undergraduate students tend to be at a time in life that is full of uncertainty, transition. and change. Typically, they are separated from their family of origin, family values, long-time friends, church family, teachers, and community while simultaneously exploring new surroundings, people, places, values, behaviors, activities, opportunities, and themselves. Professionals in the field (Amett, 2000; Calhoun et al., 2001; Erikson, 1959,1968 ) have discussed these transitions and changes as being universal and a normal part of the life-cycle-"normal crisis points."

According to Berzonsky and Kuk (2000), Byrne (1996a), and Trusty et al. (2000), this time of transition and change can be part of the reason that undergraduate students have higher mean depression scores. I would like to also suggest that peer pressure is a big part of this time of uncertainty, transition, and change for undergraduate students. Undergraduate students pay more attention to peer pressure because they are not so far removed from high school when the most significant group influencing their lives was the peer group. If they do not fit in with the new peer group in college or they are pressured to go against what they have been taught earlier, they are more uncertain about who they are, what direction they are headed, and which values they want to embrace or discard. These factors may contribute to undergraduate students having higher mean depression scores.

In comparison. graduate students tend to have often already experienced many of the same types of transitions and changes that undergraduate students are currently facing. 
Perhaps having already experienced these transitions and changes, graduate students have a stronger sense of self and direction which may lend itself in assisting graduate students to have a lower mean depression score than undergraduate students. The fact that some of the graduate students also experience some symptoms of depression suggests that growth throughout the various stages in life is an ongoing process. Obviously, graduate students are at a different stage in the life-cycle than undergraduate students. They tend to have developed a comfortable level of self-acceptance and their own value system so that they are no longer as strongly influenced by peer pressure. Graduate students tend to have more life experience and maturity and are able to handle situations more effectively. This additional life experience and maturity is what possibly leads graduate students to be more resilient to transitions and changes throughout the various stages in life. This resiliency may contribute to the mean depression scores being less severe for graduate students.

\section{Research Question 2}

Research Question 2. Do undergraduate and graduate students differ in respect to the level of self-concept?

Research Question 2 was answered by looking at Null Hypothesis 2 and was studied with univariate analysis (two-way ANOVA). Null Hypothesis 2 stated there is no significant difference between the undergraduate and graduate students with respect to the mean scores on the TSCS:2. The independent variable was program level and the dependent variables was self-concept.

The results of this study answered no to Research Question 2. The results of this 
study indicated, when looking at Null Hypothesis 2, that there were no significant differences in the level of self-concept found between the undergraduate and graduate students. Thus, Null Hypotheses 2a-j were retained because there were no significant differences found.

\section{Research Question 3}

Research Question 3. Do students at different depression levels differ in the level of self-concept?

Research Question 3 was answered by first looking at Null Hypothesis 3 and then Null Hypotheses 5 and 6. Null Hypothesis 3 was studied with univariate analysis (two-way ANOVA) and Null Hypotheses 5 and 6 were studied with multivariate analysis (discriminant analysis). The independent variable was depression group and the dependent variable was self-concept.

Null Hypothesis 3 stated there is no significant difference among the four BDI-II groups with respect to the mean scores on the TSCS:2. Null Hypothesis 5 stated there is no linear combination of the nine TSCS:2 subscale scores which significantly discriminates among the four BDI-II groups for undergraduate students. Null Hypothesis 6 stated there is no linear combination of the nine TSCS:2 subscale scores which significantly discriminates among the four BDI-II groups for graduate students.

The results of this study answered yes to Research Question 3. The results of this study indicated, when looking at Null Hypothesis 3 , that there were significant differences found between the self-concept of students at different depression groups. Thus, Null 
Hypotheses 3a-j were rejected because there were significant differences found between the self-concept of students at different depression groups.

Null Hypothesis 3a (Physical) indicated that those who were nondepressed received significantly higher Phusical Self-Concept scores than those with mild, moderate, and severe depression: those with mild or moderate depression received significantly higher Physical Self-Concept scores than those with severe depression; and there was no significant difference found in Physical Self-Concept scores between those with mild and moderate depression. These results suggest that when individuals are nondepressed the more positive they feel about their body image, appearance, and physical capabilities. In addition, these results suggest that the less depressed individuals are, the more positive they feel about their body image, appearance, and physical capabilities, or vice-a-versa.

Null Hypothesis $3 \mathrm{~b}$ (Moral) indicated that those who were nondepressed received significantly higher Moral Self-Concept scores than those with mild, moderate, and severe depression: and there was no significant difference found in Moral Self-Concept scores received among those with mild, moderate, and severe depression. These results suggest that when individuals are nondepressed the more positive they view their conduct and their values of right and wrong than those with mild, moderate, and severe symptoms of depression.

Null Hypothesis 3c (Personal) indicated that those who were nondepressed received significantly higher Personal Self-Concept scores than those with mild, moderate, and severe depression; those with mild or moderate depression received significantly higher Personal Self-Concept scores than those with severe depression: and there was no 
significant difference found in Personal Self-Concept scores between those with mild and moderate depression. These results suggest that when individuals are nondepressed the more positive they feel about themselves and their sense of personal worth. In addition. these results suggest that the less depressed individuals are, the more positive they feel about themselves and their sense of personal worth, or vice-a-versa.

Null Hypothesis 3d (Family) indicated that those who were nondepressed received significantly higher Family Self-Concept scores than those with mild, moderate, and severe depression; those with mild depression received significantly higher Family Self-Concept scores than those with severe depression: there was no significant difference found in Family Self-Concept scores between those with mild and moderate depression or between those with moderate and severe depression. These results suggest that when individuals are nondepressed the more they feel accepted and valued in their families as compared to those with mild, moderate, and severe symptoms of depression. These results also suggest that those with mild symptoms of depression tend to feel more accepted and valued in their families than those with severe symptoms of depression.

Null Hypothesis $3 e$ (Social) indicated that those who were nondepressed received significantly higher Social Self-Concept scores than those with mild and severe depression. Also, there was no significant difference found in Social Self-Concept scores between those who were nondepressed and those with moderate depression or between those with mild, moderate, or severe depression. These results suggest that when individuals are nondepressed the more positive they view themselves as a valued and competent member of society than those with mild or severe symptoms of depression. 
Null Hypothesis $3 \mathrm{f}$ (Academic/Work) indicated that those who were nondepressed and those with mild and moderate depression received significantly higher Academic/Work Self-Concept scores than those with severe depression; and there was no significant difference found in Academic/Work Self-Concept scores among those who were nondepressed and those with mild and moderate depression. These results suggest that when individuals are nondepressed or when they are experiencing mild and moderate symptoms of depression the more positively they view themselves as self-assured and capable at school or work than those with severe symptoms of depression. Interestingly enough, this scale was the only one that showed a significantly lower Academic/Work Self-Concept score only once a person was experiencing severe symptoms of depression.

Null Hypotheses $2-4 \mathrm{~g}$ (Identity) indicated that those undergraduate students who are nondepressed or those with mild depression show significantly higher Identity Self-Concept scores than those with moderate and severe depression; those with moderate depression show significantly higher Identity Self-Concept scores than those with severe depression; and there is no significant difference in Identity Self-Concept scores between those who are nondepressed and those with mild depression. The results suggest the less depressed undergraduate students are, the more positive they feel about their sense of self. Also. undergraduate students that are experiencing moderate symptoms of depression feel more positive about their sense of self than those with severe symptoms of depression.

Also for Identity, graduate students who are nondepressed show significantly higher Identity Self-Concept scores than those with mild depression; there is no significant 
difference in Identity Self-Concept scores between those who are nondepressed and those with moderate depression; and there is no significant difference in Identity Self-Concept scores between those with mild and moderate depression. The results suggest that graduate students who are nondepressed view their sense of self in a more positive manner than those with mild symptoms of depression. When comparing undergraduate and graduate students for each of the first three depression groups (minimal, mild, and moderate), there is no significant difference in Identity Self-Concept scores between undergraduate and graduate students for those who are nondepressed and those with mild and moderate depression. The results suggest that, when comparing undergraduate and graduate students, there is no significant difference in any depression level in the way they viewed their sense of self.

Null Hypothesis $3 \mathrm{~h}$ (Satisfaction) indicated that those who were nondepressed received significantly higher Satisfaction Self-Concept scores than those with mild, moderate, and severe depression; those with mild or moderate depression received significantly higher Satisfaction Self-Concept scores than those with severe depression: and there was no significant difference found in Satisfaction Self-Concept scores between those with mild and moderate depression. These results suggest that when individuals are nondepressed the more they feel content, accepting, and satisfied with themselves. In addition, these results suggest that the less depressed individuals are, the more they feel content, accepting, and satisfied with themselves, or vice-a-versa.

Null Hypothesis $3 i$ (Behavior) indicated that those who were nondepressed received a significantly higher Behavior Self-Concept score than those with mild, 
moderate, and severe depression; and there was no significant difference found in Behavior Self-Concept scores received among those with mild, moderate, and severe depression. These results suggest that when individuals are nondepressed the more positive they view their actions and behavior than those with mild, moderate, and severe symptoms of depression.

Null Hypothesis $3 \mathrm{j}$ (Total) indicated that those who were nondepressed received significantly higher Total Self-Concept scores than those with mild, moderate, and severe depression; those with mild or moderate depression received significantly higher Total Self-Concept scores than those with severe depression; and there was no significant difference found in Total Self-Concept scores between those with mild and moderate depression. These results suggest that when individuals are nondepressed the more positive they feel about their overall self-concept and level of self-esteem. In addition, these results suggest that the less depressed individuals are, the more positive they feel about their overall self-concept and level of self-esteem, or vice-a-versa.

The second way in which Research Question 3 was answered was by looking at Null Hypothesis 5. Again, Null Hypothesis 5 stated there is no linear combination of the nine TSCS:2 subscale scores which significantly discriminates among the four BDI-II groups for undergraduate students. The independent variable was TSCS:2 scores and the dependent variable was BDI-II group.

The results of Null Hypothesis 5 found that any undergraduate student, who had high Identity Self-Concept scores, high Satisfaction Self-Concept scores, low Moral Self-Concept scores, and low Social Self-Concept scores, was more likely to be 
nondepressed or to be experiencing mild depression than moderate and severe depression and more likely to be experiencing moderate depression than severe depression. The results suggest that undergraduate students, with the above mentioned self-concept scores, are more likely to experience less depression.

For undergraduate students, this time in life is often when they start reassessing their own value systems. Up until this point, they have often just embraced the value system of their parents. Many changes also tend to be occurring outside and inside of themselves such as moving away from home, creating a new peer group, and deciding what goals they have for their lives. Undergraduate students may have a core sense of identity and satisfaction with who they are at this point in time while still not be so sure of who they are morally or socially. This state of confusion in the moral and social selfconcept areas may just be a "normal" stage in life and is not necessarily pathological. It appears that if they have a good sense of who they are and are satisfied with who they are, this outweighs, or at least counterbalances, the turmoil in the areas of their moral and social value systems

It is important for psychologists to know that if undergraduate students do not have a good sense of who they are and are not satisfied with who they are, this would probably lead to more symptoms of depression than if dealing with the turmoil in their moral or social values. So, it appears very important that their sense of identity and satisfaction be strengthened or maintained as a goal for therapy.

The results of Null Hypothesis 5 also found that any undergraduate student who had low Identity Self-Concept scores and high Physical Self-Concept scores was more 
likely to be experiencing moderate depression than to be nondepressed or to be experiencing mild or severe depression and more likely to be nondepressed than to be experiencing mild or severe depression. These results suggest that undergraduate students. with the above mentioned self-concept scores, are more likely to experience moderate symptoms of depression than to be nondepressed or to be experiencing mild or severe symptoms of depression. These results also suggest that undergraduate students, with the above mentioned self-concept scores, are more likely to be nondepressed than to be experiencing mild or severe svmptoms of depression.

It appears that if undergraduate students have a low sense of identity but feel really good about their body, they might experience some symptoms of depression but will not tend to experience severe symptoms of depression. At this time in life for undergraduate students, much emphasis and importance is placed on their external looks, how in shape their body is, and how well their body performs. It might be that this external emphasis is so strong now that it outweighs the uncertainty of not knowing who they are on the inside and keeps severe depression at bay, at least for the time being.

The third way in which Research Question 3 was answered was by looking at Null Hypothesis 6. Again, Null Hypothesis 6 stated there is no linear combination of the nine TSCS:2 subscale scores which significantly discriminates among the four BDI-II groups for graduate students (used Groups 1, 2, and 3 only because Group 4 had only one case). The independent variable was TSCS: 2 scores and the dependent variable was $\mathrm{BDI}-\mathrm{II}$ group. 
When looking at Null Hypothesis 6, the results from this sample suggest that any graduate student who had high Moral, Family, Physical Self-Concept scores and low Identity, Social, Academic/Work Self-Concept scores, and high Personal and Satisfaction Self-Concept scores was more likely to be nondepressed than to be experiencing mild and moderate depression. These results suggest that graduate students, with the above mentioned self-concept scores, are more likely to be nondepressed than to be experiencing mild and moderate symptoms of depression. These results suggest that, for graduate students, combinations of self-concept subscale scores appear to be significant but the reason for such results is uncertain.

\section{Research Question 4}

Research Question f. Is the relationship between self-concept and depression different for undergraduate and graduate students?

Research Question 4 was answered by looking at Null Hypothesis 4. Null Hypothesis 4 was studied with univariate analysis (two-way ANOVA). Null Hypothesis 4 stated there is no significant interaction between program level and BDI-Il group. Null Hypotheses $4 a-j$ (except $g$ ) were retained and main effects were studied because there were no significant interactions found between the program level and BDI-II group. The independent variables were program level and depression group and the dependent variable was self-concept.

The results of this study answered no, with one exception, to Research Question 4. The exception was Identity Self-Concept ( $\mathrm{g}$ ) because there was a significant interaction 
found between the program level and BDI-II group so simple effects were studied. Thus, for Identity only, the relationship between the level of self-concept and depression is different for undergraduate and graduate students.

For undergraduate students, those who were nondepressed or those with mild depression received significantly higher Identity Self-Concept scores than those with moderate and severe depression; those with moderate depression received significantly higher Identity Self-Concept scores than those with severe depression: and there was no significant difference found in Identity Self-Concept scores between those who were nondepressed and those with mild depression. These results suggest that undergraduate students who are nondepressed or those experiencing mild symptoms of depression view their sense of self in a more positive manner than those with moderate or severe symptoms of depression. Also, those who are experiencing moderate symptoms of depression feel more positive about their sense of self than those experiencing severe symptoms of depression.

For graduate students (with the severe depression group omitted), those who were nondepressed received significantly higher Identity Self-Concept scores than those with mild depression; there was no significant difference found in Identity Self-Concept scores between those who were nondepressed and those with moderate depression; and there was no significant difference found in Identity Self-Concept scores between those with mild and moderate depression. These results suggest that graduate students who are nondepressed view their sense of self in a more positive manner than those with mild symptoms of depression. Thus, for Identity Self-Concept only, the 
relationship between self-concept and depression is different for undergraduate and graduate students.

\section{Conclusions}

Even though the literature is clear on the relationship between self-concept and depression, few studies take into consideration the population of undergraduate and graduate students. This study did that and found the following:

1. In regard to depression, there is a significant difference in the level of depression between undergraduate and graduate students. Undergraduate students had higher mean depression scores or a higher level of overall depression than graduate students. However, when the depression groups are compared. there are no significant differences found between the proportion of undergraduate and graduate students in each BDI-II group. Interestingly enough, with combining undergraduate and graduate students and using the BDI-II cut scores of 13 to identity depression, my results showed that $82.4 \%$ of my sample were nondepressed which left only approximately $17.5 \%$ of my sample experiencing mild to severe symptoms of depression. This finding does not agree with the prevailing literature which says that mild depression is on the rise, depression is often the leading emotional disorder on today's university campuses, and college students tend to experience clinical depression and dysthymia twice as often as working individuals of similar ages and background environments (American Psychiatric Association, 2000: NIMH, 1999; NIH, 2000b).

In exploring the results that the majority of my sample were nondepressed, some 
of my demographic results might shed some light or present some possible options for this finding. In my sample, $81 \%$ of the combined undergraduate and graduate students had a GPA of 3.0 or higher. GPA often plays an important factor in the life of undergraduate and graduate students. Persons with a high GPA tend to more likely be nondepressed than those students struggling with a low GPA. Those students with a low GPA may tend to have more symptoms of depression. Another finding of my sample was $80 \%$ of the combined undergraduate and graduate students were between the ages of 18-34. Furthermore, $63.2 \%$ of the combined undergraduate and graduate students were single and $30.5 \%$ were married.

2. In regard to self-concept, there is no significant difference found in the level of self-concept between undergraduate and graduate students.

3. In regard to differences between the self-concept of students at different depression groups, there are significant differences found. In general, the overall trend is when undergraduate and graduate students are nondepressed and/or the less depressed undergraduate and graduate students are then, the better they feel about themselves. Conversely, the more depressed undergraduate and graduate students are the worse they feel about themselves.

4. In regard to the relationship between self-concept and depression, for Identity Self-Concept only, the relationship between self-concept and depression is different for undergraduate and graduate students.

5. The results of this study further support the literature that suggests self-concept and depression are interrelated. 


\section{Recommendations}

Next, recommendations made from this study for future research might be the following:

1. Replication of this study using a larger sample to test the consistency of findings observed in this research project.

2. Replication of this study with subjects randomly selected and a more diverse sampling of areas such as age group, ethnic origin, marital status. religion, and geographic location would allow greater generalization of findings.

3. Further study of the content of depression and the different life stressors/issues that may trigger depression, especially between undergraduate and graduate students.

4. A longitudinal study with a larger sample to further investigate the different issues that may trigger depression throughout the different life stages.

5. Further investigation into the different issues that mav trigger depression comparing high school students and undergraduate students.

6. Further study of the relationship between maturational factors and the level of self-concept and depression.

\section{Implications}

Last. implications for practice might be the following:

1. Psychologists in the university counseling center might utilize what Beeber (1999) calls anticipatory intervention programs. These anticipatory intervention programs might include an evaluation of self-concept and depression in the screening process of incoming undergraduate and graduate students. Identified students struggling with low 
self-concept and/or symptoms of depression might receive individual therapy, group therapy, and/or training through workshops to aid in increasing the level of self-concept and lowering symptoms of depression. Another form of an anticipatory intervention program, if a screening process is not utilized, might be for psychologists to provide workshops and seminars for undergraduate and graduate students on a range of topics in areas such as personal, social, and academic issues, self-concept, and depression. These types of anticipatory intervention programs could assist individuals in building a more positive sense of self so they can be more productive in school and in life (Gladieux \& Swail, 2000: Hermon \& Hazler, 1999: O’Connor, 2001: Rundle, 2000).

2. Psychologists can be aware that it is vitally important to evaluate, diagnose, and treat depressive symptoms. especially in university students, to prevent potential problems in academic, social, and behavioral areas. Psychologists can help them explore their intrapersonal issues, relationships with others, career interests, and skills in areas such as time-management, study, stress management, social, and decision-making. Students can take some time to examine these issues and decrease their level of depression or symptoms of depression and increase their level of self-concept. This lowering of depression or symptoms of depression and building a more positive sense of self can aid the students to be more productive in school and life (Astin, 1993: Dornbusch, 2000; Paul \& Brier, 2001).

3. The results of this study suggest that therapeutic goals for students, undergraduate or graduate, with symptoms of depression would be similar, for example, in terms of a strengthening a positive sense of self and/or lowering or eliminating symptoms of depression. 
APPENDIX

Reproduced with permission of the copyright owner. Further reproduction prohibited without permission. 
Appendix A

AUTHORIZATION TO PERFORM STUDY

Reproduced with permission of the copyright owner. Further reproduction prohibited without permission. 


\section{Andrews University}

October 4, 2000

Ann Woolley

9026 Sunset Dr. \#2

Berrien Springs, MI 49103

Dear Ann:

RE: APPLICATION FOR APPROVAL OF RESEARCH INVOLVING HUMAN SUBJECTS
$\begin{array}{ll}\text { HSRB Protocol \#: } & 00-01: 423 \quad \text { Application Type: Original Dept: Ed \& Couns Psyc-0104 } \\ \text { Review Category: } & \text { Exempt } \quad \text { Action Taken: Approved } \\ \text { Protocol Title: } & \begin{array}{l}\text { Differences Among Undergraduate and Graduate Students in Self-Concept and } \\ \text { Depression. }\end{array}\end{array}$

On behalf of the Human Subjects Review Board (HSRB) I want to advise you that your proposal has been reviewed and approved. You have been given clearance to proceed with your research plans.

All changes made to the study design and/or consent form, after initiation of the project, require prior approval from the HSRB before such changes can be implemented. Feel free to contact our office if you have any questions.

The duration of the present approval is for one year. If your research is going to take more than one year, you must apply for an extension of your approval in order to be authorized to continue with this project.

Some proposal and research design designs may be of such a nature that participation in the project may involve certain risks to human subjects. If your project is one of this nature and in the implementation of your project an incidence occurs which results in a research-related adverse reaction and/or physical injury, such an occurrence must be reported immediately in writing to the Human Subjects Review Board. Any project-related physical injury must also be reported immediately to the University physician, Dr. Loren Hamel, by calling (616) 473-2222.

We wish you success as you implement the research project as outlined in the approved protocol.

Sincerely,

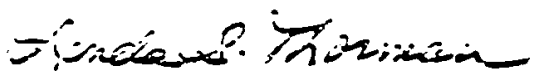

Linda Thorman. Ed.D.

Human Subjects Review Board

c: Nancy Carboneil

Ortxe of Schobuty Research, Gradunte Dean s Office, 1016 i 471.6361

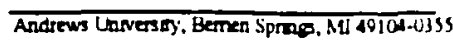

149 


\section{WESTERN MICHIGAN UNIVERSITY}

Date: 20 November 2000

ic. Nancy J. Carbonell, Pnncipal Investigatcr

Anr. L. Woolley, Studeni Invesugator for dissertation

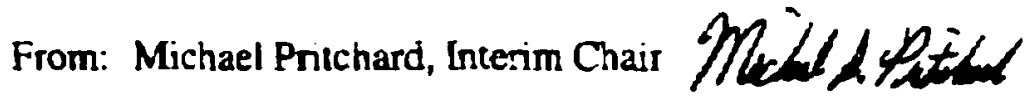

Re: $\quad$ HSRB Projed Number 00-Catbonell/Woolley (Andrews Lriversity)

This letter will serve as confirmation that your research projes: entitled "Differences Among Linderyraduate and G-aduate Students in Self-Concept and Depression" has been reviewed under ihe exempt category of review by the Human Subjects Institutional Review Bcard. Before final approvia can be guven the iollowing revisions must be submitted for HSIRB review:

1. In the research procedure section of the protocol outline (page 3):

- Responses will be anonymous. Please remove the word confidenual there and throughout your protocol-pages 6.7,8).

- Yol: say, "Those that do not w!sh to partic:pate may leave the room not and I will let you know when we are finished." Please revise this procedure. Those who choose no: to paricipate may relum blank torms. They should stay ir. their seats.

2. Subject selection seztion of the protocol (page 6)

- Please revise as above.

3. Intormed consent process section of the protoco: outline:

- Please revise as in 1 .

- Add "to each student" so your first sentence reads,... (research packet) to each student and I will say the following ..."

$\therefore$. As you know, you wiil need a WMU cuntact person.

Please sutmil one copy of the above changes in uriting to the HSIRB. 327E W'alwood Hall (Eas: Campus). Remember to include the HSIRB project number (above) and to mark the changes within the document. To avoid delays, piease do not send revisions addressed to me. Revisions should be submitzed within the next month.

Conducting this research without final approval from the HSIRB is a violation of university policy as well as state and federal regulations.

If you have ary questions. please call the research. compliance coordinator at 387-8293. 


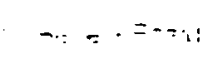

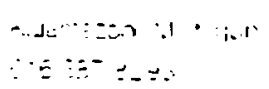

\section{WESTERN MICHIGAN UNIVERSITY}

Date: lanuary 12. 2001

To. Nancy J. Carbonell. Principai Irvestigator

Ann Woolley. Student Investigator for dissertation

Robert Bainkerboff. W.MU contact

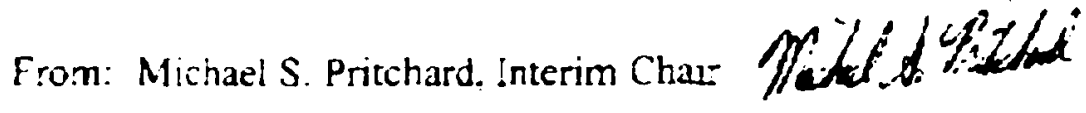

Re: HSIRB Project Number On Carbonell Wouley Andrews

This leter will serve as confirmation that your research project entitled " $\supset$ :fferences Among Undergraduate ard Graduate Students in Self-Concept and Depression" has been approved uncier the exempt category of review jy the Hur.an Subjects Institutional Review Board. The conditions and duration of this approval are specified in the Policies of W'esterm Michigan Un: vessity. You may now begin to implement the research as described in the applicatior.

Please note that you may only conduct this research exactly in the form it was approved. Yci: must seek specific bcard approval for any changes in this pro: ect. You must aiso seek reapprova: if the project exterds beyond the termination cate noted below. Ir. addition if there are ary unanticipated adverse reactions or unanticipated events associated with the conduct of this research, you should immediately suspend the project and contact the Chair o: the HSIRB for consultation.

The Boand wishes you success in the pursuit of your research goals.

Approval Terminat:on: January 12,2002 
HSIRB Proposal - Project Number 00-Carbonell/Woolley (Andrews University)

Western Michigan University

Ann L. Woolley

Ph.D. Candidate, Andrews University

\section{Project Description:}

\section{Purpose of the Study}

The purpose of this study is to compare undergraduate and graduate students with respect to their level of self-concept and depression. Students enter a university setting from a fast-paced society that tends to demand a strong sense of self and a feeling of competency. Along with developmental changes, such as leaving home, making new friends, and starting an undergraduate/graduate program, come questions surrounding one's sense of self. One's level of self-concept influences areas such as relationships, academic achievement, choosing a career, and/or choosing to obtain a graduate level of education. At the same time, feelings of depression affect areas such as relationships, academic achievement, feelings of self-worth, and choosing a career. Research has demonstrated that the onset of depression is occurring earlier than between the ages of 30 40 as once was accepted. Today, the generally accepted idea is depression often starts with mild symptoms in late adolescence/young adulthood and, with time, slowly increases in the level of severity. Depression also tends to have a high recurrence rate. Persons with mild depressive symptoms tend to be at a higher risk for developing more severe depression. If left untreated, these mild symptoms persistently recur and eventually build a lifelong pattern of depression.

It is important to evaluate, diagnose, and treat mild depressive symptoms, especially in university students, to prevent problems in academic, social, and behavioral areas. The university administration, being aware of the importance of early detection and treatment, could work with the counseling center to aid in developing programs, workshops, seminars, and therapy services for students. These types of services could aid with increasing enrollment, decreasing attrition, and improving academic performance. It might also benefit psychologists, especially in the university counseling centers, to assist students in increasing the level of self-concept and lowering depression. This lowering of depression and building a more positive sense of self can aid the students to be more productive in school and life.

\section{$\underline{\text { Research Procedure }}$}

During Fall Semester 2000, I will apply to Andrews University's (AU) Human Subjects Review Board (HSRB) for permission to conduct this research study. After HSRB approval from AU is obtained a copy of this HSRB approval and the completed Western Michigan University (WMU) application for Human Subjects Institutional Review Board 
(HSIRB) will be sent to WMU. While awaiting HSIRB approval from WMU, classes will be chosen from the Fall 2000/Winter 2001 catalogs from AU and WMU on the undergraduate and/or graduate level. Each professor of the selected class at AU will be contacted, informed of the research study, and asked to participate. Class times will be scheduled for me to meet the class and collect the data. After HSIRB approval from WMU, each professor of the selected class at WMU will be contacted, informed of the research study, and asked to participate. Class times will be scheduled for me to meet the class and collect the data.

I will, at the agreed upon date, meet with each instructor and class. At the beginning of my scheduled time, I will distribute one manila envelope (research packet)to each student and I will say the following: "My name is Ann Woolley. I am a doctoral student in Counseling Psychology at Andrews University. I am currently working on my dissertation which basically looks at what people think about themselves and what peopie feel about themselves, their world, and their future. I am here today to ask for your participation in this research study which will take about 20 minutes to complete three research instruments. Your name or identification (ID) number will not be used in any way so your responses will be anonymous. I want to emphasize that your participation in this study is completely voluntary. If you choose to not participate, you will not be penalized in any way. If you choose to participate, you are still free to withdraw at any time during the testing process without any penalty. I do not anticipate anything happening but, for example, if answering any of the questions brings up thoughts and feelings and/or issues for you, I recommend that you contact the counseling center office here at Andrews/Western to talk with someone. Are there any questions? Those who choose to not participate may return the blank forms and stay in your seats. So, let's get started. I'd like you to use a pen, if possible, to complete the instruments."

Then, as I hold up my copy of the Demographic Questionnaire. I will ask each student to take out the first page of the research packet which is the Demographic Questionnaire. I will then ask the students to read the instructions, ask any questions, and then complete the Demographic Questionnaire which will take a minute or less. Next, as I hold up my copy of the Tennessee Self-Concept Scale: Second Edition (TSCS:2). I will ask them to take out the second page of the research packet which is the TSCS:2. I will remind them to not fill in any identifying information but read the instructions, ask any questions, and then complete the TSCS:2 which will take about 12 minutes. I will instruct them that when they are through with the first page of the TSCS:2, which takes approximately 6 minutes, to just turn it over without tearing off anything and complete the second page. Next, as I hold up my copy of the Beck Depression Inventory-II (BDI-II), each student will be asked to look at the last page of the research packet which is the BDI-II. Again, they will be reminded to not fill in any identifying information but read the instructions, ask any questions, and complete the instrument which will take 2-5 minutes. After completion of the BDI-II, I will ask the students to return the three research instruments to the manila envelope, seal it, and give it to me. I will then thank them for their participation. 
$\underline{\text { Research Design }}$

A quantitative research design will be used for an ex post facto study of the differences between undergraduate students and graduate students with respect to their level of self-concept and level of depression.

\section{Location and Duration}

Classes will be chosen from the Fall 2000/Winter 2001 catalogs from AU and WMU on the undergraduate and/or graduate level. Collection of data will be conducted during the period of October 2000 to May 2001.

\section{Benefits of Research:}

Students have an opportunity for personal growth as they leam about themselves and the world around them. But this opportunity for personal growth can be colored by their level of self-concept and depression. Numerous students drop out of higher education for various reasons and can 't seem to "find themselves" throughout life. With added insight, psychologists and universities can greatly influence and assist students in their personal and professional growth. Students who participate and complete the research instruments may take the opportunity to examine their thoughts/feelings and reflect on themselves as individuals and their life goals. This examination might also encourage them to talk to someone in the university's counseling center about their issues and/or life goals.

A university might incorporate an evaluation of self-concept and depression into the screening process of incoming undergraduate and graduate students via the counseling center. Identified students struggling with low self-concept andior depression might receive individual therapy, group therapy, and/or training through workshops to aid in increasing the level of self-concept and lowering levels of depression. This type of counseling and/or training would assist these individuals in building a more positive sense of self.

\section{Subject Selection:}

During Fall Semester 2000, I will apply to Andrews University`s (AU) Human Subjects Review Board (HSRB) for permission to conduct this research study. After HSRB approval from AU is obtained, a copy of this HSRB approval and the completed Western Michigan University (WMU) application for Human Subjects Institutional Review Board (HSIRB) will be sent to WMU. While awaiting HSIRB approval from WMU, classes will be chosen from the Fall 2000/Winter 2001 catalogs from AU and WMU on the undergraduate and/or graduate level. Each professor of the selected class at AU will be contacted, informed of the research study, and asked to participate. Class times will be scheduled for me to meet the class and collect the data. After HSIRB approval from 
WMU. each professor of the selected class at WMU will be contacted, informed of the research study, and asked to participate. Class times will be scheduled for me to meet the class and collect the data.

I will, at the agreed upon date, meet with each instructor and class. At the beginning of my scheduled time, I will distribute one manila envelope (research packet) to each student and I will say the following: "My name is Ann Woolley. I am a doctoral student in Counseling Psychology at Andrews University. I am currently working on my disseration which basically looks at what people think about themselves and what people feel about themselves, their world, and their future. I am here today to ask for your participation in this research study which will take about 20 minutes to complete three research instruments. Your name or identification (ID) number will not be used in any way so your responses will be anonymous. I want to emphasize that your participation in this study is completely voluntary. If you choose to not participate, you will not be penalized in any way. If you choose to participate, you are still free to withdraw at any time during the testing process without any penalty. I do not anticipate anything happening but, for example, if answering any of the questions brings up thoughts and feelings andior issues for you, I recommend that you contact the counseling center office here at Andrews/Western to talk with someone. Are there any questions? Those who choose to not participate may return the blank forms and stay in your seats. So, let s get started. I'd like you to use a pen, if possible, to complete the instruments."

\section{Risks to Subjects:}

The only noted possible risks for subjects might include answering the questions of the TSCS:2 and the BDI-Il which brings up thoughts/feelings for them. Subjects will be advised to talk with someone in AU's or WMU's counseling center if they want to discuss their issues with someone.

\section{Protection for Subjects:}

The subjects names or identification (ID) numbers will not be used in any way so their responses will be anonymous. The participation in this study is completely voluntary. If they choose to not participate, they will not be penalized. If they choose to participate, they are still free to withdraw at any time during the testing process without any penalty. If answering any of the questions brings up thoughts and feelings and/or issues for them, it will recommended that they contact their school's counseling center to talk with someone.

\section{Confidentiality of Data:}

The name or identification (ID) number of each student will not be used in any way so the responses will be anonymous. The coding procedures for subject identification 
numbers will be to start with $00 \mathrm{I}$ and place on all three instruments in the first research packet and proceed with subsequent numbering until the final subject 's research packet is coded.

\section{Instrumentation:}

Data collection will be accomplished by the use of three instruments: (1) the Demographic Questionnaire, (2) the Tennessee Self-Concept Scale (TSCS:2). and (3) the Beck Depression Inventory-II (BDI-II).The Demographic Questionnaire, which I constructed, requests information concerning gender, age group. marital status. ethnic origin. current program level, GPA, and religion. Instructions will ask the participants to check the appropriate box in response to each question. The Demographic Questionnaire requires less than one minute to complete (see attached sheet). The TSCS:2 and the BDIII are reliable and valid instruments that have been used widely in research. Copies of these instruments are not attached but can be gladly given upon request.

\section{Informed Consent Process:}

At the beginning of my scheduled time. I will distribute one manila envelope (research packet) to each student and I will say the following: "My name is Ann Woolley. I am a doctoral student in Counseling Psychology at Andrews University. I am currently working on my dissertation which basically looks at what people think about themselves and what people feel about themselves, their world, and their future. I am here today to ask for your participation in this research study which will take about 20 minutes to complete three research instruments. Your name or identification (ID) number will not be used in any way so your responses will be anonymous. I want to emphasize that your participation in this study is completely voluntary. If you choose to not participate, you will not be penalized in any way. If you choose to participate, you are still free to withdraw at any time during the testing process without any penalty. I do not anticipate anvthing happening but, for example, if answering any of the questions brings up thoughts and feelings and or issues for you. I recommend that you contact the counseling center here at Andrews.Western to talk with someone. Are there any questions? Those who choose to not participate may retum the blank forms and stay in your seats. So, let 's get started...." 

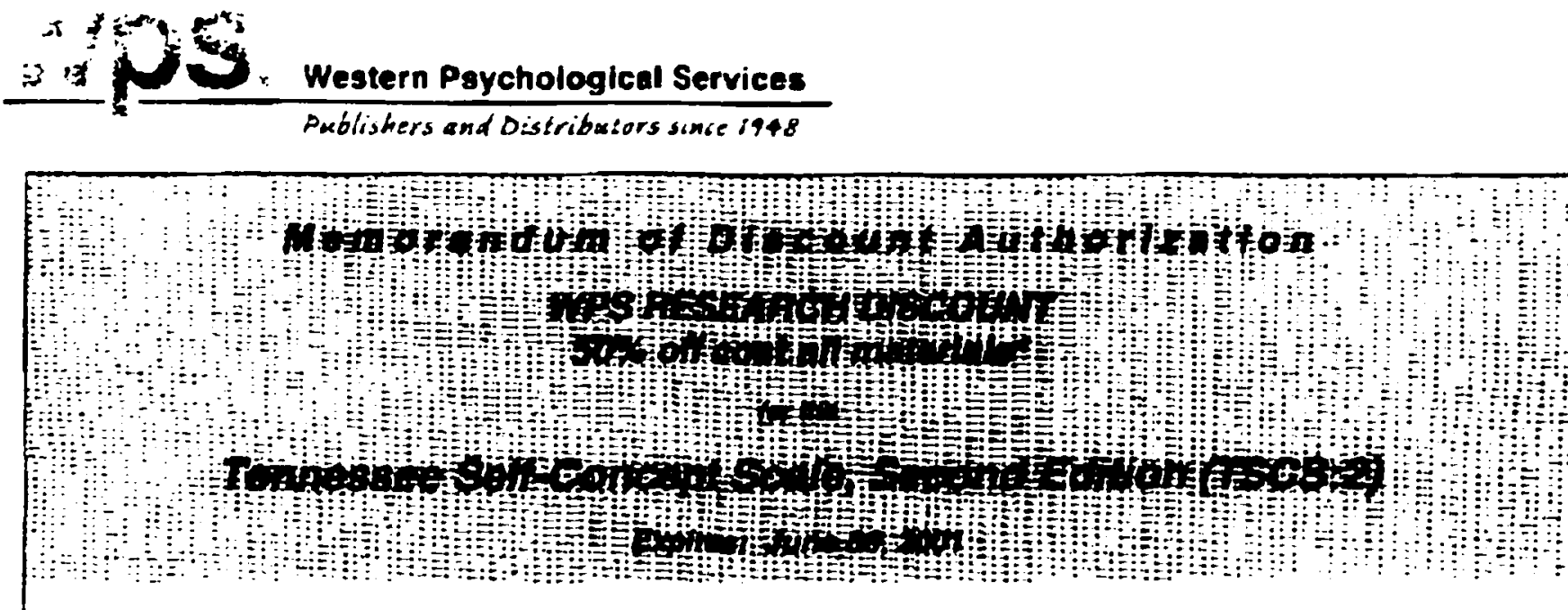

DATE: Oatober 4,2000

TO. inn L. Woolley

9026 Sunset Drive. $\$ 2$

Berrien Sprungs, MI 49103

REF.: Your fax yesterday

STUDY: Doctoral research through Ancirews University - Examining and comparzng the relationsinip setween self-concept and depression

(1) The ciscount is to be applied against the curren:. single-unit catalog price for any related product number.

(2) The discount is not retroactive, but may be applied against your research orders effective immediately, untsl ciscount auticorizaton expires as indicated above. A copy of this memorandum of cisciunt authorizacion must accompany your orders (i placing a credit card onder by phone, please be ready to reler to the date of this memorandumi.

(3) No reprociuction, adaptation or translation of the materials may be made in any formal, for any purpose, without our prior writter permission.

(4) All mater.als must be used ethically and for the purposes and in the manner for which they were intended.

(5) In excinange for receiving our Research Discount, you agree to provide WPS with one copy of all articles (including theses, dissertations, research reports, convention papers, journal submissions, etc.) that use data from ou: instrument(s) as collected in the above-described research. Please mark the articles to the attention of the WPS Reseazch Coondinator. WPS reserves the right to use any such data; you will of course receive proper acknowledgment if we use your research results.

(6) This memorandum does not serve as a price quote or as a guarantee of avalability; for more irformation, please contact WPS Customer Service at $(800 ; 648-8853$.

We kow formard to ieaming of the resuls o! your sfudy I you have any questions praase confac! Ms. Susan Junn Weinuarg en WPS. 
(4)

THF:

PSYCHOLOGICAL.

CORPOR.ATION"
The Pyichotogical Corporation

555 Acrdemic Count

San Antono. Texas 76204-2498

Te: 210-299-106:

Telex 5136015629 TPCSAT

fax 210-299-2755

January 6, 2000

Ms. Ann L Woolley

9026 Sunset Drive $\$ 2$

Berrien Springs, MI 49103

Dear Ms. Woolley:

Thank you for your letter concerning your use of the Beck Depression Invellury : Siecund Edition $\left(B D F^{*}-I I\right)$ in your dissertation research to explore the relationship between self-concept and depression in approximately 1000 graduate students.

As a responsible test publisher, we believe it is our duty to protect the security and integrity of our test instruments Therefore, we cannot allow copies of the test to be included with or stapled in your dissertation. However, two actual test items from the $B D P^{-I I}$ may be included. If you use two items, please be sure the copyright notice appears with the items along with the words "Reproduced by permission of the publisher, The Psychological Corporation"

Also, all testing must be conducted in your presence or that of another qualified individual so that all test materials remain secure.

We will gladly grant permission for the use of this test instrument if the above restrictions will be followed. Please indicate your agreement to these terms by signing and retuming this letter for our files. When you have returned the signed letter, you may contact Shirley Elizondo in Customer Service at (800) 228-0752, ext 5427, to onder your test materials. If you have already placed an order, it will be released upon receipt of this signed letter. As a student, you are eligible for a 50\% discount on these materials; however, you must pay for the order yourself and request the discount at the time you place the order.

Also, please forward a copy of your final dissertation for our library.

Thank you for your interest in our test materials. If you have further questions or needs, please contact us. Good luck with your research.

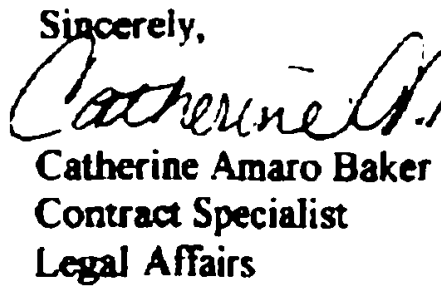

AGREED:

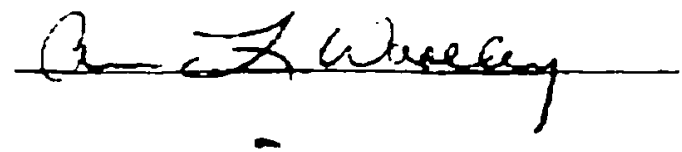


January 6, 2000

Ms. Ann L. Woolley

9026 Sunset Drive $\$ 2$

Berrien Springs, MI 49103

Dear Ms. Woolley

Thank you for your letter concerning your use of the Beck Depression Imencory ${ }^{\Phi}$. Secound Edition $(B D)^{*}-U l l$ in your dissertation research to explore the relationship between self-concept

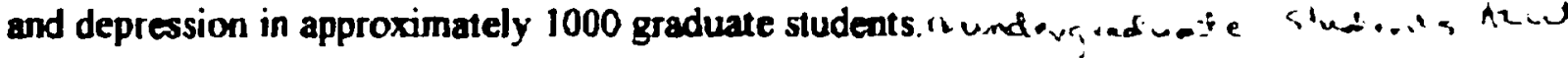

As a responsible test publisher, we believe it is our duty to protect the security and integrity of our test instruments. Therefore, we cannot allow copies of the test to be included with or stapled in your dissertation. However, two actual test items from the $B D P-\Pi$ may be included. If you use two items, please be sure the copyright notice appears with the items along with the words "Reproduced by permission of the publisher, The Psychological Corporation"

Also, all testing must be conducted in your presence or that of anotber qualified individual so that all test materials remain secure.

We will gladly grant permission for the use of this test instrument if the above restrictions will be followed. Please indicate your agreememt to these terms by signing and returning this letter for our files. When you have retumed the signed letter, you may contact Shirtey Elizondo in Customer Service at (800) 228-0752, ext. 5427, to order your test materials. If you have already placed an order, it will be released upon receipt of this signed letter. As a student, you are eligible for a $50 \%$ discount on these materials; however, you must pay for the order yourself and request the discount at the time you place the order.

Also, please forward a copy of your final dissertation for our library

Thank you for your interest in our test materials. If you have further questions or needs, please contact us. Good luck with your research.

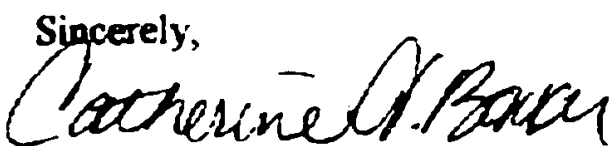

Catherine Amaro Baker

Contract Specialist

Legal Affairs

\section{AGREED:}

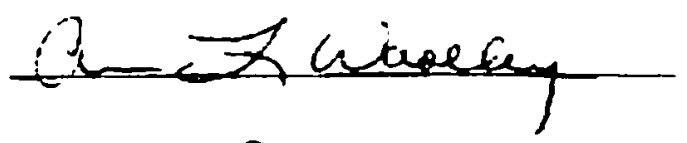


Appendix B

CORRESPONDENCE

Reproduced with permission of the copyright owner. Further reproduction prohibited without permission. 


\section{Andrews University}

October 28, 1999

Western Psychological Services

Attn. Ann Wineberg

12031 Wilshire Blvd.

Los Angeles, CA 90025

RE Use of the Tennessee Self-Concept Scale

To whom it may concem:

One of my doctoral students, who is currently working on her dissertation, Ann Woolley, is interested in using one of your instruments for her study, which is the Tennessee Self-Concept Scale. Please be informed that I will be supervising her usage of the instrument and all other aspects of her research. I am an Associate Professor at Andrews Liniversity and a fully licensed Psychologist in the state of Michigan.

Thank you for facilitating Ann's purchase and use of this assessment tool.

Sincerely,

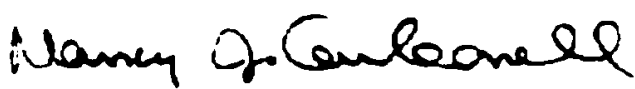

Nancy J. Carbonell., Ph.D.

Andrews Liniversity

Educational and Counseling Psychology Deparment

Berrien Springs, MD 49104 
Ann L. Woolley

9026 Sunset Drive $\# 2$

Berrien Springs, MI 49103

(616) $471-9315$

Sue Weinberg

Western Psychological Services

12031 Wilshire Blvd.

Los Angeles, CA 90025

November 02, 1999

RE: Use of the Tennessee Self-Concept Scale

Dear Ms. Weinberg:

This letter is a request to use the Tennessee Self-Concept Scale- 2nd edition as an instrument in my doctoral dissertation research. This study will explore the relationship between self-concept and depression. This study will also explore the question do graduate students differ in the level of self-concept and depression as compared to undergraduate students. After approval from the Human Subjects Review Boards, I plan to gather my data in January and February of 2000 . At this point in time, I am planning to have a sample size of approximately 300 students. The results will be distributed to my dissertation committee and then published in my Ph.D. dissertation.

Thank you for assisting me in purchasing and utilizing the Tennessee Self-Concept Scale- 2nd edition in my doctoral research.

Sincerely,

Ann L. Woolley

Ph.D. Candidate

Andrews University

Berrien Springs, MI 49104 


\section{Andrews $\$$ University}

November 18,1999

Ema Acuna

The Psychological Corporation

555 Academic Court

San Antonio. Texas 78204

RE Use of the Beck Depression Inventory

To whom it may concern.

One of my doctoral students, who is currently working on her disseration. Ann Woolley, is interesed in using one of your instruments for her study, which is the Beck Depression Inventory. Please be informed that I will be supervising her usage of the instrument and all other aspects of her research. I am an Associate Professor at Andrews Umiversity and a fully licensed Psychologist in the state of Michigan.

Thank you for facilitating Ann's purchase and use of this assessment tool.

Sincerely.

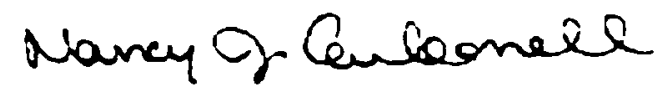

Nancy J. Carboneli., Ph.D.

Andrews Liniversity

Educational and Counseling Psychology Department

Berrien Springs, MI 49104 


\author{
Ann L. Woolley \\ 9026 Sunset Drive $\# 2$ \\ Berrien Springs, MI 49103
}

(616) $471-9315$

Erna Acuna

The Psychological Corporation

555 Academic Cour

San Antonio, Texas 78204

(800) $211-8378$

Fax $(888) 2004880$

January 04, 2000

RE: Use of the Beck Depression Inventory

Dear Ms. Acuna:

This letter is a request to use the Beck Depression Inventory-Il as an instrument in my doctoral dissertation research. This study will explore the relationship between selfconcept and depression. This study will also explore the question do graduate students differ in the level of self-concept and depression as compared to undergraduate students. After approval from the Human Subjects Review Boards, 1 plan to gather my data in February-May of 2000. At this point in time, I am planning to have a sample size of approximately 1,000 students. I will hand out the instrument to a specified class and collect it at the end of that class period. The results will be distributed to my dissertation committee and then published in my Ph.D. dissertation.

Thank you for assisting me in purchasing and utilizing the Beck Depression Inventory-II in my doctoral research.

Sincerely,

Ann L. Woolley

Ph.D. Candidate

Andrews University

Berrien Springs, Ml 49104 


\section{Fax Transmittal Sheet}

TO: Catherine A. Baker

Company: The Psychological Corporation

Phone: (800) $211-8378$

Fax: (888) $200-4880$

\section{FROM:}

$\begin{array}{ll}\text { Seader: } & \text { Ann L. Woolley } \\ \text { Phome: } & (616) 471-9315 \\ \text { Fax: } & (616) 471-9315 \\ \text { Sent: } & 01-18-00 \\ & \\ \text { Pages (including cover): } & 2\end{array}$

NOTE: As in my original letter, dated 1-04-00, 1 requested permission to use the BDI- 0 in my doctoral dissertation with graduate and undergraduate students. The letter of permission, in the first paragraph, only states graduate students. I wam to make sure this wording will not be a problem in the future. Thank you 


\section{Ann L. Woolley \\ 9026 Sunset Drive $¥ 2$ \\ Berrien Springs, MI 49103}

Dr

College of

Andrews University

Berrien Springs, MI 49014

$11-1-00$

Dear Dr.

Thank you for agreeing to allow me to meet with your class on

at

to distribute my research instruments. Enclosed is a copy of my Human

Subjects Review Board Letter of Approval for your records. Again, this will take approximately 20 minutes. I certainly appreciate your time and assistance.

Sincerely,

Ann L. Woolley 


\section{Ann L. Woolley \\ 9026 Sunset Drive $\neq 2$ \\ Berrien Springs, Ml 49103}

Dr.

College of

Andrews University

Berrien Springs, MI 49014

$12-02-00$

Dear Dr.

Thank you so much for graciously allowing me to come into your class on to distribute my research instruments. I certainly appreciated your time and assistance. I hope you and your family have a wonderful holiday season.

Sincerely.

Ann L. Woolley 


\author{
Ann L. Woolley \\ 9026 Sunset Drive $: 2$ \\ Berrien Springs, MI 49103 \\ (616) 471-9315
}

3102 Sangren Hall

Ph.D.

Westem Michigan University

Kalamazoo, $\mathrm{Ml} 49008$

$12-27-00$

Dear Dr.

My name is Ann Woolley. I am a doctoral student in Counseling Psychology at Andrews University. I am currently working on $m y$ dissertation which is exploring the differences among undergraduate and graduate students in self-concept and depression.

I have been working with the Research Compliance Coordinator, Victoria Janson, and have obtained permission from Dr. Joe Morris to contact you. My Human Subjects Institutional Review Board (HSIRB) application has been completed and everything is in order except for my obtaining a Western Michigan University (WMU) faculty member to be my contact person (HSIRB Project Number 00 - Carbonell/Woolley (Andrews University)). The faculty member does not actually have any responsibilities other than agreeing to be the contact person and being aware that I am gathering data at WMU. The contact person would be the individual I would speak with in case any problems occur while I am collecting the data. I have already gathered data at Andrews University without any problems. So, I certainly do not anticipate any problems while collecting data at WMU.

Enclosed is a copy of my HSIRB application for your review. This will give you an overview of what is involved in my research. If you have any questions about this request, please contact the Research Compliance Coordinator: Victoria Janson (387-8293), Office of the Vice President for Research, 327E Walwood Hall

Thank you so much for your time. I know the Winter Semester begins on January 2 and schedules are always busy at the stan of a new semester. But, I would appreciate your consideration in this matter at your earliest convenience. I hope to be able to gather my data at WMU during this upcoming semester. I look forward to hearing from you.

Sincerely,

Ann L. Woolley 


\section{Ann L. Woolley \\ 9026 Sunset Drive $=2$ \\ Berrien Springs, Ml 49103 \\ (616)471-9315}

Dr.

School of

Western Michigan University

Kalamazoo. MI 49008

$01-17-01$

Dear Dr

My name is Ann Woolley. I am a doctoral student in Counseling Psychology at Andrews University. I am currently working on my dissertation which is exploring the differences among undergraduate and graduate students in self-concept and depression.

I am requesting the opportunity to meet with your class, , to collect research data which will take approximately 15-20 minutes. Data collection will be accomplished by the use of three instruments: (1) the Demographic Questionnaire. (2) the Tennessee Self-Concept Scale (TSCS:2), and (3) the Beck Depression Inventory-Il (BDI-I I).

I hope to meet with the class in March or April at a time which is convenient for your schedule. I will call you within 1-2 weeks upon your receipt of this leffer to see when we can schedule a time for me to meet with your class.

Enclosed is a copy of my Human Subjects Institutional Review Board (HSIRB) Letter of Approval for your records. If you have any questions - feel free to contact me and/or the Research Compliance Coordinator, Victoria Janson (387-8293).

Sincerely.

Ann L. Woolley 


\section{Ann L. Woolley \\ 9026 Sunset Drive $¥ 2$ \\ Berrien Springs, MI 49103 \\ (616) $471-9315$}

Robert Brinkerhoff. Ph.D.

3102 Sangren Hall

Western Michigan University

Kalamazoo, Ml 49008

$01-26-01$

Dear Dr. Brinkerhoff,

Thank you so very much for "going the extra mile" and agreeing to be my contact person. I appreciate your support because it allows me to move forward with my dissertation. My next step is to contact the following professors to inquire about gathering data in their classes: 1) Dr. - ED 601 (Intro Ed Research): 2) Dr. - CECP 622 (Psy-Ed Consultation); 3) Dr. - EDLD 662 (School Business Mgmt); and

4) Dr. - SOC 607 (Logic \& Analysis of Soc Research I).

I will correspond with you again during this entire process and keep you informed.

Enclosed is a copy of my Human Subjects Institutional Review Board Letter of Approval for your records just in case you do not have a copy. Please feel free to contact me with any questions or comments. Again, thank you so much for your time.

Sincerely,

Ann L. Woolley 
Ann L. Woolley

9026 Sunset Drive $=2$

Berrien Springs, MI 49103

(616) 471-9315

Dr.

Sangren Hall

Western Michigan University

Kalamazoo, MI 49008

$01-26-01$

Dear Dr.

My name is Ann Woolley. I am a dostoral student in Counseling Psychology at Andrews University. I am currently working on my dissertation which is exploring the differences among undergraduate and graduate students in self-concept and depression.

I am requesting the opportunity to meet with your class, , to collect research data which will take approximately 15-20 minutes. Data collection will be accomplished by the use of three instruments: (1) the Demographic Questionnaire, (2) the Tennessee Self-Concept Scale (TSCS:2), and (3) the Beck Depression Inventory-II (BDI-II).

I hope to meet with the class in March or April at a time which is convenient for your schedule. I will call you within 1-2 weeks upon your receipt of this letter to see about scheduling a time for me to meet with your class.

Enclosed is a copy of my Human Subjects Institutional Review Board (HSIRB) Letter of Approval for your records. If you have any questions, feel free to contact me and/or the Research Compliance Coordinator, Victoria Janson (387-8293).

Sincerely,

Ann L. Woolley 


\section{Ann L. Woolley \\ 9026 Sunset Drive $=2$ \\ Berrien Springs, MI 49103 \\ (616) $471-9315$}

Dr.

Sangren Hall

Western Michigan University

Kalamazoo, MI 49008

$02-15-01$

Dear Dr.

Thank you so much for agreeing to allow me to meet with your class on at to distribute my research instruments. Again, this will take

approximately 15-20 minutes. I certainly appreciate your time and assistance.

Sincerely,

Ann L. Woolley

172 
Ann L. Woolley

9026 Sunset Drive $\neq 2$

Berrien Springs, MI 49103

(616) $471-9315$

Robert Brinkerhoff, Ph.D.

Western Michigan University

3102 Sangren Hall

Kalamazoo, Ml 49008

03-20-01

Dear Dr. Brinkerhoff,

As just confirmed tonight, the following professors will allow me to gather data from their class(es) next week: I) Dr. - ED 601 (Intro Ed Research): 2) Dr. - CECP 622 (Psy-Ed Consultation); and 3) Dr. - EDLD 662 (School Business Mgmt). I had contacted several other professors which were unable to allow me to meet with their classes. So, depending on the actual numbers obtained, I may have to gather more data next semester. I just wanted to keep you informed of the progress. Again, thank you so much for being my contact person.

Sincerely,

Ann L. Woolley 
Ann L. Woolley

9026 Sunset Drive $=2$

Berrien Springs, MI 49103

(616) $471-9315$

Dr.

Western Michigan University

Haworth College of Business

Kalamazoo, MI 49008

$03-30-01$

Dear Dr.

My name is Ann Woolley. I am a doctoral student in Counseling Psychology at Andrews University. I am currently working on my dissertation which is exploring the differences among undergraduate and graduate students in self-concept and depression.

I am requesting the opportunity to meet with your class, BUS 616 (Bus Policy \& Soc \& Ethical Envir), to collect research data which will take approximately 15-20 minutes. Data collection will be accomplished by the use of three instruments: (1) the Demographic Questionnaire, (2) the Tennessee Self-Concept Scale (TSCS:2), and (3) the Beck Depression Inventori-II (BDI-II).

I hope to meet with the class in May at a time which is convenient for your schedule. I will call you within I week upon your receipt of this letter to see about scheduling a possible time. Enclosed is a copy of my Human Subjects Institutional Review Board (HSIRB) Letter of Approval for your records. If you have any questions, feel free to contact me and/or the Research Compliance Coordinator, Victoria Janson (387-8293).

Sincerely;

Ann L. Woolley 
Ann L. Woolley

9026 Sunset Drive $=2$

Berrien Springs, MI 49103

(616) $471-9315$

Dr.

Western Michigan University

Sangren Hall

Kalamazoo, MI 49008

04-06-01

Dear Dr

Thank you so much for graciously allowing me to come into your classes to gather my research data. I enjoved meeting you and talking with you. You made me feel so welcomed. I hope you enjoyed the recent break. Again, it was a pleasure meeting you and thank you for your time.

Sincerely,

Ann L. Woolley 


\section{Ann L. Woolley \\ 9026 Sunset Drive $\neq 2$ \\ Berrien Springs, MI 49103 \\ (616) $471-9315$}

Rober Brinkerhoff, Ph.D

Westem Michigan University

3102 Sangren Hall

Kalamazoo, Ml 49008

$05-01-01$

Dear Dr. Brinkerhoff,

It was such a pleasure meeting you and talking with you in March. I hope you enjoyed the recent break. I wanted to let you know that the following professors have agreed to allow me to gather data from their class(es) next week: 1) Dr. - BUS 616 (Bus Policy \& Soc \& Ethical Envir) and 2) Professor - SWRK 400 (Prac Prob Solv

Proc). Again, thank you so much for taking a chance and agreeing to be my contact person. I appreciate your kindness.

Sincerely,

Ann L. Woolley 
Ann L. Woolley

9026 Sunset Drive $=2$

Berrien Springs, Ml 49103

(616) 471-9315

Dr.

Western Michigan University

Haworth College of Business

Kalamazoo, MI 49008

$05-28-01$

Dear Dr.

Thank you so much for graciously allowing me to come into your class to gather my research data. I enjoyed meeting you and talking with you. You made me feel so welcomed. I hope you have a pleasant summer.

Sincerely;

Ann L. Woolley 
Ann L. Woolley

9026 Sunset Drive $\approx 2$

Berrien Springs, MI 49103

(616) $471-9315$

Robern Brinkerhoff, Ph.D.

Westem Michigan University

3102 Sangren Hall

Kalamazoo, MI 49008

06-10-01

Dear Dr. Brinkerhoff,

The trip in May to collect data was a success. I am now officially through with collecting my data and well on my way in analyzing it!! I could not have completed the data collection process without your help. Thank you so, so very much for being my contact person. I will always remember your kindness. Later, I will send you an abstract of my dissertation findings just for your information. Again, thank you for your time.

Sincerely,

Ann L. Woolley 
Appendix C

\section{INSTRUMENTATION}




\section{DEMOGRAPHIC QUESTIONNAIRE}

Directions: Please check the appropriate box for each question.

1. Gender:

1. $\square$ Male

2. $\square$ Female

2. Age Group:

1. $\square 17$ or below

2. $\square$ 18-24

3. $\square 25-34$

4. $\square 35-44$

5. $\square 45-54$

6. $\square 55-64$

7. $\square 65$ and over

3. Marital Status: $\quad$ 1. $\square$ Single (Never Married)

2. $\square$ Cohabited

3. $\square$ Married

4. $\square$ Separated/Divorced

5. $\square$ Widowed

4. Ethnic Origin: 1. $\square$ African American

2. $\square$ African Origin

3. $\square$ Asian American

4. $\square$ Asian Origin

5. $\square$ Caribbean Origin

6. $\square$ Caucasian

7. $\square$ Latino/Hispanic

8. $\square$ Multiracial

9. $\square$ Native American

10. $\square$ Other

5. Current Program Level: $\quad$ Lndergraduate 1. $\square$ Freshman

2. $\square$ Sophomore

3. $\square$ Junior

4. $\square$ Senior

Graduate

6. GPA:

1. $\square 4.0$

5. $\square \mathrm{MA} \mathrm{I}$

6. $\square 2$

7. $\square \mathrm{PhD} \quad 1$

8. $\square \quad 2$

9. $\square 3$ -

2. $\square 3.9-3.5$

3. $\square 3.4-3.0$

4. $\square$ 2.9-2.5

5. $\square 2.4-2.0$

6. $\square 1.9-1.5$

7. $\square$ 1.4-1.0

7. Religion: 1. $\square$ Protestant

2. $\square$ Catholic

3. $\square$ Jewish

4. $\square$ Islamic

5. $\square$ Other 


\section{Appendix D}

DATA 


\section{Data Format}

Row 1 Rows per student

Columns

$\begin{array}{ll}1-2 & \text { Class Number } \\ 3-5 & \text { Student Identification Number } \\ 6 & \text { Gender } \\ 7 & \text { Age Group } \\ 8 & \text { Marital Status } \\ 9-10 & \text { Ethnic Origin } \\ 11 & \text { Current Program Level } \\ 12 & \text { GPA Group } \\ 13 & \text { Religion } \\ 14-54 & \text { Responses to Items } 1-41 \text { of TSCS:2 (Page 1) }\end{array}$

Row 2

Columns
$1-13$
Same as row 1
14-54
Responses to ltems 42-82 of TSCS:2 (Page 2)
$55-56$
Total of Responses to Items 1-21 of BDI-II 


\section{Class Number List}

Columns 1-2 on Data Format

$$
\begin{aligned}
& 01=\text { Dr. P } \\
& 02=\text { Dr. } G \\
& 03=\text { Dr. M } \\
& 04=\text { Dr. B } \\
& 05=\text { Dr. H (A) } \\
& 06=\text { Dr. H(B) } \\
& 07=\text { Dr. G } \\
& 08=\text { Dr. } F \\
& 09=\text { Dr. } W \\
& 10=\text { Dr. A (A) } \\
& 11=\text { Dr. } W \\
& 12=\text { Dr. A (B) } \\
& 13=\text { Dr. M } \\
& 14=\text { Dr. Mc }
\end{aligned}
$$


010012040534155512255225444411445535331121114111111111 01001204053415135121115115111554155555525115141315144506 010021210615533524434434553424333454334552232521232454 01002121061554545352323245345331544354534333545121553320 010031210613133343444223332422244445232552234431121233 01003121061313334255214124355353554434523224322323334409 01004121061313443244421443421423453423455112111111224 01004121061313212254414134445443334445533224432223555406 010051210612145511354224441512355535251532114111111111 01005121061214234241114145122554355544425224151413244400 010062210613554333354513524233324434443333322333343244 01006221061352532355543423241324321334323323334343223330 010072210622534513244134533324434415241232115211211534 01007221062254133144112315134453235335523234231132435422 010081210622143541354224442312344434341411123111211122 01008121062212235421214114132443134434324224141423155308 01009221061213552244324442322444344342553325111121215 01009221061213424355514504535344143443143254232134254311 010102210833533222245424344232435434252442214131122222 01010221083352435244224234243324233445332224151414244411 010112210113144035555445314322215134353545515332353152 01011221011313515255115553353253335553513354341413155534 010122210614514433123424353435523224211543115441111134 01012221061452555142323314341242354255321234343422352326 010132210113554424255414441311444424141321114111111122 01013221011342255122111215234444244543414114241534325503 010142210621504532144214432412544434342532124111121213 01014221062154344242123433244333335344534254332323453414 010152210110543552343144532312455514241551144111321131 01015221011055134132312334444552355534435413141323244403 010162210614544551355314453413335324151423113111111131 01016221061453235121224144213345344555313134131434134409 010172210713534342243243433313444344351431115111111133 01017221071352134243412253332333232344324214131144254308 010182210613555411355235441511345515151431114111211111 01018221061354135331215115124154154455335144151435111403 010192210112534433442332325234224223431345343241332244 01019221011253422344523452454243423232443243433143253238 010201210521555412144145541421545515141422125111211122 01020121052155154241113234222445255535515115141325155304 010211211013543543454444442412155515251541144221451024 01021121101353325242223444333554445544515113132212243404 010221210614554552343323334422355434351443233221111113 01022121061455333231433444423344333445225234122425143310 010231210622144523144213542412543425141552125111211234 
01023121062214143231414243344244233455434225351324545409 010241210110554511355115551511355315151511115111111111 01024121011053135111114115111344144555515115151515115500 010252210510544453245214441511444515141532115111111213 01025221051051433145314255324455155555535115351533325500 010262210433545544344445352533344533353541223121111111 01026221043353234311135344344553255555534135251515313503 010272210312554522355314353511345424151521124111111112 01027221031255434231114214231333144554525414251213134400 010281210312554522244224442412444521141542125211121113 01028121031254154241114424234553254554525115442234225400 010291210611544551153245551514415515151553525111111112 01029121061153155154415152525552454555524224451314155416 010302210412534422445444452412344424542542224111111144 01030221041254224243224334333443434444324244231324242308 010312210623544434132234425313535434251352144111111114 01031221062354243254314224234242334434333223421134255305 010322210122154321244114433313425534431322125121111145 01032221012215123141315115124454345245415114133325155524 010331210613134444243323444323434424241532224111122223 01033121061314343232244344322234233344223224342423233404 010341210613043452443224442413344334241542224111221123 01034121061303232253413324444353234444523324242432253306 010351210113545522144214452411544424231551125111111112 01035121011355153233115344411334335455515414251315455409 010361210812134443244234443333433324333343225232321232 01036121081212421255223242444344332234543244432334554414 010372210733145511155215451512555415241531114111111112 01037221073315144141115425333444244455334315241424234400 010381210623534522343423344413344444132521122111111111 01038121062354234234213224234542223444533214341212222305 010391210612144512244224452511455515241522114111141122 01039121061215322142214515223444144555424145241425244507 010401210613144542454324544413244514241541224111321111 01040121061312224204414244323544244445324224242323243408 010412210613135530244224552422444514241543124202221424 01041221061314214233214224233443024454424234241324345404 010422540724155532545415354414135515141550314111111111 01042254072412125141115135331354134455533215131333543505 010432210114554432444324442312244434241442124111121111 01043221011455324242414244423454245434414114131223243303 010442210623544442544323342322244424242432223211121123 01044221062354323242224244432444244444324224241423333400 010452210612534522343324442422334425341532123111111122 01045221061254224232324224223344233454533224231324244402 
010462330642144423143223443423544424332553224211142443 01046233064214154232214323342554233444444234232124343403 010472330543144443544323444423224424201432114111111112 01047233054314124253214224222344244454443214341423333404 010482210612534422203233545332534425231443334232122153 01048221061253334351311543225453345455443154131315133421 010491210614134453544552335354115324524354345343544245 01049121061413423344232441445231543134512334324344451256 010502210612534532245224351511544314241521114111121114 01050221061254154122114424241444144454444224241414214400 010511210623534552254324552412445424242521114221111112 01051121062354543244424344225352335334514144341324443315 010521210624544551554434442412145525241552153111111115 01052121062454424255514154255443243444514314242323353304 010532210612544521342224451312345415341531124111211112 01053221061254124142114114142553154555424114142314244401 010541210625145513244232443412444425231422225211121142 01054121062514235232124324232444145354514125241424444502 020551330552545511245215551511455415141442214111121123 02055133055254234232114124323445134544424225141513224401 020561310453544502255224351512453412241531114111221122 02056131045355235152234224220411144444324125231024333401 020572330452155542244214451412555415341343224111151124 02057233045215144211113443434454145554515114331424454409 020582310462544232242224412511443315232443324221122233 02058231046254253232233234433350343334434244231024442301 020591310453544443244335453553455444153311115111111111 02059131045355234212215245123542255555334214252125322507 020602430652243551553224454511135514151551125111111114 02060243065222115251213212132454355554324115151413135502 020612410453545413135224552511554525142542114111111122 02061241045352254131115215344554345444345115441435334401 020621030153555514155115551511554514151531114111111131 02062103015351155121110345514555155555515115141515444503 020632430652144513445224553412244425241521124111111122 02063243065214234242214424242444144454524234242424324402 020641540153134232254233523324344323453543324233342244 02064154015314245333312242224334345454333233232345233414 $0206513102521544513332244323 ! 2324414141342135111111133$ 02065131025213134243113344333343335555554134151325233408 020661430254144422344434443423334404341333324221121233 02066143025414344232222234221344233334243224232423444406 020671310253534251455205554444445515454551114111111233 02067131025354133151155544421555155544515315531515155510 030682540134534311455110452412145225141133213112111112 
03068254013451114121114114122244144555233115141414123400 030692210733544422445325353413254415331533113111111111 03069221073354213142345225123253444443244114131213343318 030702210144543244334234512213234524331211114215111313 03070221014453233133532433324333344434413234441432433405 030712210134554452553333441413155214141542224211111112 03071221013454114143214434445352454444434234131324343514 030722211033555411354134432323335325341533225211111132 03072221103353135232115334333333233345233202141323234311 030732210743154422243224342412434425241441134111121223 03073221074314144242123224344443244543445244231343344302 030742310532554321554114432411144325241351114111111115 03074231053255124151114515114354244555345115441425155406 030751211044134323354333313233224424334332113323323243 03075121104413333243223333433343233334333233332234243422 030761230644545422355423351322344424241423123111111123 03076123064453214242134324223323133454545124132445233208 030772210224544442344424342012244415241441114111111114 03077221022455124242314124244354334444424114131324134400 030782210544054431244223434314244415241531114111121131 03078221054405114143515353442344334454455214341334244402 030792210542555532154114533412535414341452145111111122 03079221054255245443313554351254244445544144131333134412 030801210642132534443223442412244314231443134321142233 03080121064213234353413234344342255433513244242323314307 030812210535524122444444314244224424444242223233332222 03081221053554432242523445244442433434322344323325222223 040822330662245522145214441413544415241542115111111114 04082233066224244131114314123444155554434125141423345405 040831330782544555355215552511355425151141125111111132 04083133078255135141315115154455145555525135111525134406 040842430173544433454433333323234424451332223222221123 04084243017354333334224333333443233434433223231223242311 040852430752155512145215541511555415141541114111211224 04085243075215155132115215122355155553235215331503324402 040862530561155512445215451512444315151542214111111111 04086253056113135111115315111555145454234115151515114402 040872330752544322444224432423234424241342124131321223 04087233075254123242424324223343234333223223231433333306 050881210633544422344224442322334434242442224221111233 05088121063353224252313224235342224434334224232233334307 050892210444144423343224443412245424141432325111111111 05089221044414234242115334214343255435315124141425245412 050902210543145312545224532312144435341542115121212344 05090221054315124142114324344444144455435125231414355421 
050912210542134422343223443423334415342542225221122234 05091221054213234232314314344334244254533243242222324315 050922211043134323435344434323244425452542223111111111 05092221104314424342213445543343235545325135431343444316 050931210642134421244224442412424514241441123111111212 05093121064215233231214124222434133454425115141325234400 050941230744554523455124451411455512141531114111111122 05094123074455114152514154524552425455214113141312134505 050952210644544433444424243313234324442443223231142434 05095221064453324242223324234343323344334224232233444207 050962210542144323434223442312233344241332124121221224 05096221054214214243214224254443234443544214232323434403 050972210442534523144224452522544424241542124111111223 05097221044254153221115424233443244455433214242323333407 050982210743534342445423422211333425331442124222222222 05098221074352423232233443432343244444422234331233253216 050992210644544532344224542322345525351552134111211224 05099221064454135242214114244443244554424125131324255401 051002430743135413545214343411244414141522115111111111 05100243074314124132115115111434144455234124241415203402 061011210333545353345445434511444515151453314111111221 06101121033351212221114115322334155555315135121415143303 061021210643545522254124552412455325251542125111111121 06102121064353145252114114245242345555524114141325145502 061031210633144523244323443423434424243532033111121232 06103121063313434243414334433443244434434224342324344409 061041210832144421344214441312335414241551115111111141 06104121083213134242213234233344445555534114131324145304 061052330132555522354345442313344434151341134111111133 06105233013254123233114133233444233455523114231433344407 061062330232545404445425451411454515441534314111110121 06106233023255143150525554413445134455205443131414032506 061072210533544433343333323223333324231432124121321222 06107221053355334243423243344343334444434223232243344418 061082210124534432353223444323325324352322333111221112 06108221012453125232323232233323234333523213131325133311 071092210151554552254243453512435425351542225121111113 07109221015153245234315255243553135555534224141314354303 071102310472545212345245432352344525231443115212111143 07110231047255124153213145244544244335235125141424144405 071111210550134322453224414233224434241441215121111123 07111121055015224352214424223253333355433125121243154308 071121310454043555152345432334444333452442133131241143 07112131045405324433424244324321444445524413431244254312 071132210753545422555315452311255515241543214111121223 
07113221075354214131114314233555244455314115141424254408 071142210653133444444222443412333515331541124121211442 07114221065315211243413232444544443434323234331323454407 071151630662144344333323233222223434242452124111221233 07115163066214424324213442433333243444334253432234445309 071162420652554422244124441311444525451332115111211123 $07116242065255144 ! 32115224122554255554115124121535145500$ 071172210652154541253113543411445524251531125111111114 07117221065215134332114223122454334555425213141324245400 071182330652544323334223343322334324232442214221131213 07118233065252233243224333333332133344443214231224334313 071192430261534433233323242411555414241431113111111124 07119243026153155433115344344444132344434213131413555502 081202540172545453343214452511435515141331114111111133 08120254017253234121115315121334244454334134131423334300 081211530673544434435334442422233434231232224111122213 08121153067353222234222443434443134444434223431444444402 081222330971145512455215551512345435151552114211111114 08122233097111135132115215143243245555342115241433245405 081232310672144442353324442214334235341443234111211145 08123231067214234241214424245244444344412114242444215322 081242530672245512355224551414335425251553215211111123 08124253067223135133213315233343245455333135151535445404 081251210662144532343411443413345324343531133121121122 08125121066215434343224333334342234555135113222213243302 081262430572145521455224442412245415241431114111111112 08126243057213134122214124131352134445224114141414134400 081272430652144522145223442411544434241531113111111113 08127243065213154232115324242444132454424114231423234300 081281310682034324445234433412244424341432114211222223 08128131068203223132114224323444144454434135241514324407 081292330772544540535333442322244435141442115111131433 08129233077254113132414154432333143455443414541354233513 081301330473534443444334343423344323342543223221111134 08130133047352134143223234332334244444322224242323344408 091311210643544542244244452412444444241542225121111214 09131121064354244252215225444443244444524134251323244401 091321210343144432344323444422344424242542224111122223 09132121034314233242224224233443234444424234232224333304 091331310142544423355235554324344445541543214111222454 09133131014255434244214444444442244444424444442454554502 091341210545144543244333435533444324234442325231131111 09134121054514244242244213455233223345515144151115155515 091352210643144432244324452312444334242533224221121123 09135221064315435243424324234244233444444224241433254405 
091361210643122412344233441412544424241532214111111212 09136121064314423253524314335443245443514224241412354405 091371210643155211343234432412355424241333224132312243 09137121064314135242313234244443255534525224141334135502 091381210642144313245124432412424425241522115121111233 09138121064215144251114244234444245544525144352214255505 091391211044554541344325551412445414141531114111111111 09139121104455225151014144554554144544514115141413234400 091401210444533443444333434234244434231421124111111111 09140121044454132233413443532444322445325113331525534306 091412430443143422355222451433445324242443224232222233 09141243044313234233234334233233323353423234232424233309 091421210443524433233324445425413243232552233331131243 09142121044354232155223432545244232344542245432425553111 091431210443524322144323354524415233322434414141132443 09143121044351253345545454443225423255552435332435442333 091441210522145312145114532412545425241552215121111133 09144121052215153222014335213454245435544114231533335503 091451210642144412255314452411444415241532124111111114 09145121064214244123112115144344234555445115341424423502 091461210343534423544244333423134414241442214222311142 09146121034354224242214424245343234444434144231244455408 091471210652144422244224443312444424241542224321513223 09147121065214144242214234334443244444424124241324244402 091481310463134443155434444534525525354554114111121113 09148131046315455435115553333555345355313334141314154423 091491310253144552343224453411344504341531134111122133 09149131025315123233425444322443344454335313242414343305 091501210454534513245323351511553524231521113111111111 09150121045452252223113355313533255453314213141513233403 091512330451545554155235442421534325443453114111121134 09151233045155144121135325132344234344443215231433523408 091521210464535204154145523434533325335453115311310354 09152121046451152355514443525141545355153134451345545215 091531430453155514345335453523344535352331135111111141 09153143045315332111515325311545155555234315351434345505 091541230454533433333344345422454424332442113211111111 09154123045454145132215344422345255545535215241314434402 091551210464535544154114453513545534241552144231113433 09155121046453453553445555414435555453434324341414444501 091562310260143344243334433423434434332442224222233234 09156231026014433242424243344443333444224234232324354406 101572310662144512344124552512444324141541115111111225 10157231066214134251115114245333245454534114141214235300 101580310662144222245244413424434425242343214122212215 
10158031066214254142214424244444244214214145241544324411 101592430661244422244314442322434325251442224111111124 10159243066124434243214224334343234444423224241324234309 101602430062054532544123452412244534341541125111122234 10160243006205125341314344344550154454525244151423135402 101612330651144231254245412311444415251141114114411143 10161233065113145132215524232443234424324144141444134416 101622210661244412254224442322434414241432124211111113 10162221066123234243112334234343334444513224231334234411 101632310652544422244324441412444314141432124111111222 10163231065254243132234324342343144444334224241434323400 101642410662144325344323323424223425133451114111223223 10164241066212322144214523444452233245423135432233545337 101652430163545501155315451513555334151542213111111113 10165243016353355133025115133345135555514225151514443510 101662420662145512355122424412344425351443114111111112 10166242066214134142114224114444144453515525141523434512 101672220651524313234124433334424324233553225221111255 10167222065151113255114433345333135334531124341421525312 101681540661144312155234332312444415241442114111121114 10168154066115334242114434244444144445524245141314134402 111692310752144422554322424322124425242532215122223233 11169231075213414133224424243444144344323255142434223316 111702340652145443254443542311445434451531134111221123 11170234065214244244214424144432345554524214151225144401 111712330663144422234223442422434424242541124221121234 11171233066313243243214224244453234443424224241424444406 111722330652244423144224431313544414241543114221111224 11172233065224254242113324245554144454524124241423344303 111732330153544522444124442322344414141241114111111223 11173233015353234233214214142445125554513115151424225507 111742310153544532344223452512344334241541134111111111 11174231015353134141115314233344234454314114141513235304 111751310653255553354224551411445525151531114111111113 11175131065321114142154134144442255555315115141335153506 111762530672544422344124443413334324241543225211111114 11176253067253234222214214245343144455333224241424235405 111772430651234522344214442414334334242434314121121233 11177243065122233243213224244232144355423235251424334409 111782310653245512254414454414445415452533124121121141 11178231065323444134114214143342145555343214151224255516 111792330652034423244224442322444424341542224221121224 11179233065205253234324334242334344344344214332424434417 111801310652544545532433433344223424332432244342222333 11180131065253253244314233334442344444424244342233333319 
111812330652153342151323324122524423241431143141221124 11181233065214444452415554454441553353425143324253135320 111822430652144512344224443412344435141432114111121224 11182243065214234242014224224444244444424124241424244405 111831321052044422244324442422434424242543223212222223 11183132105204333244224324233444144444324224231424333404 111841430662155434144113544511534515141241114111131413 11184143066213153143114133421344143455514115141413344404 111851330652545541254215542313425415252543134221111141 11185133065254255353213244233442135454514144241114335307 111862530651245512355425442512455415151434215115111124 11186253065122245143125215134445145455533135141515214501 111871330652144541154113443311444425141551134211122234 11187133065215144242114324233455244455534125141433235500 111882340662134522245314442412444424241532224111121213 11188234066214244222114224231444144554424214241514245402 121891410882545411254114542411444415141541115111111123 12189141088254144141114214333444144444334114141424135502 121902330661544422344213443322334324232553224221121245 12190233066153234243255323344343434344533234232432245412 121911330662545512255234451511555425241452224112111114 12191133066255235252114115243351144555525225141024334401 121922430661144522444123442312334425341454215111111125 12192243066115214152115423244354134455534214131443155404 121932330652144512155214451515555515151541114115111132 12193233065213345343115444333444444454514135121544442404 121941410661044322244224442424444224242444224222221224 12194141066104224242214444234244344344444244232344224401 121952410671544511544123443511214335151541114211111125 12195241067153115252212314244344143544513114131423145404 121962430661145312244234432312444225241432214112221113 12196243066112134234114344233244244444333124241434124413 121972530662443311354315444412355414351441114111111134 12197253066245415111414555144343354455534114141424144402 121982530661544333344324432423344224242444424222223223 12198253066154234232224324333444233344334224242434234403 121992440662114323345444424343324324234332113212222123 12199244066211332255213344233243254454322115332543243405 122002330662544422444224442412344425241542114211121224 12200233066253234232454244422444244454223224241524224400 122012330662144442144224442312544425242432224211111114 12201233066214234244214324233344344444443224142424244307 122022330162432332553454444233113223452152254123121154 12202233016241412442554323222141543211553324133134252128 122032330462143521555213451512145514252542114211111111 
12203233046215114132313433331543244444413224231335243409 122041310762245441155215541411554414141431124211111112 12204131076224344231114325211445255445315224241515214501 132052430143545512355124452511354415351332214111121112 13205243014353135121115313131355143454334115451534434502 132062210632543442244324442312434334341543223111231244 13206221063255333242424234243242233444344224232223244411 132072210644544524455113441311144134141531114111111111 13207221064453113142114144144343144444313124131313342405 132082210644534423444324442422244334331553114111121223 13208221064452343244224324334332244445423124231334244307 132091220943034332244434432322444434241332224224422233 13209122094303334243233234433443243434423234242333234209 132102210643045421444224442412244424241332224222222223 13210221064303224242224224223344234445334244231424234400 132112210643535333544224412145124134332155223133323245 13211221064351414242312544254133244215342244221144354333 132122540642144432244224442312444325251532315111111124 13212254064213124242224224243444244444525124241534133202 132132330642244414544324442411244515241552114111111124 13213233064222115554115314145554143453513115131333245501 132141330644244432553424233214223324442453334332333344 13214133064423224242434433334343232344435324331133244230 132152210643535522445334453412245424342432114111121123 13215221064354323243234434344454233455424234231423242413 132162210642545511355114451411454515151543114111111111 13216221064253124143114324233443155555425134141334245504 132172430642545511355215551311355415151531114111111111 13217243064253135131115411111555155555335115151515111502 132182210642233333544323333322244244242342334223322222 13218221064223224242222424244331244444444244242244334202 142191330651244312255434422212445325241532113111211112 14219133065122234143213425123333145555423115141424244404 142201330351544522244224442412555424251422224211121123 14220133035154244243215524233443244445434224242425344519 142211230650244412255424451512455425251521114111111123 14221123065024143143112115144343145555425215141435244501 142222310454544442244224442422444424242432224222221433 14222231045453244233224234333444244443424224242334233407 142231210653544523254234434322434325231542215111121223 14223121065352343253414454333334244344524234421313543420 142241430654245413354325342411344515141433113111111112 14224143065425344132444334234554234444514215431534233505 142251310262145502154324451512434415551552114111112133 14225131026213155133115154424354255554534114151314224403 
142262430653555415355114341412345415151551114111111134 14226243065353155151115115135455145555515115141524135404 142272330451545512155115551511555515151541114111121114 14227233045155255142115114143443144555424115141414245402 142281410652534432144314441511455424141531124111111113 14228141065254244252214114244444245555234124141525144301 142291530651145522244223552411534515141131114111121122 14229153065114244143114144324553134545514114141314235501 142301310450434343244333343443443434433434343222343434 14230131045043344434234444423334333334433253332343423304 142312330651544513144114543411544425241531115111111112 14231233065154155142115415434443145454534115241324441400 142321210152154511155115551511555515151521115111111111 14232121015215155151115135114533155555515115151415155502 142332330662133453243224442412444424141552114111111144 14233233066214244252414324432553455454524214351314344302 142341310150544424454243535334313234231444435324423334 14234131015053134344312443334243232254523353452445255216 1423513104535344433332333434333334333343422222222232333 14235131045353432333433233333332333333323324332233433311 142362310453544524344324352412354433241542124121121123 14236231045354244231435514244331233444324313232325243313 142371310662144522244234552511434535241542114111111112 14237131066215144153115115234554155554424125251413235503 1423823104525344551433234433233535533442442132121121234 14238231045251342242212244331241322325435113221135454415 142391310451434513334233451412353323151552115311111443 14239131045144144123215414243233333354224113231332554408 


\section{REFERENCE LIST}




\section{REFERENCE LIST}

Abel, M. H. (1996). Self-esteem: Moderator or mediator between perceived stress and expectancy of success? Psychological Reports, 79(2), 635-641.

Abraham, K. \& Jones, E. (1979). Selected papers of Karl Ahraham. M.D.: With an introductory memoir (D. Bryan \& A. Strachey, Trans.). New York: Brunner/Mazel (Original work published 1927)

Abramson, L. Y., Metalsky, G. I., \& Alloy, L. B. (1989). The hopelessness theory of depression: Does the research test the theory? In L. Y. Abramson (Ed.), Social cognution and clinical psychology: A synthesis (pp. 33-65). New York: Guilford Press

Abramson, L. Y., Seligman, M. E. P., \& Teasdale, J. D. (1978). Leamed helplessness in humans: Critique and reformulation. Journal of Abnormal Psychology. 87(1), 49-74.

Abrahamson, D. J., Hornyak, L. M., \& Rehm, L. P. (1998). How psychotherapy helps people recover from depression. American Psychological Associanion Help(enter [On-line]. Available: apa.org, psychologists section, online brochures.

Affsprung, E. H. (1998). Assessing for a history of serious depression among first-year college students. Journal of ( ollege Student Psychotherapy. I2(3), 61-65.

Alden, L. E., Bieling, P. J., \& Meleshko, K. G. A. (1995). An interpersonal comparison of depression and social anxiety. In K. D. Craig \& K. S. Dobson (Eds.), Anxiety and depression in adults and chldren (pp. 57-81). Thousand Oaks, CA: Sage.

Alfeld-Liro, C., \& Sigelman, C. K. (1998). Sex differences in self-concept and symptoms of depression during the transition to college. Journal of Youth and Adolescence. $27(2), 219-244$.

Alford, B. A., \& Beck, A. T. (1997). The integrative power of cognitive therapy. New York: Guilford Press.

Allen, B. P. (1990). Personality, social and biological perspectives on personal adjusıment. Pacific Grove, CA: Brooks/Cole. 
Alloy, L. B., \& Abramson, L. Y. (1982). Leamed helplessness, depression, and the illusion of control Journal of Personality and Social Psychology. +2(6), 1114-1126.

American Psychiatric Association. (1994). Diagnostic and statistical manual of mental disorders ( $4^{\text {th }}$ ed. $)$. Washington, DC: Author.

American Psychiatric Association. (2000). Dlagnostic and statıstical manual of mental disorders ( $4^{\text {th }}$ ed., Text Revision). Washington, DC: Author.

Anderson, D. Y., \& Hayes, C. L. (1996). Gender, identity, and self-esteem: A new look at adult development. New York: Springer.

Anderson, E. C. (1985). Forces influencing students' persistence and achievement. In U. Delworth \& G. R. Hanson (Eds.), Increasing student retention: Effective programs and practices for reducing the dropout rate (pp. 44-61). San Francisco: Jossey-Bass.

Anderson, K. M. (1992). Self-complexity and self-esteem in middle childhood. In R. P. Lipka \& T. M. Brinthaupt (Eds.), Self-perspectives across the lifespan (pp. 11-52). Albany, NY: State University of New York Press.

Andersen. S. M.. Reznik, I. \& Chen. S. (1997). The self in relation to others: Cognitive and motivational underpinnings. In J. G. Snodgrass \& R. L. Thompson (Eds.), The self across psychology: Self-Recognition, self-awareness, and the self concept (Vol. 818: pp. 233-275). New York: New York Academy of Sciences.

Angst, J., \& Merikangas, K. (1997). The depressive spectrum: Diagnostic classification and course. Journal of Affective Disorders, $+5(1-2), 31-39$.

Archambault, F. X.. Jr. (1992). Review of the Tennessee Self-Concept Scale [Revised]. In J. J. Kramer \& J. C. Conoley (Eds.), The eleventh mental measurements yearbooks (pp. 931-933). Lincoln, NE: Buros Institute of Mental Measurements.

Archer, S. L. (1982). The lower age boundaries of identity development. Child Development. 53(6), 1551-1556.

Armor, D. A., \& Taylor, S. E. (1998). Situated optimism: Specific outcome expectancies and self-regulation. In M. P. Zanna (Ed.), Advances in experimental social psychologv (Vol. 30, pp. 309-379). New York: Academic Press.

Arnett, J. J. (2000). Emerging adulthood: A theory of development from the late teens through the twenties. American Psychologist, 55(5), 469-480. 
Arnstein. R. L. (1979). The adolescent identity crisis revisited. Adolescent Psychutrn: $7,71-84$.

Arnstein, R. L. (1980). The student, the family, the university, and transition to adulthood. Adolescent Psychiarn. 8, 160-172.

Amstein, R. L. (1984a). Developmental issues for college students. Psychiatric Annals, It(9), 647-65I

Arnstein, R. L. (1984b). Young adulthood: Stages of maturity. In D. Offer \& M. Sabshin (Ed.), Normality and the life cycle: A critical integration (pp. 108-144). New York: Basic Books.

Arnstein R. L. (1989). Chronically disturbed students. In P. A. Grayson \& K. Cauley (Eds.), College psychotherupy (pp. 29-47). New York: Guilford Press.

Astin, A. W. (1993). What matters in college?: Four critical years revisited. San Francisco: Jossey-Bass.

Bachman, J. G., O’Malley, P. M., \& Johnston, J. (1978). Youth in transition: Adolescence 10 adulthood-( 'hange and stability in the lives of voung men (Vol. 4). Ann Arbor. MI: Institute for Social Research.

Backman, C. W., Secord, P. F., \& Pierce, J. R. (1982). Resistance to change in the self-concept as a function of consensus among significant others. In $\mathrm{M}$. Rosenberg \& H. B. Kaplan (Eds.), Social psychology of the self-concept (pp. 179-186). Arlington Heights, IL: Harlan Davidson.

Bacon, J. F. (1993). The relationships among obesity, self concept and depression in female registered nursing students. Unpublished master's thesis, Valdosta State College.

Bailey, J. P. (1997). Loss of self-esteem prior to the onset of depression (Doctoral dissertation, The University of Texas at Austin, 1997). Dissertation Abstracts International, 59, 0409.

Bandura, A. (1982). The self and mechanisms of agency. In J. Suls (Ed.), Psychological perspectives on the self (Vol. 1, pp. 3-39). Hillsdale, NJ: Lawrence Erlbaum.

Barkham, M., Rees, A., Stiles, W. B., Shapiro, D. A., Hardy, G. E., \& Reynolds, S. (1996). Dose-effect relations in time-limited psychotherapy for depression. Journal of Consulting and Clinical Psychology. 6+(5), 927-935. 
Barnes, G. E. (1993). Depression in general practice attenders. In P. Cappeliez \& R. J. Flynn (Eds.), Depression and the social environment: Research and intervention with neglected populations (pp. 150-184). Montreal: McGill-Queen`s University Press.

Barnett, P. A., \& Gotlib, I. H. (1988). Psychosocial functioning and depression: Distinguishing among antecedents, concomitants, and consequences. Psichological Bulletın, $10+(1), 97-126$.

Baron, P., \& Campbell, T. L. (1993). Gender differences in the expression of depressive symptoms in middle adolescents: An extension of earlier findings. Adolescence. $28(112), 903-911$.

Baron, P., \& Perron, L. M. (1986). Sex differences in the Beck Depression Inventory scores of adolescents. Journal of Youth and Adolescence, 15(2), 165-171.

Basch, M. F. (1983). The concept of "self": An operational definition. In B. Lee \& G. G. Noam (Eds.), Developmental approaches to the self (pp. 7-58). New York: Plenum.

Baumeister, R. F. (1993). Understanding the inner nature of low self-esteem: Uncertain, fragile, protective, and conflicted. In R. F. Baumeister (Ed.), Self-esteem: The puzzle of low self-regard (pp. 201-218). New York: Plenum.

Beatty, S., \& Hewitt, J. (1995). Affective reactions to failure as a function of effort and depression. Perceptual and Motor Skills, 80(1), 33-34.

Beck, A. T. (1967). Depression: ('linical, experimental, and theoretical aspects. New York: Harper \& Row.

Beck, A. T. (1972). Measuring depression: The depression inventory. In T. A. Williams, M. M. Katz, \& J. A. Shields (Eds.), Recent advances in the psychobiology of the depressive illnesses (pp. 299-302). Washington, DC: U. S. Government Printing Office.

Beck, A. T. (1973). The diagnosis and management of depression. Philadelphia: University of Pennsylvania Press.

Beck, A. T. (1976). Cognutive therapy and the emotional disorders. New York: International Universities Press.

Beck, A. T. (1991). Cognitive therapy: A 30-year retrospective. American Psychologıst, $+6(4), 368-375$. 
Beck. A. T., Freeman, A., \& Associates. (1990). Cognutive therapy of personality disorders. New York: Guilford.

Beck, A. T., Rush. A. J., Shaw, B. F., \& Emery, G. (1979). Cognituve therapy of depression. New York: Guilford Press.

Beck, A. T., Steer, R. A., Ball, R., \& Ranieri, W. F. (1996). Comparison of Beck depression inventories-IA and -II in psychiatric outpatients. Journal of Personality Assessment, 67(3), 588-597.

Beck, A. T., Steer, R. A., \& Brown, G. K. (1996). Manual for the Beck Depression Inventory-II ( $2^{\text {nd }}$ ed. ). San Antonio, TX: Psychological Corporation.

Beck, A. T., Steer, R. A., \& Garbin, M. G. (1988). Psychometric properties of the Beck Depression Inventory: Twenty-five years of evaluation. Clinical Psychologv Review, 8(1) 77-100.

Beck, A. T., Ward, C. H., Mendelson, M., Mock, J., \& Erbaugh, J. (1961). An inventory for measuring depression. Archives of General Psychiarn, 4, 561-571.

Bednar, R. L., Wells, M. G., \& Peterson, S. R. (1989). Self-esteem: Paradoxes and innovations in clinical theon' and practice. Washington. DC: American Psychological Association.

Bee, H. L. (1987). The journey of adulthood. New York: Macmillan.

Beeber, L. S. (1999). Testing an explanatory model of the development of depressive symptoms in young women during a life transition. The Journal of American (ollege Health. 47(5), 227-234.

Bemporad, J. R. (1995). In E. E. Beckham \& W. R. Leber (Eds.), Handbook of depression ( $2^{\text {nd }}$ ed., pp. 391-403). New York: Guilford.

Berndt, T. J., \& Burgy, L. (1996). Social self-concept. In B. A. Bracken (Ed.), Handhook of self-concept: Developmental, social, and clinical consideratıons (pp. 171-209). New York: John Wiley \& Sons.

Bertoia, A. E. (1992). ('oping with depression by college students. Unpublished master's thesis, State University of New York College at Plattsburgh.

Berzonsky, M. D., \& Kuk, L. S. (2000). Identity status, identity processing style, and the transition to university. Journal of Adolescent Research [On-line], 15(1), 81-98. Available: Academic Search Elite. 
Bimie-Lefcovitch, S. J. (1996). Adaptation during the transition from high school to university: An examination of selected person, environment and transition perception variables (Doctoral dissertation, Wilfrid Laurier University [Canada]. 1996/1997). Dissertation Abstracts International. $58,3435$.

Birtchnell, J. A. (1996). The management and resolution of dependency in the depressed client. In J. Lonsdale (Project Ed.), The Hatherleigh guide to managing depression (pp. 179-189). New York: Hatherleigh Press.

Bishop, S. L., Walling, D. P., \& Walker, B. A. (1997). The emperor's clothes: Assessing the validity of scores on the Tennessee Self-Concept Scale. Educational and Psychological Measurement, 57(1), 150-163.

Blaine, B., \& Crocker, J. (1993). Self-esteem and self-serving biases in reactions to positive and negative events: An integrative review. In R. F. Baumeister (Ed.), Self-esteem: The puz=le of low self-regard (pp. 55-85). New York: Plenum.

Blaine, B. E., \& Trivedi, P. (1998). Religious belief and the self-concept: Evaluating the implications for psychological adjustment. Personaliy and Social Psychology Bulletin [On-line], 2+(10), 1040-1052. Available: Academic Search Elite.

Blatt. S. J. (1995). The destructiveness of perfectionism: Implications for the treatment of depression. American Psychologist, 50(12), 1003-1020.

Blatt, S. J., \& Bers, S. A. (1993). The sense of self in depression: A psychodynamic perspective. In Z. V. Segal \& S. J. Blatt (Eds.), The self in emotional distress: (ognimve and psychodynamic perspectives (pp. 171-210). New York: Guilford

Blinne, W. R., \& Johnston, J. A. (1998). Assessing the relationships between vocational identity, academic achievement, and persistence in college. Journal of (ollege Student l.evelopment, 39(6), 569-576.

Blocher. D. H.. \& Rapoza, R. S. (1981). Professional and vocational preparation. In A.W. Chickering \& Associates (Eds.), The modern American college: Responding to the new realities of diverse students and a changing society (pp. 212-231). San Francisco: Jossey-Bass.

Blustein, D. L., \& Palladino, D. E. (1991). Self and identity in late adolescence: A theoretical and empirical integration. Journal of Adolescent Research, 6(4), $437-453$.

Bolton, B. (1976). Factorial validity of the Tennessee Self-Concept Scale. Psychological Reports, 39, 947-954. 
Bosse, J. J., Croghan, L. M., Greenstein, M. B., Katz, N. W., Oliver, J. M., Powell, D. A., et al. (1975). Frequency of depression in the freshman year as measured in a random sample by a retrospective version of the Beck Depression Inventory. Journal of Consulting and Clinical Psychologv, 43(5), 746-747.

Bosson, J. K., \& Swann, W. B., Jr. (1999). Self-Liking, self-competence, and the quest for self-verification. Personality and Social Psychology Bulletin [On-line], 25(10), 1230-1244. Available: Academic Search Elite.

Bowen, W. G. (1997). No limits. In R. G. Ehrenberg (Ed.), The American university: National treasure or endangered species (pp. 18-42). Ithaca, NY: Cornell University Press.

Boyle, E. S., \& Larson, P. C. (1981). Factor structure of the Tennessee Self-Concept Scale for an institutionalized, disabled population. Perceptual and Motor Skills, 52, 575-582.

Bracken. B. A. (1996). Clinical applications of a context-dependent, multidimensional model of self-concept. In B. A. Bracken (Ed.), Handbook of self-concept: Developmental, social, and clinical considerations (pp. 463-504). New York: John Wiley \& Sons.

Bracken, B. A., \& Mills, B. C. (1994). School counselors' assessment of self-concept: A comprehensive review of 10 instruments. The School (ounselor, $42,14-31$.

Branden, N. (1993). The art of self-discovery. New York: Bantam.

Branden, N. (1994). The six pillars of self-esteem. New York: Bantam.

Brandtstadler, J., \& Renner, G. (1992). Coping with discrepancies between aspirations and achievements in adult development: A dual-process model. In L. Montade, S. H. Filipp, \& M. J. Lerner (Eds.), Life crises and experiences of loss in adulthood (pp. 301-320). Hillsdale, NJ: Lawrence Erlbaum.

Bray, N. J., Braxton, J. M., \& Sullivan, A. S. (1999). The influence of stress-related coping strategies in college students' departure decisions. Journal of (ollege Student Development, $40(6), 645-657$.

Bricker, D., Young, J. E., \& Flanagan, C. M. (1993). In K. T. Kuehlwein \& H. Rosen (Eds.), Cognitive therapies in action: Evolving innovative practice (pp. 88-125). San Francisco: Jossey-Bass. 
Broughton, J. M. (1983). The cognitive-developmental theory of adolescent self and identity. In B. Lee \& G. G. Noam (Eds.), Developmental approaches to the self (pp. 215-268). New York: Plenum Press.

Brown, J. D. (1993a). Motivational conflict and the self: The double-bind of low selfesteem. In R. F. Baumeister (Ed.), Self-esteem: The puz=le of low self-regard (pp. 117-130). New York: Plenum Press.

Brown, J. D. (1993b). Self-esteem and self-evaluation: Feeling is believing. In J. Suls (Ed.), Psychological perspectives on the self: The self in social perspective (Vol. 4, pp. 27-58). Hillsdale, NJ: Lawrence Erlbaum.

Brown, G. W., Bifulco, A., \& Andrews, B. (1990a). Self-esteem and depression: III. Aetiological issues. Social Psychiatn and Psychiatric Epidemiologn: 25(5), 235-243.

Brown, G. W., Bifulco, A., \& Andrews, B. (1990b). Self-esteem and depression: IV. Effect on course and recovery. Social Psychiatry and Psychiatric Epidemioiogi: 25(5), 244-249.

Brown, G. W., \& Harris, T. (1978). Social orıgins of depression: A study of psychiatric disorder in women ( $1^{\text {st }}$ American ed. ). New York: Free Press.

Bruner, J. (1997). A narrative model of self-construction. In J. G. Snodgrass \& R. L. Thompson (Eds.). The self across psychologn': Self-Recognition, self-awareness, and the self concept (Vol. 818; pp. 145-161). New York: New York Academy of Sciences.

Buckman, S. (1988). Depression among college students. Unpublished master's thesis, Northem Arizona University.

Bumberry, W., Oliver, J. M.. \& McClure, J. N. (1978). Validation of the Beck Depression Inventony in a university population using psychiatric estimate as the criterion. .Journal of (onsulting and Clinical Psychology, $46(1), 150-155$.

Burns, D. D. (1980). Feeling good: The new mood therapy: New York: Avon Books.

Burns, D. D. (1989). The feeling good handbook. New York: Plume.

Burns, R. B. (1979). The self concept in theory: measurement, development and hehaviour. London: Longman. 
Burns, O. D.. \& Beck, A. T. (1978). Cognitive behavior modification of mood disorders. In J. P. Foreyt \& D. P. Rathjen (Eds.), Cognitive behavior therapy (pp. 109-134). New York: Plenum Press.

Buros, O. K. (1972). The seventh mental measurements vearbook (Vol. 1, pp. 364-370). Highland Park, NJ: Gryphon Press.

Bush, S. I., Ballard, M. E., \& Fremouw, W. (1995). Attributional style, depressive features, and self-esteem: Adult children of alcoholic and nonalcoholic parents. Iournal of Youth and Adolescence, 2+(2), 177-185.

Byme, B. M. (1984). The general/academic self-concept nomological network: A review of construct validation research. Review of Educational Research. 5ł(3), 427-456.

Byrne, B. M. (1996a). Academic self-concept: Its structure, measurement, and relations to academic achievement. In B. A. Bracken (Ed.), Handbook of self-concept:

Developmental, social, and clinical considerations (pp. 287-316). New York: John Wiley \& Sons.

Byme, B. M. (1996b). Measuring self-concept across the life span: Issues and instrumentation. Washington, DC: American Psychological Association.

Byrne, B. M., \& Baron, P. (1993). The Beck Depression Inventory: Testing and crossvalidating a hierarchical factor structure for nonclinical adolescents. Measurement and Evaluation in Counseling and Development, 26(3), 164-178.

Byrne, B. M., Baron, P., \& Balev, J. (1998). The Beck Depression Inventory: A cross-validated test of second-order factorial structure for Bulgarian adolescents. Educational and Psychological Measurement, 58(2), 241-251.

Calhoun, G. B., Glaser. B. A., \& Bartolomucci, C. L. (2001). The juvenile counseling and assessment model and program: A conceptualization and intervention for juvenile delinquency. Journal of Counseling and Development, 79(2), 131-141.

Campbel., J. D., Chew. B., \& Scratchley, L. S. (1991). Cognitive and emotional reactions to daily events: The effects of self-esteem and self-complexity. Journal of Personalin, 59(3), 473-505.

Campbell, J. D., \& Lavellee, L. F. (1993). Who am I?: The role of self-concept confusion in understanding the behavior of people with low self-esteem. In R. F. Baumeister (Ed.), Self-esteem: The puz=le of low' self-regard (pp. 3-20). New York: Plenum Press. 
Cantor, P. C. (1990). Symptoms, prevention, and treatment of attempted suicide. In B. B. Wolman \& G. Stricker (Eds.), Depressive disorders: Facts, theuries, and treatment methods (pp. 189-202). New York: John Wiley \& Sons.

Cappeliez, P., \& Flynn, R. J. (1993). Implications for assessment, the understanding of social etiology, and intervention. In P. Cappeliez \& R. J. Flynn (Eds.), Depression and the soctal environment: Research and intervention with neglected populations (pp. 393-413). Montreal: McGill-Queen’s University Press.

Carver, C. S. (1998). Generalization, adverse events, and development of depressive symptoms. Journal of Personality, 66(4), 607-619.

Chamberlin, J. (2000). An historic meeting of the minds: The fathers of cognitive therapy and rational-emotive therapy exchanged banter at APA's 2000 Annual Convention. Monitor on Psychology, 31(9), 23.

Chan, D. W. (1995). Depressive symptoms and coping strategies among chinese adolescents in Hong Kong. Journal of Yourh and Adolescence, 24(3), 267-279.

Chang, E. C. (2000). Perfectionism as a predictor of positive and negative psychological outcomes: Examining a mediation model in younger and older adults. Journal of Counseling Psychologn: $f^{7}(1), 18-26$.

Chang, E. C., \& Rand. K. L. (2000). Perfectionism as a predictor of subsequent adjustment: Evident for a specific diathesis-stress mechanism among college students. Journal of (ounseling Psychology, f7(1), 129-137.

Chang, E. C., \& Strunk, D. R. (1999). Dysphoria: Relations to appraisals, coping, and adjustment. Journal of Counseling Psychology, +6(1), 99-108.

Cheek, J. M., \& Hogan, R. (1983). Self-concept, self-presentations, and moral judgements. In J. Suls \& A. G. Greenwald (Eds.), Psychological perspectives on the self (Vol. 2, pp. 249-273). Hillsdale. NJ: Lawrence Erlbaum.

Chickering, A. W., \& Havighurst, R. J. (1981). In A. W. Chickering \& Associates (Eds.), The modern american college: Responding to the new realities of diverse students and a changing society (pp. 16-50). San Francisco: Jossey-Bass.

Christensen, K. J. (1981). Description and evaluation in the measurement of self-esteem (Doctoral dissertation, University of Minnesota, 1981). Dissertation Abstracts International, 42, 0130. 
Clark, D. A.. \& Beck A. T. (with Alford, B. A.). (1999). Sctentific foundanions of cognutive theory and therapy of depression. New York: John Wiley \& Sons.

Clark, D. A., Beck, A. T., \& Stewart, B. (1990). Cognitive specificity and positive-negative affectivity: Complementary or contradictory views on anxiety and depression. . Journal of Abnormal Psychologv. 99(2), 148-155.

Clark, D. A., Crewdson, N., \& Purdon, C. (1998). No worries, no cares: An investigation into self-reported "nondistress" in college students. Cognittve Therapy' and Research, 22(3), 209-224.

Clarke, G., Lewinsohn, P., \& Hops, H. (1990). Leader's manual for adolescent groups: Adolescent coping with depression course. Eugene, OR: Castalia.

Cohen, J. (1969). Statıstical power analysis for the behavioral sciences. New York: Academic Press.

Conway, M., \& Giannopoulos, C. (1992). Self-esteem and specificity in self-focused attention. The Journal of Social Psycholog. 133(1), 121-123.

Cooper, S. H. (1993). The self construct in psychoanalytic theory: A comparative view. In Z. V. Segal \& S. J. Blatt (Eds.). The self in emotional distress: (ognuttve and psychodynamic perspectıves (pp. 41-67). New York: Guilford Press.

Coopersmith, S. (1989). Manual for the SEI: Self-esteem inventories. Palo Alto, CA: Consulting Psychologists Press.

Coopersmith, S. (1990). The antecedents of s-e (Rev. ed.). Palto Alto, CA: Consulting Psychologists Press.

Copeland, M. E. (1996). Alleviating symptoms of depression. In J. Lonsdale (Project Ed.), The Hatherleigh guide to managing depression (pp. 243-264). New York: Hatherleigh Press.

Corr, P. J., \& Gray, J. A. (1996). Structure and validity of the attributional style questionnaire: A cross-sample comparison. Journal of Psvchology Interdisciplinan \& Applied [On-line], 130(6), 645-658. Available: Academic Search Elite.

Cote, J. E., \& Levine, C. (1988). The relationship between ego identity status and Erikson's notions of institutionalized moratoria, value orientation stage, and ego dominance. Journal of Youth and Adolescence, 17(1), 81-99. 
Craig, K. D., \& Dobson, K. S. (1995). Introduction: Perspectives on anxiety and depression in adults and children. In K. D. Craig \& K. S. Dobson (Eds.), Anxiery and depression in adults and children (pp. xi-xix). Thousand Oaks, CA: Sage.

Craighead, L. W., Craighead, W. E., Kazdin, A. L., \& Mahoney, M. J. (1994). Principles of behavior and cognitive change. In L. W. Craighead, W. E. Craighead, A. L. Kazdin, $\&$ M. J. Mahoney (Eds.), Cognitive and hehavioral interventions: An empirical approach to mental health problems (pp. 29-46). Boston: Allyn and Bacon.

Crain, R. M. (1996). The influence of age, race, and gender on child and adolescent multidimensional self-concept. In B. A. Bracken (Ed.), Handbook of self-concept: Developmental, social, and clinical considerations (pp. 395-420). New York: John Wiley \& Sons.

Crider, A. B., Goethals, G. R., Kavanaugh, R. D., \& Solomon, P. R. (1989). Psychologv $\left(3^{\text {th }}\right.$ ed. ). Glenview, IL: Scott, Foresman and Company.

Culbertson, F. M. (1997). Depression and gender: An international review. American Psychologist, 52(1), 25-31.

Curtis, R. (1990). Mood disorders and self-defeating behaviors. In B. B. Wolman \& G. Stricker (Eds.). Depressive disorders: Facts, theories, and treatment methods (pp. 162-188). New York: John Wiley \& Sons.

Daughtry, D., \& Kunkel, M. A. (1993). Experience of depression in college students: A concept map. Journal of Counseling Psychology, $40(3), 316-323$.

Davison, G. C., \& Neale, J. M. (1994). Abnormal psychology' (6 ${ }^{\text {th }}$ ed. ). New York: John Wiley $\&$ Sons.

Dean, D., \& Ensel, W. M. (1983). The epidemiology of depression in young adults: The centrality of social support. Journal of Psychatric Treatment \& Evaluation. $5(2-3), 195-207$

Dean, P. J., \& Range, L. M. (1996). The escape theory of suicide and perfectionism in college students. Death Studies, 20(4), 415-424.

DeAngelis, T. (2001). Surviving a patient's suicide. Monitor on Psychology, 32(10), 70-73.

Demo, D. H. (1985). The measurement of self-esteem: Refining our methods. Journal of Personality and Social Psychology, $48,1490-1502$. 
Demo, D. H., \& Savin-Williams, R. C. (1992). Self-concept stability and change during adolescence. In R. P. Lipka \& T. M. Brinthaupt (Eds.), Self-perspectives across the lifespan (pp. 116-150). Albany, NY: State University of New York Press.

Dixon, W. A. (2000). Problem-solving appraisal and depression: Evidence for a recovery model. Journal of (ounseling and Development, $78(1), 87-91$.

Dixon, W. A., \& Reid, J. K. (2000). Positive life events as a moderator of stress-related depressive symptoms. Journal of Counseling and Development, 78(3), 343-347.

Dornbusch, S. M. (2000). Transitions from adolescence: A discussion of seven articles. Journal of Adolescent Research [On-line], 15(1), 173-177. Available: Academic Search Elite.

Douvan, E. (1981). Capacity for intimacy. In A. W. Chickering \& Associates (Eds.), The modern american college: Responding to the new realitles of diverse siudents and a changing society (pp. 191-211). San Francisco: Jossey-Bass.

Dukes, R. L., \& Martinez, R. (1994). The impact of ethgender on self-esteem among adolescents. Adolescence, 29(113), 105-116.

Dunner, D. L. (1997). ('urrent psichutric therapy' I/ (2 $2^{\text {nd }}$ ed.). Philadelphia: W. B. Saunders.

Dunning, D. (1993). Words to live by: The self and definitions of social concepts and categories. In J. Suls (Ed.), Psychological perspectives on the self: The self in social perspective (Vol. 4, pp. 99-126). Hillsdale, NJ: Lawrence Erlbaum.

Dunphy, L., Miller. T. E., Woodruff, T., \& Nelson, J. E. (1987). Exemplary retention strategies for the freshman year. In M. M. Stodt \& W. M. Klepper (Eds.), Increasing retention: Academic and student affairs administrators in partnership (Vol. 15. No. 4, pp. 39-60). San Francisco: Jossey-Bass.

Duprez. C. J. (1987). Levels of depression and self esteem in adult children of alcoholics and adult children of non-alcoholics (Doctoral dissertation, United States International University, 1987). Dissertation Abstracts International. $\$ 8,1800$.

Dusek, J. B., \& Flaherty, J. F. (1981). The development of the self-concept during the adolescent years (Vol. 46, No. 4). Chicago: The University of Chicago Press.

Dyk, P. A., \& Adams, G. R. (1987). The association between identity development and intimacy during adolescence: A theoretical treatise. Journal of Adolescent Research, 2(3), 223-235. 
Eaves, G., \& Rush, A. J. (1984). Cognitive patterns in symptomatic and remitted unipolar major depression. Journal of Ahnormal Psychology: 93(1), 31-40.

Eisenstadt. S. N. (1965). Archetypal patterns of youth. In E. H. Erikson (Ed.). The challenge of youth (pp. 29-50). Garden City, NY: Anchor Books.

Elliott, G. C. (1986). Self-esteem and self-consistency: A theoretical and empirical link between two primary motivations. Social Psychology Quarterly, +9(3), 207-218.

Endler, N. S., Rutherford, A., \& Denisoff, E. (1999). Beck Depression Inventory: Exploring its dimensionality in a nonclinical population. Journal of (linical Psychology, 55(10), 1307-1312.

Enelow, A. J. (1970). Overview and conclusion. Depression: Recognition and management. In A. J. Enelow (Ed.), Depression in medical practice (pp. 193-214).West Point, PA: Merck and Company.

Epstein. S. (1973). The self-concept revisited: Or a theory of a theory. American Psychologist, 28(1), 404-416.

Epstein, S. (1980). The self-concept: A review and the proposal of an integrated theory of personality. In E. Staub (Ed.), Personality: Basic aspects and current research (pp. 82-132). Englewood Cliffs, NJ: Prentice-Hall.

Epstein, R., \& Koerner, J. (1986). The self-concept and other daemons. In J. Suls \& A. G. Greenwald (Eds.), P'svchological perspectuve on the self (Vol. 3, pp. 27-53). Hillsdale, NJ: Lawrence Erlbaum.

Erikson. E. H. (1959). Identty and the life cycle (Vol. 1, No. 1, Monograph 1). New York: International Universities Press.

Erikson. E. H. (1963). ( hildhood and socien ( $2^{\text {nd }}$ ed.). New York: W. W. Nonton

Erikson, E. H. (1965). Youth: Fidelity and diversity. In E. H. Erikson (Ed.), The challenge of youth (pp. 1-28). Garden Ciry, NY: Anchor Books.

Erikson, E. H. (1968). Identıty: Youth and crisis. New York: W. W. Norton.

Erikson, E. H., \& Erikson, J. M. (1997). The life cycle completed (Extended version). New York: W. W. Norton. 
Ernst. C., Schmid. G.. \& Angst, J. (1992). The Zurich Study: XVI. Early antecedents of depression: A longitudinal prospective study on incidence in young adults. European Archives of Psychiarn and (linical Neuroscience, 2\$2(2), 142-151.

Evans, R. I. (1981). Dialogue with Erik Erikson: Reactions from Earnest Jones. New York: Praeger.

Feaster, H. T. (1996). A comparison of iraditional and nontraditional college students on the Beck Depression Inventory: Unpublished master's thesis, Emporia State University.

Feiring, C., \& Taska, L. S. (1996). Family self-concept: Ideas on its meaning. In B. A. Bracken (Ed.), Handbook of self-concept: Developmental, social, and clinical considerations (pp. 317-373). New York: John Wiley \& Sons.

Felix, C. L. (2000). The relationship between depression and academic performance in college students. Unpublished doctoral dissertation, Minnesota School of Professional Psychology.

Felson, R. B. (1993). The (somewhat) social self: How others affect self-appraisals. In J. Suls (Ed.), Psychological perspectives on the self: The self in social perspective (Vol. 4, pp. 1-26). Hillsdale, NJ: Lawrence Erlbaum.

Fennell, J. A. (1992). A study of the relationship hetween religious beliefs, self-concept and self-esteem. Unpublished master's thesis, Andrews University.

Fernald. P. S. (2000). Carl Rogers: Body-centered counselor. Journal of (ounseling and Development, $78(2), 172-179$.

Ferrari, M. (1998). Being and becoming self-aware. In M. D. Ferrari \& R. J. Stemberg (Eds.), Self-Awareness: Its nature and development (pp. 387-422). New York: Guilford Press.

Fiske, M., \& Chiriboga, D. A. (1990). ('hange and continuity in adult life. San Francisco: Jossey-Bass.

Fitts, W. H. (1965). Manual for Tennessee (I)epartment of Mental Health) Self ('oncept Scale. Nashville TN: Counselor Recordings and Tests.

Fitts, W. H. (1970). Interpersonal competence: The wheel model (Research Monograph No. 2). Nashville, TN: Dede Wallace Center. 
Fitts. W. H. (1972a). The self-concept and performance (Research Monograph No. 5). Nashville, TN: Dede Wallace Center.

Fitts, W. H. (1972b). The self-concept and hehavior: Overview and supplement (Research Monograph No. 7). Nashville, TN: Dede Wallace Center.

Fitts, W. H., Adams. J. L., Radford, G., Richard, W. C., Thomas, B. K.. Thomas, M. M. et al. (1971). The self-concept and self-actualization (Research Monograph No. 3). Nashville, TN: Dede Wallace Center.

Fitts, W. H., \& Hamner, W. T. (1969). The Self concept and delinquency (Research Monograph No. 1). Nashville, TN: Nashville Mental Health Center.

Fitts. W. H., \& Warren, W. L. (1996). Tennessee Self-Concept Scale (TSCS:2): Manual $\left(2^{\text {nd }}\right.$ ed. ). Los Angeles: Western Psychological Services.

Fleming, J. S., \& Courtney, B. E. (1984). The dimensionality of self-esteem: II. Hierarchical facet model for revised measurement scales. Journal of Personalıny and Social Psychology, +6(2), 404-421.

Flett, G. L., Vredenburg, K.. \& Krames, L. (1995). The stability of depressive symptoms in college students: An empirical demonstration of regression to the mean. Journal of Psychopathology and Behavuoral Assessment. 17(4), 403-415.

Flynn, R. J., \& Cappeliez, P. (1993). An integrative cognitive-environmental view of depression. In P. Cappeliez \& R. J. Flynn (Eds.), Depression and the soctal environment: Research and intervention with neglected populations (pp. 1-12). Montreal, Canada: McGill-Queen`s University Press.

Formanek, R., \& Gurian, A. (1987). Introduction. In R. Formanek \& A. Gurian (Eds.), Women and depression: A lifespan perspectlve (pp. xiii-xxi). New York: Springer.

Forrest, L. (1997). A comparative study of stressors among undergraduate students at Grand Valley State University (Michigan) (Doctoral dissertation. Andrews University, 1997). Dissertation Abstracts International, 58, 3018.

Foxhall. K. (2001). Adolescents aren't getting the help they need: Most adolescents who enter substance abuse treatment have psychological problems and many emerge from treatment with mental health challenges, a major study suggests. Monitor on Psychologv, 32(6), 56-58.

France, R., \& Robson, M. (1997). Cognutive hehavioural therapy in priman' cure: A practical guide. London: Jessica Kingsley. 
Freeman, A. A. (1993). Psychosocial approach for conceptualizing schematic development for cognitive therapy. In K. T. Kuehlwein \& H. Rosen (Eds.), Cognitive therapies in action: Evolving innovative practice (pp. 54-87). San Francisco: Jossey-Bass.

Freud, S. (1968). Mourning and Melancholia. In W. Gaylin (Ed.), The meaning of despair: Psychoanalytic contributions to the understanding of depression (pp. 50-69). New York: Science House.

Frey, D., \& Carlock, C. J. (1989). Enhancing self estecm (2 ${ }^{\text {nd }}$ ed. ). Muncie, IN: Accelerated Development.

Frydenberg, E. (1997). Adolescent coping: Theoretical and research perspectives. New York: Routledge.

Futral, C. (1980). The relationship of self-concept and selected demographic variables to students' perceptions of the university environment (Doctoral dissertation, University of Southern Mississippi, 1980). Dissertation Abstracts International, + l, 4577 .

Gaber, L. B. (1984). Structural dimensions in aged self-concept: A Tennessee Self Concept study. British Journal of Psychologi: 75(Part 2), 207-212.

Gaff, J. G., \& Gaff, S. S. (1981). Student-Faculty relationships. In A. W. Chickering \& Associates (Eds.), The modern American college: Responding to the new realitics of diverse students and a changing society (pp. 642-656). San Francisco: Jossey-Bass.

Gardner, O. S. (1992). Postsecondary education opportunities as perceived by Black high school seniors. In M. Lang \& C. A. Ford (Eds.), Sirategies for retaining minority students in higher education (pp. 54-63). Springfield, IL: Charles C. Thomas.

Gaylin, W. (1968). The meaning of despair. In W. Gaylin (Ed.), The meaning of despair: Psychoanalytic contributions to the understanding of depression (pp. 3-25). New York: Science House.

Gecas, V., \& Mortimer, J. T. (1987). Stability and change in the self-concept from adolescence to adulthood. In T. H. Honess \& K. Yardley (Eds.), Self and idenity:: Perspectives across the lifespan (pp. 265-286). New York: Routledge \& Kegan Paul.

Geller, M. H. (1989). Relationships. In P. A. Grayson \& K. Cauley (Eds.), College psychotherapy (pp. 113-135). New York: Guilford Press. 
Gerdes, H., \& Mallinckrodt, B. (1994). Emotional, social, and academic adjustment of college students: A longitudinal study of retention. Journal of ('ounseling and Development, 2(3), 281-288.

Gergen, K. J. (1982). From self to science: What is there to know? In J. Suls (Ed.), Psychological perspectives on the self (Vol. 1, pp. 129-149). Hillsdale, NJ: Lawrence Erlbaum.

Gladieux, L. E., \& Swail, W. S. (2000). Beyond access: Improving the odds of college success. Phi Delia Kappan, 8I(9), 688-692.

Glick, M., \& Zigler, E. (1985). Self-image: A cognitive-developmental approach. In R. L. Leahy (Ed.), The development of the self (pp. 1-53). New York: Academic Press.

Gold, J. R. (1990). Levels of depression. In B. B. Wolman \& G. Stricker (Eds.), Depression disorders: Facts, theories and treatment methods (pp. 203-228). New York: Wiley.

Goldston, D. B., O’Hara, M. W., \& Schartz, H. A. (1990). Reliability, validity, and preliminary normative data for the inventory to diagnose depression in a college population. Psychological Assessment: A Journal of Consulting and ('linical Psychologi: 2(2), 212-215.

Golin, S., \& Hartz, M. A. (1979). A factor analysis of the Beck Depression Inventory in a mildly depressed population. Journal of Clinical Psychologi: 35(2), 322-325.

Gordon, V. N. (1985). Students with uncertain academic goals. In U. Delworth \& G. R. Hanson (Eds.), Increasing student retention: Effective programs and practices for reducing the dropout rate (pp. 116-137). San Francisco: Jossey-Bass.

Gorenstein, C., Pompeia, S., \& Andrade, L. (1995). Scores of Brazilian university students on the Beck Depression and the State-Trait Anxiety Inventories. Psychological Reports, $77(2), 635-641$.

Gotlib, I. H. (1984). Depression and general psychopathology in university students. Journal of Abnormal Psychologi, 93(1), 19-30.

Gotlib, I. H., Wallace, P. M., \& Colby, C. A. (1990). Marital and family therapy for depression. In B. B. Wolman \& G. Stricker (Eds.), Depression disorders: Facts, theories and treatment methods (pp. 396-424). New York: Wiley. 
Gottschalk, L. A. (1990). Origins and evolution of narcissism through the life cycle. In R. A. Nemiroff \& C. A. Colarusso (Eds.), New dimensions in adult development (pp. 73-94). New York: Basic Books.

Gray-Little, B., \& Williams, V. S. L. (1997). An item response theory analysis of the Rosenberg Self-Esteem Scale. Personality and Social Psychology Bulletin [On-line], 23(5), 443-443. Available: EBSCO host.

Grayson, P. A. (1989). The college psychotherapy client: An overview. In P. A. Grayson \& K. Cauley (Eds.), College psychotherapy (pp. 8-28). New York: Guilford Press.

Grayson, P. A., \& Meilman, P. W. (1999). Beating the college blues (2 ${ }^{\text {nd }}$ ed.). New York: Checkmark Books.

Greenwald, A. G., Bellezza, F. S., \& Banaji, M. R. (1988). Is self-esteem a central ingredient of the self-concept? Personality and Social Psychology Bulletin. It(1), $34-45$.

Griffin, O. T. (1992). The impacts of academic and social integration for black students in higher education. In M. Lang \& C. A. Ford (Eds.), Strategies for retaining minority students in higher education (pp. 25-44). Springfield, IL: Charles C. Thomas.

Gumport, P. J. (1999). Graduate education and research: Interdependence and strain. In P. G. Altbach, R. O. Berdahl, \& P. J. Gumport (Eds.), American higher education in the twenty-first century: Social, political, and economic challenges (pp. 396-426). Baltimore, MD: Johns Hopkins University Press.

Haines. M. E., Norris, M. P., \& Kashy, D. A. (1996). The effects of depressed mood on academic performance in college students. Journal of College Student Development, 37(5), 519-526.

Halgin, R. P., \& Leahy, P. M. (1989). Understanding and treating perfectionistic college students. Journal of ( ounseling and Development, 68(2), 222-225.

Hallett, K. A. (1998). The college Iransition: Self-esteem, social support and depressive outcomes. Unpublished Bachelor of Arts Honors Thesis, Wheaton College, MA.

Hamachek, D. E. (1971). Encounters with the self. New York: Holt, Rinehart and Winston.

Hammen, C. L. (1978). Depression, distortion, and life stress in college students. (ognitive Therapy and Research, 2(2), 189-192. 
Hammen, C. (1995). The social context of risk for depression. In K. D. Craig \& K. S. Dobson (Eds.), Anxiety and depression in adults and children (pp. 82-98). Thousand Oaks, CA: Sage.

Hammond, W. A., \& Romney, D. M. (1995). Cognitive factors contributing to adolescent depression. .ournal of Youth and Adolescence, $2+(6), 667-683$.

Hansen, J. C., \& Maynard, P. E. (1973). Youth: Self-concept and behavior. In H. Peters (Ed.), Counseling youth series (pp. 1-101). Columbus, $\mathrm{OH}$ : Charles E. Merrill.

Hart, D., \& Damon, W. (1985). Contrasts between understanding self and understanding others. In R. L. Leahy (Ed.), The development of the self (pp. 151-178). New York: Academic Press.

Harter, S. (1985). Competence as a dimension of self-evaluation: Towards comprehensive model of self-worth. In R. L. Leahy (Ed.), The development of the self (pp. 55-121). New York: Academic Press.

Harter, S. (1986). Processes underlying the construction, maintenance, and enhancement of the self-concept in children. In J. Suls \& A. G. Greenwald (Eds.), Psychological perspective on the self (Vol. 3, pp. 137-172). Hillsdale, NJ: Lawrence Erlbaum.

Harter, S. (1996). Historical roots of contemporary issues involving self-concept. In B. A. Bracken (Ed.), Handbook of self-concept: Developmental, social, and clinical considerations (pp. 1-37). New York: John Wiley \& Sons.

Harwood, R. L. (1998). The survival of the self. Aldershot, Hants, England: Ashgate.

Hattie, J. (1992). Self-Concept. Hillsdale, NJ: Lawrence Erlbaum.

Hattie, J. \& Marsh, H. W. (1996). Future directions in self-concept research. In B. A. Bracken (Ed.), Handbook of self-concept: Developmental, social, and clinical constderations (pp. 421-462). New York: John Wiley \& Sons.

Hatzenbuehler, L. C., Parpal, M., \& Matthews, L. (1983). Classifying college students as depressed or nondepressed using the Beck Depression Inventory: An empirical analysis. Journal of ('onsulting and Clinical Psychology, 5l(3), 360-366.

Hayes, J. A. (1997). What does the Brief Symptom Inventory measure in college and university counseling center clients? Journal of (ounseling Psychologw. $t+(4)$, 360-367. 
Hayes, L. L. (2000). Tools of the counseling trade: With the number of suicides rising daily, a new suicide prevention tool aims to help save the lives of elementary, junior and senior high students across the nation. (ounseling Todan, $+3(1), 8-10$.

Head, R. (1978). Cognitive therapy with depressed college students. Unpublished master's thesis, University of Miami.

Hergenhahn, B. R. (1992). An introduction to the history of psychology (2 ${ }^{\text {nd }}$ ed.). Pacific Grove, CA: Brooks/Cole.

Hermon, D. A., \& Hazler, R. J. (1999). Adherence to a wellness model and perceptions of psychological well-being. Journal of (ounseling and Development. 77(3), 339-343.

Higgins, N. C., Zumbo, B. D., \& Hay, J. L. (1999). Construct validity of attributional style: Modeling context-dependent item sets in the attributional style questionnaire. Educational \& Psychological Measurement [On-line], 59(5), 804-821. Available: Academic Search Elite.

Hill, A. B., Kemp-Wheeler, S. M., \& Jones, S. A. (1986). What does the Beck Depression Inventory measure in students? Personality \& Individual Differences, $7(1), 39-47$.

Hines, J. D. (1998). Variables that discriminate between persisting and nonpersisting, firstyear undergraduate students in an open-admissions. multicampus, commuter college system (Doctoral dissertation, Andrews University, 1998). Disscrtation Abstracts International, 60, 1040.

Hirschfeld. R. M. A., \& Cross, C. K. (1987). The measurement of personality in depression. In A. J. Marsella, R. M. A. Hirschfeld, \& M. M. Katz (Eds.), The measurement of depression (pp. 331-335). New York: Guilford Press.

Hirst. W., Manier, D.. \& Apetroaia, I. (1997). The social construction of the remembered self: Family recounting. In J. G. Snodgrass \& R. L. Thompson (Eds.), The self across psychologn: Self-Recognition, self-awareness, and the self concept (Vol. 818: pp. 163-188). New York: New York Academy of Sciences.

Hoffman, R. A., \& Gellen, M. L. (1983). The Tennessee Self-Concept Scale: A revisit. Psychological Reports, 53, $1199-1204$.

Hoge, R. D. (1999). Assessing adolescents in educatıonal, counseling, and other settings. Mahwah. NJ: Lawrence Erlbaum. 
Hokanson, J. E., Ruber, M. P., Welker. R. A., Hollander, G. R., \& Hedeen. C. (1989). Interpersonal concomitants and antecedents of depression among college students. Journul of Ahnormal Psychologi: 98(3), 209-217.

Hollon, S. D., \& Carter, M. M. (1994). Depression in adults. In L. W. Craighead, W. E. Craighead. A. L. Kazdin, \& M. J. Mahoney (Eds.), (ognutve and hehaviorul interventions: An empirical approach to mental health problems (pp. 89-104). Boston: Allyn and Bacon.

Hollon, S. D., DeRubeis, R. J., \& Seligman, M. E. P. (1992). Cognitive therapy and the prevention of depression. Applied \& Preventive Psychologn: I(2), 89-95.

Hollon, S. D., Shelton, R. C., \& Davis, D. D. (1993). Cognitive therapy for depression: Conceptual issues and clinical efficacy. Journal of (onsulting and Clinical Psuchology. 6l(2), 270-275.

Hormuth, S. E. (1990). The ecology of the self: Relocation and self-concept change. Cambridge: Cambridge University Press.

Horwath, E., Johnson, J., Klerman. G. L.. \& Weissman, M. M. (1992). Depressive symptoms as relative and attributable risk factors for first-onset major depression. Archives (ieneral Psychiañ: 49(9), 817-823.

House, J. D. (1992). The relationship between academic self-concept, achievement-related expectancies, and college attrition. Journal of College Student Development, $33(1)$, $5-10$.

Hudson, F. M. (1991). The adult vears: Mastering the art of self-renewal. San Francisco: Jossey-Bass

Ingram, R. E., Miranda, J., \& Segal, Z. V. (1998). ('ognitive vulnerabilitu to depression. New York: Guilford Press.

Jack, D. C. (1993). Silencing the self: Women and depression. New York: Harper Collins.

Jackson, S., \& Bosma, R. (1990). Coping and self in adolescence. In H. A. Bosma \& A. E. Jackson (Eds.), ('oping and self-concept in adolescence (pp. 1-11). New York: Springer-Verlag.

James, W. (1890). The principles of psychology (Vols. 1-2). New York: Henry Holt.

James, W. (1985). The self. In G. Allport (Ed.), William James psychologn: The briefer course (pp. 43-83). Notre Dame, IN: University of Notre Dame Press. 
Jarrett, R. B., \& Rush, A. J. (1996). Cognitive therapy for depression. In J. Lonsdale (Project Ed.), The Hatherleigh guide to managing depression (pp. 127-146). New York: Hatherleigh Press.

Jobes, D. A., Jacoby, A. M., Cimbolic, P., \& Hustead, L. A. T. (1997). Assessment and treatment of suicidal clients in a university counseling center. Journal of Counseling Psychology, $+4(4), 368-377$.

Johnson, N. G. (2001). Psychology's mission includes health: An opportunity. Monutor on Psychology. 32(4), 5.

Joseph, S. (1987). Cognitive theory. In R. Formanek \& A. Gurian (Eds.), Women and depression: A lifespan perspective (pp. 46-53). New York: Springer.

Joseph, S., Lewis, C. A., \& Olsen, C. (1996). Convergent validity of the depression-happiness scale with measures of depression. Journal of (linical Psychology, 52(5), 551-554.

Juhasz, A. M. (1992). Significant others in self-esteem development: Methods and problems in measurement. In T. M. Brinthaupt \& R. P. Lipka (Eds.), The self: Definitional and methodological issues (pp. 204-235). Albany, NY: State University of New York Press.

Kagan, J. (1998). Is there a self in infancy? In M. Ferrari \& R. J. Sternberg (Eds.), Self-Awareness: Its nature and development (pp. 137-147). New York: Guilford Press.

Kao, E. M., Nagata, D. K., \& Peterson, C. (1997). Explanatory style, family expressiveness, and self-esteem among Asian American and European American college students. Journal of Social Psychology. 137(4), 435-444.

Kaplan, H. I., \& Sadock, B. J. (1998). Synopses of psychiatry: Behcrvioral sciences clinical psychiarry $\left(8^{\text {th }}\right.$ ed.). Baltimore, MD: Williams \& Wilkins.

Kaplan, R. M., \& Saccuzzo, D. P. (1993). Psychological testung: Principles, applications, and issues $\left(3^{\text {rd }}\right.$ ed.). Pacific Grove, CA: Brooks/Cole.

Karp, D. A. (1996). Speaking of sadness: Depression, disconnection, and the meanings of illness. New York: Oxford University Press. 
Katz. J. (1975). Psychodynamics of development during the college years. In B. L. Bloom \& D. Adelson (Eds.), Psychological stress in the campus community: Theory; research, and action (Community Psychology Series, Vol. 3, pp. 43-76). New York: Behavioral Publications.

Katz. M. M. (1969). Reflections on the williamsburg workshop: Classification and measurement of the psychopathology of depression. In T. A. Williams, M. M. Katz, \& J. A. Shield (Eds.), Recent advances in the psychobiology of the depressive illnesses: Proceedings of a workshop sponsored by the clinical research brand division of extramural research programs (pp. 367-375). Washington. DC: National Institute of Mental Health.

Keith, L. K., \& Bracken, B. A. (1996). Self-concept instrumentation: A historical and evaluative review. In B. A. Bracken (Ed.), Handbook of self-concept: Developmental, social, and clinical considerations (pp. 91-170). New York: John Wiley \& Sons.

Kelly, W. E., Kelly, K. E., Brown, F. C., \& Kelly, H. B. (1999). Gender differences in depression among college students: A multi-cultural perspective. College Situdents Journal [On-line], 33(1). 72-76. Available: Academic Search Elite.

Kendall, P. C., Hollon, S. D., Beck, A. T., Hammen. C. L., \& Ingram, R. E. (1987). Issues and recommendations regarding use of the Beck Depression Inventory. Cognitive Therapy and Research, /1(3), 289-299.

Kenny, M. E., \& Perez, V. (1996). Attachment and psychological well-being among racially and ethically diverse first-year college students. Iournal of Collcge Student Development, 37(5) 527-535.

Kernis. M. H. (1993). The roles of stability and level of self-esteem in psychological functioning. In R. F. Baumeister (Ed.), Self-esteem: The puz=le of low self-regard (pp. 167-182). New York: Plenum Press.

Kernis, M. H., Grannemann, B. D., \& Mathis, L. C. (1991). Stability of self-esteem as a moderator of the relation between level of self-esteem and depression. Journal of Personality and Social Psychologn: 6l(1), 80-84.

Kernis, M. H. Whisenhunt, C. R., Waschull, S. B., Greenier, K. D., Berry, A. J., Herlocker, C. E., et al. (1998). Multiple facets of self-esteem and their relations to depressive symptoms. Personality and Social Psychology Bulletin [On-line], 2+(6), 657-669. Available: Academic Search Elite. 
Kiah. C. W. (1992). The relationship of black students' achievement motivation to family cohesion and specific aspirations. In M. Lang \& C. A. Ford (Eds.), Strategies for retaining minority' students in higher education (pp. 45-53). Springfield, IL: Charles C. Thomas.

Kihlstrom, J. F., \& Klein, S. B. (1997). Self-knowledge and self-awareness. In J. G. Snodgrass \& R. L. Thompson (Eds.), The self across psychologv: Self-Recognition. self-awareness, and the self concept (Vol. 818; pp. 5-17). New York: New York Academy of Sciences.

Killgore, W. D. S. (1999). Empirically derived factor indices for the Beck Depression Inventory. Psychological Reports. 8t, 1005-1013.

Kinch, J. W. (1963). Research note: A formalized theory of the self-concept. American Journal of Sociologn: 68, 481-486.

Klar, Y. (1992). Direction in the study of personal-change endeavors by clinical and social psychologists: An introduction. In Y. Klar, J. D. Fisher, J. M. Chinsky, \& A. Nadler (Eds.), Self change: Social psychological and clinical perspectives (pp. 1-20). New York: Springer-Verlag.

Klerman, G. L. (1987). The nature of depression: Mood, symptom, disorder. In A. J. Marsella, R. M. A. Hirschfeld, \& M. M. Katz (Eds.), The measurement of depression (pp. 3-19). New York: Guilford Press.

Kohlberg, L., \& Armon, C. (1984). Three types of stage model used in the study of adult development. In M. L. Commons, F. A. Richards, \& C. Armon (Eds.), Beyond formal operations: Late adolescent and adult cognitive development (pp. 383-394). New York: Praeger.

Kovacs, M., \& Beck, A. T. (1978). Maladaptive cognitive structures in depression. The American Journal of Psychiatry. 135(5), 525-533.

Kreger, D. W. (1995). Self-esteem, stress, and depression among graduate students. Psychological Reports, 76(1), 345-346.

Kroger, J. (1989). Identity in adolescence: The balance between self and other. New York: Routledge.

Kroger, J., \& Haslett, S. J. (1991). A comparison of ego identity status transition pathways and change rates across five identity domains. International Journal of Aging and Human Development, 32(4), 303-330. 
Kuehlwein. K. T. (1993). A survey and update of cognitive therapy systems. In K. T. Kuehlwein \& H. Rosen (Eds.), (ognitive therapies in action: Evolving innovative practice (pp. 1-32). San Francisco: Jossey-Bass.

Kuiper, N. A., MacDonald, M. R., \& Derry, P. A. (1983). Parameters of a depressive selfschema. In J. Suls \& A. G. Greenwald (Eds.), Psychological perspectives on the self( Vol. 2, pp. 191-217). Hillsdale, NJ: Lawrence Erlbaum.

Kutcher, S., Marton. P., \& Boulos, C. (1993). Adolescent depression. In P. Cappeliez \& R. J. Flynn (Eds.). Depression and the social environment: Research and intervention with neglected populations (pp. 73-92). Montreal: McGill-Queen's University Press.

Lang, R. J., \& Vernon, P. E. (1977). Dimensionality of the perceived self: The Tennessee Self-Concept Scale. British Journal of Social and (inical Psichologi: 16(4), 363-371.

Lazarus, R. S. (1991). Emotion and adaptation. New York: Oxford University Press.

Lent. R. W., Brown, S. D., \& Hackett. G. (2000). Contextual supports and barriers to career choice: A social cognitive analysis. Journal of (ounseling Psychology, $+7(1), 36-49$.

Levin, J. D. (1992). Theories of the self. Washington, DC: Taylor \& Francis.

Levin. J., Karni, E., \& Frankel, Y. (1978). Analysis of the Tennessee Self-Concept Scale as a faceted instrument. Psychological Reports, 43, 619-623.

Levy. K. St. C. (1997). The contribution of self-concept in the etiology of adolescent delinquency. Adolescence [On-line], 32(127), 671-686. Available: Academic Search Elite.

Levy-Warren, M. H. (1996). The adolescent journey: Development, identity formation. and psichotherupy: Northvale, NJ: Jason Aronson.

Lewinsohn, P. M., Antonuccio, D. O., Steinmetz, J. L., \& Teri, L. (1984). The coping with depression course: A prychoeducational imervention for unipolur depression. Eugene, OR: Castalia.

Lewinsohn, P. M., Munoz, R. F., Youngren, M. A., \& Zeiss, A. N. (1986). ('ontrol your depression: Revised and updated. New York: Prentice Hall Press. 
Lewinsohn, P. M., \& Rohde, P. (1987). Psychological measurement of depression: Overview \& conclusions. In A. J. Marsella, R. M. A. Hirschfeld, \& M. M. Katz (Eds.), The measurement of depression (pp. 244-250). New York: Guilford Press.

Lewis, M. (1997). The self in self-conscious emotions. In J. G. Snodgrass \& R. L. Thompson (Eds.), The self across psychologw: Self-Recognution. self-awareness. and the self concept (Vol. 818; pp. 119-142). New York: New York Academy of Sciences.

Lieberman, M. A. (1992). Perceptions of changes in the self: The impact of life events and large group awareness training. In Y. Klar, J. D. Fisher, J. M. Chinsky, \& A. Nadler (Eds.), Self change: Social psychological and clinical perspectives (pp. 43-61). New York: Springer-Verlag.

Lightsey, O. R., Jr., \& Christopher, J. C. (1997). Stress buffers and dysphoria in a non-western population. Journal of Counseling and Development, $75(6), 451-459$.

Lips, H. M. \& Ng, M. (1985). Use of the Beck Depression Inventory with three non-clinical populations. ('anadian Journal of Behavioural Science, 18(1), 62-74.

Lisser, E., de (2002, May 21). Panel calls on primary doctors to test patients for depression. The Wall Street Journal, p. D4.

Little, B. R. (1993). Personal projects and the distributed self: Aspects of a cognitive psychology. In J. Suls (Ed.). Psychological perspectives on the self: The self in social perspective (Vol. 4, pp. 157-185). Hillsdale, NJ: Lawrence Erlbaum.

Lopez, F. G. (1986). Family structure and depression: Implications for the counseling of depressed college students. Journal of ('ounseling and Development, 64, 508-511.

Lopez-Culver. A. (1991). Depression in college students: Relationship to gender, age, marital and parental status. Unpublished master's thesis, State University of New York College at New Paltz.

Lucas, M. (1997). Identity development, career development, and psychological separation from parents: Similarities and differences between men and women. Journal of (ounseling Psychology, $f+(2), 123-132$.

Lucas, M. S., Skokowski, C. T., \& Ancis. J. R. (2000). Contextual themes in career decision making of female clients who indicate depression. Journal of Counseling and Development, 78(3), 316-325. 
Lutterman, L. A. (1991). The relationship of depression to self-esteem. Unpublished master's thesis, University of Wisconsin-Stout.

Maddux, J. E., \& Meier. L. J. (1995). Self-efficacy and depression. In J. E. Maddux (Ed.). Self-efficacy, adaptation, and adjustment: Theory, research and application (pp. 143-169). New York: Plenum Press.

Madison, P. (1969). Personality development in college. Reading, MA: Addison-Wesley.

Magen, Z. (1998). Exploring adolescent happiness: Commitment, purpose, and fulfillment. Thousand Oaks, CA: Sage.

Maier, W., Gansicke, M.. \& Weiffenbach, O. (1997). The relationship between major and subthreshold variants of unipolar depression. Journal of Affective Disorders. $+5(1-2), 41-51$.

Marcia, J. E. (1987). The identity status approach to the study of ego identity development. In T. Honess \& K. Yardley (Eds.), Self and identıty: Perspectives across the lifespan (pp. 161-171). New York: Routledge \& Kegan Paul.

Markus. H. \& Kunda, Z. (1986). Stability and malleability of the self-concept. Journal of Personality and Social Psychology, $5 /(4), 858-866$.

Marsh. H. W. (1989). Age and sex effects in multiple dimensions of self-concept: Preadolescence to early adulthood. Journal of Educational Psychology, 8/(3), 417-430.

Marsh, H. W. (1993). Academic self-concept: Theory, measurement, and research. In J. Suls (Ed.), Psychological perspectives on the self: The self in social perspective (Vol. 4, pp. 59-98). Hillsdale, NJ: Lawrence Erlbaum.

Marsh, H. W., Barnes, J., \& Hocevar, D. (1985). Self-other agreement on multidimensional self-concept ratings: Factor analysis and multitrait-multimethod analysis. Journal of Personality and Social Psychologn: +9(5), 1360-1377.

Marsh, H. W., Bryne, B. M., \& Shavelson, R. J. (1988). A multifaceted academic selfconcept: Its hierarchical structure and its relations to academic achievement. Journal of Educational Psychology, 80(3), 366-380.

Marsh, H. W., \& Hattie, J. (1996). Theoretical perspectives on the structure of selfconcept. In B. A. Bracken (Ed.), Handbook of self-concept: Developmental, social, and clinical considerations (pp. 38-90). New York: John Wiley \& Sons. 
Marsh, H. W., Hey. J., Roche, L. A.. \& Perry, C. (1997). Structure of physical self-concept: Elite athletes and physical education students. Journal of Educational Psychology. $89(2), 369-380$.

Marsh, H. W., \& Richards, G. E. (1988). Tennessee Self Concept Scale: Reliability, internal structure, and construct validity. Journal of Personality and Social Psychology, 55(4), 612-624.

Marsh. H. W., \& Smith, I. D. (1982). Multitrait-multimethod analyses of two self-concept instruments. Journal of Educational Psychology, $7+(3), 430-440$.

Marsh, H. W., Smith. I. D., Barnes, J., \& Butler, S. (1983). Self concept: Reliability, stability, dimensionality, validity, and the measurement of change. Journal of Educutional Psychology; 75(5), 772-790.

Martin, C. J. (1996). The relationship of student retention to teacher/student personality types at summit christian college (Doctoral dissertation, Andrews University, 1996). Dissertation Abstracts International, 57, 4261.

Marx, R. W., \& Winne, P. H. (1978). Construct interpretations of three self-concept inventories. American Educational Research Journal. 15(1), 99-109.

Marx, R. W., \& Winne. P. H. (1980). Self-concept validation research: Some current complexities. Measurement and Evaluation in Guidance, 13(2), 72-82.

Maslach, C. (1982). Burnout--The cost of caring. Englewood Cliffs, NJ: Prentice-Hall.

Maslow, A. H. (1954). Motivation and personality. New York: Harper \& Brothers.

Maslow, A. H. (1959). Psychological data and value theory. In A. H. Maslow (Ed.), New' knowledge in human values (pp. 119-136). New York: Harper \& Row.

McCrae, R. R., \& Costa, P. T., Jr. (1982). Self-concept and the stability of personality: Cross-sectional comparisons of self-reports and ratings. Journal of Personality and Social Psychologi, +3(6), 1282-1292.

McGuire, B., \& Tinsley, H. E. A. (1981). A contribution to the construct validity of the Tennessee Self-Concept Scale: A confirmatory factor analysis. Applied Psychological Measurement. 5(4), 449-457.

McGuire, P. A. (1998). Seligman touts the art of arguing with yourself: The link between pessimism and depression begins in the way we talk to our inner selves. Monitor on Psychology. 29(10), 13-14. 
McGuire, W. J., \& McGuire, C. V. (1982). Significant others in self-space: Sex differences and developmental trends in the social self. In J. Suls (Ed.), Psychological perspectives on the self (Vol. 1, pp. 71-96). Hillsdale, NJ: Lawrence Erlbaum.

McIntosh, J. L. (2000). U. S. A. suicide: 1998 official final data. American Association of Sucidology [On-line], Available: wuw suicidolog:org.

McLean, P. (1982). Behavioral therapy: Theory and research. In A. J. Rush (Ed.), Short-term psychotherapies for depression: Behavioral, interpersonal, cognitive, and psychodvnamic approaches (pp. 19-45). New York: The Guilford Press.

McLennan, J. (1992). 'University blues': Depression among tertiary students during an academic year. British Journal of Guidance and Counselling, 20(2), 186-192.

McWhinter, B. T. (1997). Loneliness, learned resourcefulness, and self-esteem in college students. Journal of Counseling and Development, 75(6), 460-469.

Mead, B. T. (1970). Reactive depression in young adults. In A. J. Enelow (Ed.), Depression in medical practice (pp. 71-84). West Point, PA: Merck.

Melendez, J. (1997). Analysis of university personnel's perception of institutional factors impacting students persistence/retention (Doctoral dissertation, Andrews University, 1997). Dissertation Abstracts International, 59, 1418.

Mendels, J. (1970). Concepts of depression. New York: John Wiley \& Sons.

Mendelson, M. (1990). Psychoanalytic views on depression. In B. B. Wolman \& G. Stricker (Eds.), Depressive disorders: Facts, theories and treatment (pp. 22-37). New York: Wiley.

Merkley, B. A. (1997). An assessment of the random version of the Beck Depression Inventory II (Masters Thesis, Lakehead University, 1997). Masters Abstracts International, 37(3), 1051.

Merriam, S. B., \& Clark. M. C. (1991). Lifelines: Patterns of work. love, and learning in adulthood. San Francisco: Jossey-Bass.

Meyer, B. Y. (2000). Study: $62 \%$ of school counselors feel unprepared to curb suicides. ('ounseling Today, +2(9), 18.

Meyer, R. G., \& Deitsch, S. E. (1996). The clinictan's handbook: Integrated diagnostics, assessment, and intervention in adult and adolescent psychopathology $\left(4^{\text {th }} \mathrm{ed}\right.$.). Boston: Allyn and Bacon. 
Miller, T. K., \& Jones, J. D. (1981). Out-of-class activities. In A. W. Chickering \& Associates (Eds.), The modern american college: Responding to the new realities of diverse students and a changing society (pp. 657-671). San Francisco: Jossey-Bass.

Millon, T., \& Kotik-Harper, D. (1995). The relationship of depression to disorders of personality. In E. E. Beckham \& W. R. Leber (Eds.), Handhook of depression $\left(2^{\text {nd }}\right.$ ed., pp. 107-136). New York: Guilford Press.

Miranda. J., \& Munoz, R. (1994). Intervention for minor depression in primary care patients. Psychosomatic Medicine, 56, 136-142.

Mitchell, J. V., Jr. (1983). Tennessee Self Concept Scale. In J. V. Mitchell (Ed.), Tests in Print III: An index to tests, test reviews, and the literature on specific tests (Vol. 3, pp. 418-420). Lincoln, NE: Buros Institute of Mental Measurement.

Moore, M. A., \& Britt, T. W. (1997). Integrating social and counseling psychological perspectives on the self. Counseling Psychologist [On-line], 25(2), 220-240. Available: Academic Search Elite

Morrel, A. O. (1983). Conscious and unconscious aspects of self-esteem (Doctoral dissertation, Fordham University, 1983). Dissertation Abstracts International, +4 , 1970 .

Morse, S. J., \& Gergen, K. J. (1982). Social comparison, self-consistency, and the concept of self. In M. Rosenberg \& H. B. Kaplan (Eds.), Social prychology of the self-concept (pp. 187-199). Arlington Heights, IL: Harlan Davidson.

Mortimer, J. T., \& Lorence. J. (1981). Self-concept stability and change from late adolescence to early adulthood. Research in (ommunity and Mental Health. 2, $5-42$.

Morton, P. M. (1984). Self-esteem as a determinant of depression in college graduate and undergraduat' students. Unpublished master`s thesis, Northwestern State University of Louisiana.

Mosher, R. L. (1986). Foreword: Why character education in college? In J. C. Loxley \& J. M. Whiteley (Eds.), (haracter development in college students: The curriculum and longitudinal results (Vol. 2, pp. xiii-xxix). Schenectady, NY: Character Research Press. 
Mueller, J. H., Johnson, W. C.. Dandoy, A., \& Keller, T. (1992). Trait distinctiveness and age specificity in the self-concept. In R. P. Lipka \& T. M. Brinthaupt (Eds.), Selfperspectives across the lifespan (pp. 223-255). Albany, NY: State University of New York Press.

Munoz, R. F. (1993). The prevention of depression: Current research and practice. Applied \& Preventive Psychologn; 2(1), 21-33.

Munoz, R. F., Hollon, S. T., McGrath, E., Rehm, L. P., \& VandenBos, G. R. (1994). On the AHCPR depression in primary care guidelines: Further considerations for practitioners. American Psychologist, $49(1), 42-61$.

Munoz, R. F., \& Ying, Y. W. (1993). The prevention of depression: Research and practice. Baltimore, MD: Johns Hopkins University Press.

Muran, J. C., \& Safran, J. D. (1993). In K. T. Kuehlwein \& H. Rosen (Eds.), Cognitıve theraples in action: Evolving innovative practice (pp. 185-212). San Francisco: Jossey-Bass.

Murphy, L. L., Conoley, J. C., \& Impara, J. C. (1994). Tennessee Self-Concept Scale [Revised]. In L. L. Murphy, J. C., Conoley, \& J. C. Impara (Eds.). Tests in Print IV: An index to tests, test reviews, and the literature on specific tests (Vol. 4, pp. 876-877). Lincoln, NE: Buros Institute of Mental Measurement.

Myers, J. E., Sweeney, T. J., \& Witmer, J. M. (2000). The wheel of wellness counseling for wellness: A holistic model for treatment planning. Journal of (ounseling and Development, 78(3), 251-266.

National Depressive and Manic-Depressive Association. (1999). A gude to depressive and manic-depressive illness: Diagnosis, treatment and support [Brochure]. Chicago: Author.

National Depressive and Manic-Depressive Association. (2000). ('onsumer's guide to depression and manic depression [Brochure]. Chicago: Author.

National Institutes of Health. (2000a, February). What do these students have in common? They are college students who got depressed... got treatment . . and got hetter (NIMH Publication No. 00-4266) [Brochure]. Bethesda, MD: National Institute of Mental Health.

National Institutes of Health. (2000b, April). What to do when a friend is depressed. . find out more about depression (NIMH Publication No. 00-3824) [Brochure]. Bethesda, MD: National Institute of Mental Health. 
National Institute of Mental Health. (1995). Depression co-occurring w'th other illnesses (NIMH Publication No. OM 00-4163) [Brochure]. Bethesda, MD: Author.

National Institute of Mental Health. (1997). Helpful facts about depressive illnesses (NIMH Publication No. 97-3875) [Brochure]. Bethesda, MD: Author.

National Institute of Mental Health. (1999). Depression research at the Nat ional Institute of Mental Health: Fuct Sheet (NIMH Publication No. 99-4501) [Brochure]. Bethesda, MD: Author.

National Institute of Mental Health. (2000). Depression (NIMH Publication No. 00-3561) [Brochure]. Bethesda, MD: Author.

National Research Council. (1996). The path to the Ph. D.: Measuring graduate attrition in the sciences and humanities. Washington, DC: National Academy Press.

Natsoulas, T. (1998). Consciousness and self-awareness. In M. Ferrari \& R. J. Stemberg (Eds.), Self-Awareness: Its nature and development (pp. 12-33). New York: Guilford Press.

Neisler, O. J. (1992). Access and retention strategies in higher education: An introductory overview. In M. Lang \& C. A. Ford (Eds.), Strategies for retaining minority students in higher education (pp. 3-24). Springfield, IL: Charles C. Thomas.

Neisser. U. (1997). The roots of self-knowledge: Perceiving self, it, and thou. In J. G. Snodgrass \& R. L. Thompson (Eds.), The self across psychologv: Self-Recognition. self-awareness, and the self concept (Vol. 818; pp. 19-33). New York: New York Academy of Sciences.

Nemiroff, R. A., \& Colarusso, C. A. ( 1990). Discussion. In R. A. Nemiroff \& C. A. Colarusso (Eds.), New dimensions in adult development (pp. 91-94). New York: Basic Books.

Newman, C. F., \& Beck, A. T. (1990). Cognitive therapy of affective disorders. In B. B Wolman \& G. Stricker (Eds.), Depressive disorders: Facts, theories, and treatment methods (pp. 343-367). New York: John Wiley \& Sons.

Newman, P. R., \& Newman, B. M. (1978). Identity formation and the college experience. Adolescence, 13(50), 311-326.

Noam, G. G., Kohnlen, L., \& Snarey, J. (1983). Steps toward a model of the self. In B. Lee \& G. G. Noam (Eds.), Developmental approaches to the self (pp. 59-141). New York: Plenum Press. 
Noel, L. (1985). Increasing student retention: New challenges and potential. In U.

Delworth \& G. R. Hanson (Eds.), Increasing student retention: Effective programs and practices for reducing the dropout rate (pp. 1-27). San Francisco: Jossey-Bass.

Nolen-Hoeksema, S., \& Girgus, J. S. (1994). The emergence of gender differences in depression during adolescence. Psychological Bulletin. II5(3), 424-443.

Novick, N., Cauce, A. M., \& Grove, K. (1996). Competence self-concept. In B. A. Bracken (Ed.), Handhook of self-concept: Developmental, social, and clinical considerations (pp. 210-258). New York: John Wiley \& Sons.

O'Connor, E. M. (2001). Student mental health: Secondary education no more. Monutor on Psychology. 32(8), 44-47.

Offer, D.. \& Spiro, R. P. (1987). The disturbed adolescent goes to college. Journal of American College Health. 35(5), 209-214.

Olbrich, E. (1990). Coping and development. In H. A. Bosma \& A. E. Jackson (Eds.), (oping and self-concept in adolescence (pp. 35-47). New York: Springer-Verlag.

Oliver, J. M.. \& Burkham, R. (1979). Depression in university students: Duration, relation to calendar time, prevalence, and demographic correlates. Journal of Abnormal Psychology, 88(6), 667-670

Oliver, J. M., \& McGee, J. (1982). Cognition as a function of depression in a student population: Content and complexity of cognitions. (ognutive Therapy and Research, 6(3), 275-286.

O'Neil, M. K., \& Marziali. E. (1976). Depression in a university clinic population. ('unadian Psychiarric Assuciation Journal, 21(7), 477-481.

Osman, A., Downs, W. R., Barrios, F. X., Kopper, B. A., Gutierrez, P. M., \& Chiros, C. E. (1997). Factor structure and psychometric characteristics of the Beck Depression Inventory-Il. . Jurnal of Psvchopalhology and Behavioral Assessment. 19(4), 359-376.

Oyserman, D., \& Markus, H. R. (1993). The sociocultural self. In J. Suls (Ed.), Psychological perspectives on the self: The self in social perspective (Vol. 4, pp. 187-220). Hillsdale, NJ: Lawrence Erlbaum.

Padula. M. A., Conolev, C. W., \& Garbin, C. P. (1998). The dimensions underlying loneliness counseling interventic ns: A multidimensional scaling solution. Journal of Counseleng and Development, 76(4), 442-451. 
Papalia, D. E., \& Olds, S. W. (1992). Human development (5 $5^{\text {th }}$ ed.). New York: McGraw-Hill.

Papolos, D., \& Papolos, J. (1997). Overcoming depression: The definitive resource for patients and families who live with depression and manic-depression ( $3^{\text {rd }}$ ed. ). New York: Harper Perennial.

Pappas, J. P., \& Loring, R. K. (1985). Returning learners. In U. Delworth \& G. R. Hanson (Eds.), Increasing student retention: Effective programs and practices for reducing the dropout rate (pp. 138-161). San Francisco: Jossey-Bass.

Paul, E. L., \& Brier, S. (2001). Friendsickness in the transition to college: Precollege predictors and college adjustment correlates. Journal of Counseling and Development, $79(1), 77-89$.

Pecuch, J. P. (1997). Depression, self-esteem and attributional style among community college students (Doctoral dissertation, Adler School of Professional Psychology, 1997). Dissertation Abstracts International, 58, 6244.

Pelham, B. W. (1993). On the highly positive thoughts of the highly depressed. In R. F. Baumeister (Ed.), Self-esteem: The pu=zle of low self-regard (pp. 183-199). New York: Plenum Press.

Perkins, T. A. (1994). Selected demographic variables as predictors of ego-identity confusion among george fox college students (Doctoral dissertation, George Fox College, 1994). Dissertation Abstracts International, 55, 1202.

Peterson. C. (2000). The future of optimism. American Psychologist, 55(1), 44-55.

Peterson, C., \& Seligman, M. E. P. (1984). Causal explanations as a risk factor for depression: Theory and evidence. Psychological Review, 91(3), 347-374.

Peterson. C., Semmel, A., von Baeyer, C., Abramson, L. Y., Metalsky, G. I., \& Seligman. M. E. P. (1982). The Attributional Style Questionnaire. Cognitıve Therapy and Research, 6(3), 287-300.

Petiprin, G. L., \& Johnson, M. E. (1991). Effects of gender, attributional style, and item difficulty on academic performance. Journal of Psychology Interdisciplinary and Applied [Online], 125(1), 45-50. Available: EBSCO Host Full Display.

Polster, E. (1995). A population of selves: A therapeutic exploration of personal diversity $\left(1^{\text {st }}\right.$ ed.). San Francisco: Jossey-Bass. 
Pound, R. E., Hansen, J. C., \& Putnam, B. A. (1977). An empirical analysis of the Tennessee Self Concept Scale. Educational and Psychological Measurement. $37(2), 545-551$.

Prochaska, J. O., DiClemente, C. C., \& Norcross, J. C. (1992). In search of the structure of change. In Y. Klar, J. D. Fisher, J. M. Chinsky, \& A. Nadler (Eds.). Self chunge: Social psychological and clinical perspectives (pp. 86-114). New York: Springer-Verlag.

Prout, H. T., \& Prout, S. M. (1996). Global self-concept and its relationship to stressful life conditions. In B. A. Bracken (Ed.), Handbook of self-concept: Developmental. social, and clinical considerations (pp. 259-286). New York: John Wiley \& Sons.

Rachlin. H. (1997). Self and self-control In J. G. Snodgrass \& R. L. Thompson (Eds.), The self across psychology: Self-Recognition, self-awareness, and the self concept (Vol. 818; pp. 85-97). New York: New York Academy of Sciences.

Rangell, L. (1990). Seventeen: The approach to the portal of adult life. In R. A. Nemiroff \& C. A. Colarusso (Eds.), New dimensions in adult development (pp. 3-21). New York: Basic Books.

Reed, P. F., Fitts, W. H., \& Boehm, L. (1980). Tennessee Self C'oncept Scale: Bibliography of rescarch studies (Rev. ed.). Los Angeles: Western Psychological Services.

Regeth, R. A. (1997). Relativistic thinking and identity development in college students (Doctoral dissertation, University of New Hampshire, 1997). Dissertation Abstracts International, 58, 5167.

Regier, D. A., Hirschfeld, R. M. A., Goodwin, F. K., Burke, J. D., Lazar, J. B., \& Judd, L. L. (1988). The NIMH depression awareness, recognition, and treatment program: Structure, aims, and scientific basis. The American Journal of Psychiatry, $1+5(11)$, 1351-1357.

Rehm, L. P. (1987). The measurement of behavioral aspects of depression. In A. J. Marsella. R. M. A. Hirschfeld. \& M. M. Katz (Eds.), The measurement of depression (pp. 199-239). New York: Guilford Press.

Rehm. L. P. (1990). Cognitive and behavioral theories. In B. B. Woiman \& G. Stricker (Eds.), Depressive disorders: Facts, theories, and treatment methods (pp. 64-91). New York: John Wiley \& Sons. 
Rehm, L. P. (1995). Psychotherapies for depression. In K. D. Craig \& K. S. Dobson (Eds.), Anxiety and depression in adults and children (pp. 183-208). Thousand Oaks, CA: Sage.

Resnick, H., Fauble, M. L., \& Osipow, S. H. (1970). Vocational crystallization and self-esteem in college students. Journal of Counseling Psychologn, 17(5), 465-467.

Reynolds, W. M., Ramirez. M. P., Magrina, A., \& Allen, J. E. (1980). Initial development and validation of the academic self-concept scale. Educational and Psychological Measurement, 40(4), 1013-1016.

Rice, K. G., Ashby, J. S., \& Slaney, R. B. (1998). Self-esteem as a mediator between perfectionism and depression: A structural equations analysis. Journal of (ounseling Psychologn: $+5(3), 304-314$

Rice, K. G., \& Meyer, A. L. (1994). Preventing depression among young adolescents: Preliminary process results of psycho-educational intervention program. Journal of Counseling and Development. 73(2), 145-152.

Rizley, R. (1978). Depression and distortion in the attribution of causality. Journal of Abnormal Psychologu, 87(1), 32-48.

Roba, A. L. (1988). ('orrelates of depression in college students. Unpublished master's thesis, East Tennessee State University.

Robbins. P. R. (1993). Linderstanding depression. Jefferson, NC: McFarland.

Roberts, J. E., \& Monroe, S. M. (1994). A multidimensional model of self-esteem in depression. Clinical Psychology Review, $l+(3), 161-181$.

Robinson, J. P., \& Shaver, P. R. (1973). Measures of social psychological attitudes (Rev. ed. ). Ann Arbor, MI: University of Michigan, Institute of Social Research.

Robinson, L. A., Berman, J. S., \& Neimeyer, R. A. (1990). Psychotherapy for the treatment of depression: A comprehensive review of controlled outcome research. Psychological Bulletin. 108(1), 30-49.

Roffe, M. W. (1981). Factorial structure of the Tennessee Self-Concept Scale. Psvchological Reports, $+8(1), 455-462$.

Rogers, C. R. (1942). ('ounseling and psychotherapy: Newer concepts in practice. New York: Houghton Mifflin. 
Rogets. C. R. (1951). (Tient-Centered therapy: Its current practice, implications, and theory. New York: Houghton Mifflin.

Rogers, J. R. (2001). Theoretical grounding: The "missing link" in suicide research. Journal of (ounseling and Development, 79(1), 16-25.

Roid, G. H. \& Fitts, W. H. (1989). Tennessee Self-('oncept Scale 7S( S): Revised manual. Los Angeles: Western Psychological Services.

Rosenberg. M. (1965). Society and the adolescent self-image. Princeton, NJ: Princeton University Press.

Rosenberg, M. (1979). ('oncelving the self. New York: Basic Books.

Rosenberg, M. (1985). Self-concept and psychological well-being in adolescence. In R. L. Leahy (Ed.). The development of the self (pp. 205-246). New York: Academic Press.

Rosenberg, M. (1986). Self-concept from middle childhood through adolescence. In J. Suls \& A. G. Greenwald (Eds.), Psychological perspective on the self (Vol. 3, pp. 107-136). Hillsdale, NJ: Lawrence Erlbaum.

Rosenberg, M. (1989). Self-concept research: A historical overview. Social forces, $68(1)$, 34-44.

Rosenberg, M., \& Pearlin, L. I. (1982). Social class and self-esteem among children and adults. In M. Rosenberg \& H. B. Kaplan (Eds.). Social psychology of the self-concept (pp. 268-288). Arlington Heights, IL: Harlan Davidson.

Rudd, M. D. (1989). The prevalence of suicidal ideation among college students. Suicide and life-Threatening Behavior, 19(2), 173-183.

Rundle, R. L. (2000, January 12). Intervention found to aid depression treatment. The Hall Street Journal, p. B9.

Rush, A. J. (1982). Diagnosing depression. In A. J. Rush (Ed.), Short-lerm psychotherapies for depression: Behavioral, interpersonal, cognutive, and psychodynamic approaches (pp. 1-17). New York: Guilford Press.

Rush, A. J. (1987). Measurement of the cognitive aspects of depression. In A. J. Marsella. R. M. A. Hirschfeld, \& M. M. Katz (Eds.), The measurement of depression (pp. 267-296). New York: Guilford Press. 
Rush, A. J., \& Giles, D. E. (1982). Cognitive therapy: Theory and research. In A. J. Rush (Ed.), Short-lerm psychotherapies for depression: Behavioral, interpersonal, cognitive, and psychodynamic approaches (pp. 143-181). New York: Guilford Press.

Salmela-Aro, K., \& Nurmi, J. E. (1997). Goal contents, well-being, and life context during transition to university: A longitudinal study. The International Socten for the Study of Behavioral Development, 20(3), 471-491.

Salovey, P., Rothman, A. J., Detweiler, J. B., \& Steward, W. T. (2000). Emotional states and physical health. American Psychologist, 55(1), 110-121.

Samuels. S. C. (1977). Enhancing self-concept in early childhood: Theory and practice. New York: Human Sciences Press.

Sarbin, T. R. (1952). A preface to a psychological analysis of the self. Psychological Review, 59(1), 11-22.

Savin-Williams, R. C., \& Jaquish, G. A. (1981). The assessment of adolescent self-esteem: A comparison of methods. Journal of Personality, $19(3), 324-335$.

Schafer, R. B., \& Keith, P. M. (1985). A causal model approach to the symbolic interactionist view of the self-concept. Journal of Personality and Socral Psychology. $+8(4), 963-969$.

Scheffe', H. (1959). The analysts of variance. New York: John Wiley \& Sons.

Scheier, M. F., Carver, C. S., \& Bridges, M. W. (1994). Distinguishing optimism from neuroticism (and trait anxiety, self-mastery. and self-esteem): A reevaluation of the Life Orientation Test. Journal of Personality and Social Psychologw. 67(6), 1063-1078.

Schmidt, N. B., Joiner, T. E., Jr., Young, J. E., \& Telch, M. J. (1995). The schema questionnaire: Investigation of psychometric properties and the hierarchical structure of a measure of maladaptive schemas. ('ognitive Therapy and Research. $19(3), 295-321$.

Schmitt, S. M. (1999). Depression in the workplace recognized. ('ounseling Today. $+2(4), 20$.

Schultheiss, D. P., \& Blustein, D. L. (1994). Contributions of family relationship factors to the identity formation process. Journal of ('ounseling and Development, 73(2). 159-166. 
Schultz, D.. \& Schultz. S. E. (1994). Theories of personuling $\left(5^{\text {th }}\right.$ ed.). Pacific Grove, CA: Brooks/Cole.

Schwab, J. J. (1970). Depression in medical and surgical patients. In A. J. Enelow (Ed.), Depression in medical pracuce (pp. 109-138). West Point. PA: Merck Sharp \& Dohme.

Secunda, S. K., Katz, M. M., Freedman, R. J., \& Schuyler, D. (1973). The depressive disorders. Washington, DC: U. S. Department of Health Education and Welfare, Health Services and Mental Health Administration.

Segal, Z. V.. \& Mural, J. C. (1993). Cognitive perspective on self-representation in depression. In Z. V. Segal \& S. J. Blatt (Eds.), The self in emotional distress: (ognutue and prychodynamic perspectives (pp. 131-163). New York: Guilford Press.

Seiffge-Krenke, I. (1990). Developmental processes in self-concept and coping behaviour. In H. A. Bosma \& A. E. Jackson (Eds.), ('oping and self-concept in adolescence (pp. 49-68). New York: Springer-Verlag.

Seligman, M. E. P. (1990). learned optimusm: How to change your mind and your life. New York: Pocket Books.

Seligman. M. E. P. (1998). Why therapy works. American Psychological Associanion Monitor [On-line], 29(12), 1-2. Available: apa.org, monitor, dec98, pc.

Seligman, M. E. P., Abramson, L. Y.. Semmel, A., \& von Baever, C. (1979). Depressive attributional style. Journal of Abnormal Psychology, 88(3), 242-247.

Settlage, C. F. (1990). Childhood to adulthood: Structural change in development toward independence and autonomy. In R. A. Nemiroff \& C. A. Colarusso (Eds.), New dimensions in adult development (pp. 26-42). New York: Basic Books.

Shakespeare, W. (1959). Hamlet. In G. B. Harrison, W. J. Bate. B. H. Bronson, R. A. Brower. D. Bush, H. Davis, et al. (Eds.), Major Brutsh wrtters l: (haucer. Spenser. Shakespeare, Bacon, Donne, Milion, Dryden, Swifi. Pope. Johnson, Boswell (p. 245). New York: Harcourt, Brace, \& World.

Shapiro, H. T. (1997). Cognition, character, and culture in undergraduate education: Rhetoric and reality. In R. G. Ehrenberg (Ed.), The American university: National treasure or endangered species (pp. 58-99). Ithaca, NY: Cornell University Press. 
Shaveison, R. J., \& Bolus. R. (1982). Self-concept: The interplay' of theory and methods. Journal of Educational Psychology. $7+(1), 3-17$.

Shavelson. R. J., Hubner, J. J. \& Stanton, G. C. (1976). Self-Concept: Validation of construct interpretations. Review of Educarional Research, t6(3), 407-441.

Shevlin. M. E., Bunting, B. P., \& Lewis. C. A. (1995). Confirmatory factor analysis of the Rosenberg Self-Esteem Scale. Psychological Reports, 76 (Part 1), 707-710

Shilkret. R., \& Nigrosh, E. E. (1997). Assessing students` plans for college. Journal of ('ounseling Psychology, $+4(2), 222-231$.

Shirk, S. R., \& Renouf, A. G. (1992). The tasks of self-development in middle childhood and early adolescence. In R. P. Lipka \& T. M. Brinthaupt (Eds.), Self-perspectives across the lifespan (pp. 53-92). Albany, NY: State University of New York Press.

Shirley, S. K. H. (1990). The prevalence of depression as measured by the Beck Inventory and the characteristics associated with depression among students in three illinois public community colleges: The college of dupage, truman college, and mchenry county college (Doctoral dissertation, University of Illinois at Urbana-Champaign, 1990). Dissertation Abstracts International, 52, 0856.

Siebert. A. (1996). The survivor personality: Why some people are stronger, smarter, and more skillful a! handling life's difficulties ... and how' vou can he, loo. New York: Berkley Publishing Group.

Silvernail, D. L. (1985). Developing posttive students self-concept ( $2^{\text {nd }}$ ed.). Washington, DC: National Education Association.

Simmons, R. G. (1987). Self-esteem in adolescence. In T. H. Honess \& K. Yardley (Eds.), Self und dentity: Perspectives across the lifespan (pp. 172-192). New York: Routledge \& Kegan Paul.

Smith. S. E. (1997). An intervention to reduce student anxiety. The Journal of ('ollege Admission, 157, 8-15.

Smith, J., Dixon, R. A., \& Baltes, P. A. (1989). Expertise in life planning: A new research approach to investigating aspects of wisdom. In M. L. Commons. J. D. Sinnott, F. A. Richards, \& C. Armon (Eds.), Adult development: Vol. l. ('omparisons and applications of developmental models (pp. 307-331). New York: Praeger.

Smith, C., \& Erford, B. T. (1998). Test review: Beck Depression Inventory-II. Association for Assessment in (ounseling (AAC) Newsnotes. 33(1), 3-4. 
Smits. M. R. \& Oliver, J. M. (1982). Perceptions of university and family environments as functions of depression in university students. Cognitive Therapy and Research. $6(4), 447-454$.

Snodgrass, J. G., \& Thompson, R. L. (1997). Preface. In J. G. Snodgrass \& R. L. Thomp.ion (Eds.). The self across psychologi: Self-Recognition, self-awareness, and the relf concept (Vol. 818; pp. 1-4). New York: The New York Academy of Sciences.

Snyder, M., \& Campbell, B. H. (1982). Self-monitoring: The self in action. In J. Suls (Ed.), Psychological perspectives on the self (Vol. 1, pp. 185-207). Hillsdale, NJ: Lawrence Erlbaum.

Spitzer, S. P., Couch, C. J., \& Stratton, J. R. (1971). The assessment of the self. Iowa City, IA: Escort, Sernoll.

Sprinthall, N. A., Bertin, B. D., \& Whiteley, J. M. (1986). Accomplishment after college: A rationale for developmental education. In J. C. Loxley \& J. M. Whiteley (Eds.), ('haracter development in college students: The curriculum and longitudinal results (Vol. 2, pp. 33-50). Schenectady, NY: Character Research Press.

Staub, E. (1980a). Defining personality: Personality as the study of universal principles and individual differences. In E. Staub (Ed.), Personalıt?: Basic aspects and current research (pp. 2-34). Englewood Cliffs, NJ: Prentice-Hall.

Staub. E. (1980b). Social and prosocial behavior: Personal and situational influences and their interactions. In E. Staub (Ed.), Personality: Basic aspects and current research (pp. 237-294). Englewood Cliffs, NJ: Prentice-Hall.

Steer, R. A., Ball, R., Ranieri, W. F., \& Beck, A. T. (1997). Further evidence for the construct validity of the Beck Depression Inventory-II with psychiatric outpatients. Psychological Reports, 80, 443-446.

Steer. R. A.. Ball, R., Ranieri, W. F., \& Beck, A. T. (1999). Dimensions of the Beck Depression Inventory-II in clinically depressed outpatients. Journal of ( linical Psichologi, 55(1). 117-128.

Steer, R. A., \& Clark, D. A. (1997). Psychometric characteristics of the Beck Depression Inventory-II with college students. Measurement and Evahution in ('ounseling and Development, 30(3), 128-136. 
Steer, R. A., Clark, D. A., Beck, A. T., \& Ranieri. W. F. (1998). Common and specific dimensions of self-reported anxiety and depression: The BDI-II versus the BDI-IA. Behaviour Research and Therapy: 37(2), 183-190.

Steer, R. A., Kumar, G., Ranieri, W. F., \& Beck, A. T. (1998). Use of the Beck Depression Inventory-Il with adolescent psychiatric outpatients. Journal of Psychopathology and Behavioral Assessment. 20(2), 127-137.

Steer. R. A., Rissmiller. D. J., \& Beck, A. T. (2000). Use of the Beck Depression Inventory-II with depressed geriatric inpatients. Behaviour Research and Therapy, $38(3), 311-318$.

Stehouwer, R. S. (1985). Beck Depression Inventory. In D. J. Keyser \& R. C. Sweetland (Eds.). Test (rutiques $=2$ (Vol. 2, pp. 83-87). Kansas City, MO: Test Corporation of America.

Stein, R. J. (1996). Physical self-concept. In B. A. Bracken (Ed.), Handbook of self-concept: Developmental, social, and clinical considerations (pp. 374-394). New York: John Wiley \& Sons.

Stevens-Long. J. (1990). Adult development: Theories past and future. In R. A. Nemiroff \& C. A. Colarusso (Eds.), New dimensions in adult development (pp. 125-164). New York: Basic Books.

Stevens-Long, J., \& Commons, M. L. (1992). Adult life: Developmental processes ( $4^{\text {th }}$ ed.). Mountain View, CA: Mayfield.

Stodt, M. M. (1987). Educational excellence as a prescription for retention. In M. M. Stodt \& W. M. Klepper (Eds.), Increasing retention: Academic and student affairs administrators in partnership (Vol. 15, No. 4, pp. 5-14). San Francisco: Jossey-Bass.

Stoppard, J. M. (1993). Gender, psychosocial factors and depression. In P. Cappeliez \& R. J. Flynn (Eds.), Depresston and the soctal environment: Research and intervention w'th neglected populatıons (pp. 121-149). Montreal: McGill-Queen`s University Press.

Strauman, T. J., \& Higgins, E. T. (1993). The self construct in social cognition: Past, present and future. In Z. V. Segal \& S. J. Blatt (Eds.), The self in emotional distress: (ognitive and psychodynamic perspectives (pp. 3-40). New York: Guilford Press. 
Strauss. J. L. (1998). The efficacy of a cognitive-behavioral bibliotherapy for the reduction of depressive symptoms in a college student sample. Unpublished master's thesis, University of Miami.

Strein, W. (1993). Advances in research on academic self-concept: Implications for school psychology. School Psichologi Review, 22(2), 273-284

Suls, J. M., \& Mullen, B. (1982). From the cradle to the grave: Comparison and self-evaluation across the life-span. In J. Suls (Ed.), Psychological perspectives on the self (Vol. I, pp. 97-128). Hillsdale, NJ: Lawrence Erlbaum.

Swallow, S. R. \& Segal, Z. V. (1995). A course for the treatment of depression among adolescents. In K. D. Craig \& K. S. Dobson (Eds.), Anxiety and depression in adults and children (pp. 230-245). Thousand Oaks, CA: Sage.

Swann, W. B., Jr. (1983). Self-verification: Bringing social reality into harmony with the self. In J. Suls \& A. G. Greenwald (Eds.), Psychological perspectives on the self (Vol. 2, pp. 33-66). Hillsdale, NJ: Lawrence Erlbaum.

Swann, W. B., Jr., \& Read, S. J. (1981). Self-verification processes: How we sustain our self-conceptions. Journal of Experimental Social Psychology, 17(4), 351-372.

Sweeney, P. D., Anderson, K., \& Bailey. S. (1986). Attributional style in depression: A meta-analytic review. Journal of Personality and Social Psychology, 50(5), 974-991

Taylor, S. E., Kemeny, M. E., Reed, G. M., Bower, J. E., \& Gruenewald, T. L. (2000). Psychological resources, positive illusions, and health. American Psychologist. $55(1), 99-109$.

Tennen, H., \& Affleck. G. (1993). The puzzles of self-esteem: A clinical perspective. In R. F. Baumeister (Ed.), Self-esteem: The puz=le of low self-regard (pp. 241-262). New York: Plenum Press

Tennen, H., \& Herzberger, S. (1986) Attributional Style Questionnaire. In R. C. Sweetland \& D. J. Keyser ( Eds.), Test (riliques : 5 (Vol. 5, pp. 20-32). Kansas City, MO: Test Corporation of America.

Tesser, A., \& Campbell, J. (1983). Self-definition and self-evaluation maintenance. In J. Suls \& A. G. Greenwald (Eds.). P.sychological perspectives on the self (Vol. 2, pp. 1-31). Hillsdale, NJ: Lawrence Erlbaum. 
Thompson, R. L. (1997). The human self and the animal self: Behavioral problems with few answers. In J. G. Snodgrass \& R. L. Thompson (Eds.), The self across psycholog:: Self-Recognution. self-awareness, and the self concept (Vol. 818; pp. 284-290). New York: New York Academy of Sciences.

Tinto, V. (1985). Dropping out and other forms of withdrawal from college. In U. Delworth \& G. R. Hanson (Eds.), Increasing student retention: Effective programs and practices for reducing the dropout rate (pp. 28-43). San Francisco: Jossey-Bass.

Tough, A. (1981). Interests of adult learners. In A. W. Chickering \& Associates (Eds.), The modern American college: Responding to the new realities of diverse students and a changing sociery (pp. 296-305). San Francisco: Jossey-Bass.

Tousignant, M., \& Hanigan, D. (1993). Suicidal behaviour and depression in young adults. In P. Cappeliez \& R. J. Flynn (Eds.), Depression and the social environment: Research and intervention with neglected populations (pp. 93-120). Montreal: McGill-Queen's University Press.

Toy. T. J. (1985). Increasing faculty involvement in retention efforts. In U. Delworth \& G. $\mathrm{R}$. Hanson (Eds. ), Increasing student retention: Effective programs and practices for reducing the dropout rate (pp. 383-401). San Francisco: Jossey-Bass.

Treadgold, R. (1999). Transcendent vocations: Their relationship to stress, depression, and clarity of self-concept. Journal of Humanisuc Psychologv [On-line], 39(1), 81-105. Available: Academic Search Elite.

Trusty, J., Robinson, C. R., Plata, M., \& Ng, K-M. (2000). Effects of gender, socioeconomic status, and early academic performance on postsecondary educational choice. Journal of ('ounseling and Development, 78(4), 463-472.

Tzeng, O. C. S., Maxey, W. A., Fortier, R., \& Landis, D. (1985). Construct evaluation of the Tennessee Self Concept Scale. Educational and Psychological Measurement. $+5(1), 63-78$.

Vacchiano, R. B., \& Strauss, P. S. (1968). The construct validity of the Tennessee Self-Concept Scale. Journal of ('linical Psychologn, 2+(3), 323-326.

van der Werff, J. J. (1985). Individual problems of self-definition: An overview, and a view. International Journal of Behavioral Development, 8(4), 445-471. 
van der Werff. J. J. (1990). The problem of self-conceiving. In H. A. Bosma \& A. E. Jackson (Eds.), ('oping and self-concept in adolescence (pp. 13-33). New York: Springer-Verlag.

Van Tuinen, M., \& Ramaraiah, N. V. (1979). A multimethod analysis of selected self-esteem measures. Journal of Research in Personalitı. 13, 16-24.

Verkuyten, M. (1995). Self-esteem, self-concept stability, and aspects of ethnic identity among minority and majority youth in the Netherlands. Jiurnal of Kourh and Adolescence, $2+(2), 155-168$.

Vest. C. M. (1997). Research universities: overextended, underfocused: overstressed. underfunded. In R. G. Ehrenberg (Ed.), The American university: National treasure or endangered species (pp. 43-57). Ithaca, NY: Comell University Press.

Vredenburg, K., Flett, G. L., \& Krames, L. (1993). Analogue versus clinical depression: A critical reappraisal. Psychological Bulletın. 1/3(2), 327-344.

Vredenburg, K., Krames, L., \& Flett, G. L. (1985). Re-examining the Beck Depression Inventory: The long and shor of it. Psychological Reports, 56, 767-778.

Wall, T. N., \& Hayes, J. A. (2000). Depressed clients' attributions of responsibility for the causes of and solutions to their problems. Journal of ('ounseling and Development. $78(1), 81-86$.

Waller, N. G. (1998). Review of the Beck Depression Inventory. In J. C. Impara \& B. S. Plake (Eds.), The thirteenth mental measurements yearbook (13 th ed. pp. 120-122). Lincoln, NE: Buros Institute of Mental Measurements.

Walsh, W. A., \& Banaju. M. (1997). The collective self. In J. G. Snodgrass \& R. L. Thompson (Eds.), The self across psychology: Self-Recognition, self-awareness, and the self concept (Vol. 818; pp. 193-214). New York: New York Academy of Sciences.

Walter, P. A., Jr. (1989). Depression. In P. A. Grayson \& K. Cauley (Eds.), College psichotherapy (pp. 136-149). New York: Guilford Press.

Watkins, J. (1981). The relationship of physical-self concept and identity to anxiety, depression and academic performance (Doctoral dissertation, The American University, 1981). Dissertation Abstracts International, +2, 2586. 
Weathersby, R. P. (1981). In A. W. Chickering \& Associates (Eds.), The modern American college: Responding to the new realities of diverse students and a changing society (pp. 51-75). San Francisco: Jossey-Bass.

Weigar, A. J. (1983). Identity: Its emergence within sociological psychology. Sumbolıc Interaction, 6(2), 183-206.

Weinmann, L. L., \& Newcombe, N. (1990). Relational aspects of identity: Late adolescents perceptions of their relationships with parents. Journal of Experimental Child Psychologw, 50(3), 357-369.

Wells, A. J. (1992). Variations in self-esteem in daily life: Methodological and developmental issues. In R. P. Lipka \& T. M. Brinthaupt (Eds.), Self-perspectives across the lifespan (pp. 151-185). Albany, NY: State University of New York Press.

Wells, L. E., \& Marwell, G. (1976). Self-esteem: Its conceptualization and measurement (Vol. 20). London: Sage.

Westefeld, J. S., Cardin, D., \& Deaton, W. L. (1992). Development of the college student reasons for living inventory. Suclde and life-Threatening Behavior, 22(4). $442-452$.

Whisman, M. A., Perez, J. E., \& Ramel, W. (2000). Factor structure of the Beck Depression Inventory - Second Edition (BDI-II) in a student sample. Journal of (.linical Psychology, j6(4), 545-551.

Whiteley, J. M. (1982). Introduction. In J. M. Whiteley, B. D. Bertin, J. S. Jennings, L. Lee, H. A. Magana, \& A. Resnikoff (Eds.), (haracter development in college students: Folume l. The freshman year (pp. xxvii-xxix). Schenectady, NY: Character Research Press.

Whybrow: P. C. (1996). Adaptive styles in the etiology of depression. In J. Lonsdale (Project Ed.), The Hatherleigh guide to managing depression (pp. 1-14). New York: Hatherleigh Press.

Willemsen, E. W., \& Waterman, K. K. (1991). Ego identity status and family environment: A correlational study. Psychological Reports, 69(3, Pt. 2), 1203-1212.

Williams, J. M. G. (1984). The psychological treatment of depression: A guide to the theory and practice of cognitive-behavior therap!. New York: Macmillan. 
Williams, J. M. G. (1995). The psichologucal treatment of depressun: A gunde to the theory and practice of cognitive behaviour therapy ( $2^{\text {nd }}$ ed. ). New York: Routledge.

Williams, T. A., Friedman. R. J., \& Secunda. S. K. (1970). Special report: The depressive illnesses. Rockville, MD: National Institute of Mental Health.

Wilson, A. R..\& Krane, R. V. (1980). Change in self-esteem and its effects on symptoms of depression. Cognitive Therapy and Research. f(4), 419-421.

Wilson, S. B., Mason, T. W.. \& Ewing, M. J. M. (1997). Evaluating the impact of receiving university-based counseling services on student retention. Journal of (i)unseling Psychologn; $f+(3), 316-320$.

Wiseman, H., \& Guttfreund, D. G. (1995). Gender differences in loneliness and depression of university students seeking counselling. British. Fournal of (juadance \& ('ounselling [On-line], 23(2), 231-245. Available: Academic Search Elite.

Witherspoon, A. D., Long, C. K., \& Chubick, J. D. (1999). Research in brief-prediction of college student dropouts using EDS scores. Journal of ('ollege Student Development, $f(0)(1), 82-86$.

Wolman, B. B. (1985). Handbook of intelligence: Theories, measurements, and applıcatıons. New York: Wiley.

Wolman. B. B. (1990). Depression: The psychosocial theory. In B. B. Wolman \& G. Stricker (Eds. ), Depressive disorders: Facts, theories, and treatment methods (pp. 92-124). New York: John Wiley \& Sons.

Wong, J. L., \& Whitaker, D. J. (1993). Depressive mood states and their cognitive and personality correlates in college students: They improve over time. Journal of ('inical Psychology, $+9(5), 615-621$.

Workman. J. F.. Bloland, P. A., Grafton. C. L., \& Kester, D. L. (1986-87). Changes in self-concept, locus of control, and anxiety among female college students as related to assertion training. Fducational Research ()uarterly; //(2). 21-28.

Wylie, R. C. (1961). The self concept: A critucal survey of pertinent research literature. Lincoln, NE: University of Nebraska Press.

Wylie, R. C. (1974). The self-concept: $A$ reviev: of methodological considerarmons and measuring insiruments (Rev. ed., Vol. 1). Lincoln, NE: University of Nebraska Press. 
Wylie, R. C. (1979). The self-concept: Theory and research on selected topus (Rev. ed., Vol. 2). Lincoln, NE: University of Nebraska Press.

Wylie, R. C. (1989). Meusures of self-concept. Lincoln, NE: University of Nebraska Press.

Xenikou, A., Furnham, A., \& McCatrey, M. (1997). Attributional style for negative events: A proposition for a more reliable and valid measure of attributional style. British Journal of Psychology [On-line], 88(1). 53-69. Available: Academic Search Elite

Young, J. E., Beck, A. T., \& Weinberger, A. (1993). Depression. In D. H. Barlow (Ed.), Clinical handbook of psychological disorders: A step-by-step treatment manual (2 ${ }^{\text {nd }}$ ed., pp. 240-277). New York: Guilford Press.

Zaiden, J. (1982). Psychodynamic therapy: Clinical applications. In A. J. Rush (Ed.), Short-term psychotherapies for depression: Behavioral, interpersonal, congnitive. and psychodynamic approaches (pp. 251-310). New York: Guilford Press.

Zimbardo, P. G., \& Leippe, M. R. (1991). The psychology of attitude change and social influence. Philadelphia: Temple University Press.

Zimmerman, $M(1986)$. The stability of the revised Beck Depression Inventory in college students: Relationship with life events. ('ognutive therapy and Research, $10(1)$, $37-43$. 
VITA

Reproduced with permission of the copyright owner. Further reproduction prohibited without permission. 


\section{VITA \\ ANN L. WOOLLEY}

\section{Licensure}

Limited License Psychologist - MA, State of Michigan, I.D. \#6301010067, Exp. 8/31/02

National Certified Counselor, NBCC. I.D. $=39587$, Exp. 6:30:05

Registered Nurse, State of Michigan, Permanent I.D. $\$ 4704209067$, Exp. 3/31/04

\section{Educational Background}

Ph.D., Counseling Psychology

Andrews University, Berrien Springs, Michigan

Master of Arts, Community Counseling, June 1995, Andrews University

\section{Professional Experience}

- $\quad$ Pre-Doctoral Internship

August 1998 to September 1999

Janet Wattles Mental Health Center, Rockford, Illinois

- Therapist. Ph.D. Practicum, Counseling and Psychological Services June 1995 to March 1997; Andrews University

- $\quad$ Supervisor, Ph.D. Supervision of M.A. Students: Standardized Group Testing January 1997 to June 1997; September 1994 to May 1995, Andrews University

- Leader/Co-Leader. Therapy/Suppon Groups for M.A. Students. Incest Survivors, Eating Disorders/Body Image, Divorce Recovery, 1994-1996: Andrews University

- Therapist, M.A. Practicum in Counseling (I and II): M.A. Internship in Counseling January 1994 to May 1994; September 1994 to May 1995

Counseling and Psych Services/Counseling and Testing Center, Andrews University

\section{Honors}

Outstanding Young

Women in America 1997
Psy Chi

Pi Lambda Theta
Phi Delta Kappa

Pi Gamma Mu

\section{Bibliography}

Woolley, A. L., \& Tucker, D. C. (1991). Sympathetic Innervation Increases Growth of Embryonic Rat Heart. Southeastern Undergraduate Psych. Research Conference Abstract.

Acknowledged for contribution to Tucker, D. C., Askari, M., \& Bishop, S. P. (1992). Effects of sympathetic innervation on size of myocytes in embryonic rat heart cultured in oculo. Joumal of Molecular Cellular Cardiology, 24, 925-935. 